\title{
BALANÇO DE NITROGÊNIO EM MICROBACIAS PAREADAS (FLORESTA vs. PASTAGEM) NO ESTADO DE RONDÔNIA
}

\author{
ADRIANA LUCIA CASTELLANOS BONILLA
}

Dissertação apresentada à Escola Superior de Agricultura “Luiz de Queiroz”, Universidade de São Paulo, para obtenção do título de Mestre em Ecologia de Agroecossistemas.

P I R A C I C A B A

Estado de São Paulo - Brasil

Março - 2005 


\title{
BALANÇO DE NITROGÊNIO EM MICROBACIAS PAREADAS (FLORESTA vs. PASTAGEM) NO ESTADO DE RONDÔNIA
}

\author{
ADRIANA LUCIA CASTELLANOS BONILLA \\ Microbióloga
}

Orientador: Prof. Dr. ALEX VLADIMIR KRUSCHE

\begin{abstract}
Dissertação apresentada à Escola Superior de Agricultura “Luiz de Queiroz”, Universidade de São Paulo, para obtenção do título de Mestre em Ecologia de Agroecossistemas.
\end{abstract}

P I R A C I C A B A

Estado de São Paulo - Brasil

Março - 2005 
Dados Internacionais de Catalogação na Publicação (CIP) DIVISÃO DE BIBLIOTECA E DOCUMENTAÇÃO - ESALQ/USP

Castellanos Bonilla, Adriana Lucia

Balanço de nitrogênio em microbacias pareadas (Floresta vs. Pastagem) no Estado de Rondônia / Adriana Lucia Castellanos Bonilla. - - Piracicaba, 2005.

69 p. : il.

Dissertação (mestrado) - - Escola Superior de Agricultura Luiz de Queiroz, 2005.

Bibliografia.

1. Ciclo de nitrogênio 2. Desmatamento 3. Ecologia 4. Floresta 5. Microbacia hidrográfic 6. Pastagem I. Título

CDD 574.5222

“Permitida a cópia total ou parcial deste documento, desde que citada a fonte - O autor" 
Os céus proclamam a

glória de Deus e

o firmamento anuncia a obra

das suas mãos

(Salmos 19:1) 
A Deus ofereço, a meus queridos pais Marcos e Esther dedico 


\section{AGRADECIMENTOS}

Ao Prof. Dr. Alex Vladimir Krusche pela orientação e revisões deste trabalho.

Ao Prof. Efraín Ruiz Sepúlveda pela oportunidade oferecida para fazer este curso.

Ao Dr. Chris Neill pela ajuda e sugestões feitas a este trabalho.

A Sergio, Sonja, Beata, Alex e Marcos pelas contribuições nas atividades de campo.

Ao senhor Schmitz e sua família na fazenda Rancho Grande pelo apoio logístico e permissão para o desenvolvimento deste trabalho.

À Cristiane Tumang pela orientação, colaboração e dedicação no desenvolvimento das atividades de laboratório.

Ao Prof. Dr. Jorge Moraes pela paciência e toda a ajuda prestada na área de hidrologia.

Aos pesquisadores Mauricio Ranzini e Enrique Gamero pela ajuda e sugestões oferecidas.

A Xanda, Mayra, Adriane, Gustavo, Robson e Toninha pelo apoio nas atividades de laboratório.

A Nora, Isabel, Oscar, Catia, Fátima, Vânia Neu, Michelle, Lais, Vânia Korman, Gabriela, Christie, Nei, Marcos, Sergio, José Mauro, Daniel, Santiago, Rafael (Pira), Edgar, pela amizade e, as pequenas e grandes ajudas de todos os dias.

Ao senhor Antônio, dona Dalva e Cristiane Tremocoldi (minha família brasileira), pela boa acolhida e carinho que me têm manifestado.

A meus amigos Marcos Bombo e Daniela Tonin, pela amizade, companhia e orações. 
A minha família, que sempre me tem apoiado e ajudado na realização de meus objetivos e sonhos.

Este estudo contou com o apoio financeiro dos projetos temáticos NASA/LBAND-03 “Key Connections in Amazonian Stream Corridors”, FAPESP: “Alterações na dinâmica da matéria orgânica em rios de micro e meso escala do estado de Rondônia em função das mudanças do uso da terra”, NSF Ecosystems Studies: "Nitrogen movement from uplands to streams in forested and deforested tropical watersheds” e IAI (InterAmerican Institute for Global Change Research), através do projeto “Análise e Monitoramento de rios Amazônicos Andinos”. 


\section{SUMÁRIO}

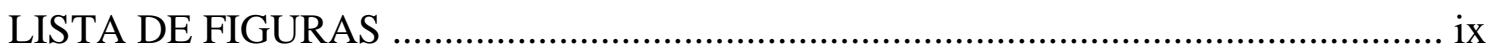

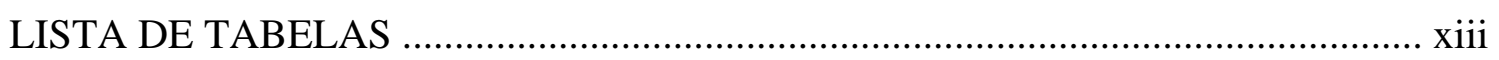

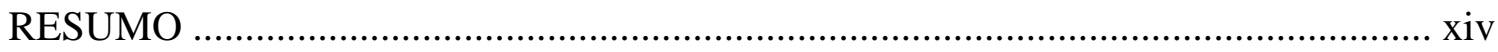

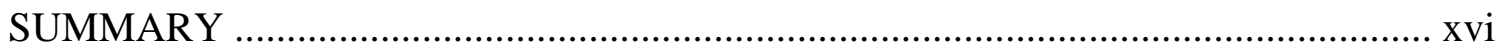

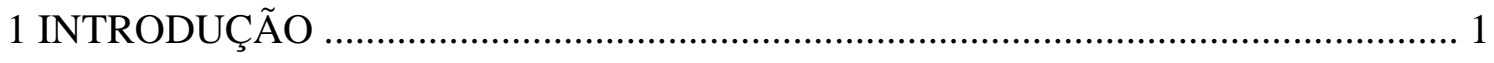

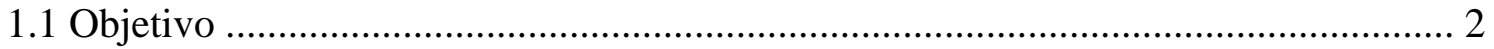

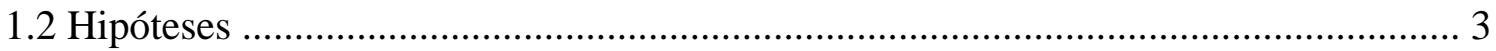

2 REVISÃO DE LITERATURA _....................................................................... 4

2.1 Conseqüências biogeoquímicas do desmatamento e implantação de pastagens ........ 4

2.2 Alterações no ciclos do nitrogênio ...................................................................... 5

2.3 Vias hidrológicas e o ciclo do nitrogênio ............................................................. 5

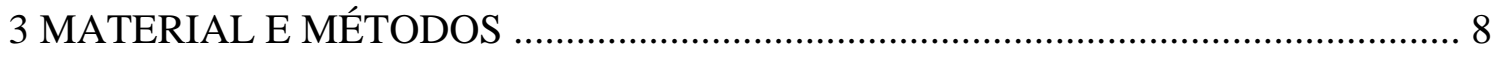

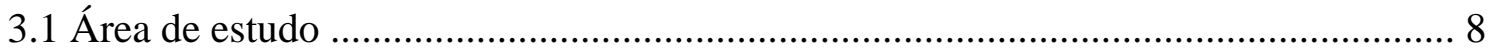

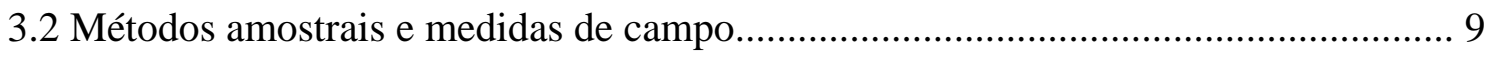

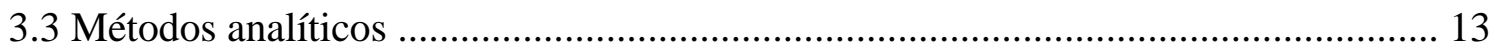

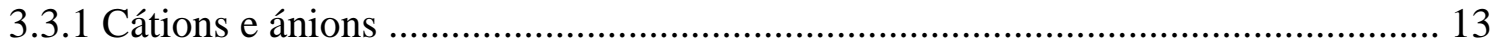

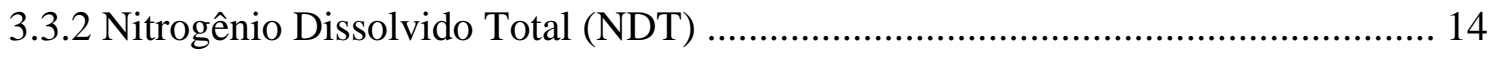

3.3.3 Nitrogênio Particulado (NP) e Carbono Particulado (CP) ................................... 14

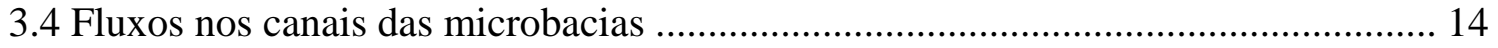

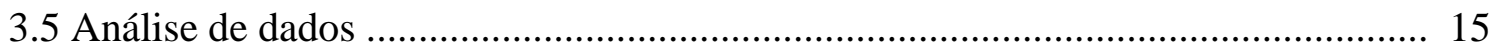

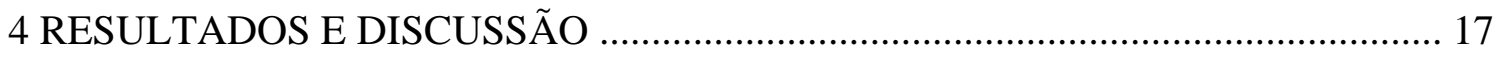

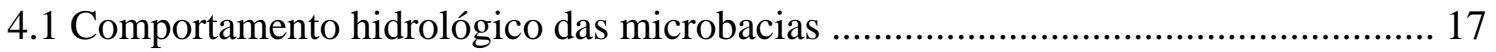

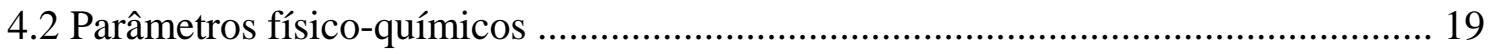


4.3 Comparação das principais formas de nitrogênio ............................................... 22

4.4 Balanço de nitrogênio por evento de chuva ......................................................... 26

4.5 Vias hidrológicas e transporte de nitrogênio ...................................................... 30

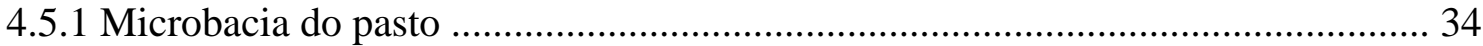

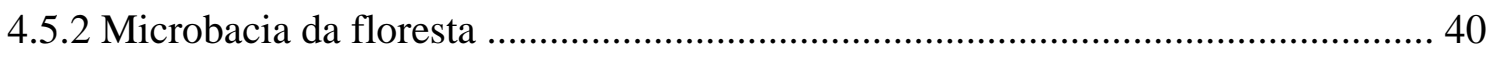

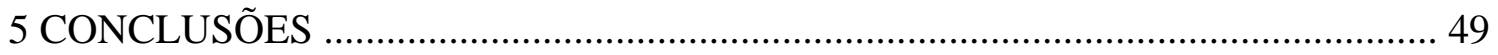

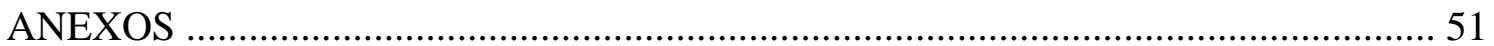

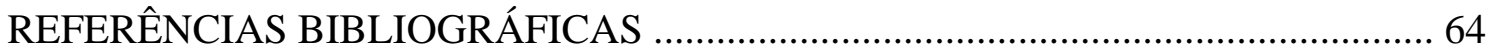




\section{LISTA DE FIGURAS}

Página

1 Localização da área de estudo e imagem Landsat TM apresentando a Fazenda Rancho Grande e a representação esquemática das bacias de

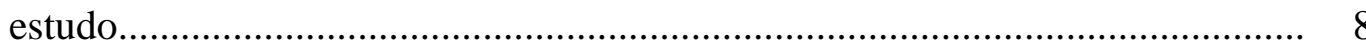

2 Coletor de chuva na bacia do pasto (a) e coletor de precipitação interna na floresta (b) ..................................................................................... 10

3 Localização dos coletores de precipitação interna e dos poços na floresta ........ 10

$4 \quad$ Coletores de escoamento superficial na floresta ....................................... 11

$5 \quad$ Nascentes de água subsuperficial no pasto (a) e na floresta (b) ....................... 12

6 Localização dos poços de amostragem de água subterrânea no pasto ............... 12

7 Localização dos poços de amostragem de água subterrânea na floresta ............ 12

$8 \quad$ Vertedouro do (a) pasto e da (b) floresta ................................................... 15

9 Dados históricos de precipitação média comparados com os meses do período

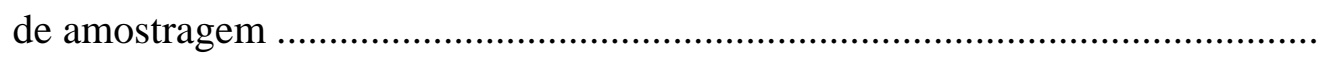


10 Valores de $\mathrm{pH}$ obtidos para as microbacias de (a) floresta e (b) pasto. $\mathrm{P}=$ Precipitação, PI = Precipitação Interna, ES = Escoamento Superficial, SS = Água Subsuperficial, SB = Água Subterrânea, EB = Escoamento Base

11 Valores de alcalinidade obtidos para as microbacias de (a) floresta e (b) pasto. $\mathrm{P}=$ Precipitação, PI = Precipitação Interna, ES = Escoamento Superficial, SS = Água Subsuperficial, SB = Água Subterrânea, EB = Escoamento Base .........

12 Valores de condutividade elétrica obtidos para as microbacias da (a) floresta e (b) pasto. $\mathrm{P}=$ Precipitação, PI = Precipitação Interna, ES = Escoamento Superficial, SS = Água Subsuperficial, SB = Água Subterrânea, EB = Escoamento Base

13 Comparação dos valores de STS nas microbacias do pasto e da floresta 22

14 Concentrações de $\mathrm{NO}_{3}{ }^{-}, \mathrm{NH}_{4}{ }^{+}$, NOD na precipitação (P) e na precipitação interna (PI)

15 Concentrações de $\mathrm{NO}_{3}{ }^{-}, \mathrm{NH}_{4}{ }^{+}$, NOD no escoamento superficial nas microbacias do pasto (P) e da floresta (F)

16 Concentrações de $\mathrm{NO}_{3}{ }^{-}, \mathrm{NH}_{4}{ }^{+}$, NOD na água subsuperficial nas microbacias do pasto (P) e da floresta (F)

17 Concentrações de $\mathrm{NO}_{3}{ }^{-}, \mathrm{NH}_{4}{ }^{+}$, NOD na água subterrânea nas microbacias do pasto (P) e da floresta (F)

18 Concentrações de $\mathrm{NO}_{3}{ }^{-}, \mathrm{NH}_{4}{ }^{+}$, NOD nos igarapés das microbacias do pasto (P) e da floresta (F) 
19 Porcentagens de NP, NDT, NID, NOD, $\mathrm{NH}_{4}{ }^{+}$e $\mathrm{NO}_{3}{ }^{-}$exportado por evento de chuva nas bacias da floresta e do pasto

20 Comparações das concentrações de Alcalinidade, Cloreto e Sódio nos compartimentos e vias hidrológicas da floresta (a) e do pasto (b). $\mathrm{P}=$ Precipitação, PI = Precipitação Interna, ES = Escoamento Superficial, SS = Água Subsuperficial, SB = Água Subterrânea, EB = Escoamento Base

21 Comparação das concentrações de Magnésio, Potássio e Cálcio nos compartimentos e vias hidrológicas da floresta (a) e do pasto (b). $\mathrm{P}=$ Precipitação, PI = Precipitação Interna, ES = Escoamento Superficial, SS = Água Subsuperficial, SB = Água Subterrânea, EB = Escoamento Base

22 Hietógrafo e hidrógrafo (a), e quimiógrafos para o $\mathrm{Cl}^{-}$(b), $\mathrm{NH}_{4}^{+}$(c), $\mathrm{NO}_{3}^{-}$(d), NOD (e) e NDT (f) para o evento de 4 de fevereiro na microbacia do pasto. $\mathrm{EB}=$ Escoamento Base, $\mathrm{SB}=$ Água Subterrânea, $\mathrm{P}=$ Precipitação, $\mathrm{ES}=$ Escoamento Superficial, SS = Água Subsuperficial

23 Hietógrafo e hidrógrafo (a), e quimiógrafos para o $\mathrm{Cl}^{-}$(b), $\mathrm{NH}_{4}{ }^{+}$(c), $\mathrm{NO}_{3}^{-}$(d), NOD (e) e NDT (f) para o evento de 15 de fevereiro na microbacia do pasto. $\mathrm{EB}=$ Escoamento Base, $\mathrm{SB}=$ Água Subterrânea, $\mathrm{P}=$ Precipitação, $\mathrm{ES}=$ Escoamento Superficial, SS = Água Subsuperficial

24 Hietógrafo e hidrógrafo (a), e quimiógrafos para o $\mathrm{Cl}^{-}$(b), $\mathrm{NH}_{4}^{+}$(c), $\mathrm{NO}_{3}^{-}$(d), NOD (e) e NDT (f) para o evento de 17 de fevereiro na microbacia do pasto. $\mathrm{EB}=$ Escoamento Base, $\mathrm{SB}=$ Água Subterrânea, $\mathrm{P}=$ Precipitação, ES = Escoamento Superficial, SS = Água Subsuperficial

25 Hietógrafo e hidrógrafo (a), e quimiógrafos para o $\mathrm{Cl}^{-}$(b), $\mathrm{NH}_{4}^{+}$(c), $\mathrm{NO}_{3}^{-}$(d), NOD (e) e NDT (f) para o evento de 19 de fevereiro na microbacia do pasto. 
$\mathrm{EB}$ = Escoamento Base, $\mathrm{SB}=$ Água Subterrânea, $\mathrm{P}=$ Precipitação, ES = Escoamento Superficial, SS = Água Subsuperficial ...........................................

26 Hietógrafo e hidrógrafo (a) e quimiógrafo para o $\mathrm{Cl}^{-}$(b), $\mathrm{NH}_{4}{ }^{+}$(c), $\mathrm{NO}_{3}{ }^{-}$(d), NOD (e) e NDT (f) para o evento de 4 de fevereiro na microbacia da floresta. $\mathrm{P}=$ Precipitação, PI = Precipitação Interna, ES = Escoamento Superficial, SS = Água Subsuperficial, SB = Água subterrânea ..................................................

27 Hietógrafo e hidrógrafo (a) e quimiógrafo para o $\mathrm{Cl}^{-}$(b), $\mathrm{NH}_{4}{ }^{+}$(c), $\mathrm{NO}_{3}^{-}$(d), NOD (e) e NDT (f) para o evento de 15 de fevereiro na microbacia da floresta. $\mathrm{P}=$ Precipitação, PI = Precipitação Interna, ES = Escoamento Superficial, SS = Água Subsuperficial, SB = Água subterrânea

28 Hietógrafo e hidrógrafo (a) e quimiógrafo para o $\mathrm{Cl}^{-}$(b), $\mathrm{NH}_{4}{ }^{+}$(c), $\mathrm{NO}_{3}{ }^{-}$(d), NOD (e) e NDT (f) para o evento de 17 de fevereiro na microbacia da floresta. $\mathrm{P}=$ Precipitação, $\mathrm{PI}=$ Precipitação Interna, ES = Escoamento Superficial, SS = Água Subsuperficial, SB = Água subterrânea

29 Hietógrafo e hidrógrafo (a) e quimiógrafo para o Cl- (b), $\mathrm{NH}_{4}{ }^{+}$(c), $\mathrm{NO}_{3}^{-}$(d), NOD (e) e NDT (f) para o evento de 19 de fevereiro na microbacia da floresta. $\mathrm{P}=$ Precipitação, PI = Precipitação Interna, ES = Escoamento Superficial, SS = Água Subsuperficial, SB = Água subterrânea

30 Resumo esquemático dos principais resultados obtidos na microbacia da

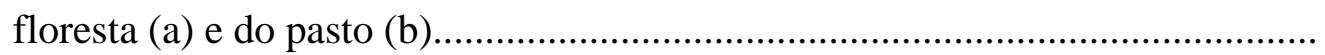




\section{LISTA DE TABELAS}

1 Parâmetros físicos das microbacias............................................................. 9

2 Valores de precipitação total, intensidade e duração dos eventos de precipitação, escoamento total e máximos de vazão para os eventos de chuva

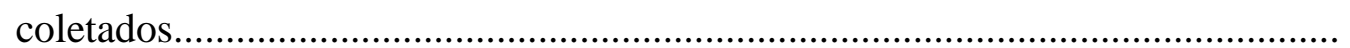

3 Balanço de por evento de chuva das diferentes formas de nitrogênio ( $\mathrm{g} \mathrm{ha}^{-1} \mathrm{~h}^{-1}$ )

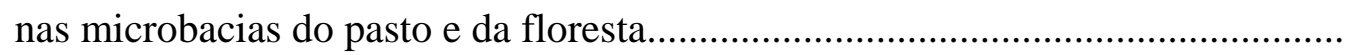




\title{
BALANÇO DE NITROGÊNIO EM MICROBACIAS PAREADAS (FLORESTA vs, PASTAGEM) NO ESTADO DE RONDÔNIA
}

\author{
Autora: ADRIANA LUCIA CASTELLANOS BONILLA \\ Orientador: Prof. Dr. ALEX VLADIMIR KRUSCHE
}

\section{RESUMO}

O ciclo do nitrogênio vem sendo alterado pelas atividades antropogênicas, em função do incremento de culturas, como as leguminosas, a queima de combustíveis fósseis e o desmatamento de florestas para uso agrícola e pecuário. Em regiões de climas temperados, existem muitas informações sobre o ciclo biogeoquímico deste elemento e sobre o papel das alterações antropogênicas no mesmo. Entretanto, em regiões tropicais, onde o ritmo do desmatamento ainda é intenso, poucas são as informações sobre este elemento. Em função disto, o presente trabalho visa fornecer informações sobre possíveis alterações nas formas de nitrogênio transportadas por pequenos igarapés, após a conversão de florestas em pastagens de regiões tropicais. Para tal, selecionaram-se duas microbacias, uma coberta com floresta primária e outra com pastagem, no estado de Rondônia (Cacaulândia). Em ambas foram realizados balanços, por eventos de chuva, das formas e quantidades de nitrogênio transportadas desde a precipitação até a água dos rios. As coletas foram realizadas durante a estação chuvosa, de 21 de janeiro a 27 de fevereiro de 2004. Como resultado, observou-se: (1) um maior fluxo de água na microbacia da pastagem, e como conseqüência, uma maior exportação de nitrogênio na mesma; (2) diferenças nas formas de nitrogênio predominantes em cada compartimento estudado. O nitrogênio orgânico dissolvido predominou na precipitação interna, no escoamento superficial e nos igarapés, enquanto que, o 
amônio predominou na água subsuperficial e na água subterrânea; (3) diferenças nas formas de nitrogênio inorgânico dissolvido presentes nos igarapés de cada microbacia, sendo o nitrato a principal forma observada na floresta, e o amônio na pastagem; (4) o nitrogênio orgânico dissolvido no igarapé da pastagem provem principalmente do escoamento superficial, enquanto que, no igarapé da floresta não foi possível identificar a principal fonte desta forma de nitrogênio. Este estudo mostra mudanças significativas no ciclo do nitrogênio como conseqüência do desmatamento e da implantação de pastagens. 


\title{
NITROGEN BALANCE IN PAIRED SMALL CATCHMENTS (FOREST vS. PASTURE) IN RONDONIA STATE
}

\author{
Author: ADRIANA LUCIA CASTELLANOS BONILLA \\ Adviser: Prof. Dr. ALEX VLADIMIR KRUSCHE
}

\section{SUMMARY}

The nitrogen cycle has been altered by anthropogenic activities, in response to the increment of cultures such, as the leguminous, fossil fuel use, and deforestation for agricultural uses and cattle raising. In temperate regions, there is considerable information about the biogeochemical cycle of nitrogen and the role of anthropogenic alterations on this cycle. However, in tropical regions, where deforestation rates are significant, there is little available information about these processes. The objective of the present work was to provide information on possible alterations in nitrogen forms transported in small catchments (igarapés) of tropical regions, after the conversion of forests into pastures. Two small catchments, one covered by primary forest, and another one covered by pasture, were selected in Rondonia State (Cacaulândia). At both catchments, balances of nitrogen forms and of quantities transported from the rain water to the rivers were calculated, employing a rain event approach. Sampling was done during the wet season, from January 21 to February 27, 2004. We observed: (1) higher discharges at pasture catchment, which resulted in larger nitrogen fluxes; (2) differences in the predominant nitrogen forms at each studied compartment. Dissolved organic nitrogen predominated in the internal precipitation, overland flow, and stream water, while ammonium predominated in the subsurface water and groundwater; (3) differences in the predominat dissolved inorganic nitrogen forms in stream waters of each catchment, nitrate in the forest, and 
ammonium in the pasture; (4) Dissolved organic nitrogen in the pasture stream comes primarily from overland flow but, for the forest stream, it was not possible to clearly identify the main source of this nitrogen form. This study shows significant changes in nitrogen cycling in small tropical catchments, as a result of deforestation for pasture. 


\section{INTRODUÇÃO}

Certas atividades do homem, tais como a fertilização agrícola, o desmatamento e a geração de resíduos industriais, têm alterado o ciclo do nitrogênio, aumentando sua disponibilidade e mobilidade. Naturalmente, a fixação biológica introduz entre 90 e 130 $\operatorname{Tg~N}$ ano ${ }^{-1}\left(\mathrm{Tg}=10^{12} \mathrm{~g}\right)$ aos continentes mas, pela ação antrópica são introduzidas 150 $\operatorname{Tg} \mathrm{N}$ ano $^{-1}$ adicionais. Este excesso de nitrogênio pode ocasionar desequilíbrio nutricional nas plantas, lixiviação de nutrientes, acidificação do solo e maior emissão de gases do efeito estufa $\left(\mathrm{N}_{2} \mathrm{O}\right)$. Nos ecossistemas aquáticos, uma maior entrada deste elemento pode produzir acidificação da água, hipóxia ou anóxia, perda de biodiversidade e eutrofização de zonas costeiras (Galloway, 1998; Rabalais, 2002; Smil, 1997; Vitousek et al., 1997a, 1997b).

Nas regiões tropicais, o desmatamento de florestas é uma das principais atividades antrópicas que altera o ciclo do nitrogênio. A taxa de desmatamento na Amazônia brasileira de 1996 a 2002 foi de $17.921 \mathrm{~km}^{2}$ ano-1 $^{-1}$ (Instituto Nacional de Pesquisas Espaciais, 2003), sendo a implementação de pastagens para criação de gado o principal uso das áreas desmatadas (Alves, 2002). O estado de Rondônia apresenta uma das maiores taxas de perda de floresta para implementação de pastagens. Até o ano 2002 foram dematadas $57.355 \mathrm{~km}^{2}$ de suas florestas, o equivalente a $24 \%$ do seu território (Alves et al., 2003; Instituto Nacional de Pesquisas Espaciais, 2003; e Pedlowski et al., 1997).

Tais alterações podem modificar os fluxos de nitrogênio nos ecossistemas aquáticos. A remoção da vegetação conduz a mudanças nas características físicas e químicas dos rios como estrutura, quantidade de luz solar que atinge a superficie, 
temperatura da água e concentração do material dissolvido e particulado exportado pelos mesmos (Neill et al., 2001; Williams et al., 1997).

Em comparação com ecossistemas temperados, alterações no ciclo biogeoquímico do nitrogênio na Amazônia poderiam ter efeitos mais significativos devido à baixa capacidade de retenção deste elemento por parte dos ecossistemas terrestres (Jordan, 1985; Matson et al., 1999) e por ser limitante na produtividade de ecossistemas de água doce (Downing et al., 1999). No entanto, parece que tal resposta pode ser influenciada pelo tamanho do rio. Bacias cobertas por pastos e drenadas por rios de ordem superior apresentam maiores concentrações de $\mathrm{NO}_{3}{ }^{-}$, enquanto que em rios de primeira ou segunda ordem, as concentrações de $\mathrm{NO}_{3}{ }^{-}$são menores que na floresta, como resultado da invasão do canal por gramíneas que, ao aumentar o aporte de matéria orgânica e as taxas respiratórias, conduzem ao aumento das taxas de desnitrificação. (Thomas et al., 2004).

Tendo em vista a importância do $\mathrm{N}$ na produtividade primária dos rios, e a escassa quantidade de informações sobre a ciclagem do mesmo em regiões com clima tropical, este trabalho visa fornecer informações mais detalhadas sobre os efeitos da mudança de florestas em pastagens sobre o ciclo biogeoquímico deste elemento nestas áreas.

\subsection{Objetivo}

Estudar algumas das alterações no ciclo do $\mathrm{N}$, após a conversão de floresta a pastagem, em duas microbacias pareadas com relação aos seguintes aspectos: (i) concentrações e formas de $\mathrm{N}$ predominante nas águas da chuva, precipitação interna, água subsuperficial, água subterrânea, escoamento superficial e água do igarapé; (ii) quantidade e formas de nitrogênio exportadas por cada microbacia e; (iii) vias hidrológicas pelas quais o nitrogênio atinge o igarapé. 


\subsection{Hipóteses}

A conversão de florestas em pastagens deve aumentar a exportação deste elemento através da descarga dos rios, como conseqüência da baixa capacidade de retenção do N em bacias de drenagem de rios tropicais, e à alteração das características hidráulicas dos solos (compactação em pastagens).

Nos igarapés de primeira ordem, onde a vegetação ripária é composta de gramíneas que invadem o canal dos rios, o aumento das taxas respiratórias resultaria em uma menor concentração de nitrogênio nestas águas superficiais, em função do aumento das taxas de desnitrificação. 


\section{REVISÃO DE LITERATURA}

\subsection{Conseqüências biogeoquímicas do desmatamento e implantação de pastagens}

Estima-se que entre 1977 e 2002, foram convertidos a pastagens 451,354 km² da Amazônia brasileira (Instituto Nacional de Pesquisas Espaciais, 2003). O método mais comumente usado nesta conversão é o de “corte e queima”, o qual ocasiona a disrupção dos ciclos biogeoquímicos, com liberação de nutrientes imobilizados na biomassa florestal e emissão de partículas e gases para a atmosfera. A remoção da vegetação também afeta o ciclo hidrológico, já que as taxas de evapotranspiração são menores na pastagem e a geração de escoamento superficial é maior (Diaz Filho et al., 2001; Fearnside 1996).

O efeito imediato depois da queima é o desaparecimento da serapilheira e um incremento do $\mathrm{pH}$ devido às cinzas. Como resultado, ocorre um incremento transitório das condições de fertilidade do solo, já que o pH mais elevado favorece a taxa de troca de cátions e aumentam os teores de $\mathrm{P}, \mathrm{K}$ e $\mathrm{Mg}$. No entanto, estes teores não são suficientes para a nutrição das plantas e, geralmente, no decorrer dos anos, voltam às concentrações similares às da floresta de origem. Também é observado um aumento da densidade nas camadas mais superficias do solo, o qual é atribuído às mudanças do sistema radicular, ao pisoteio do gado, e à destruição dos complexos argila / matéria orgânica, os quais se dispersam em partículas finas, causando a obstrução dos microporos (Diez et al., 1997; Martins et al., 1991 e Moraes et al., 1996). 


\subsection{Alterações no ciclo do nitrogênio}

O trabalho desenvolvido por Piccolo et al. (1996), no estado de Rondônia, mostrou possíveis mudanças nas fontes de $\mathrm{N}$ nas pastagens, as quais apresentaram os menores valores superficias de ${ }^{15} \mathrm{~N}$. Como a matéria orgânica do solo é mais enriquecida com ${ }^{15} \mathrm{~N}$ do que o $\mathrm{N}_{2}$ atmosférico, este resultado indicaria uma melhor fixação de nitrogênio por parte de bactérias de vida livre associadas às pastagens. Esta fixação seria favorecida pelas condições de alto $\mathrm{pH}$ e maior disponibilidade de fósforo.

As formas predominantes de nitrogênio também são afetadas pelas mudanças nas propriedades físicas e químicas do solo. Estudos feitos no estado de Rondônia mostraram que as pastagens continham teores mais altos de amônio $\left(\mathrm{NH}_{4}^{+}\right)$do que nitrato $\left(\mathrm{NO}_{3}^{-}\right)$, enquanto na floresta as concentrações dos dois compostos eram similares. Além disso, as taxas de mineralização e nitrificação foram mais baixas nas pastagens, e diminuíam à medida que a idade dessas pastagens aumentava. Estes resultados foram atribuídos ao fato das concentrações de carbono em pastagens serem maiores do que as de nitrogênio, favorecendo a imobilização deste elemento (Neill et al., 1995, 1999 e Piccolo et al., 1994). Outro fator importante é a maior umidade do solo na pastagem, a qual ocasiona uma menor difusão de $\mathrm{O}_{2}$ e, como conseqüência taxas de nitrificação menores (Neill et al., 1995).

Devido ao fato do óxido nítrico (NO) e do óxido nitroso $\left(\mathrm{N}_{2} \mathrm{O}\right)$ serem produzidos a partir da desnitrificação, as florestas tropicais apresentam maiores emissões destes gases, enquanto que nas pastagens a producão está limitada pela baixa produção de $\mathrm{NO}_{3}{ }^{-}$ (Garcia-Montiel et al., 2001; Melillo et al., 2001 e Neill et al., 1997, 2001).

\subsection{Vias hidrológicas e o ciclo do nitrogênio}

$\mathrm{O} \mathrm{NO}_{3}{ }^{-}$e o nitrogênio orgânico dissolvido (NOD) são as principais formas de perda de nitrogênio em solução dos ecossistemas, enquanto que o $\mathrm{NH}_{4}{ }^{+}$pode ser absorvido pelas plantas e microrganismos ou ficar adsorvido às partículas carregadas negativamente e à matéria orgânica do solo. $\mathrm{O} \mathrm{NO}_{2}{ }^{-}$geralmente não se acumula no solo 
uma vez que é transformado rápidamente a $\mathrm{NO}_{3}{ }^{-}$ou desnitrificado (Chapin III et al., 2002 e Paul \& Clark, 1989).

$\mathrm{O} \mathrm{NO}_{3}{ }^{-}$é a principal forma de $\mathrm{N}$ lixiviado às águas subterrâneas pois, sendo um íon negativamente carregado, é repelido pelas partículas de solo e pode ser carreado com a água que percola. $\mathrm{O}$ movimento do $\mathrm{NO}_{3}{ }^{-}$através do solo depende, principalmente do fluxo de massa com a solução de solo, e da difusão dentro da solução de solo (Chapin III et al., 2002; Follet \& Delgado, 2002).

Entre os fatores que controlam as concentrações do $\mathrm{NO}_{3}{ }^{-}$na água subterrânea, estão a diluição e a proximidade de fontes de N. A água subterrânea flui de áreas de maior a menor pressão. Este movimento é lento e há pouca mistura entre as diferentes fontes de água (Follet $\&$ Delgado, 2002).

Por outro lado, pouco se sabe dos fatores que controlam a lixiviação do NOD. Alguns trabalhos desenvolvidos em regiões temperadas sugerem que a exportação de NOD é regulada pelos fatores bióticos e abióticos que controlam a produção de carbono orgânico dissolvido (COD) (Goodale et al., 2000; Neff et al., 2000; Qualls et al., 2000).

As características das vias hidrológicas, como volume de água, velocidade do fluxo e capacidade redutora, influem na concentração e forma química nas quais os nutrientes entram nos rios. Além das características das vias hidrológicas, as caraterísticas físicas do solo e a topografia do terreno interagem com a chuva, determinando, desta forma, as vias que são ativadas durante a precipitação (McClain \& Elseenber, 2001).

Solos com baixo potencial de escoamento usualmente têm altas taxas de infiltração e são formados principalmente por areia ou cascalho. Solos com alto potencial de escoamento possuem pelo menos uma das seguintes características: taxas de infiltração lentas, favorecidas por alto conteúdo de argila e umidade, lençol freático raso, e solos superficiais sobre camadas subsuperficiais impermeáveis. A quantidade e velocidade do escoamento superficial aumentam com precipitações intensas e vertentes inclinadas. O contrário ocorre quando a topografia do terreno apresenta depressões, vegetação ou resíduos de culturas (Follet \& Delgado, 2002). 
Nos solos da Amazônia, mudanças na condutividade hidráulica determinam as vias pelas quais a água atinge o rio (Elseenber et al., 1999). Estudos desenvolvidos por Elseenber \& Lack, 1996b, demonstraram que os Latossolos apresentam uma maior condutividade hidráulica no subssolo que os Argissolos. Estes tipos de vias superficias conduzem rapidamente a água até o canal do rio, impedindo que ocorram transformações químicas importantes, como remoção de $\mathrm{N}$, que ocorreria a maiores profundidades, onde a velocidade do fluxo é menor e permite um maior contato do elemento com o solo (Follet \& Delgado, 2002).

Embora existam poucos estudos desenvolvidos sobre a dinâmica do $\mathrm{N}$ em florestas tropicais, sabe-se que a vegetação das margens dos rios exerce um papel fundamental na eliminação deste elemento através da desnitrificação (McDowell et al., 1992; McClain et al., 1994 e Williams et al., 1997). No entanto, Neill et al. (2001), encontraram altas concentrações de $\mathrm{NO}_{3}{ }^{-}$, tanto na solução do solo, como no igarapé de uma floresta com a zona ripária intacta. O papel da zona ripária nesta bacia não foi descartado devido a estudos desenvolvidos por outros autores terem demonstrado a remoção do nitrogênio nas margens do rio, e a produção de $\mathrm{NO}_{3}{ }^{-}$dentro do canal a partir da mineralização de matéria orgânica. No mesmo estudo desenvolvido por Neill et al. (2001), foram determinadas baixas concentrações de $\mathrm{NO}_{3}{ }^{-}$no igarapé que drenava uma pastagem. Este resultado foi relacionado com as baixas concentrações de $\mathrm{NO}_{3}{ }^{-}$ encontradas na solução de solo desta bacia. 


\section{MATERIAL E MÉTODOS}

\section{1 Área de estudo}

O estudo foi desenvolvido no estado de Rondônia na Fazenda Rancho Grande (10²'S; 6252'O), na altitude de $143 \mathrm{~m}$ (acima do nível do mar), localizada aproximadamente a $50 \mathrm{~km}$ ao sudeste de Ariquemes, na região central de Rondônia (Figura 1).

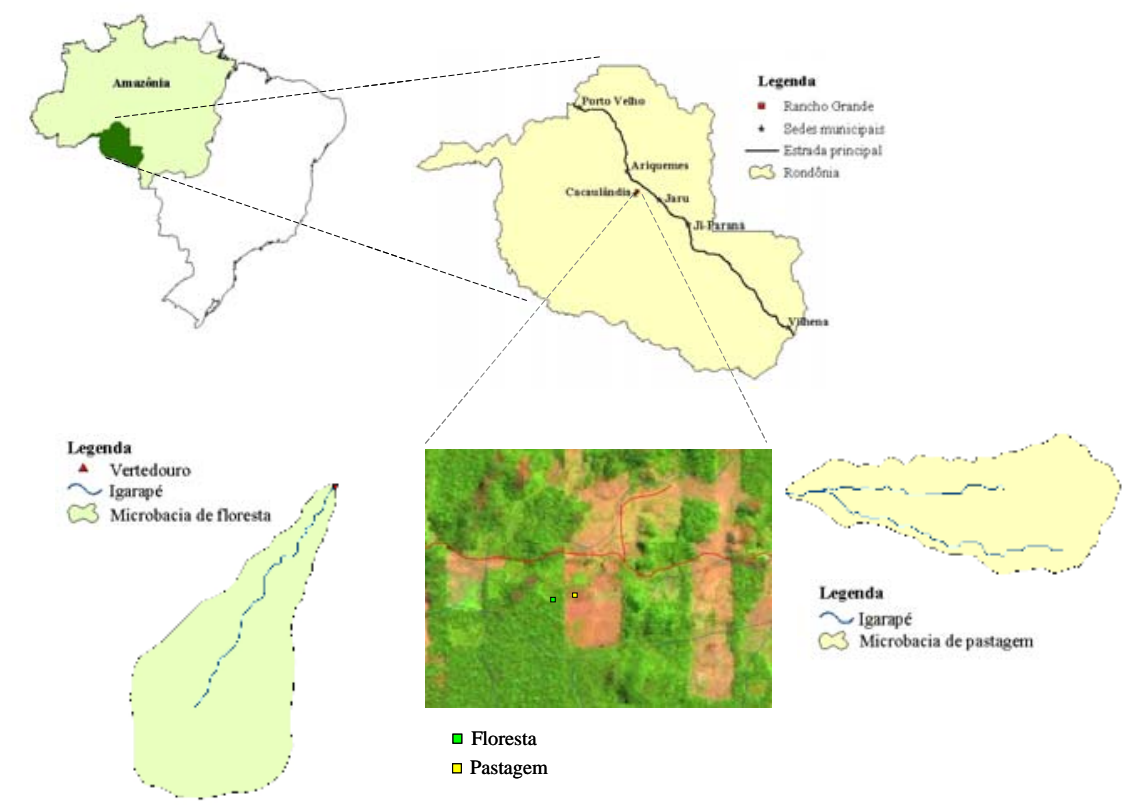

Figura 1 - Localização da área de estudo e imagem Landsat TM apresentando a Fazenda Rancho Grande e a representação esquemática das bacias de estudo 
Os solos da fazenda são classificados como Latossolos (segundo nomenclatura EMBRAPA de 1999). O clima da região é tropical úmido, com uma pequena, mas definida, estação seca entre Junho e Agosto. A temperatura média anual na fazenda é de $27.7^{\circ} \mathrm{C}$ e a precipitação de 2246 mm (H. Schmitz, comunicação pessoal., Godsey, \& Elsenbeer, 2002).

Foram selecionadas duas microbacias, uma coberta por floresta e outra por pasto, dentro da área da fazenda. A bacia da floresta tem uma área de $8295 \mathrm{~m}^{2}$ e sua cobertura vegetal nativa consiste de floresta tropical primária de clima úmido com grande número de palmeiras. O igarapé da floresta é efêmero, apresentando escoamento somente com chuvas intensas. A bacia do pasto tem uma área de $6822 \mathrm{~m}^{2}$ e está coberta principalmente por Brachiaria brizantha e Brachiara decumbens. A ocupação média dos pastos é em torno de 2 animais por hectare. A floresta que ocupava a bacia do pasto foi cortada em 1979 e queimada pela primeira vez no mesmo ano. Durante dois anos formou-se uma capoeira, a qual foi cortada e queimada em 1981. Neste ano foi plantado milho junto com o pasto. Em 1982 foi retirado o milho, permanecendo apenas o pasto. O solo nunca foi mecanizado ou adubado (H. Schmitz, comunicação pessoal). O igarapé desta bacia é intermitente, formando-se somente em épocas de chuva. Outros parâmetros físicos das microbacias são apresentados na Tabela 1.

Tabela 1. Parâmetros físicos das microbacias

\begin{tabular}{lcc}
\hline \multicolumn{1}{c}{ Parâmetro } & Floresta & Pasto \\
\hline Área $\left(\mathrm{m}^{2}\right)$ & 8298 & 6822 \\
Perímetro (m) & 422,93 & 402,62 \\
Declividade (graus) & $4,05-$ desvio 3,7 & $2,14-$ desvio 1,4 \\
Largura média da bacia (m) & 48,6 & 37,5 \\
Comprimento do canal (m) & 198 & 180 \\
\hline
\end{tabular}

\subsection{Métodos amostrais e medidas de campo}

As coletas foram realizadas entre 21 de Janeiro e 26 de Fevereiro do 2004. 
A entrada de nutrientes via atmosfera foi obtida a partir de um coletor de PVC com uma abertura de $140 \mathrm{~cm} \mathrm{x} 7 \mathrm{~cm}$, a $1 \mathrm{~m}$ do solo na bacia do pasto. Cinco coletores com as mesmas características foram instalados em diferentes pontos da floresta para caracterizar a precipitação interna “Throughfall” (Figuras 2 e 3). As amostras de cada coletor da floresta foram analisadas separadamente.

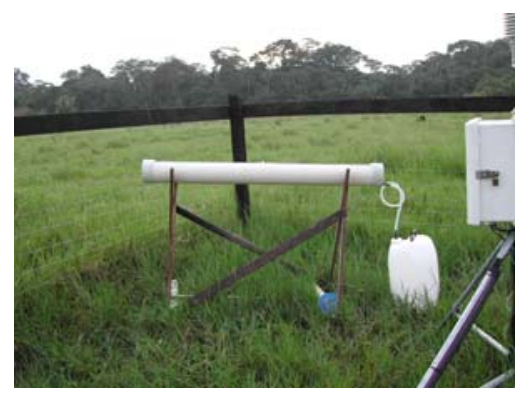

(a)

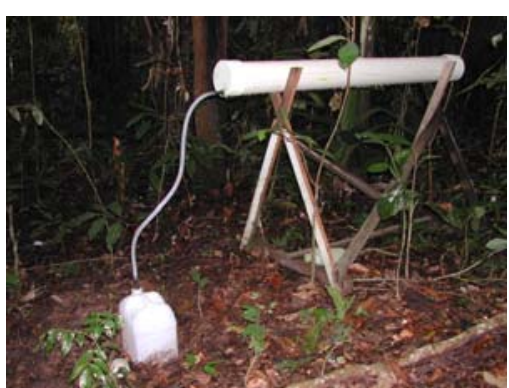

(b)

Figura 2 - Coletor de chuva na bacia do pasto (a) e coletor de precipitação interna na floresta (b)

7 Vertedouro

$\triangle$ Poços de Água

Subterrânea

Lisímetros

Piezômetros

[

Coletor Precipitação Interna

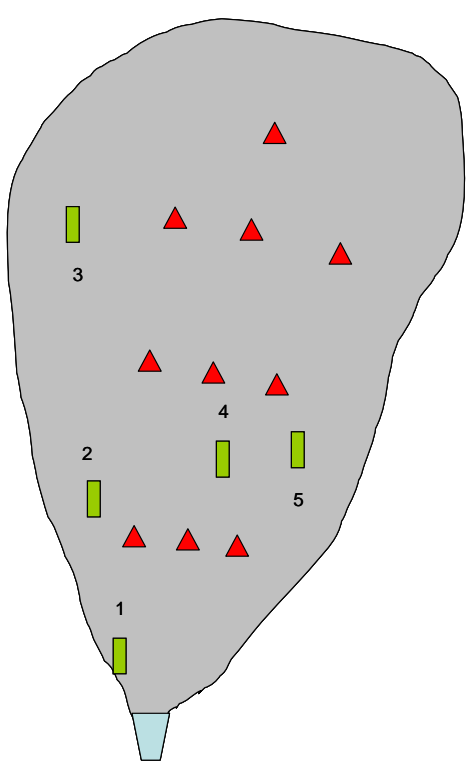

Figura 3 - Localização dos coletores de precipitação interna e dos poços na floresta 
Amostras de escoamento superficial "overland flow" foram obtidas de 24 coletores instalados na floresta e 14 no pasto. Estes coletores consistiam em tubos de PVC de $30 \mathrm{~cm}$ de comprimento. Com o objetivo de permitir a entrada da água superficial, se fizeram varios furos na lateral do tubo que estava em contacto com o solo (Figura 4).
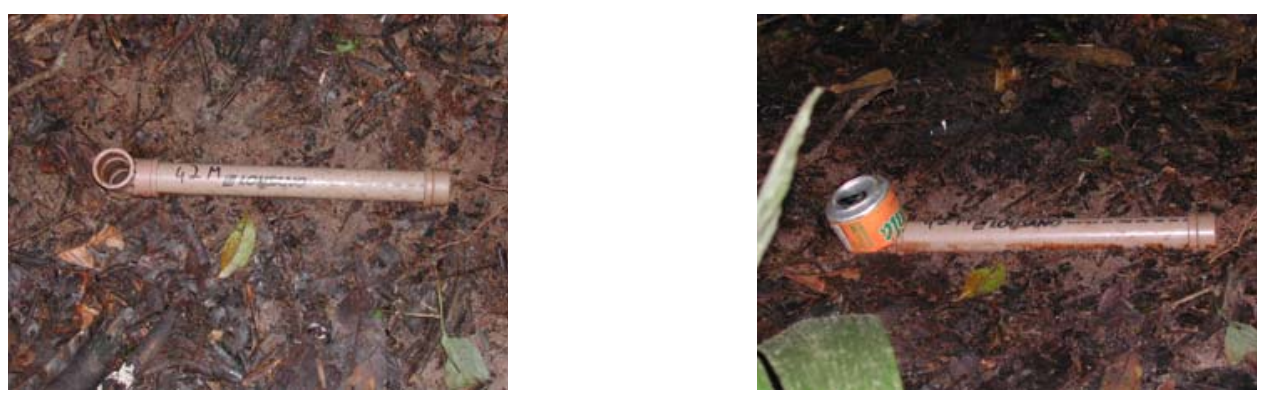

Figura 4 - Coletores de escoamento superficial na floresta

Uma amostra de água subsuperficial foi coletada diariamente em nascentes de água perto dos igarapés (Figura 5). No pasto, a nascente encontrava-se a aproximadamente $30 \mathrm{~cm}$ da superficie, enquanto que na floresta a água atingia a superficie.

Com o objetivo de ter a composição química do igarapé do pasto nas condições de escoamento base, coletou-se uma amostra de água por dia. Amostras de água subterrâneas foram tomadas diariamente a partir de 3 poços cavados no pasto e 3 na floresta. Estas amostras foram processadas separadamente. Nas Figuras 6 e 7 pode-se observar a distância entre os poços e sua profundidade.

As amostras dos igarapés foram coletadas durante os eventos de chuva com a ajuda de equipamentos automatizados (ISCO, Modelo 6700). As primeiras 16 garrafas foram coletadas a cada 5 minutos e as últimas 8 garrafas a cada 20 minutos.

Após a coleta, as amostras foram processadas no menor tempo possível no laboratório, da seguinte forma: 


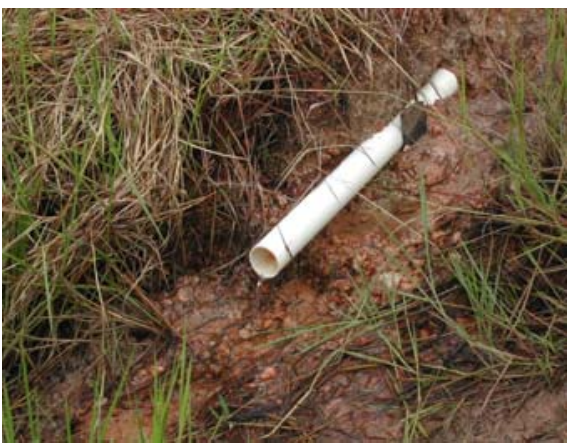

(a)

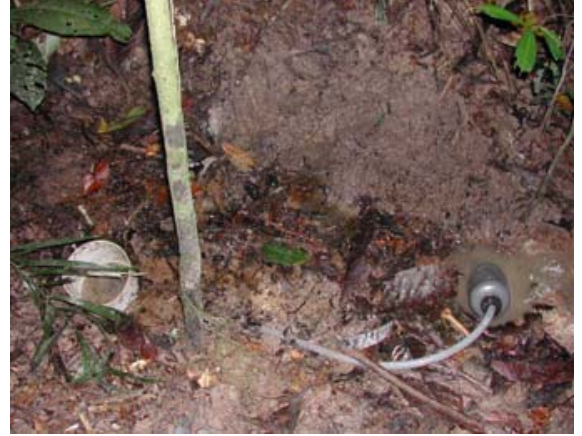

(b)

Figura 5 - Nascentes de água subsuperficial no pasto (a) e na floresta (b)
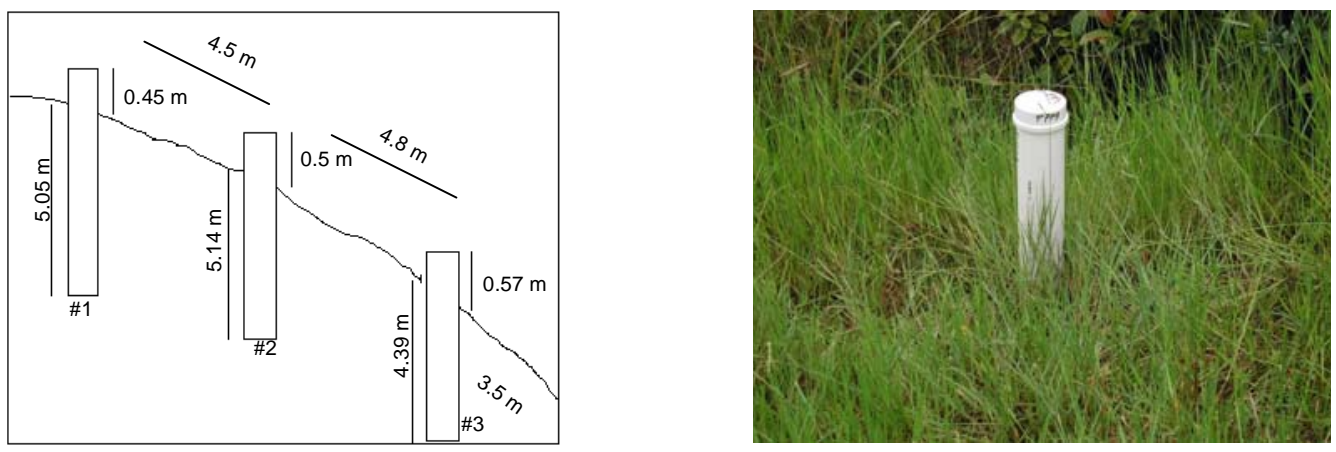

Figura 6 - Localização dos poços para amostragem de água subterrânea no pasto
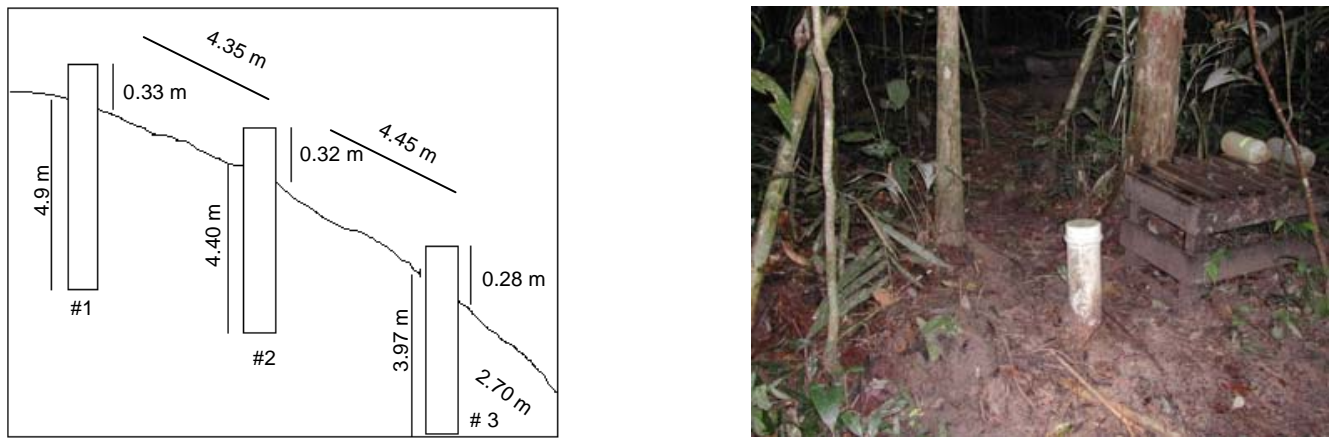

Figura 7 - Localização dos poços para amostragem de água subterrânea na floresta 
A partir de cada amostra filtraram-se $160 \mathrm{ml}$ de água, usando filtros de fibra de vidro (WHATMAN, $47 \mathrm{~mm}$ ) pré-calcinados a $550{ }^{0} \mathrm{C}$ por 5 horas. A alíquota era distribuída em frascos para sua posterior análise química como segue :

- $50 \mathrm{ml}$ em garrafa de polietileno preservados com Thymol (10 mg) e armazenada em freezer, para análise de cátions e ánions.

- $50 \mathrm{ml}$ em garrafa de polietileno, armazenados em freezer, para determinação de nitrogênio total dissolvido.

Para as amostras do igarapé foram também determinadas as concentrações de sólidos totais em suspensão (STS), nitrogênio particulado (NP) e carbono particulado (CP), usando filtros de fibra de vidro (WHATMAN, $25 \mathrm{~mm}$ ) previamente pesados e

pré-calcinados a $550{ }^{0} \mathrm{C}$ por 5 horas. Com ajuda de um sistema a vácuo, passou-se a maior quantidade possível de água, até que o filtro ficasse saturado. A quantidade de água filtrada foi registrada, e os filtros secos a temperatura ambiente por 24 horas em placas de petri. No laboratório foram colocados novamente a $45^{\circ} \mathrm{C}$ em estufa por 48 horas para secagem e pesagem. A concentração de sedimentos foi calculada a partir da diferença entre o peso final e inicial dos filtros.

$\mathrm{O} \mathrm{pH}$ e a condutividade elétrica (C.E) foram determinados, no campo, com equipamentos portáteis, peagômetro ORION, modelo 250A, e condutivímetro Amber Science, modelo 2052. A alcalinidade foi determinada por titulação potenciométrica com ácido sulfúrico 0,16 N (HACH Test Kit Digital Titrator).

\subsection{Métodos analíticos}

\subsubsection{Cátions e ánions}

As concentrações dos cátions (sódio, cálcio, magnésio, potássio e amônio) e dos ânions (cloreto, sulfato, nitrato e nitrito) foram determinadas através da técnica de cromatografia líquida de troca iônica, empregando um equipamento Dionex DX-500. Amostras dos eventos de chuva selecionados que apresentaram concentrações de nitrato ou amônio menores ao limite de detecção do equipamento $\left(0,05 \mathrm{mg} \cdot \mathrm{L}^{-1}\right)$, foram 
analisadas novamente empregando colorimetria em sistema de análise por injeção em fluxo automatizado Foss Tecator, modelo FIASTAR 5000.

\subsubsection{Nitrogênio Dissolvido Total (NDT)}

Para determinar as concentrações de nitrogênio total dissolvido utilizou-se o método de digestão com persulfato de potássio $\left(\mathrm{K}_{2} \mathrm{~S}_{2} \mathrm{O}_{8}\right)$ para posterior leitura num sistema de análise por injeção em fluxo automatizado Foss Tecator, modelo FIASTAR 5000, empregando a reação de Griess. Para calcular a eficiência da digestão, que foram

maiores que $80 \%$, utilizaram-se soluções de 0,25 mg. $\mathrm{L}^{-1}$ e $1 \mathrm{mg} \cdot \mathrm{L}^{-1}$ de glicina e ácido nicotínico.

O nitrogênio orgânico dissolvido (NOD), foi calculado subtraindo-se a concentração de nitrogênio inorgânico $\left(\mathrm{NH}_{4}{ }^{+}-\mathrm{N}+\mathrm{NO}_{3}{ }^{-}-\mathrm{N}\right)$ do valor do nitrogênio dissolvido total. Na soma das formas inorgânicas não foi incluído o $\mathrm{NO}_{2}^{-}$, uma vez que as concentrações estavam abaixo do limite de detecção do equipamentoDIONEX $(0,05$ mg. $\left.\mathrm{L}^{-1}\right)$.

\subsubsection{Nitrogênio Particulado (NP) e Carbono Particulado (CP)}

Após a pesagem dos filtros de STS, os mesmos foram utilizados para a determinação de nitrogênio particulado em analisador elementar Carlo Erba EA 1110, acoplado a espectrômetro de massa Finnigan Delta Plus.

\subsection{Fluxos nos canais das microbacias}

Vertedouros tipo $\mathrm{H}$ foram instalados, tanto na floresta quanto no pasto para determinar a descarga. A altura do nível da água foi registrada a cada 5 minutos com equipamentos automatizados das marcas Global Water e Truetrack (Figura 8). 
Os valores de vazão foram calculados a partir da altura registrada pelo transdutor de pressão mediante a equação utilizada por Bos, 1978 (Eq. 1):

$$
Q=10^{(0,0206+2,5902(\operatorname{logh})+0,2281(\operatorname{logh}) \wedge 2)} \times 1000(\text { Eq.1) }
$$

Onde h é altura, em metros, do nível da água. O resultado é expresso em L. s-1

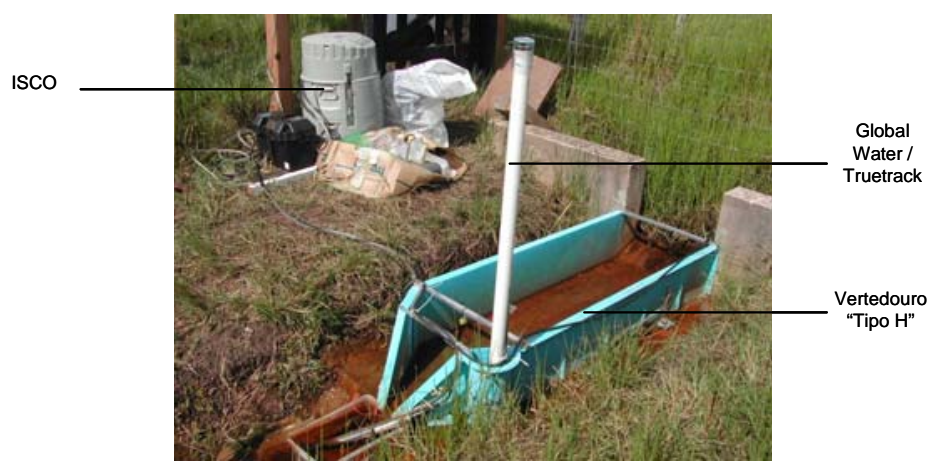

(a)

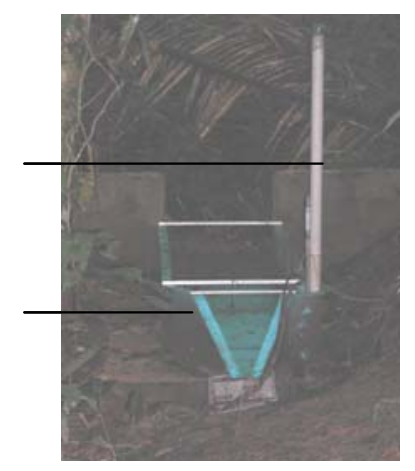

(b)

Figura 8 - Vertedouro do (a) pasto e da (b) floresta

\subsection{Análise de dados}

Para calcular o balanço de nitrogênio por evento de chuva e analisar as vias hidrológicas pelas quais o elemento é transportado, selecionaram-se os eventos de 4, 15, 17, e 19 de fevereiro, porque, além de serem simultâneos, tinham uma quantidade suficiente de amostras de deflúvio na floresta.

Os fluxos de nitrogênio foram quantificados de acordo com a expressão:

Fluxo de $N\left(g \cdot h a^{-1} \cdot h^{-1}\right)=($ P ou $V) x C / A x T$

Onde, 
$P$ é o volume total de água que entra na bacia, em L;

$V$ é o volume de água que sai da bacia, em L;

$C$ é a concentração de nitrogênio em, g. $\mathrm{L}^{-1}$

$T$ é o tempo decorrido, em h;

A é área da bacia, em ha.

Para comparar as concentrações dos elementos e os parâmetros físico-químicos entre as duas microbacias nos diferentes compartimentos, foi realizado o teste estatístico U de Mann - Whitney. As diferenças foram consideradas estatisticamente significativas para $\mathrm{p}<0,05$.

Um teste de Kruskal-Wallis, seguido de um teste de comparações múltiplas (Tukey não- paramétrico), foi realizado para determinar as possíveis diferenças entre os parâmetros físico-químicos e as espécies de nitrogênio em cada fonte de água dentro de cada microbacia, também empregando $\mathrm{p}<0,05$. 


\section{RESULTADOS E DISCUSSÃO}

\subsection{Comportamento hidrológico das microbacias}

Na Figura 9 observam-se os dados de precipitação média mensal desde 1984 até 2002. Pode-se observar que, no período amostrado, a precipitação do mês de Janeiro foi superior à média mensal, enquanto que o mês de fevereiro manteve-se dentro da média.

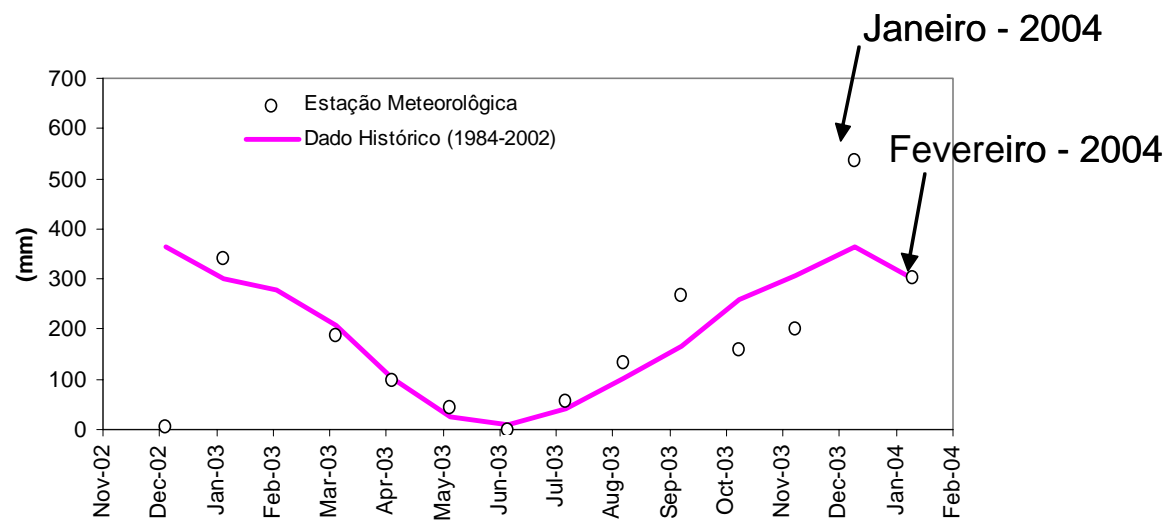

Figura 9 - Dados históricos de precipitação média comparados com os meses do período de amostragem

Na Tabela 2 encontram-se os valores de precipitação, escoamento total e vazões máximas para os eventos amostrados nas microbacias de estudo. A partir desta, pode-se observar que o escoamento total e os valores de vazão máxima sempre foram maiores no pasto que na floresta. Como exemplo, no evento de 4 de fevereiro, o escoamento total no pasto foi de 0,855 mm, enquanto que na floresta foi de 0,005 $\mathrm{mm}$. Da mesma forma, a vazão máxima foi maior no pasto $\left(2,285{\mathrm{~L} . \mathrm{s}^{-1}}^{-1}\right.$ que na floresta $\left(0,036 \mathrm{~L} . \mathrm{s}^{-1}\right)$ durante este evento de chuva. Estes resultados estariam relacionados com os valores de 
condutividade hidráulica saturada (Ksat), determinados por Godsay \& Elsenbeer (2002) para solos cobertos por floresta e pastagem na mesma fazenda onde foi desenvolvido este estudo. Estes autores encontraram que a 12,5 cm de profundidade, o solo do pasto apresentava menor Ksat que a floresta $\left(50 \mathrm{~mm} \cdot \mathrm{h}^{-1}\right.$ e $250 \mathrm{~mm} \cdot \mathrm{h}^{-1}$ respectivamente). Estes valores diminuíram com a profundidade e não se obtiveram diferenças significativas entre os dois solos a 20 e $30 \mathrm{~cm}$ de profundidade. Estes resultados mostrariam a existência de uma camada de impedimento de drenagem a $12,5 \mathrm{~cm}$ no pasto a qual permitiria freqüentemente a formação de escoamento superficial. A ausência de diferenças na Ksat a 20 cm foi atribuida à rápida recuperação do solo no pasto ou a uma menor influência do pisoteio do gado nesta profundidade. A baixa Ksat a $30 \mathrm{~cm}$ é relacionada novamente com uma camada de impedimento tanto no pasto como na floresta.

Tabela 2. Valores de precipitação total, intensidade e duração dos eventos de precipitação, escoamento total e máximos de vazão para os eventos de chuva coletados

\begin{tabular}{|c|c|c|c|c|c|c|c|}
\hline Data & $\begin{array}{c}\text { Precipitação } \\
\text { Total } \\
(\mathrm{mm})\end{array}$ & $\begin{array}{l}\text { Duração } \\
\text { (min) }\end{array}$ & $\begin{array}{l}\text { Intensidade } \\
\text { média } \\
\left(\mathrm{mm} \cdot \mathrm{h}^{-1}\right)\end{array}$ & $\begin{array}{c}\text { Escoamento Total } \\
\text { Floresta } \\
(\mathrm{mm})\end{array}$ & $\begin{array}{l}\text { Máxima } \\
\text { Floresta } \\
\left(\text { L.S }^{-1}\right)\end{array}$ & $\begin{array}{c}\text { Escoamento Total } \\
\text { Pasto } \\
(\mathrm{mm})\end{array}$ & $\begin{array}{c}\text { Máxima } \\
\text { Pasto } \\
\left(\text { L.s. }{ }^{-1}\right)\end{array}$ \\
\hline $21 / 1 / 2004$ & 22,35 & 230 & 5,83 & n.c & n.c & n.c & n.c \\
\hline $27 / 1 / 2004$ & 13,21 & 20 & 39,62 & 0,004 & 0,079 & 0,722 & 3,399 \\
\hline $31 / 1 / 2004$ & 7,87 & 30 & 15,75 & 0,0002 & 0,03 & 0,086 & 0,256 \\
\hline $4 / 2 / 2004$ & 16,76 & 130 & 7,74 & 0,005 & 0,036 & 0,855 & 2,285 \\
\hline $15 / 2 / 2004$ & 9,14 & 30 & 18,29 & 0,003 & 0,029 & 0,101 & 0,268 \\
\hline $17 / 2 / 2004$ & 35,30 & 285 & 7,43 & 0,017 & 0,042 & 9,240 & 6,974 \\
\hline $19 / 2 / 2004$ & 79,50 & 230 & 20,74 & 4,510 & 15,32 & $43,455^{\star}$ & $67,349 *$ \\
\hline $25 / 2 / 2004$ & 46,99 & 50 & 56,40 & n.c & n.c & $23,554^{*}$ & $62,291^{*}$ \\
\hline $27 / 2 / 2004$ & 8,64 & 35 & 14,80 & n.c & n.c & n.c & n.c \\
\hline
\end{tabular}

$1 \mathrm{~mm}=1 \mathrm{~L} \cdot \mathrm{m}^{-2}$

n.c $=$ valores não calculados

*Nestes eventos o vertedouro do pasto transbordou e, portanto, representam valores subestimados.

A menor condutividade hidráulica na superfície do pasto foi atribuida à compactação do solo, como resultado da pressão exercida pelo pisoteio do gado e pelo impacto da chuva no mesmo. Outros fatores que favorecem a compactação do solo no pasto nos primeiros anos após a queima são: (i) a exposição do solo mineral após o 
desmatamento, a qual pode causar uma menor infiltração da água de chuva, como conseqüência do aquecimento e ressecamento da superfície do solo; (ii) o desaparecimento da matéria orgânica e das comunidades da fauna edáfica e; (iii) o incremento de ácido fúlvico e a diminuição de ácido húmico, ocasionando a destruição dos complexos argila/matéria orgânica e a obstrução dos microporos do solo, aumentando, assim, a densidade (Brujinzeel, 1996 e Martins et al., 1991). Na floresta, a maior permeabilidade está relacionada com a presença de matéria orgânica proveniente da decomposição da serapilheira e às alterações do solo pela fauna edáfica (Dunne ${ }^{1}$ e Bonnel $^{2}$ citados por Schuler, 2003). Elsenbeer et al. (1999) propuseram que a forte anisotropia (variações bruscas ao longo do perfil de profundidade) observada para estes solos levaria a um escoamento superficial por saturação e a um fluxo lateral subsuperficial independentemente do tipo de cobertura vegetal.

Resultados semelhantes foram obtidos por Schuler (2003) para Latossolos em Paragominas (PA). Neste estudo, foram observadas diferenças na porosidade e condutividade hidráulica do solo na camada superficial, com redução da condutividade a $15 \mathrm{~cm}$ de profundidade da ordem de 100 na floresta para 1 na pastagem.

\subsection{Parâmetros físico-químicos}

Nas Figuras 10, 11 e 12 estão representados os valores de $\mathrm{pH}$, alcalinidade e condutividade elétrica obtidos para as diferentes fontes de água nas microbacias do pasto e da floresta. Nestas, pode-se observar, que a precipitação apresentou os menores valores de alcalinidade, e condutividade elétrica (C.E), os quais refletem sua baixa concentração de íons. Após a passagem pelo dossel, a composição química da chuva é modificada devido à lixiviação de substâncias solúveis orgânicas e inorgânicas presentes nas folhas das árvores ou provenientes do excremento de animais que vivem no dossel da floresta.

\footnotetext{
${ }^{1}$ DUNNE, T. Relation of field studies and modeling in the prediction of storm runoff. Journal of Hidrology, v.65, p.25-48, 1983.

${ }^{2}$ BONNEL, M. Select challenges in runoff generation research in forest from the hillslope to headwater drainage basin scale. Journal of the American Water Resources Association, v.34, n.4, p.765-785, 1998.
} 


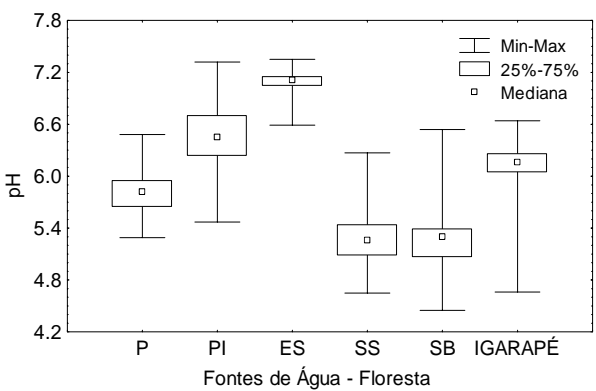

(a)

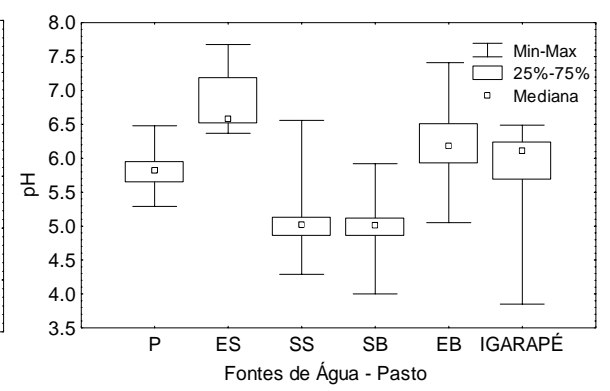

(b)

Figura 10 - Valores de $\mathrm{pH}$ obtidos para as microbacias de (a) floresta e (b) pasto $\mathrm{P}=$ precipitação, $\mathrm{PI}=$ Precipitação Interna, ES = Escoamento Superficial, SS = Água Subsuperficial, SB = Água Subterrânea, EB = Escoamento Base

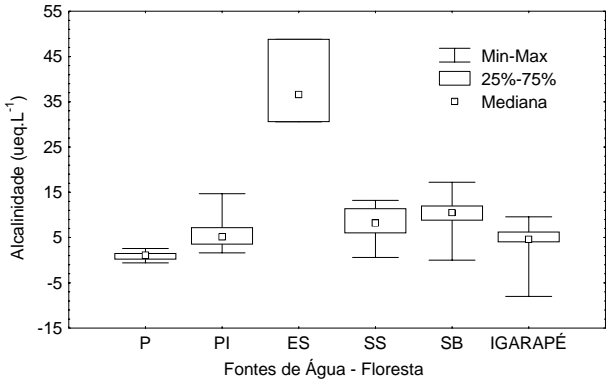

(a)

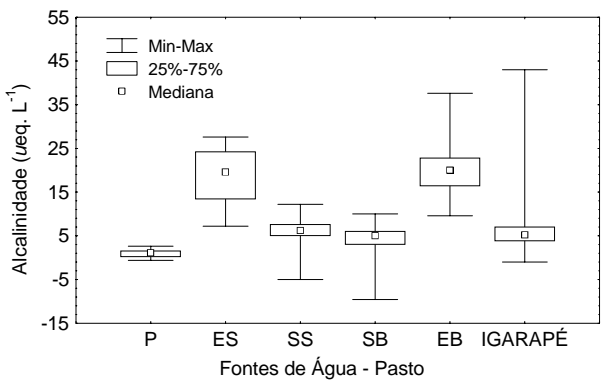

(b)

Figura 11 - Valores de alcalinidade obtidos para as microbacias de (a) floresta e (b) pasto. $\mathrm{P}=$ precipitação, $\mathrm{PI}=$ Precipitação Interna, $\mathrm{ES}=$ Escoamento Superficial, SS = Água Subsuperficial, SB = Água Subterrânea, EB = Escoamento Base

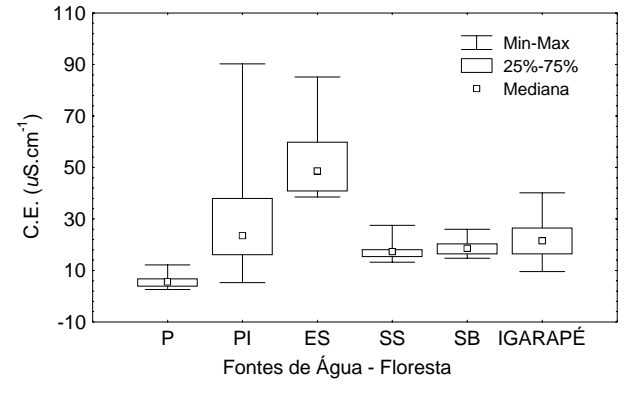

(a)

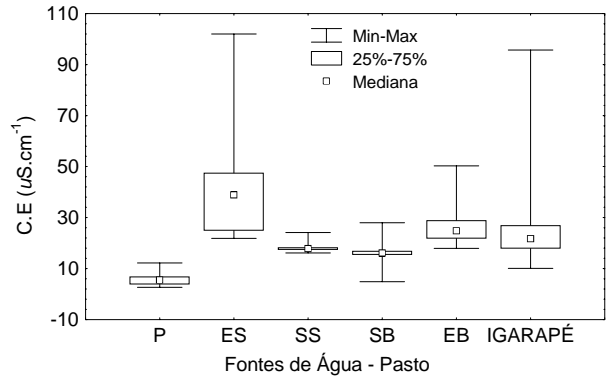

(b)

Figura 12 - Valores de condutividade elétrica obtidos para as microbacias de (a) floresta e (b) pasto. $\mathrm{P}=$ precipitação, $\mathrm{PI}=$ Precipitação Interna, ES = Escoamento Superficial, $\mathrm{SS}=$ Água Subsuperficial, $\mathrm{SB}=$ Água Subterrânea, EB = Escoamento Base 
Este aumento de compostos reflete-se num aumento significativo de $\mathrm{pH}$, alcalinidade e C.E com respeito à precipitação.

Também se encontraram diferenças significativas nos valores de $\mathrm{pH}$, alcalinidade e condutividade elétrica na água subterrânea das duas microbacias, sendo maiores os valores obtidos na floresta (Figuras 10, 11 e 12).

Os valores de $\mathrm{pH}$ na água subsuperficial e no igarapé das duas microbacias foram significativamente diferentes, sendo maiores os valores encontrados na floresta (Figura 10).

Nas Figuras 10, 11 e 12 observa-se que nas duas microbacias, os valores de $\mathrm{pH}$, alcalinidade e C.E no escoamento superficial foram maiores que os obtidos na água subsuperficial. No entanto, esta diferença não foi estatisticamente significativa, devido possivelmente à reduzida quantidade de amostras de escoamento superficial em cada microbacia (8 amostras para o pasto e 6 para a floresta).

Na floresta, os valores de pH nas águas subsuperficial e subterrânea foram significativamente menores que nas outras fontes de água desta microbacia (Figura 10). No pasto, a C.E foi maior na água subsuperficial que na água subterrânea, fato que pode ser atribuído à maior concentração de alguns íons, como $\mathrm{Mg}^{+2}, \mathrm{~K}^{+}, \mathrm{Cl}^{-}, \mathrm{Na}^{+}$(dados não mostrados) na água subsuperficial (Figura 12).

A partir dos baixos valores de alcalinidade encontrados, associados aos valores de $\mathrm{pH}$ levemente ácidos, pode-se deduzir que a alcalinidade é devida principalmente aos bicarbonatos (Roldán, 1992).

Estudos desenvolvidos em rios de ordem superior mostram que a perda de cobertura florestal traz como conseqüência o maior transporte de sólidos totais em suspensão (STS), (Williams et al., 1997; Ross et al., 1990). No entanto, na Figura 13 observa-se que, neste estudo, os maiores valores de STS foram obtidos na floresta. Além da declividade na microbacia da floresta ser maior que no pasto (4,05 e 2,14 graus respectivamente), este fato pode decorrer também da invasão do canal do igarapé por gramíneas na microbacia do pasto, enquanto na floresta o igarapé corre livremente pela superfície, arrastando partículas de solo. Outros fatores que favorecem a erosão, como a 
permeabilidade e a estrutura do solo, são descartados, uma vez que os valores de Ksat, anteriormente mencionados, foram maiores na floresta.

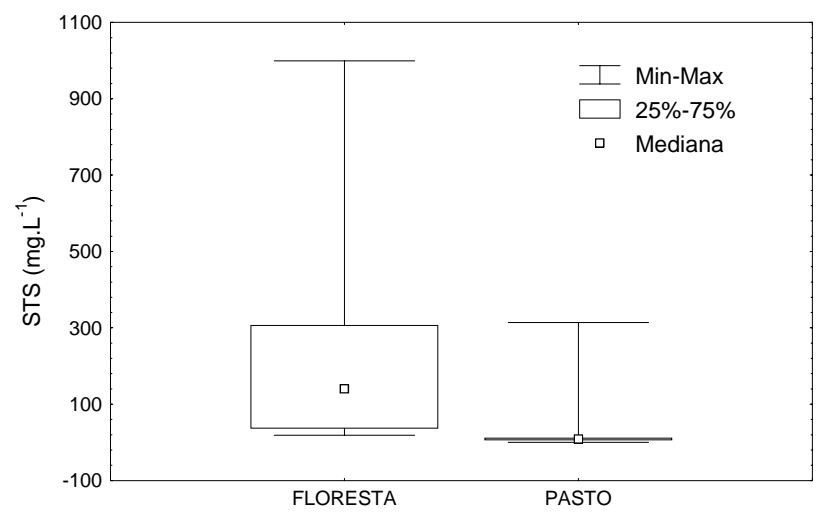

Figura 13 - Comparação dos valores de STS nas microbacias do pasto e da floresta.

\subsection{Comparação das principais formas de nitrogênio}

A partir da Figura 14, pode-se observar que as concentrações das diferentes formas de $\mathrm{N}$ na precipitação aumentam ao passar pelo dossel, especialmente o NOD. Este aumento é explicado pela dissolução na água de chuva de compostos produzidos pelas folhas e organismos que habitam este extrato da floresta.

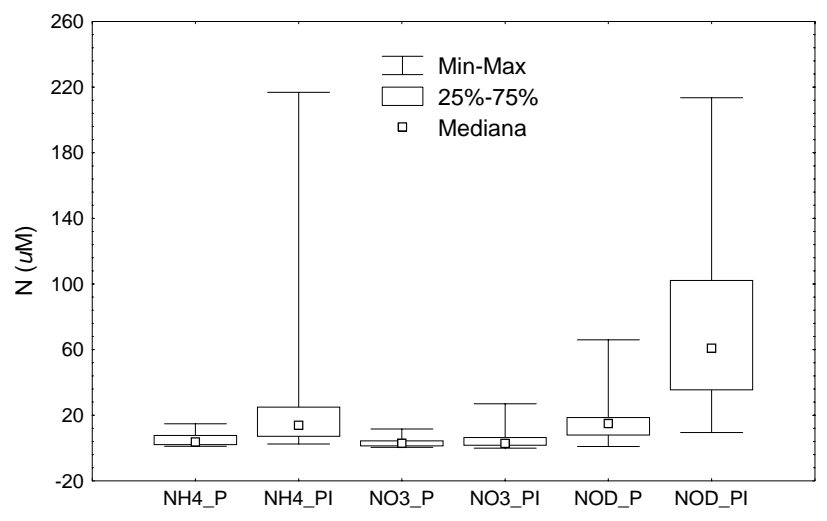

Figura 14 - Concentrações de $\mathrm{NO}_{3}{ }^{-}, \mathrm{NH}_{4}{ }^{+}$, $\mathrm{NOD}$ na precipitação (P) e na precipitação interna (PI) 
Não se encontraram diferenças significativas entre as concentrações de $\mathrm{NH}_{4}{ }^{+}$e NOD no escoamento superficial da floresta e no escoamento superficial do pasto, no entanto as concentrações de $\mathrm{NO}_{3}{ }^{-}$foram significativamente maiores no escoamento superficial da floresta (Figura 15).

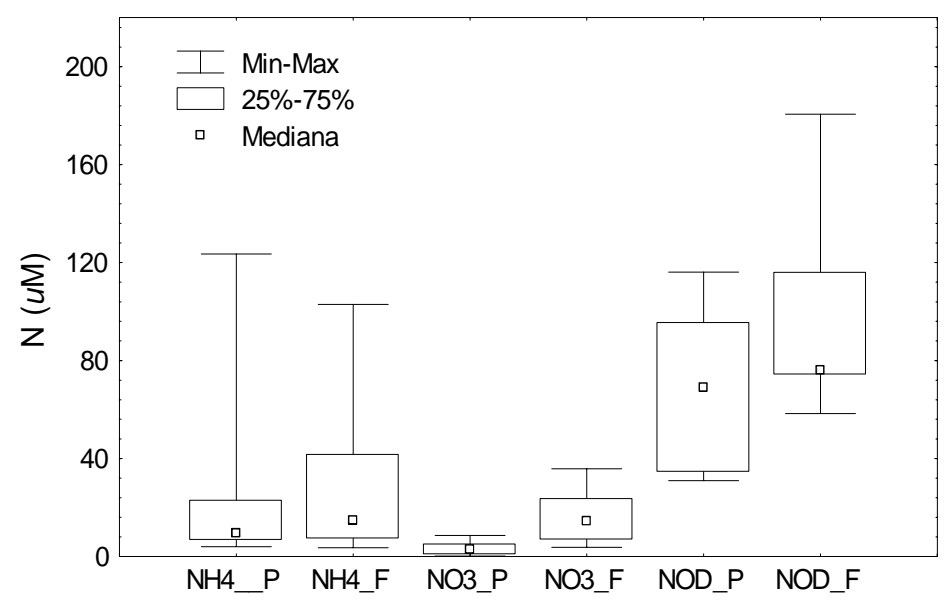

Figura 15 - Concentrações de $\mathrm{NO}_{3}{ }^{-}, \mathrm{NH}_{4}{ }^{+}$, NOD no escoamento superficial nas microbacias do pasto (P) e da floresta (F)

$\mathrm{Na}$ água subsuperficial, as concentrações de $\mathrm{NO}_{3}{ }^{-}$foram inferiores ao limite de detecção (0,05 mg. $\left.\mathrm{L}^{-1}\right)$ nas duas microbacias. De forma semelhante, na água subsuperfcial do pasto, as concentrações de nitrogênio dissolvido total (NDT) apresentaram valores inferiores ao limite de detecção $\left(<0,025 \mathrm{mg} . \mathrm{L}^{-1}\right)$. No caso da floresta, não foi determinada a concentração de NDT. Portanto, a forma predominante de nitrogênio inorgânico nesta fonte de água foi o $\mathrm{NH}_{4}{ }^{+}$, e não se encontraram diferenças estatisticamente significativas entre as duas microbacias (Figura 16).

No referente à água subterrânea, observaram-se concentrações significativamente maiores de $\mathrm{NO}_{3}{ }^{-}$e $\mathrm{NH}_{4}{ }^{+}$na microbacia da floresta (Figura 17). 


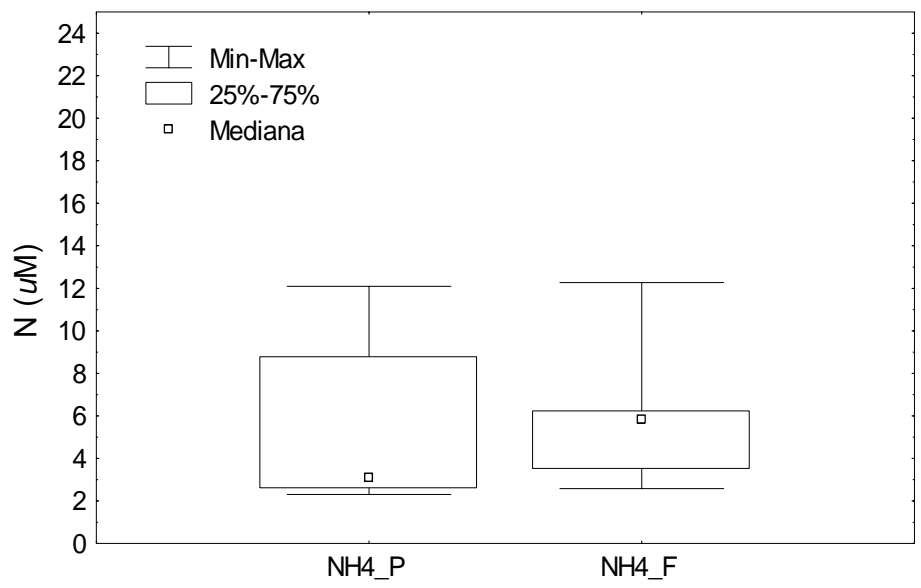

Figura 16 - Concentrações de $\mathrm{NO}_{3}{ }^{-}, \mathrm{NH}_{4}{ }^{+}$, NOD na água subsuperficial nas microbacias do pasto (P) e da floresta (F)

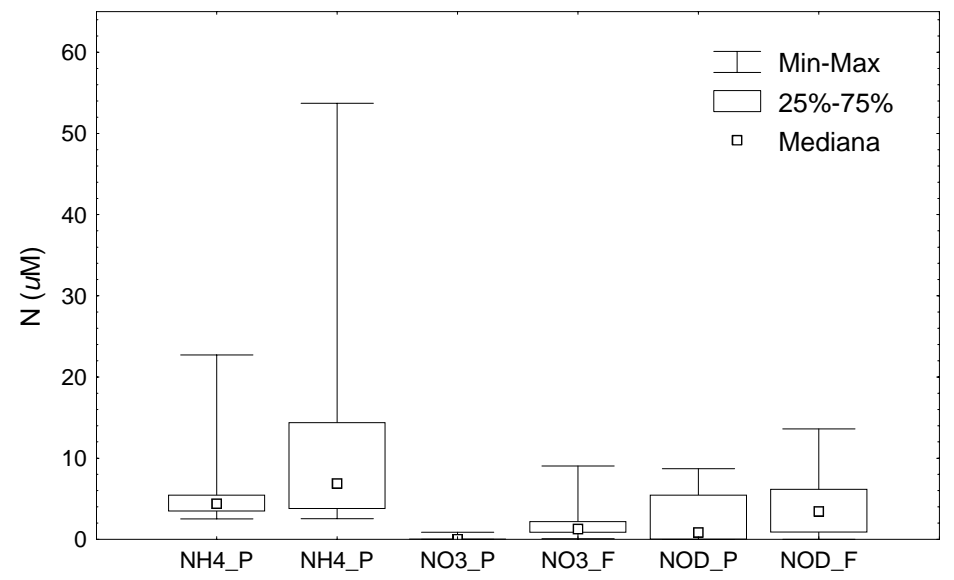

Figura 17 - Concentrações de $\mathrm{NO}_{3}{ }^{-}, \mathrm{NH}_{4}{ }^{+}$, NOD na água subterrânea nas microbacias do pasto (P) e da floresta (F)

No igarapé da floresta, as concentrações de $\mathrm{NO}_{3}{ }^{-}, \mathrm{NH}_{4}^{+}$, $\mathrm{NOD}$ e $\mathrm{NP}$ foram maiores que as determinadas no igarapé do pasto. Também observaram-se diferenças nas formas inorgânicas de $\mathrm{N}$. Enquanto no igarapé da floresta predomina o $\mathrm{NO}_{3}{ }^{-}$, no igarapé do pasto, o $\mathrm{NH}_{4}{ }^{+}$representou aproximadamente $100 \%$ do nitrogênio inorgânico dissolvido (Figura 18). 


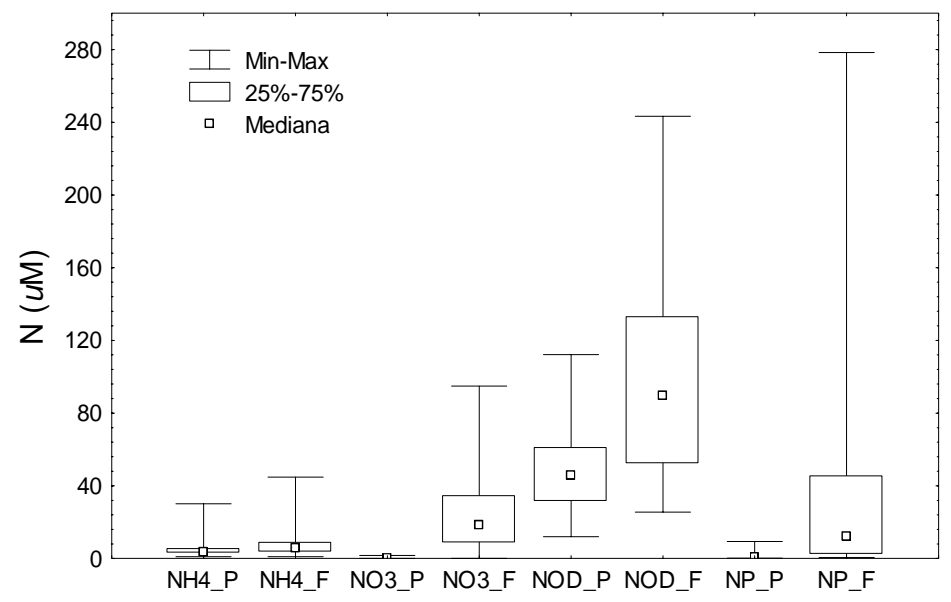

Figura 18 - Concentrações de $\mathrm{NO}_{3}{ }^{-}, \mathrm{NH}_{4}{ }^{+}$, NOD e NP nos igarapés das microbacias do pasto (P) e da floresta (F)

Nas Figuras 14, 15 e 18 também pode-se observar que o nitrogênio orgânico dissolvido (NOD) foi a principal forma de $\mathrm{N}$ dissolvido na precipitação interna, no escoamento superficial e nas águas dos igarapés das duas microbacias.

As altas concentrações de $\mathrm{NO}_{3}{ }^{-}$e $\mathrm{NH}_{4}{ }^{+}$no igarapé da floresta, e as baixas concentrações destes compostos no igarapé do pasto podem estar relacionadas com as taxas de mineralização e nitrificação. Neill et al. (1999) quantificaram tais taxas em solos cobertos por floresta e pasto no estado de Rondônia (RO). Segundo estes autores as maiores taxas de mineralização e nitrificação foram observadas na floresta, enquanto que no pasto, estas taxas foram menores. Como conseqüência, o solo da floresta apresentou teores mais elevados de $\mathrm{NO}_{3}{ }^{-}$e $\mathrm{NH}_{4}{ }^{+}$que o pasto. Tais resultados foram atribuídos ao fato do carbono apresentar menores concentrações do que o nitrogênio na floresta, resultando em um aumento nas taxas de mineralização. Porém, em pastagens, as concentrações de carbono são maiores que as de nitrogênio, favorecendo a imobilização deste elemento. As taxas de nitrificação também são influenciadas pela umidade; quanto maior a umidade do solo, menor a concentração de $\mathrm{O}_{2}$ e, como conseqüência, as taxas de nitrificação são menores (Neill et al., 1999, 1995 e Piccolo et al., 1994). 
$\mathrm{O}$ predomínio de $\mathrm{NH}_{4}{ }^{+}$na água susbsuperficial e subterrânea das duas microbacias sugere condições de anóxia nestas fontes de água. Assim, as baixas concentrações de $\mathrm{O}_{2}$ favoreceriam os processos de amonificaçâo e impediriam o processo de nitrificação. Também é possível que o $\mathrm{NO}_{3}{ }^{-}$que atinge estas fontes de água por percolação seja desnitrificado. McClain et al. (1994) na Amazônia Central e McDowell et al. (1992) em Icacos, Porto Rico, encontraram maiores concentrações de $\mathrm{NH}_{4}{ }^{+}$em água subterrânea perto da zona ripária, a qual teria menores concentrações de $\mathrm{O}_{2}$ que à água subterrânea em terra firme. Nossos resultados sugerem uma dinâmica similar nestas microbacias de Rondônia.

\subsection{Balanço de nitrogênio por evento de chuva}

Os balanços obtidos para os eventos de 4, 15, 17 e 19 de fevereiro são apresentados na Tabela 3. Embora o pasto tenha apresentado as menores concentrações das diferentes formas de $\mathrm{N}$, a exportação de nitrogênio foi maior nesta bacia, como conseqüência do maior fluxo de água. Como exemplo, podem-se citar os eventos de chuva de 15 e 17 de fevereiro. A precipitação de 15 de fevereiro foi de 9,14 mm, e o escoamento total foi de $0,101 \mathrm{~mm}$ no pasto e $0,003 \mathrm{~mm}$ na floresta, resultando em uma exportação de nitrogênio no pasto de $0,3294 \mathrm{~g} \cdot \mathrm{ha}^{-1} \cdot \mathrm{h}^{-1}$ e na floresta de $0,0429 \mathrm{~g} \cdot \mathrm{ha}^{-1} \cdot \mathrm{h}^{-1}$.

Da mesma forma, a precipitação de 17 de fevereiro foi de 35,306 mm, e o escoamento foi de 9,240 $\mathrm{mm}$ no pasto e 0,017 $\mathrm{mm}$ na floresta. O nitrogênio total exportado foi de 9,8695 g.ha ${ }^{-1} \cdot \mathrm{h}^{-1}$ no pasto, enquanto que na floresta foi de 0,103 g.ha ${ }^{-1}$. $\mathrm{h}^{-1}$. Além destes resultados, observou-se que nos eventos de chuva de menor escoamento (4 e 15 de Fevereiro) os balanços foram positivos, indicando que o ecossistema reteve N. Por outro lado, no pasto, os balanços dos eventos de 17 e 19 de fevereiro, que apresentaram maior escoamento, foram negativos, indicando que o ecossistema perdeu N. Tais eventos apresentaram maior escoamento que os eventos de 4 e 15 de fevereiro (Tabela 2). Este fato corrobora o controle dos fluxos de $\mathrm{N}$ pelo volume de água e não em função das concentrações observadas. 
Tabela 3. Balanço por evento de chuva das diferentes formas de nitrogênio (g.ha ${ }^{-1} \cdot \mathrm{h}^{-1}$ ) nas microbacias do pasto e da floresta

\begin{tabular}{|c|c|c|c|c|c|c|}
\hline \multicolumn{4}{|c|}{ FLORESTA } & \multicolumn{3}{|c|}{ PASTO } \\
\hline \multicolumn{7}{|c|}{4 de Fevereiro } \\
\hline Nutriente & Entrada & Saida & Balanço & Entrada & Saida & Balanço \\
\hline $\mathrm{NH}_{4}^{+}-\mathrm{N}$ & 1,3088 & 0,0012 & 1,0376 & 1,3088 & 0,1767 & 1,1321 \\
\hline $\mathrm{NO}_{3}^{-}-\mathrm{N}$ & 1,2463 & 0,0023 & 1,244 & 1,2463 & 0,0054 & 1,2409 \\
\hline NID & 2,5550 & 0,0035 & 2,5515 & 2,5550 & 0,1821 & 2,3729 \\
\hline NOD & $*$ & 0,0124 & $-0,0124$ & $*$ & 1,4595 & $-1,4595$ \\
\hline NP & 0 & 0,0344 & $-0,0344$ & 0 & 0,0002 & $-0,0002$ \\
\hline TOTAL $^{(1)}$ & 2,5550 & 0,0503 & 2,5047 & 2,5550 & 1,6418 & 0,9132 \\
\hline \multicolumn{7}{|c|}{15 de Fevereiro } \\
\hline Nutriente & Entrada & Saida & Balanço & Entrada & Saida & Balanço \\
\hline $\mathrm{NH}_{4}^{+}-\mathrm{N}$ & 4,22 & 0,0008 & 4,2192 & 4,22 & 0,0212 & 4,1988 \\
\hline $\mathrm{NO}_{3}^{-}-\mathrm{N}$ & 2,17 & 0,0015 & 2,1685 & 2,17 & 0,0006 & 2,1694 \\
\hline NID & 6,39 & 0,0023 & 6,3877 & 6,39 & 0,0218 & 6,3682 \\
\hline NOD & 2,072 & 0,0150 & 2,057 & 2,072 & 0,3046 & 1,7674 \\
\hline NP & 0 & 0,0256 & $-0,0256$ & 0 & 0,0030 & $-0,0030$ \\
\hline TOTAL & 8,462 & 0,0429 & 8,4191 & 8,462 & 0,3294 & 8,1326 \\
\hline \multicolumn{7}{|c|}{17 de Fevereiro } \\
\hline Nutriente & Entrada & Saida & Balanço & Entrada & Saida & Balanço \\
\hline $\mathrm{NH}_{4}^{+}-\mathrm{N}$ & 0,9202 & 0,0030 & 0,9172 & 0,9202 & 0,5385 & 0,3817 \\
\hline $\mathrm{NO}_{3}^{-}-\mathrm{N}$ & 0,3796 & 0,0207 & 0,3589 & 0,3796 & 0,0364 & 0,3432 \\
\hline NID & 1,3 & 0,0237 & 1,2763 & 1,3 & 0,5749 & 0,7251 \\
\hline NOD & n.c & 0,0593 & $-0,0593$ & n.c & 9,2128 & $-9,2128$ \\
\hline NP & 0 & 0,0200 & $-0,0200$ & 0 & 0,0818 & $-0,0818$ \\
\hline TOTAL $^{(2)}$ & 1,3 & 0,103 & 1,197 & 1,3 & 9,8695 & $-8,5695$ \\
\hline \multicolumn{7}{|c|}{19 de Fevereiro } \\
\hline Nutriente & Entrada & Saida & Balanço & Entrada & Saida & Balanço \\
\hline $\mathrm{NH}_{4}^{+}-\mathrm{N}$ & 3,1898 & 0,3674 & 2,8224 & 3,1898 & 2,7382 & 0,4516 \\
\hline $\mathrm{NO}_{3}^{-}-\mathrm{N}$ & 1,1483 & 1,4920 & $-0,3437$ & 1,1483 & 0,1403 & 1,008 \\
\hline NID & 4,3381 & 1,8594 & 2,4787 & 4,3381 & 2,8785 & 1,4596 \\
\hline NOD & n.c & 9,1176 & $-9,1176$ & n.c & 13,2744 & $-13,2744$ \\
\hline NP & 0 & 2,9429 & $-2,9429$ & 0 & 0,1539 & $-0,1539$ \\
\hline TOTAL $^{(3)}$ & 4,3381 & 13,9199 & $-9,5818$ & 4,3381 & 16,3068 & $-11,9687$ \\
\hline
\end{tabular}

n.c = não calculado

(1) Não foi calculado o NOD da precipitação porque o NOD foi um pouco menor ao NID (5,037 g. ha $\left.\mathrm{h}^{-1} \cdot \mathrm{h}^{-1}\right)$. O balanço foi calculado com o valor do NID da precipitação.

(2) O NDT na precipitação foi menor al limite de detecção $(0,025 \mathrm{mg} \mathrm{L-1})$. O balanço foi calculado com o NID da precipitação. O vertedouro do pasto transbordou neste evento de chuva, portanto, os valores estariam subestimados para esta microbacia.

(3) Não se têm amostras de NP no igarapé do pasto. Os valores foram calculados assumindo as porcentagens 99\% NDT e 1\% NP que apresentaram os outros eventos estudados nesta microbacia. 
As porcentagens das diferentes espécies de nitrogênio exportadas por evento de chuva são apresentadas na Figura 19. Para os eventos de 4 e 15 de fevereiro na floresta, o NP representou, respectivamente, 68\% e 59\% do nitrogênio total (NT), enquanto que o NDT equivaleu a $32 \%$ e $41 \%$, respectivamente. Um comportamento diferente observou-se nos eventos de 17 e 19 de fevereiro, no qual o NDT representou 81\% e $79 \%$ respectivamente do NT.

No pasto, o NDT foi responsável por praticamente o 100\% do nitrogênio total exportado. A baixa porcentagem de NP no igarapé do pasto poderia explicar-se pela menor quantidade de sólidos em suspensão transportados, como conseqüência da invasão do canal do igarapé por gramíneas, bem como, pela menor declividade do terreno.

Quanto ao NDT, o NOD foi a principal forma exportada, e representou entre $71 \%$ e $84 \%$ na floresta e, entre $82 \%$ e $94 \%$ no pasto. Por outro lado, o $\mathrm{NO}_{3}{ }^{-}$ compreendeu a maior parte do NID na floresta, apresentando valores de $63 \%$ a $87 \%$. O contrário ocorre no pasto, onde o $\mathrm{NH}_{4}{ }^{+}$equivale à aproximadamente $100 \%$ do NID exportado.

As conseqüências da maior exportação de $\mathrm{N}$ no igarapé do pasto dependeriam das características do rio que recebe este $\mathrm{N}$. Rios pequenos, de fluxo lento e alto conteúdo de matéria orgânica poderiam ter suas taxas de desnitrificação elevadas, enquanto que, em rios profundos e de fluxo rápido poderia haver aumento da nitrificação dentro do canal. Thomas et al. (2004) encontraram que, para rios de terceira ordem que drenam pastos, as concentrações de oxigênio, clorofila, sólidos totais em suspensão, carbono, $\mathrm{NP}, \mathrm{NO}_{3}{ }^{-}, \mathrm{NH}_{4}{ }^{+}$e $\mathrm{PO}_{4}{ }^{-3}$ assemelhavam-se mais àquelas do igarapé de segunda ordem na floresta que ao rio de segunda ordem no pasto. Neill et al. (2001), encontraram que, em igarapés que drenam florestas, o desenvolvimento do perifiton estava limitado por luz, enquanto que, no pasto, estava limitado por N. Neste caso, o aporte adicional de $\mathrm{N}$ poderia provocar o aumento da produtividade primária. 


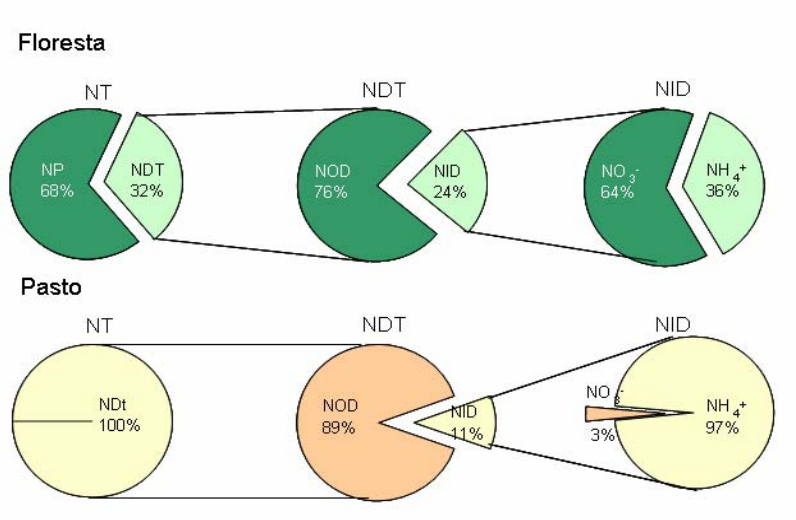

(a) 4 de Fevereiro

\section{Floresta}

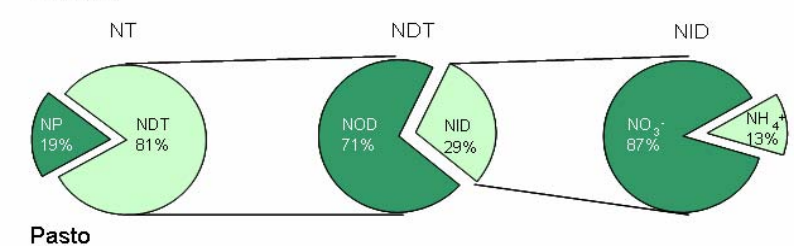

$$
\text { Pasto NT }
$$

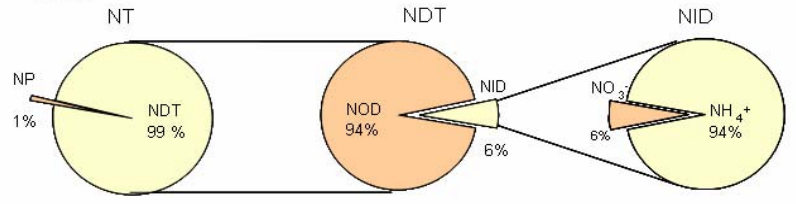

(c) 17 de Fevereiro

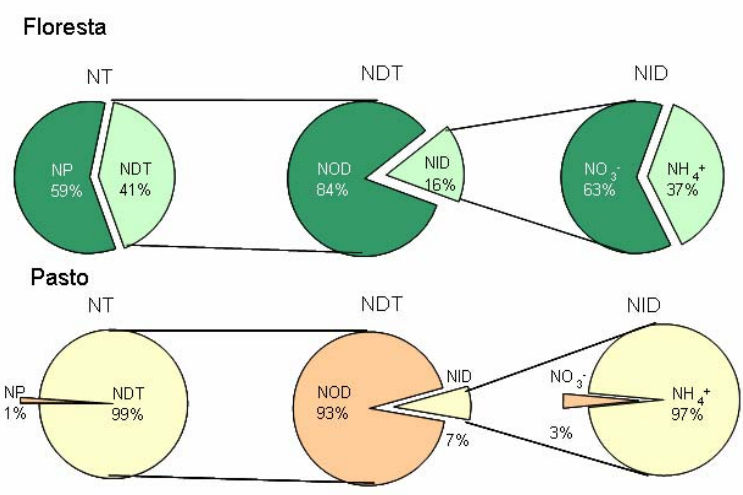

(b) 15 de Fevereiro

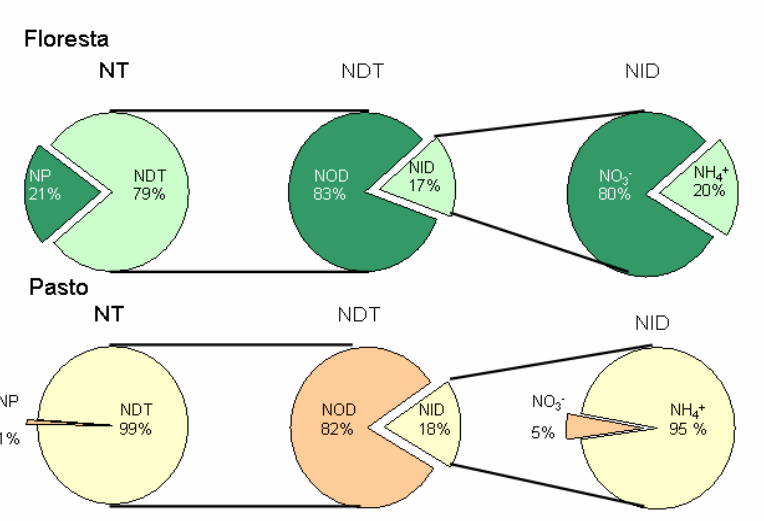

(c) 19 de Fevereiro

Figura 19 - Porcentagens de NP, NDT, NID, NOD, $\mathrm{NH}_{4}{ }^{+}$e $\mathrm{NO}_{3}{ }^{-}$exportado por evento de chuva nas bacias da floresta e do pasto 


\subsection{Vias hidrológicas e transporte de nitrogênio}

Com o objetivo de separar as fontes de água baseando-se em sua composição química, elaboraram-se diagramas de "box-plot", relacionando a concentração de diferentes elementos com as diferentes fontes de água no pasto e na floresta.

Nas Figuras 20 (a) e 21(a) pode-se observar que na floresta a chuva é enriquecida pelos cátions e ânion presentes no dossel da floresta. Nestas águas, as concentrações foram semelhantes àquelas do escoamento superficial, com exceção do Ca, que aumentou significativamente neste compartimento. Também pode-se observar o baixo conteúdo de cátions e ânions na água subterrânea. No entanto, não foi possível identificar claramente, a partir do diagrama, as principais vias hidrológicas que contribuem à formação do igarapé durante os eventos de chuva. Não há diferença clara entre a precipitação interna e o escoamento superficial. Da mesma forma não há um elemento que diferencie a água subsuperficial da água subterrânea.

No pasto, (Figuras 20 (b) e 21(b)), pode-se observar que o conteúdo de íons no escoamento superficial é maior que na precipitação. Da mesma forma que na floresta, não foi possível separar com precisão as vias hidrológicas a partir destes diagramas. Observa-se que as concentrações de $\mathrm{K}, \mathrm{Mg}, \mathrm{Na}$, e $\mathrm{Cl}$ na água subsuperficial são ligeiramente maiores que aquelas das águas subterrâneas. Igualmente, não há uma diferença clara entre o escoamento superficial, a água subsuperficial, a água subterrânea, o escoamento base e o igarapé.

Elsenbeer et al. (1995), em estudo similar realizado em uma microbacia coberta por floresta no oeste do Amazonas (La Cuenca, Perú), mostrou que a química do fluxo base do igarapé era constituída principalmente por água subterrânea, mas era fortemente influenciada pelo escoamento superficial durante os eventos de chuva. Devido à impossibilidade de encontrar um único elemento como traçador, Elsenbeer \& Lack (1996a), determinaram a relação $\mathrm{K} / \mathrm{SiO}_{4}$ para conseguir este objetivo, assumindo que o

$\mathrm{K}$ seria lixiviado principalmente pela vegetação, e o $\mathrm{Si}$, que estava presente em altas concentrações na água subterrânea, seria liberado pelas rochas. Desta forma o K seria um indicador de vias rápidas que estão em contato com o sistema biológico, enquanto 

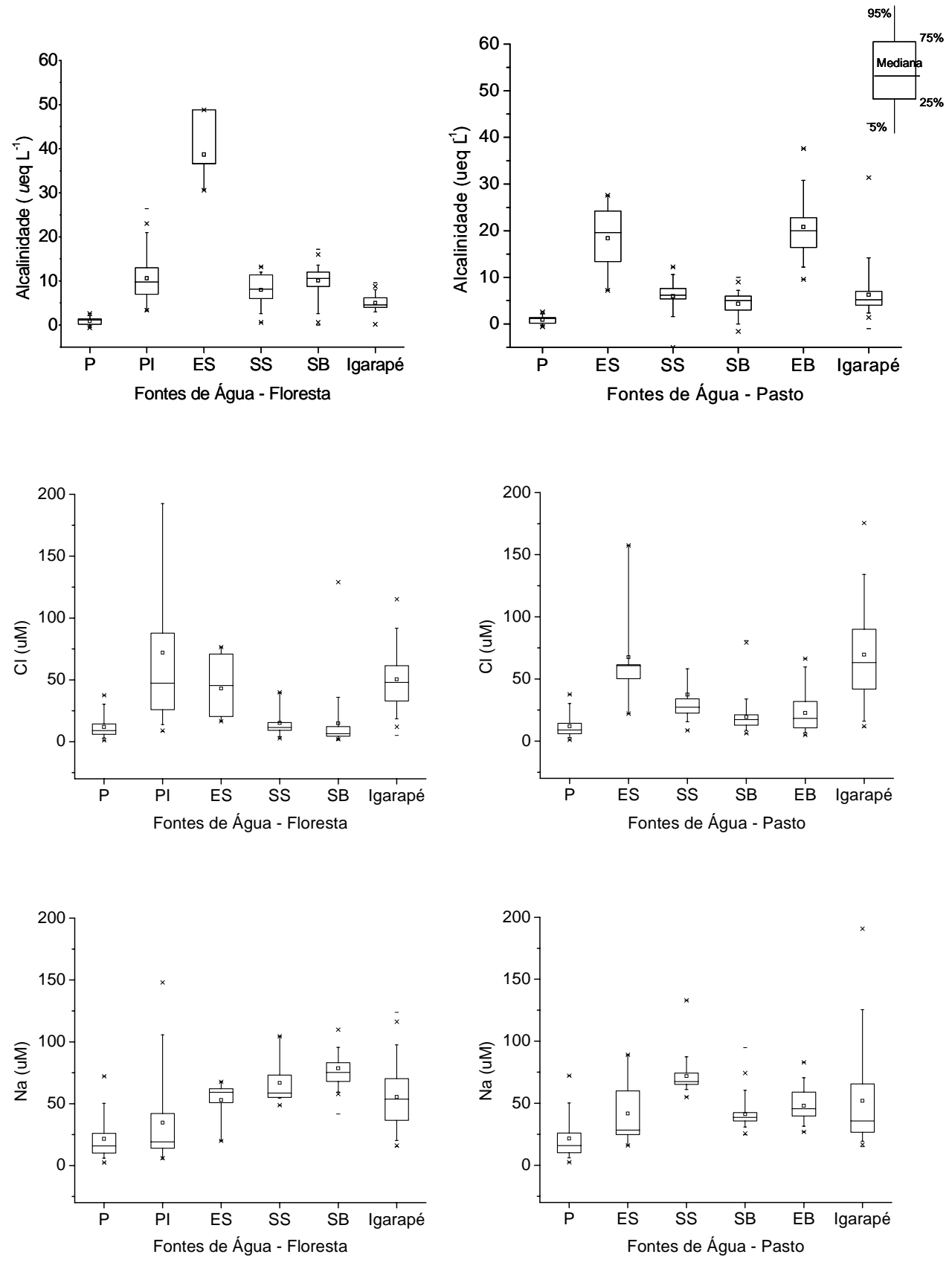

(a)

(b)

Figura 20 - Comparação das concentrações de Alcalinidade, Cloreto e Sódio nos compartimentos e vias hidrológicas da floresta (a) e do pasto (b). $\mathrm{P}=$ Precipitação, PI = Precipitação Interna, ES = Escoamento Superficial, SS = Água Subsuperficial, SB = Água Subterrânea, EB = Escoamento Base 

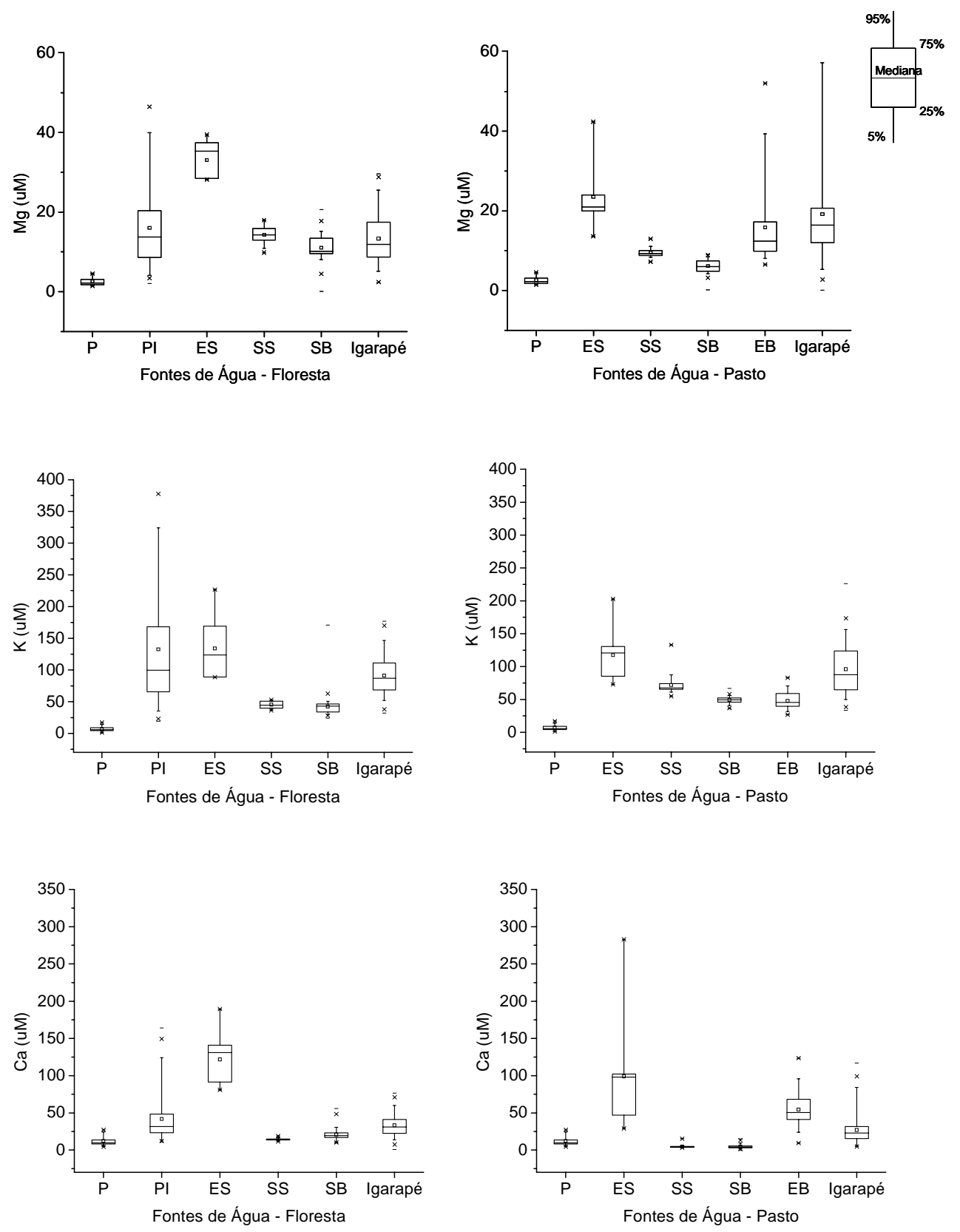

(a)

(b)

Figura 21 - Comparação das concentrações de Magnésio, Potássio e Cálcio nos compartimentos e vias hidrológicas da floresta (a) e do pasto (b). $\mathrm{P}=$ Precipitação, PI = Precipitação Interna, ES = Escoamento Superficial, SS = Água Subsuperficial, SB = Água Subterrânea, EB = Escoamento Base 
que o Si seria característico de vias lentas, que estão em contato com o sistema geológico. Além da análise química de cada fonte de água, o estudo foi complementado com medidas hidrométricas que corroboraram o escoamento superficial como uma via hidrológica importante. Outros estudos realizados no Sul dos Montes Apalaches (Mulholland et al., ${ }^{3}$ e Mulholland ${ }^{4}$ citados por Elsenbeer \& Lack 1996a) e no Sul da Grécia (Elsenbeer et al., 1994), também apontam o escoamento superficial como componente importante do igarapé durante eventos de chuva.

No Rancho Grande, não se realizaram análises de $\mathrm{SiO}_{4}$, e segundo os diagramas de "box plot" construídos com os dados disponíveis, não há um elemento ou composto que possa ser utilizado como indicador de vias hidrológicas lentas, isto é, um elemento que esteja presente em altas concentrações na água subterrânea, mas não na água superficial, dificultando, portanto, a possibilidade de fazer o cálculo de uma relação similar à realizada em La Cuenca.

No entanto, é possível que no Rancho Grande as vias superficiais também desempenhem um papel importante na formação dos igarapés durante as precipitações, uma vez que foi demonstrada a diminuição da Ksat com a profundidade em solos próximos as microbacias de estudo, fato que também foi observado em La Cuenca (Elsenbeer \& Lack, 1996b). Além disto, as concentrações dos elementos mais conservativos nas águas do igarapé é muito similar àqueles do escoamento superficial durante os eventos de precipitação.

Apesar da dificuldade para encontrar um traçador hidrológico adequado, elaboraram-se quimiógrafos para o $\mathrm{NO}_{3}{ }^{-}, \mathrm{NH}_{4}{ }^{+}$, $\mathrm{NDT}$, NOD, com o objetivo de tentar fazer uma aproximação das vias pelas quais o $\mathrm{N}$ atinge o igarapé. Estes quimiógrafos foram feitos para os eventos de 4, 15, 17 e 19 de fevereiro nas duas microbacias, e comparados com aqueles feitos para as concentrações de $\mathrm{Cl}^{-}$(um possível traçador).

\footnotetext{
${ }^{3}$ MULHOLLAND, P.J.; WILSON, G.V.; JARDINE, P.M. Hydrogeochemical response of a forested watershed to storms: effects of preferential flow along shallow and deep pathways. Water Resourch Research. v.26, p.3021-3036, 1990.

${ }^{4}$ MULHOLLAND, P.J. Hydrometric and stream chemistry evidence of three storm flowpaths in Walker Branch Watershed. Journal of Hydrology. v.151, p.291-316, 1993.
} 


\subsubsection{Microbacia do pasto}

Os quimiógrafos correspondentes ao 4 de fevereiro na microbacia do pasto encontram-se na Figura 22. As concentrações de $\mathrm{Cl}^{-}$no igarapé foram próximas às do escoamento superficial, indicando que esta seria a fonte do elemento no mesmo. $\mathrm{O}$ mesmo comportamento é observado para o NOD e o NDT, uma vez que o NOD é seu principal componente.

No caso do $\mathrm{NH}_{4}{ }^{+}$, observou-se um pico na concentração antes da vazão máxima, com posterior diminuição, e mantendo-se em valores próximos do escoamento superficial e da água subterrânea.

As concentrações de $\mathrm{NO}_{3}{ }^{-}$foram similares ao escoamento superficial e menores que as concentrações determinadas na precipitação.

O evento de 15 de fevereiro (Figura 23) teve um comportamento similar para o $\mathrm{Cl}^{-}$. Observa-se uma pequena diluição com o pico de descarga e as concentrações foram semelhantes às do escoamento superficial.

As concentrações de NOD e NDT foram inicialmente baixas, apresentando um pico com a vazão máxima, para depois diminuir a concentrações menores que as do escoamento superficial. As concentrações de $\mathrm{NH}_{4}{ }^{+}$e $\mathrm{NO}_{3}{ }^{-}$foram próximas da água subterrânea e da precipitação.

No evento de 17 de fevereiro (Figura 24), as concentrações de $\mathrm{Cl}^{-}$foram menores que no escoamento superficial. Também se observa que as concentrações do $\mathrm{Cl}^{-}$e as diferentes formas de $\mathrm{N}$ são inicialmente baixas e aumentam durante o evento. No caso do NOD e o NDT, as concentrações terminam próximas às do escoamento superficial. A concentração de $\mathrm{NH}_{4}{ }^{+}$foi menor que a encontrada na água subterrânea e maior à determinada na precipitação. As concentrações de $\mathrm{NO}_{3}{ }^{-}$no igarapé foram próximas às do escoamento superficial e menores que as da precipitação. 


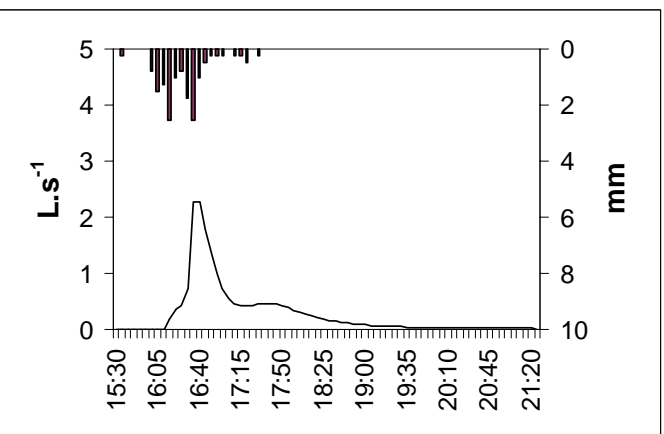

(a)

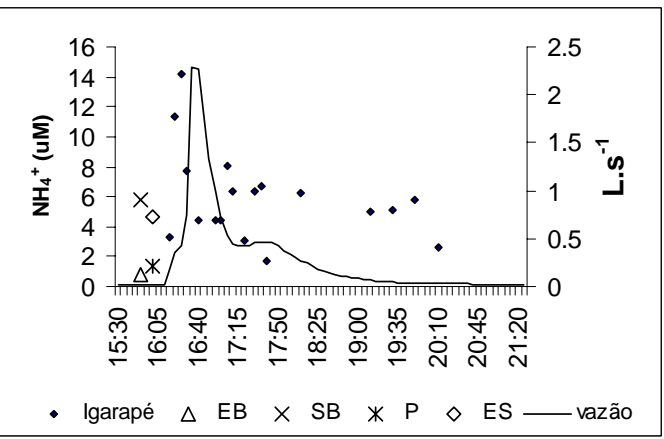

(c)

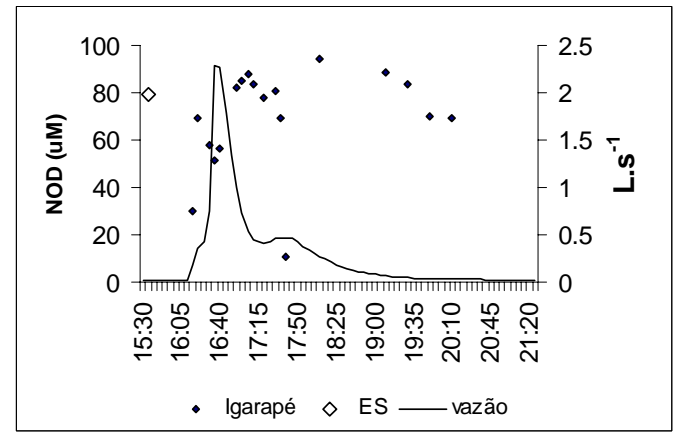

(e)

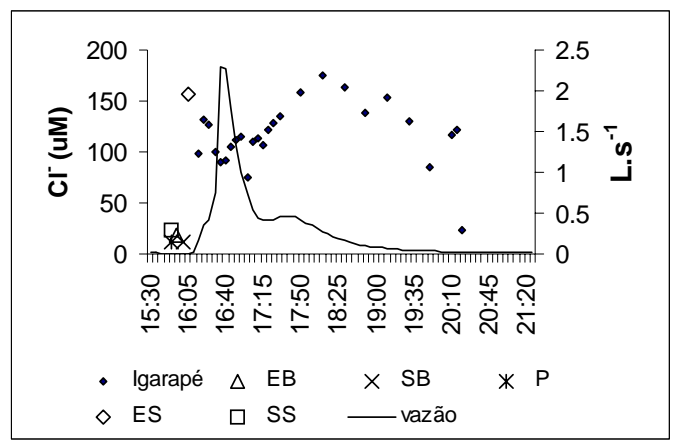

(b)

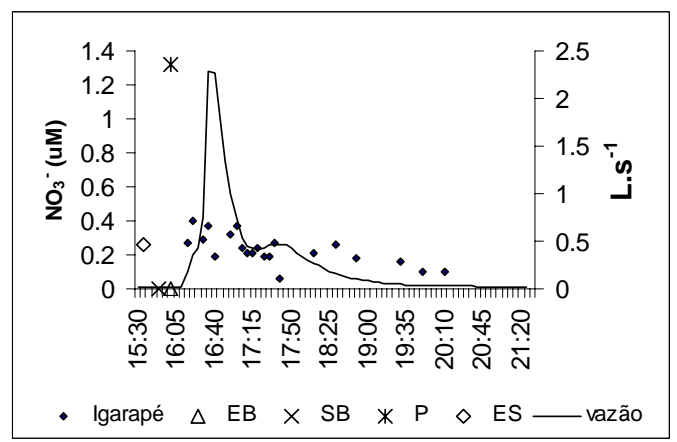

(d)

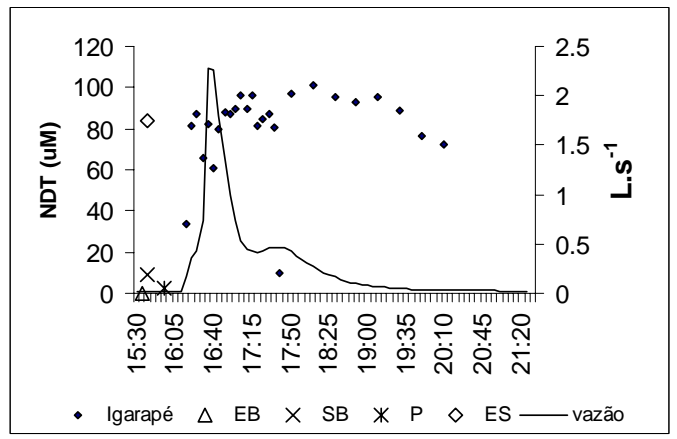

(f)

Figura 22 - Hietógrafo e hidrógrafo (a), e quimiógrafos para o $\mathrm{Cl}^{-}$(b), $\mathrm{NH}_{4}^{+}$(c), $\mathrm{NO}_{3}{ }^{-}$ (d), NOD (e) e NDT (f) para o evento de 4 de fevereiro na microbacia do pasto. EB = Escoamento Base, SB = Água Subterrânea, $\mathrm{P}=$ Precipitação, ES = Escoamento Superficial, SS = Água Subsuperficial 


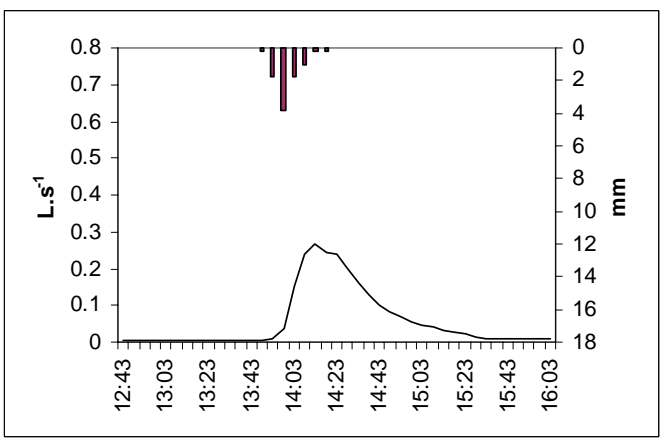

(a)

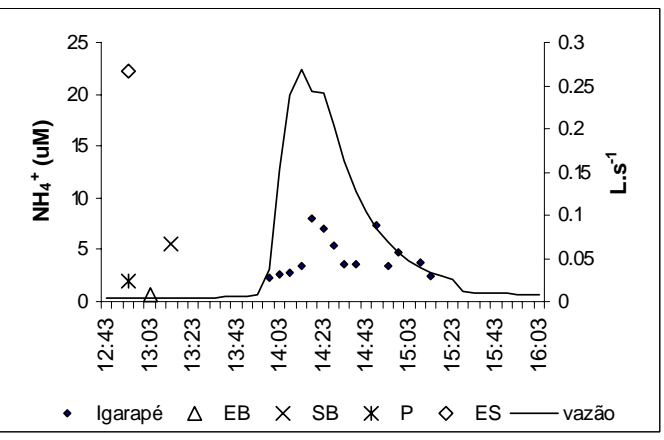

(c)

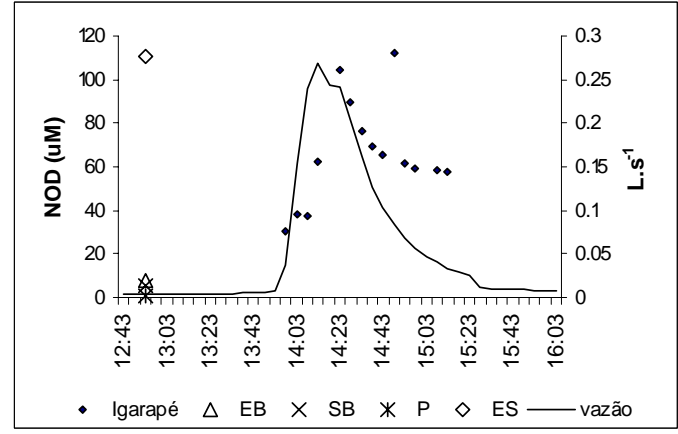

(e)

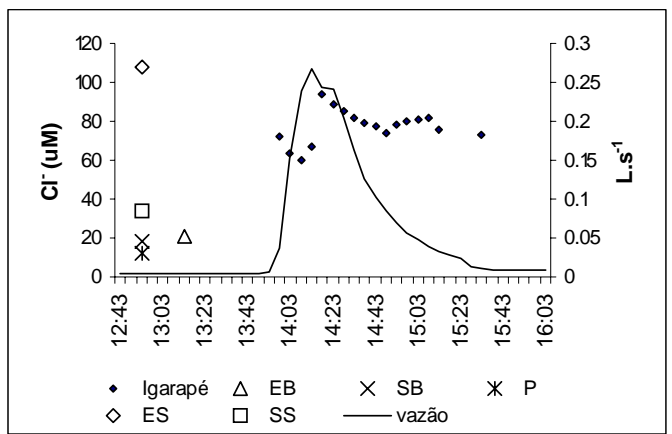

(b)

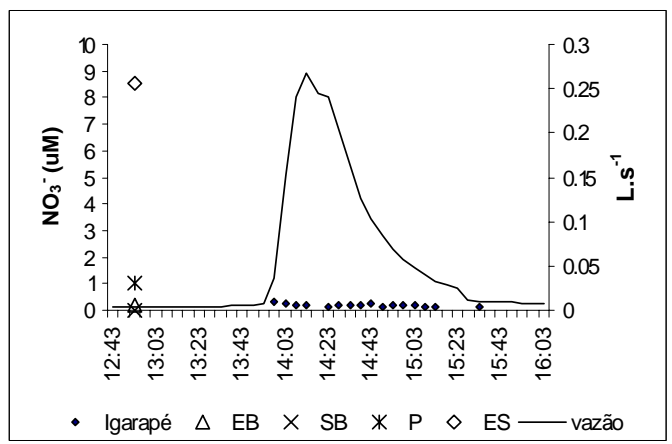

(d)

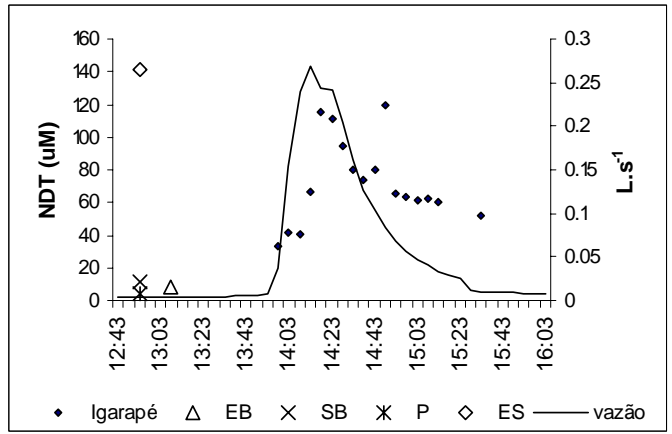

(f)

Figura 23 - Hietógrafo e hidrógrafo (a), e quimiógrafos para o $\mathrm{Cl}^{-}$(b), $\mathrm{NH}_{4}{ }^{+}$(c), $\mathrm{NO}_{3}{ }^{-}$ (d), NOD (e) e NDT (f) para o evento de 15 de fevereiro na microbacia do pasto. EB = Escoamento Base, SB = Água Subterrânea, $\mathrm{P}=$ Precipitação, ES = Escoamento Superficial, SS = Água Subsuperficial 


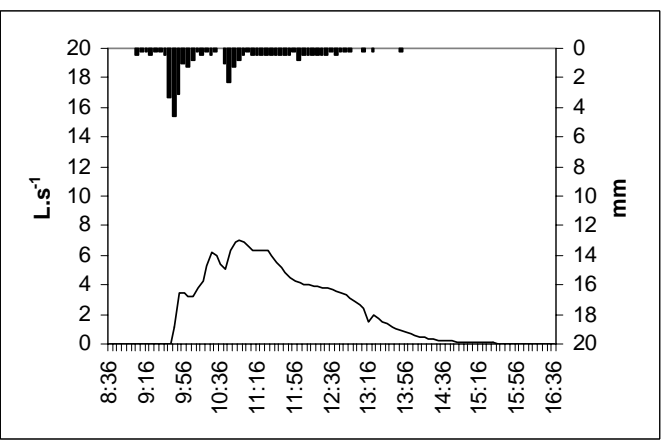

(a)

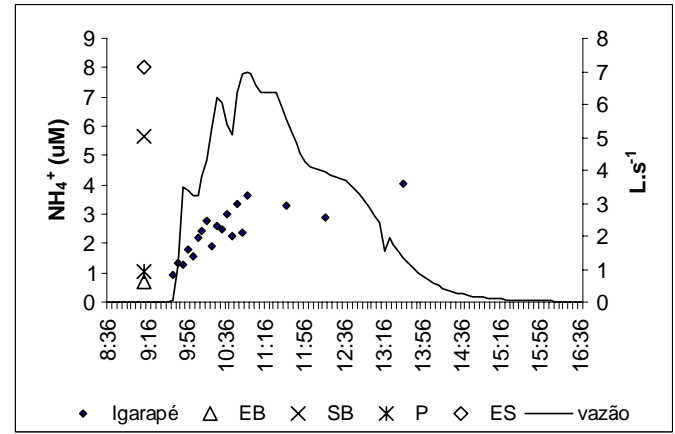

(c)

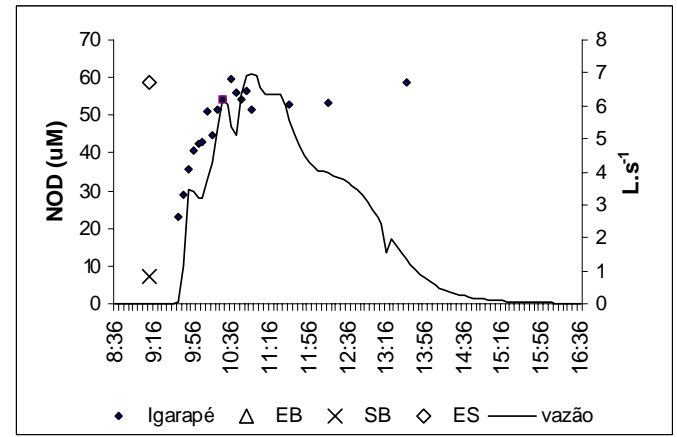

(e)

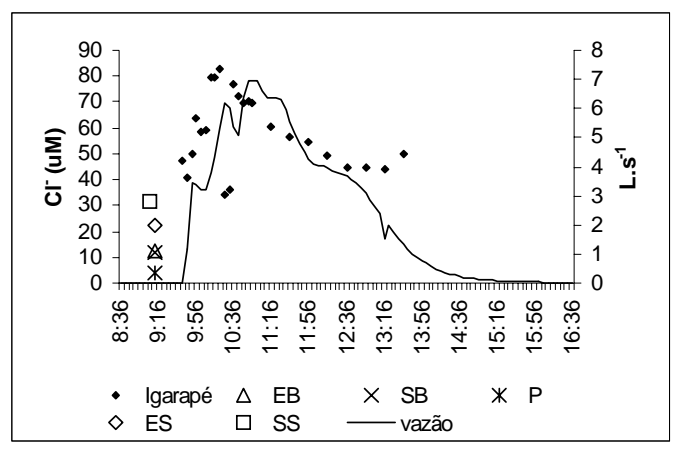

(b)

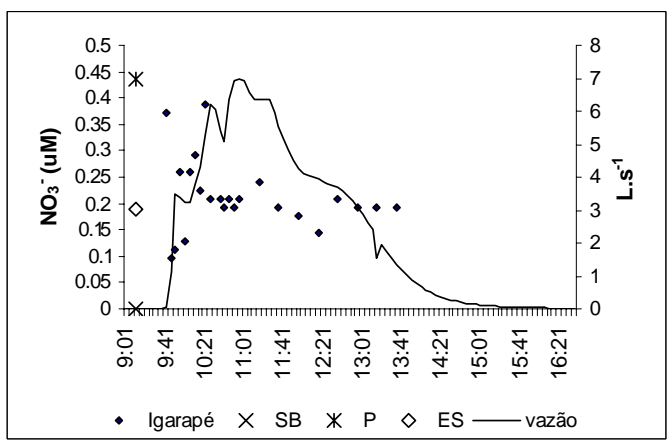

(d)

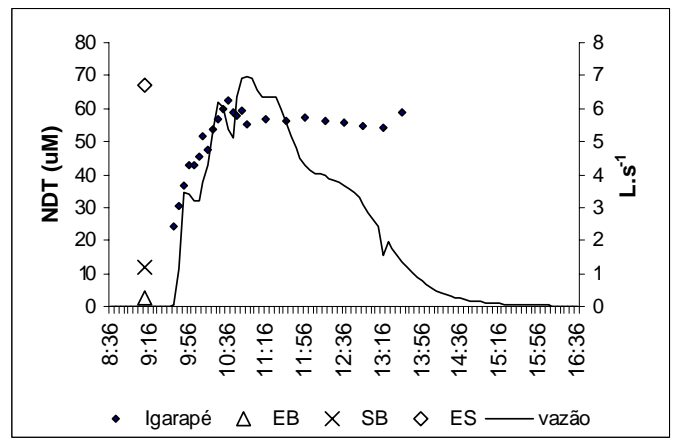

(f)

Figura 24 - Hietógrafo e hidrógrafo (a), e quimiógrafos para o $\mathrm{Cl}^{-}$(b), $\mathrm{NH}_{4}^{+}$(c), $\mathrm{NO}_{3}{ }^{-}$ (d), NOD (e) e NDT (f) para o evento de 17 de fevereiro na microbacia do pasto. EB = Escoamento Base, SB = Água Subterrânea, $\mathrm{P}=$ Precipitação, ES = Escoamento Superficial, SS = Água Subsuperficial 


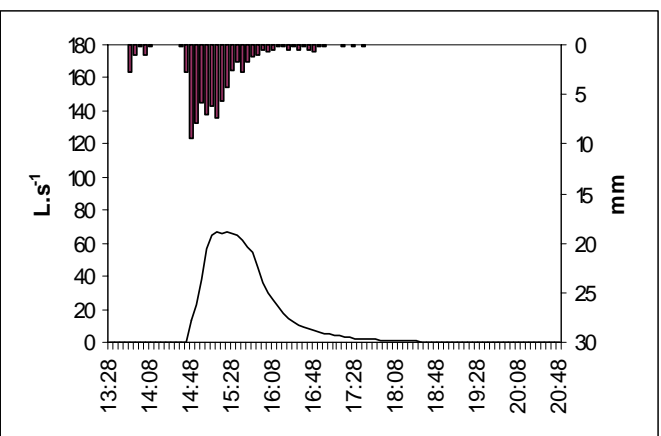

(a)

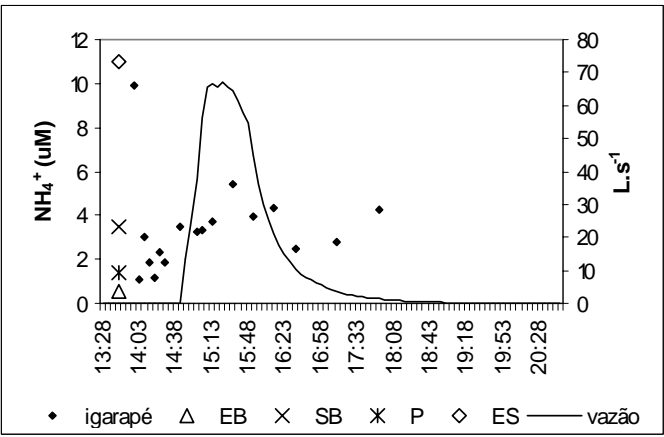

(c)

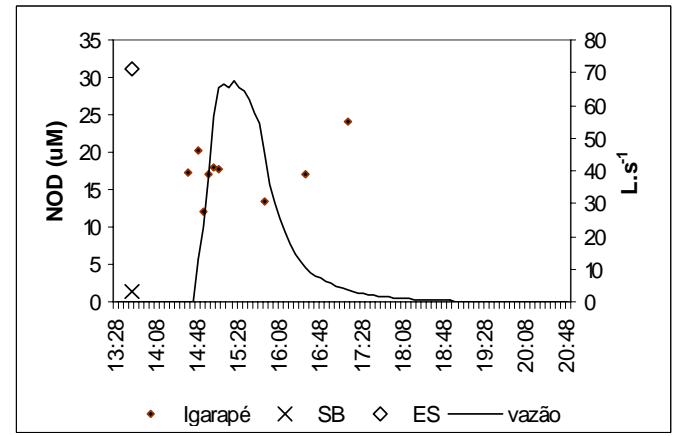

(e)

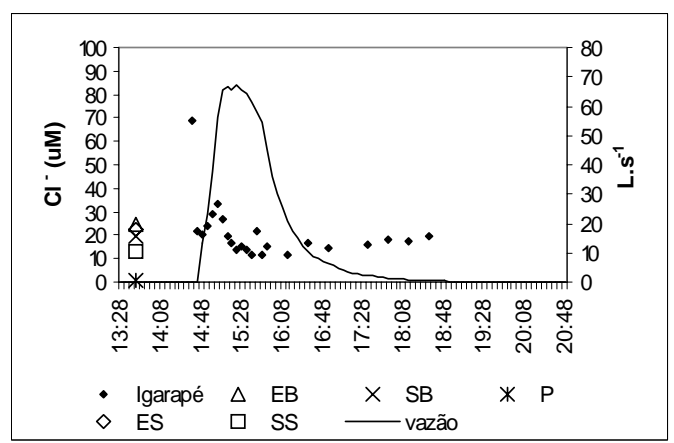

(b)

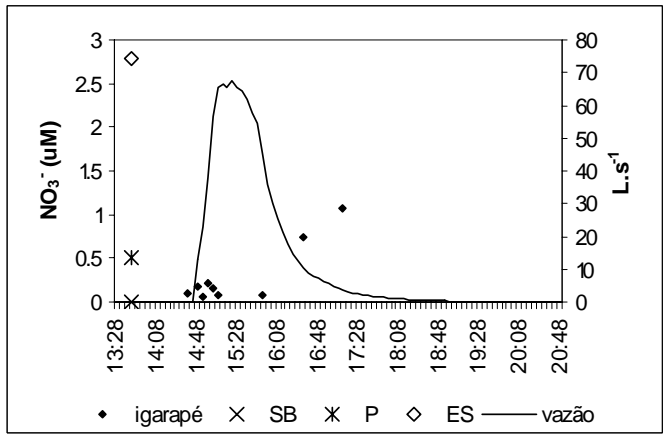

(d)

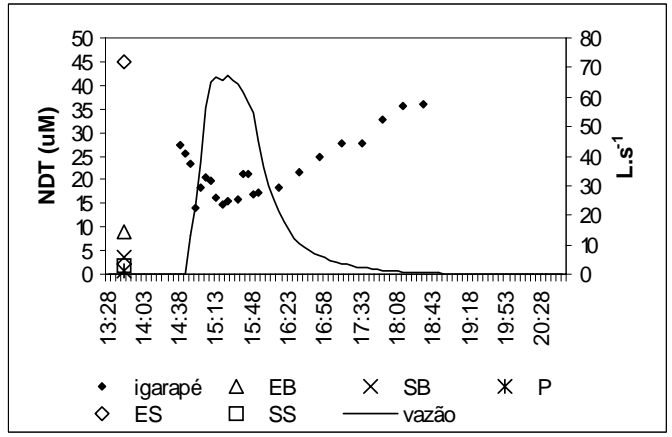

(f)

Figura 25 - Hietógrafo e hidrógrafo (a), e quimiógrafos para o $\mathrm{Cl}^{-}$(b), $\mathrm{NH}_{4}^{+}$(c), $\mathrm{NO}_{3}{ }^{-}$ (d), NOD (e) e NDT (f) para o evento de 19 de fevereiro na microbacia do pasto. EB = Escoamento Base, SB = Água Subterrânea, $\mathrm{P}=$ Precipitação, ES = Escoamento Superficial, SS = Água Subsuperficial 
No evento de 19 de fevereiro (Figura 25), as concentrações de $\mathrm{Cl}^{-}$no escoamento superficial, escoamento base e água subterrânea foram bastante próximas e semelhantes às concentrações deste elemento no igarapé. As concentrações de $\mathrm{NH}_{4}{ }^{+}$iniciaram próximas às concentrações determinadas na precipitação, e durante o evento de chuva, atingiram valores próximos aos da água subterrânea. $\mathrm{O} \mathrm{NO}_{3}{ }^{-}$apresentou concentrações semelhantes às da água subterrânea e da precipitação. As concentrações de NDT foram menores às encontradas no escoamento superficial, e maiores às determinadas nas outras fontes de água. Este mesmo comportamento foi observado para o NOD. Neste evento de chuva o vertedouro do pasto transbordou, e portanto, os valores máximos de vazão podem estar subestimados.

A tendência das concentrações de NOD e NDT de manterem-se próximas às concentrações determinadas no escoamento superficial estariam relacionadas à maior concentração de matéria orgânica e biomassa microbiana na camada superficial do solo (Cerri et al., 1985), e ao tipo de ligações que fazem os compostos orgânicos nos horizontes orgânico e mineral do solo. Enquanto que nas camadas superficiais do solo os compostos orgânicos se encontram unidos à matéria orgânica mediante forças de Van der Walls ou pontes de hidrogênio, no horizonte mineral os compostos orgânicos são complexados por hidróxidos de Fe e Al (Qualls, 2000).

Jordan et al. (1997) ressaltaram a importância das propriedades hidrológicas da bacia nas concentrações de $\mathrm{N}$ que atingem o rio. Estes autores encontraram que, em solos bem drenados, o $\mathrm{NO}_{3}{ }^{-}$pode ser lixiviado além do sistema radicular, até atingir a água subterrânea. Por outro lado, solos com menor capacidade de infiltração permitiriam que o $\mathrm{NO}_{3}{ }^{-}$ficasse na superfície do solo onde pode ser facilmente assimilado pelas plantas ou desnitrificado. Por outro lado, N e C orgânicos, por serem menos propensos à lixiviação, seriam transportados mais efetivamente por fluxos superficiais ou subsuperficiais. $\quad \mathrm{O} \mathrm{NO}_{3}{ }^{-}$lixiviado até a água subterrânea poderia ser desnitrificado na zona ripária como foi demonstrado em estudos anteriores desenvolvidos em regiões temperadas (Groffman et al., 1992 e Hill, 1996).

Na microbacia do pasto no Rancho Grande, aparentemente o escoamento superficial conduz até o igarapé as formas de $\mathrm{N}$ presentes na superfície do solo, sem 
permitir que ocorram transformações do elemento em vias profundas, onde a velocidade do fluxo da água é menor e há maior contato com a zona ripária. As concentrações de $\mathrm{NH}_{4}{ }^{+}$e $\mathrm{NO}_{3}{ }^{-}$, similares às da chuva e da água subterrânea, refletem as baixas taxas de mineralização. É provável que ocorra uma mistura de fontes de água, uma proveniente de água subsuperficial com baixas concentrações de $\mathrm{N}$, e outra do escoamento superficial, com maiores concentrações de N. A existência de uma nascente de água subsuperficial próxima à superfície do igarapé pode ser um indicativo da existência de um lençol raso que atinge a mesma durante as chuvas, o que ajudaria a explicar esta suposta mistura de fontes.

Nos quimiógrafos não foram apresentados os valores das diferentes formas de $\mathrm{N}$ na água subsuperficial, uma vez que estes foram inferiores ao limite de detecção $(<0,05$ $\mathrm{mg} \mathrm{L}^{-1}$ para $\mathrm{NH}_{4}{ }^{-}$e $\mathrm{NO}_{3}{ }^{-}$, e $<0,025$ mg. $\mathrm{L}^{-1}$ para NDT).

\subsubsection{Microbacia da floresta}

Na microbacia da floresta obtiveram-se maiores variações e diferenças entre os eventos, quando comparados com aqueles do pasto. No evento de 4 de fevereiro (Figura 26) observa-se que as concentrações de $\mathrm{Cl}^{-}$foram próximas àqueles do escoamento superficial e da água subterrânea. As concentrações de $\mathrm{NH}_{4}{ }^{+}$parecem ser uma mescla de água subterrânea e água subsuperficial, enquanto que as de $\mathrm{NO}_{3}{ }^{-}$iniciam com valores similares aos da precipitação interna e incrementam durante o evento, atingindo valores semelhantes aos do escoamento superficial. Para este evento o NOD e o NDT parecem provir principalmente da precipitação interna.

O escoamento superficial parece ser a fonte de $\mathrm{Cl}^{-}$durante o evento de 15 de fevereiro (Figura 27), enquanto que as concentrações de $\mathrm{NH}_{4}{ }^{+}$parecem ser uma mistura da água de chuva e da precipitação interna. Os valores para o $\mathrm{NO}_{3}{ }^{-}$foram menores que os obtidos para o escoamento superficial e maiores que os da precipitação e da água subterrânea. As concentrações deste composto na precipitação interna e na água subsuperficial foram menores que o limite de detecção e, por este motivo, não aparecem 
no quimiógrafo. As concentrações de NDT parecem ser próximas às da precipitação interna.

No evento de 17 de fevereiro (Figura 28), as concentrações de $\mathrm{Cl}^{-}$, NOD, NDT e $\mathrm{NO}_{3}{ }^{-}$iniciaram-se próximas às concentrações destas espécies de $\mathrm{N}$ na precipitação interna e depois aumentaram a concentrações muito maiores do que as determinadas nas diferentes fontes de água. Este aumento observa-se depois do primeiro pico de vazão e parece diminuir depois do segundo pico de descarga. Este comportamento não foi observado nas concentrações de $\mathrm{NH}_{4}{ }^{+}$, que se iniciaram perto da concentração na água da chuva e depois aumentaram a valores próximos aos da água subterrânea, que neste caso foram maiores aos de outras fontes de água.

No evento de 19 de fevereiro (Figura 29), as concentrações de $\mathrm{Cl}^{-}$no igarapé iniciaram-se mais altas do que a concentração determinada no escomento superficial, mas durante o evento de chuva, permaneceram próximas às concentrações do escoamento superficial, precipitação interna e água subsuperficial. Por outro lado, as concentrações de $\mathrm{NH}_{4}{ }^{+}$foram semelhantes às determinadas na precipitação interna. As concentrações de $\mathrm{NO}_{3}{ }^{-}$no igarapé iniciaram-se em valores próximos aos da precipitação interna, e terminaram em valores maiores aos do escoamento superficial. Este mesmo comportamento foi observado para o NDT.

Segundo os resultados obtidos para estes eventos de chuva, a precipitação interna e o escoamento superficial possivelmente desempenhariam um papel importante como fonte de $\mathrm{N}$ na floresta. No entanto, há variações nas respostas para cada evento, e portanto, é difícil chegar a conclusões a partir destes.

Análises de mais eventos de chuva e outras fontes de água nas duas microbacias seriam úteis para determinar o papel de cada uma destas fontes na química observada nas águas dos igarapés. 


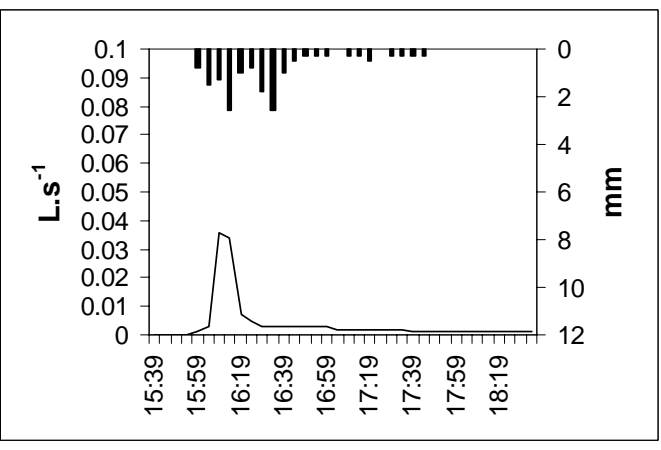

(a)

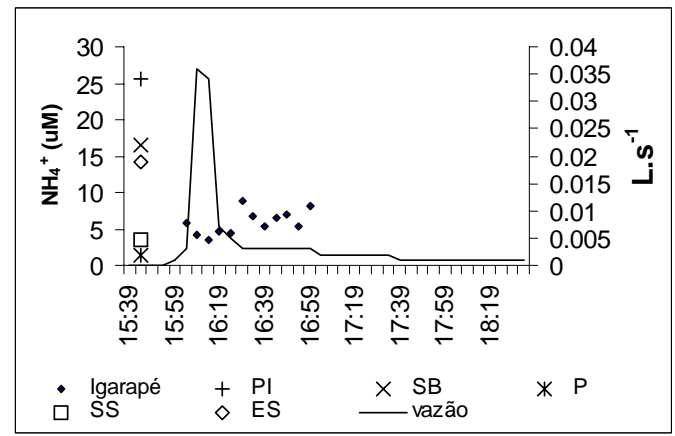

(c)

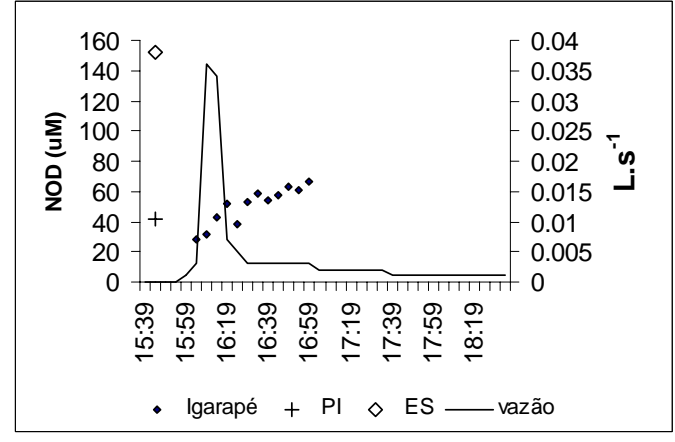

(e)

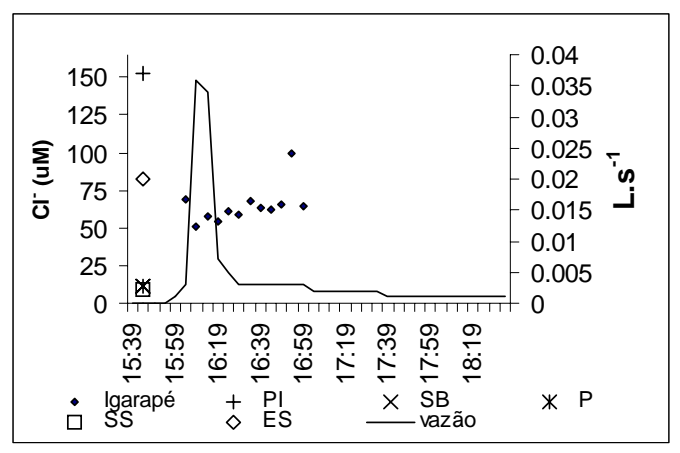

(b)

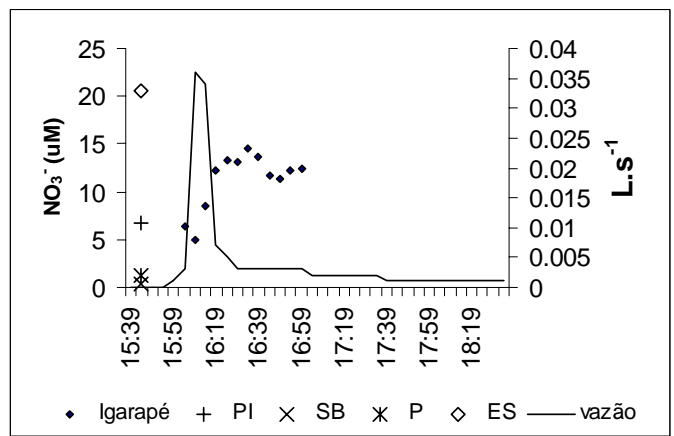

(d)

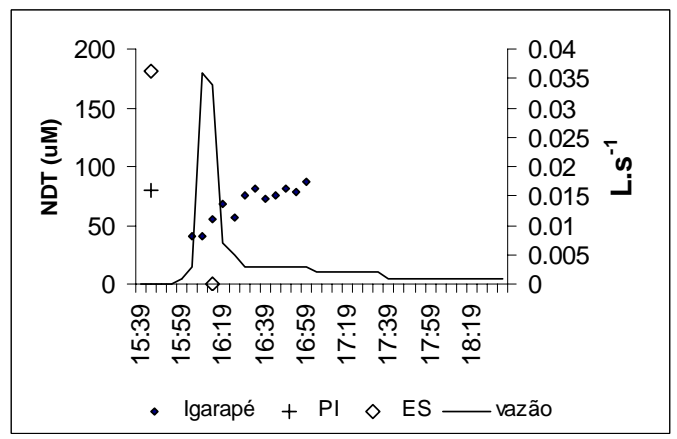

(f)

Figura 26 - Hietógrafo e hidrógrafo (a), e quimiógrafos para o $\mathrm{Cl}^{-}$(b), $\mathrm{NH}_{4}^{+}$(c), $\mathrm{NO}_{3}^{-}$ (d), NOD (e) e NDT (f) para o evento de 4 de fevereiro na microbacia da floresta. $\mathrm{P}=$ Precipitação, $\mathrm{PI}=$ Precipitação Interna, ES = Escoamento Superficial, SS = Água Subsuperficial, SB = Água Subterrânea 


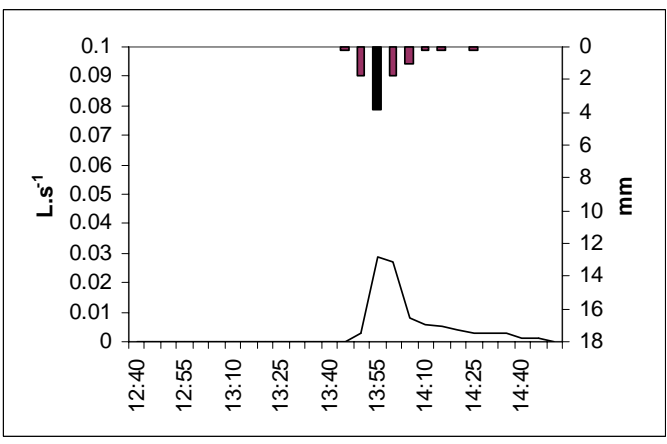

(a)

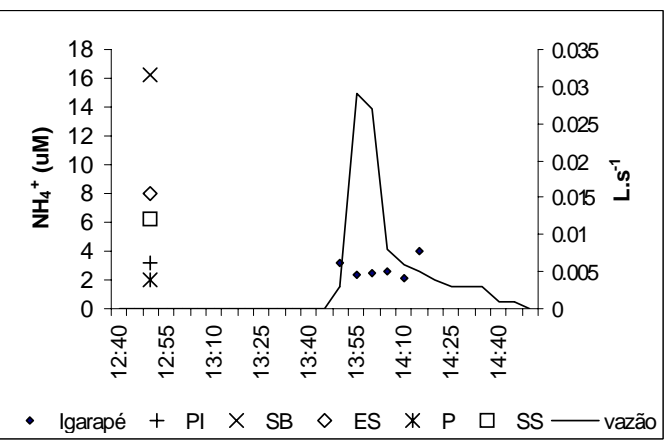

(c)

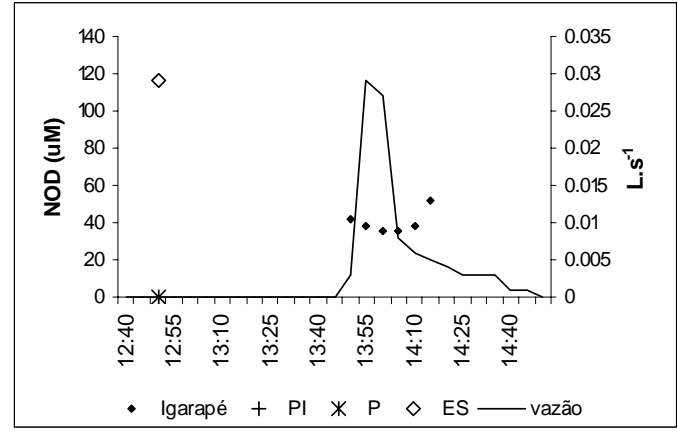

(e)

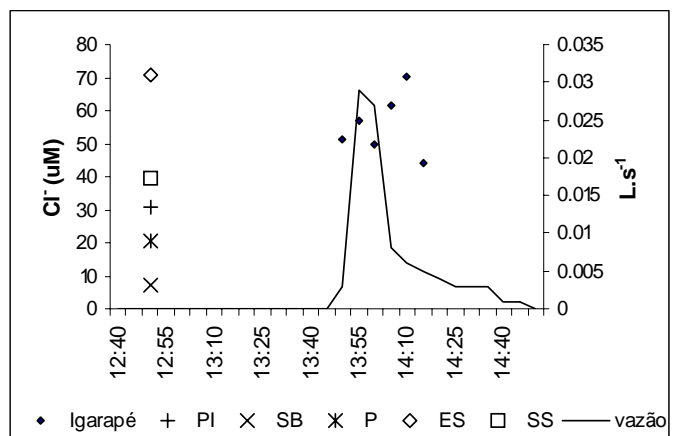

(b)

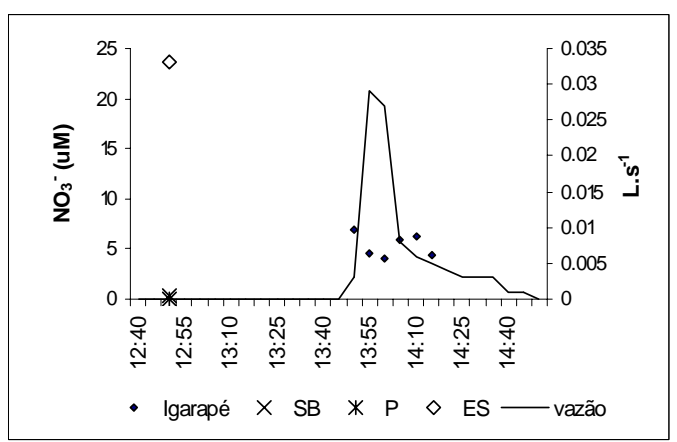

(d)

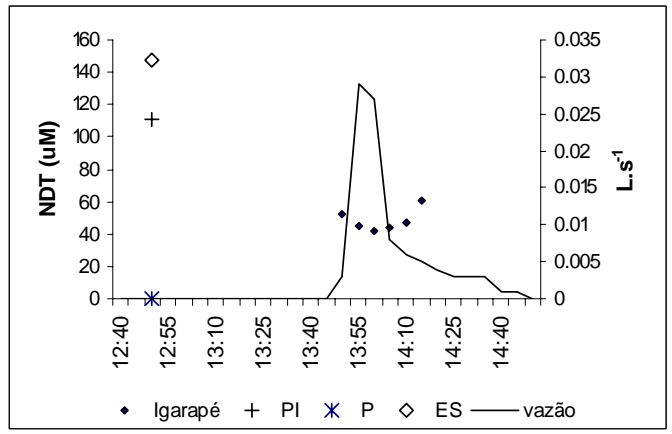

(f)

Figura 27 - Hietógrafo e hidrógrafo (a), e quimiógrafos para o $\mathrm{Cl}^{-}$(b), $\mathrm{NH}_{4}^{+}$(c), $\mathrm{NO}_{3}{ }^{-}$ (d), NOD (e) e ND (f) para o evento de 15 de Fevereiro na microbacia da floresta. . P = Precipitação, PI = Precipitação Interna, ES = Escoamento Superficial, SS = Água Subsuperficial, SB = Água Subterrânea 


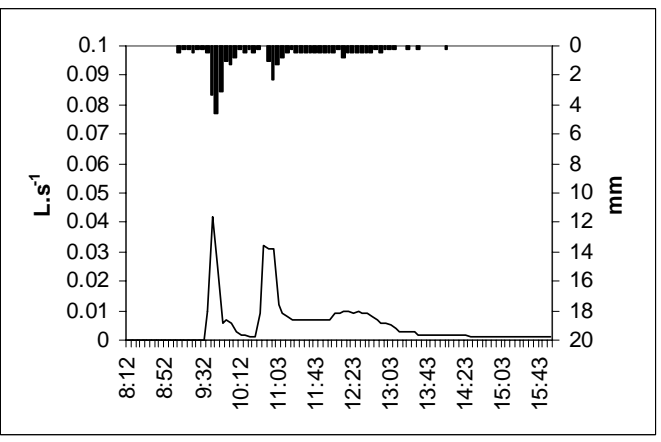

(a)

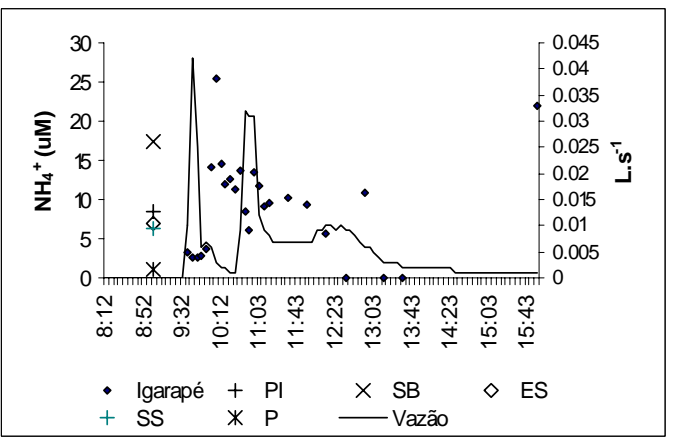

(c)

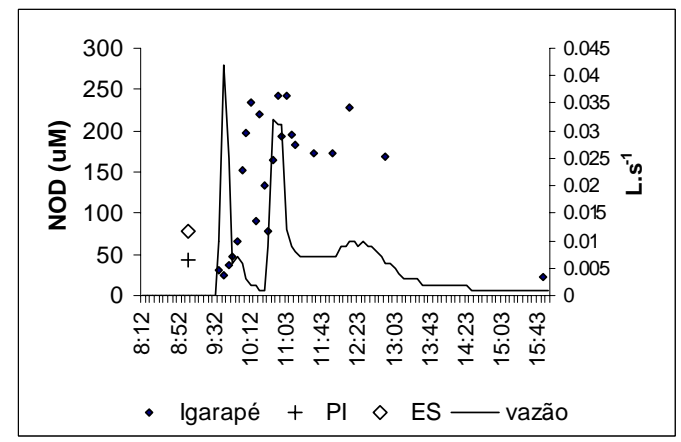

(e)

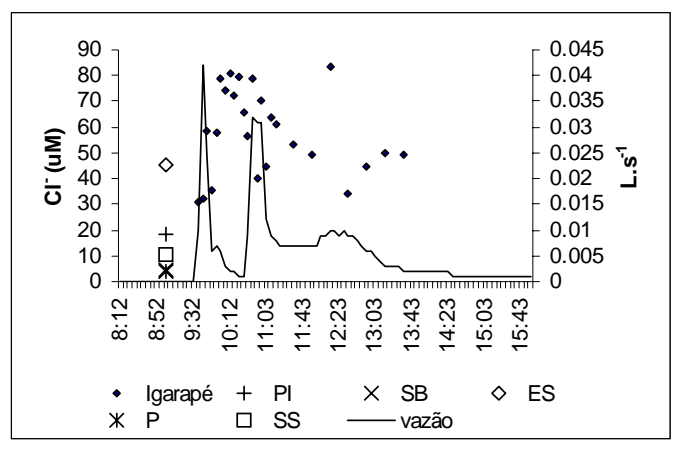

(b)

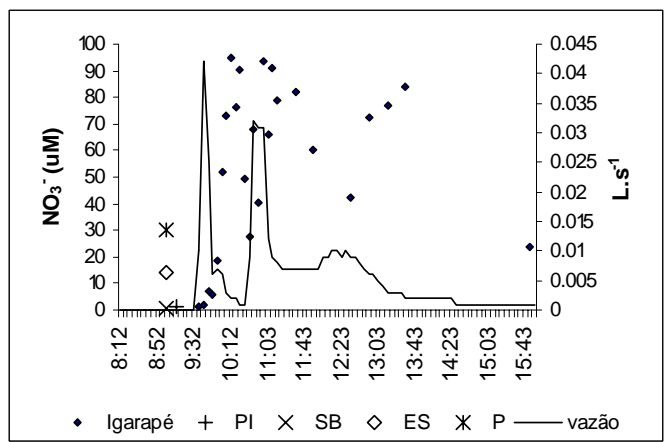

(d)

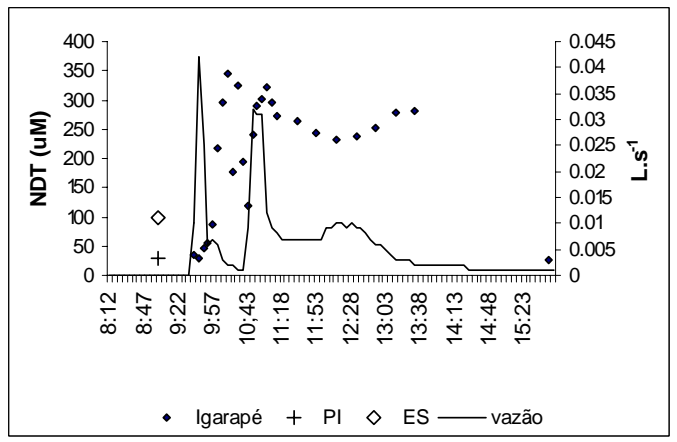

(f)

Figura 28 - Hietógrafo e hidrógrafo (a), e quimiógrafos para o $\mathrm{Cl}^{-}$(b), $\mathrm{NH}_{4}^{+}$(c), $\mathrm{NO}_{3}{ }^{-}$ (d), NOD (e) e ND (f) para o evento de 17 de Fevereiro na microbacia da Floresta. $\mathrm{P}=$ Precipitação, $\mathrm{PI}=$ Precipitação Interna, ES = Escoamento Superficial, SS = Água Subsuperficial, SB = Água Subterrânea 


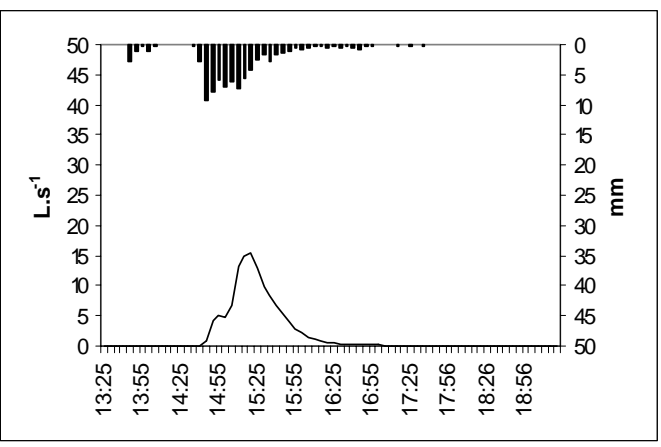

(a)

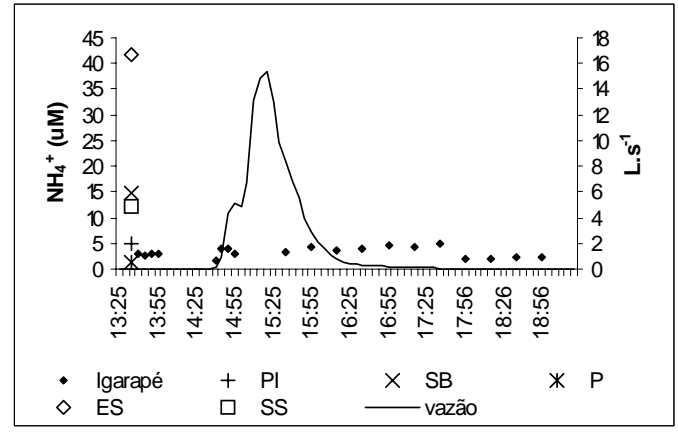

(c)

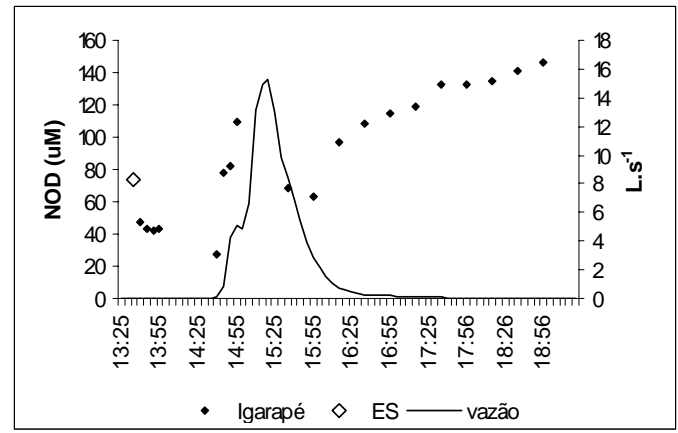

(e)

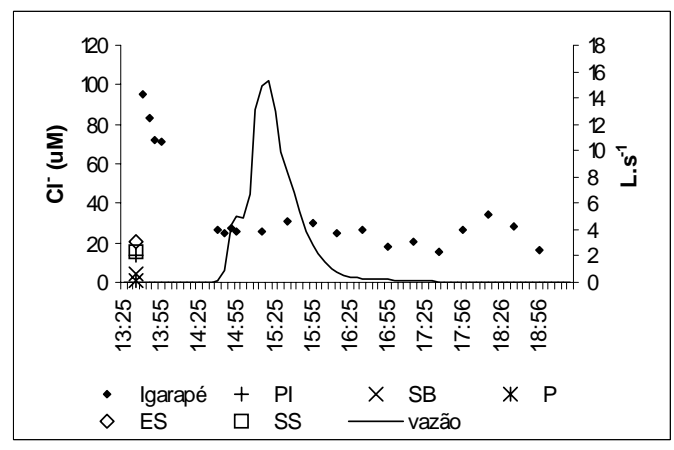

(b)

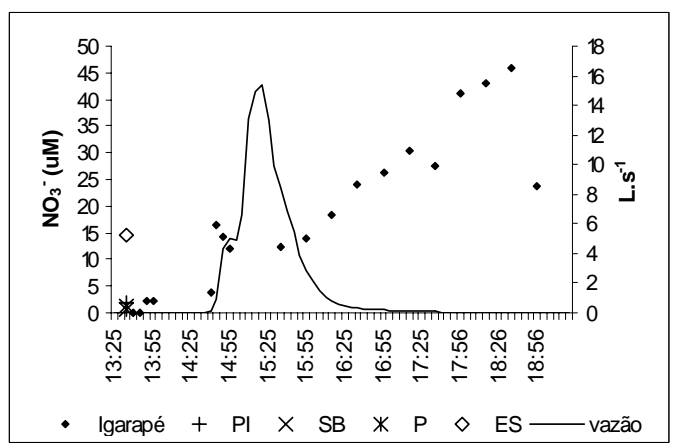

(d)

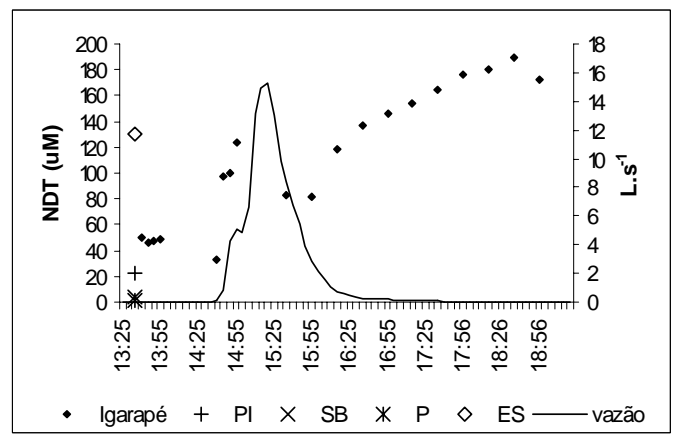

(f)

Figura 29 - Hietógrafo e hidrógrafo (a), e quimiógrafos para o $\mathrm{Cl}^{-}$(b), $\mathrm{NH}_{4}^{+}$(c), $\mathrm{NO}_{3}{ }^{-}$ (d), NOD (e) e ND (f) para o evento de 19 de Fevereiro na microbacia da Floresta. $\mathrm{P}=$ Precipitação, $\mathrm{PI}=$ Precipitação Interna, ES = Escoamento Superficial, SS = Água Subsuperficial, SB = Água Subterrânea 
Na Figura 30 apresenta-se um resumo dos resultados obtidos neste estudo. Dentro das caixas encontram-se as concentrações médias de $\mathrm{NOD}, \mathrm{NO}_{3}{ }^{-}$, e $\mathrm{NH}_{4}{ }^{+}$para cada compartimento estudado. Os fluxos de água no solo estão representados, esquematicamente, com flechas.

A partir desta figura, pode-se observar que, na floresta, a água da chuva ao atravessar o dossel foi enriquecida com as diferentes formas de N. Estas concentrações aumentaram no escoamento superficial e diminuíram na água subsuperficial e subterrânea. Observaram-se mudanças nas formas de $\mathrm{N}$ predominantes, sendo o nitrogênio orgânico dissolvido a forma predominante na precipitação interna, no escoamento superficial e a água do igarapé. $\mathrm{O} \mathrm{NH}_{4}^{+}$predominou na água subsuperficial e subterrânea. Tais diferenças poderiam ser atribuídas a mudanças nas concentrações de oxigênio em cada compartimento estudado. Possíveis condições de anóxia poderiam restringir a nitrificação na água subsuperficial e subterrânea. A maior permeabilidade do solo na microbacia da floresta é indicada pela seta no sentido vertical. Como conseqüência da maior permeabilidade, a formação de escoamento superficial foi menor e conduziu a menores vazões no igarapé. A menor descarga de água ocasionou menor exportação de nitrogênio. Devido às altas concentrações de $\mathrm{NOD}, \mathrm{NO}_{3}{ }^{-}$e $\mathrm{NH}_{4}{ }^{+}$ encontradas no igarapé da floresta, é possível supor o predomínio de vias hidrológicas superficiais, já que as águas subsuperficial e subterrânea não apresentaram concentrações elevadas destas formas de $\mathrm{N}$.

No pasto, as concentrações de $\mathrm{N}$ na água da chuva aumentaram ao atingirem o escoamento superficial. A compactação do solo na superfície desta microbacia ocasionou menor infiltração e maior formação de escoamento superficial. Maiores vazões conduziram a maior exportação de N. No escoamento superficial e no igarapé desta microbacia, predominou o $\mathrm{NOD}$ e o $\mathrm{NH}_{4}{ }^{+}$, enquanto na água subsuperficial e subterrânea predominou o $\mathrm{NH}_{4}{ }^{+}$. As concentrações das diferentes formas de $\mathrm{N}$ no igarapé do pasto foram menores que as encontradas no igarapé da floresta. 
(a)

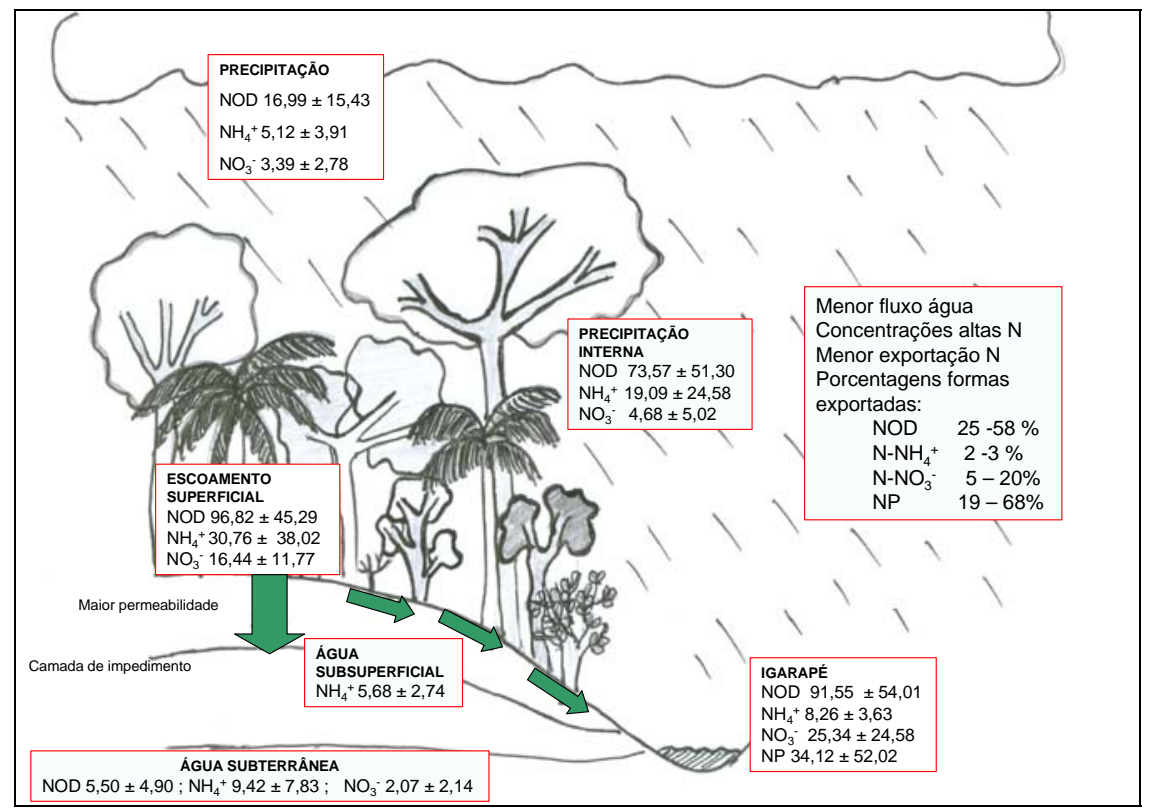

(b)

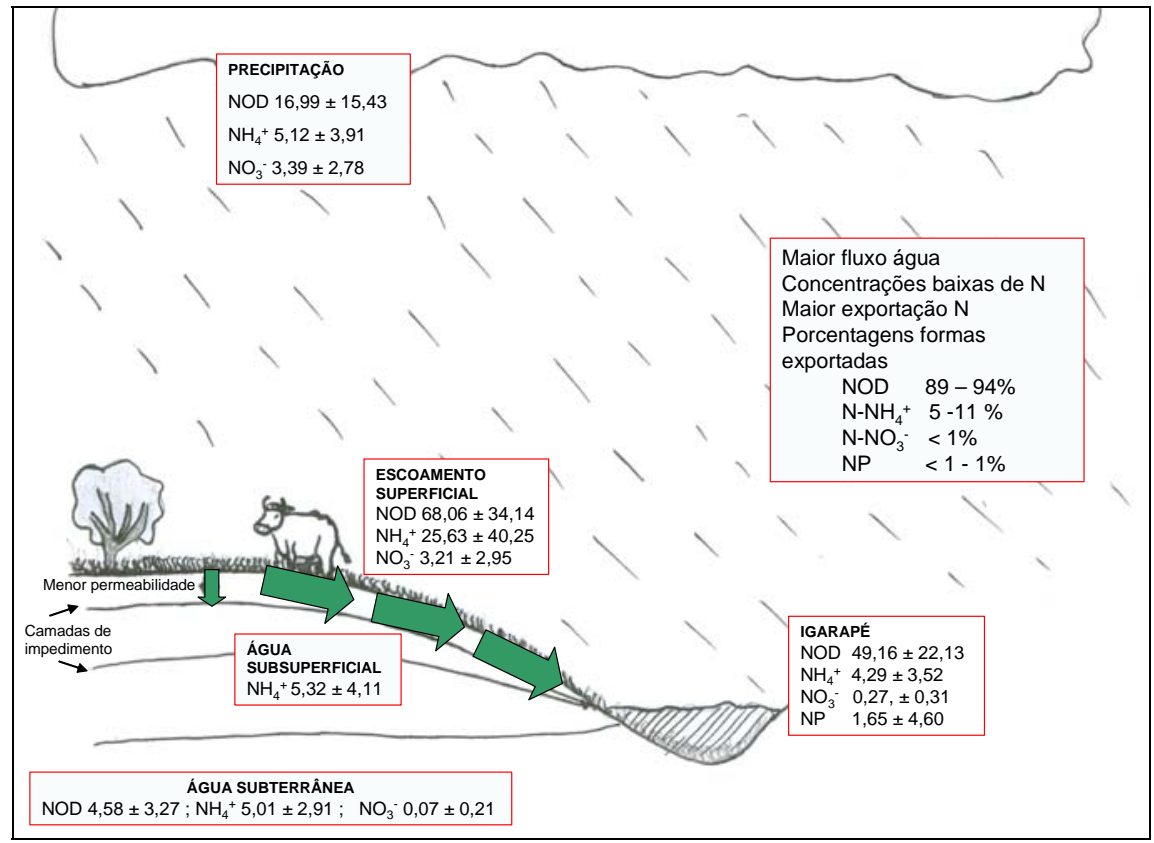

Figura 30 - Resumo esquemático dos principais resultados obtidos nas microbacias estudadas (a) floresta e (b) pasto. (Valores médios expressos em $\mu \mathrm{M}$ ) 
O predomínio de $\mathrm{NH}_{4}{ }^{+}$e as baixas concentrações de $\mathrm{NO}_{3}{ }^{-}$no igarapé do pasto estariam refletindo mudanças no processamento do $\mathrm{N}$, como conseqüência de mudanças nas características físicas do solo desta microbacia. A menor permeabilidade na superfície do solo, ocasionada pelo pisoteio do gado, faz que o canal do igarapé permaneça com água correndo lentamente durante a estação chuvosa. Nestas condições, a água tem um maior contacto com os sedimentos do fundo, onde ocorrem os principais processos de remoção de $\mathrm{N}$ (Conn, 2003).

Estudos desenvolvidos em regiões temperadas mostraram que rios de primeira a quarta ordem e fluxo lento poderiam remover quantidades maiores de $\mathrm{N}$, pelo fato de ter um maior contacto com os sedimentos, detritos bentônicos e biofilmes presentes no fundo dos mesmos. Adicionalmente, a maior relação volume/superfície permitiria processar grandes quantidades de N (Conn, 2003; Peterson et al., 2001). Analogamente, sob condições de anóxia devidas às altas taxas respiratórias, elevadas concentrações de matéria orgânica disponível e sedimentos finos, também contribuem à remoção de $\mathrm{N}$ mediante desnitrificação. Portanto, na microbacia do pasto de este estudo, é possível que as menores concentrações de $\mathrm{NOD}, \mathrm{NO}_{3}{ }^{-}$e $\mathrm{NH}_{4}{ }^{+}$sejam reguladas pelas baixas taxas de mineralização e nitrificação e, o $\mathrm{NO}_{3}{ }^{-}$produzido poderia ser desnitrificado dentro do canal do igarapé.

Haupert et al. (2004), comparando dois igarapés que drenam pastos no estado de Rondônia, encontraram que a assimilação de $\mathrm{NH}_{4}{ }^{+}$é mais rápida em rios pequenos que em rios de ordem superior. Os autores também mostraram que o $\mathrm{N}$ pode ser retido por gramíneas que invadem o canal e por matéria orgânica bentônica. Portanto, é provável que no igarapé do pasto deste estudo, o $\mathrm{N}$ também seja assimilado mais rapidamente, fato que também explicaria as baixas concentrações de $\mathrm{N}$ no igarapé.

O efeito no ecossistema da maior exportação de $\mathrm{N}$ pelo igarapé do pasto depende das características físicas, químicas e biológicas do rio que recebe este N (Conn, 2003). No entanto, a maior exportação de nitrogênio poderia causar eutrofização e mudanças na biodiversidade. 


\section{CONCLUSÕES}

- Como conseqüência de mudanças na estrutura físca do solo, observaram-se maiores fluxos de água na microbacia coberta por pasto. Este aumento na descarga teve como conseqüência uma maior exportação de nitrogênio

- Encontraram-se diferenças nas formas de nitrogênio predominantes em cada compartimento estudado. A pesar do nitrogênio orgânico dissolvido não ter sido determinado na água subsuperficial da floresta, para os outros compartimentos estudados, o mesmo predominou na precipitação interna, no escoamento superficial e nos igarapés. O amônio predominou na água subsuperficial e na água subterrânea. Os resultados observados para as formas inorgânicas de nitrogênio indicam que cada compartimento apresenta diferentes condições de oxi-redução, ao passo que as formas orgânicas são controladas pela interação da água da chuva com o dossel e com os solos.

- Observaram-se mudanças nas formas de nitrogênio inorgânico presentes no igarapé de cada microbacia. Na floresta, o nitrato foi a principal forma de nitrogênio inorgânico dissolvido, enquanto o amônio predominou no pasto. Tais diferenças indicam que o nitrogênio está sendo processado de forma diferente em cada microbacia, sendo as taxas de mineralização e nitrificação mais altas na floresta do que no pasto. Também é possível que as baixas quantidades de nitrato produzidas no pasto sejam desnitrificadas dentro do canal do igarapé devido às baixas concentrações de oxigênio no mesmo.

- Não foi possível identificar um elemento que permitisse diferenciar claramente as diferentes fontes de água em cada microbacia. No entanto, é possível que o 
escoamento superficial desempenhe um papel importante na formação dos igarapés durante as precipitações, uma vez que, em estudos anteriores, foi observada uma diminuição da condutividade hidráulica nas camadas superficiais de solos próximos a estas microbacias. Esta via hidrológica poderia ser a principal fonte de nitrogênio orgânico dissolvido na microbacia do pasto, enquanto a precipitação interna e o escoamento superficial seriam possíveis fontes de $\mathrm{N}$ na floresta. 
ANEXOS 
Anexo A. Valores dos parâmetros físico-químicos e concentrações dos elementos e compostos analisados no escoamento superficial da floresta

\begin{tabular}{|c|c|c|c|c|c|c|c|c|c|c|c|c|c|c|c|}
\hline Fonte & Hora & Data & Alc & $\mathrm{pH}$ & C.E & $\mathrm{Ca}(\mathrm{UM})$ & $\mathrm{Mg}(\mathrm{UM})$ & $\mathrm{K}(\mathrm{UM})$ & $\mathrm{NH4}$ (uM) & $\mathrm{Na}(\mathrm{UM})$ & $\mathrm{C}(\mathrm{UM})$ & $\mathrm{NO} 3(\mathrm{UM})$ & TDN(UM) & NID(UM) & NOD(UM) \\
\hline ES & $8: 05$ & 22-Jan-04 & 48.8 & 6.59 & 59.8 & 189.47 & 35.33 & 123.37 & 21.44 & 62.04 & 28.04 & 3.77 & 83.59 & 25.21 & 58.38 \\
\hline ES & 9:34 & 14-Fev-04 & n.a & 7.35 & 85.2 & 130.87 & 39.42 & 226.74 & 102.89 & 57.84 & 76.53 & 35.78 & 319.24 & 138.67 & 180.57 \\
\hline ES & $16: 50$ & 15-Fev-04 & n.a & 7.04 & 45.3 & 80.91 & 29.48 & 168.95 & 8.06 & 59.30 & 70.81 & 23.66 & 147.73 & 31.72 & 116.01 \\
\hline ES & $17: 30$ & 17-Fev-05 & 30.6 & 7.14 & 40.8 & 97.01 & 28.18 & 105.43 & 6.93 & 67.77 & 45.45 & 14.16 & 99.15 & 21.09 & 78.06 \\
\hline ES & $9: 05$ & 19-Fev-04 & 36.6 & 7.08 & 51.9 & 140.78 & 37.44 & 88.95 & 41.63 & 20.03 & 20.46 & 14.71 & 130.19 & 56.34 & 73.85 \\
\hline ES & $8: 44$ & 27-fev-04 & n.a & 7.15 & 38.5 & 91.46 & 28.46 & 88.76 & 3.60 & 50.85 & 16.65 & 6.54 & 84.18 & 10.14 & 74.04 \\
\hline
\end{tabular}

$<$ l.d = menor ao limite de detecção

n.a = não analisado

n.c $=$ não calculado

Alc. $=$ Alcalinidade (ueq. $\mathrm{L}^{-1}$ )

C. $\mathrm{E}=$ Condutividade elétrica $\left(\mathrm{uS} . \mathrm{cm}^{-1}\right)$

Anexo B. Valores dos parâmetros físico-químicos e concentrações dos elementos e compostos analisados no escoamento superficial do pasto

\begin{tabular}{|c|c|c|c|c|c|c|c|c|c|c|c|c|c|c|c|}
\hline Fonte & Hora & Data & Alc & $\mathrm{pH}$ & C.E & $\mathrm{Ca}(\mathrm{UM})$ & $\mathrm{Mg}(\mathrm{uM})$ & K(UM) & $\mathrm{NH} 4(\mathrm{uM})$ & $\mathrm{Na}$ (UM) & Cl(uM) & NO3(UM) & NDT(uM) & NID (uM) & NOD(UM) \\
\hline$E S$ & $21: 14$ & 04-Fev-04 & 24.2 & 6.57 & 50.6 & 102.15 & 30.59 & 130.45 & 4.65 & 64.94 & 157.45 & 0.26 & 84.03 & 4.91 & 79.12 \\
\hline ES & $9: 15$ & 08-Fev-04 & n.a & 7.68 & 102 & 283.02 & 42.32 & 143.24 & 123.49 & 89.07 & 59.04 & 4.55 & 244.21 & 128.07 & 116.13 \\
\hline ES & $15: 02$ & 10-Fev-04 & n.a & 7.21 & 42.3 & 98.15 & 20.89 & 120.47 & 23.70 & 28.43 & 60.70 & 5.66 & 110.06 & 29.37 & 80.69 \\
\hline ES & $16: 00$ & 15-Fev-04 & 19.6 & 6.59 & 44.2 & 73.58 & 23.97 & 202.69 & 22.29 & 59.92 & 107.49 & 8.56 & 141.20 & 30.86 & 110.34 \\
\hline ES & $15: 25$ & $17-\mathrm{Fev}-04$ & 13.4 & 6.47 & 26.5 & 46.84 & 20.93 & 111.59 & 8.01 & 27.30 & 22.07 & 0.19 & 67.03 & 8.20 & 58.83 \\
\hline ES & $15: 30$ & 19-Fev-04 & 27.6 & 7.17 & 35.5 & 118.28 & 19.92 & 73.77 & 10.96 & 23.17 & 22.35 & 2.79 & 44.79 & 13.75 & 31.04 \\
\hline ES & 18:05 & $25-\mathrm{Fev}-04$ & 7.2 & 6.37 & 21.8 & 28.88 & 13.59 & 85.32 & 3.98 & 15.95 & 61.46 & 0.68 & 35.59 & 4.66 & 30.93 \\
\hline ES & $10: 04$ & 27 -fev-04 & n.a & 6.55 & 23.4 & 40.60 & 15.80 & 72.83 & 7.96 & 24.61 & 50.23 & 3.02 & 48.40 & 10.98 & 37.42 \\
\hline
\end{tabular}

$<$ l.d $=$ menor ao limite de detecção

n.a = não analisado

n.c $=$ não calculado

Alc. $=$ Alcalinidade (ueq. $\mathrm{L}^{-1}$ )

C. $\mathrm{E}=$ Condutividade elétrica $\left(\mathrm{uS} . \mathrm{cm}^{-1}\right.$ ) 
Anexo C. Valores dos parâmetros físico-químicos e concentrações dos elementos e compostos analisados na água subsuperficial da floresta

\begin{tabular}{|c|c|c|c|c|c|c|c|c|c|c|c|c|c|c|c|}
\hline Fonte & Hora & Data & Alc & $\mathrm{pH}$ & C.E & $\mathrm{Ca}(\mathrm{uM})$ & $\mathrm{Mg}$ (UM) & K(UM) & $\mathrm{NH} 4(\mathrm{uM})$ & $\mathrm{Na}(\mathrm{UM})$ & Cl(UM) & NO3(UM) & TDN(UM) & $\operatorname{NID}(\mathrm{uM})$ & $\mathrm{NOD}(\mathrm{uM})$ \\
\hline SS & $9: 26$ & $02-\mathrm{Fev}-04$ & 2.6 & 4.65 & 17.3 & 13.94 & 9.86 & 36.55 & 5.83 & 54.82 & 14.66 & $<$ l.d & n.a & n.c & n.c \\
\hline SS & $7: 40$ & 03-Fev-04 & 11.4 & 6.09 & 15.3 & 18.83 & 12.68 & 39.94 & 3.90 & 73.16 & 21.00 & $<$ I.d & n.a & n.c & n.c \\
\hline SS & $9: 20$ & 04-Fev-04 & 6 & 5.08 & 17.8 & 17.03 & 13.01 & 44.53 & 3.45 & 57.47 & 9.14 & $<$ I.d & n.a & n.c & n.c \\
\hline sS & $7: 33$ & 06-Fev-04 & 6 & 4.97 & 17.5 & 13.76 & 15.15 & 50.75 & 3.46 & 48.73 & 2.84 & $<$ I.d & n.a & n.c & n.c \\
\hline ss & 7:38 & 07-Fev-04 & 13.2 & 5.16 & 18.1 & 13.35 & 14.01 & 50.95 & 2.58 & 104.44 & 40.00 & $<$ I.d & n.a & n.c & n.c \\
\hline SS & 9:47 & 08-Fev-04 & 8.2 & 5.42 & 18.5 & 13.80 & 16.13 & 52.77 & 3.39 & 77.17 & 11.70 & $<$ I.d & n.a & n.c & n.c \\
\hline SS & $10: 25$ & 09-Fev-04 & 11.6 & 5.33 & 18.2 & 14.80 & 17.91 & 51.17 & 4.03 & 60.28 & 4.15 & $<$ I.d & n.a & n.c & n.c \\
\hline SS & $9: 40$ & 10-Fev-04 & 0.6 & 4.68 & 17.3 & 14.30 & 18.03 & 52.09 & 9.38 & 58.66 & 9.17 & $<$ l.d & n.a & n.c & n.c \\
\hline SS & 7:50 & $12-\mathrm{Fev}-04$ & 8.2 & 6.27 & 27.5 & 13.45 & 15.18 & 46.20 & 6.11 & 55.97 & 8.62 & $<$ I.d & n.a & n.c & n.c \\
\hline SS & $8: 45$ & 13-Fev-04 & 9.8 & 5.44 & 15.5 & 13.23 & 14.27 & 44.64 & 7.01 & 64.52 & 11.45 & $<$ I.d & n.a & n.c & n.c \\
\hline ss & 9:00 & $15-\mathrm{Fev}-04$ & 12 & 5.92 & 15.2 & 14.90 & 12.96 & 38.21 & 6.23 & 104.56 & 39.52 & $<$ I.d & n.a & n.c & n.c \\
\hline SS & 9:07 & 17-Fev-04 & 8 & 5.25 & 15.3 & 11.60 & 10.96 & 36.94 & 6.21 & 54.49 & 10.48 & $<$ l.d & ก.a & n.c & n.c \\
\hline SS & 9:30 & 18-Fev-04 & n.a & n.a & n.a & 17.62 & 15.89 & 42.28 & 12.27 & 55.14 & 15.47 & $<$ I.d & n.a & n.c & n.c \\
\hline SS & $8: 40$ & 24-Fev-04 & 6.2 & 5.26 & 13.2 & n.a & n.a & n.a & n.a & n.a & n.a & n.a & n.a & n.c & n.c \\
\hline
\end{tabular}

$<$ l.d = menor ao limite de detecção

n.a = não analisado

n.c = não calculado

Alc. = Alcalinidade (ueq. $\mathrm{L}^{-1}$ )

C. $\mathrm{E}=$ Condutividade elétrica $\left(\mathrm{uS} . \mathrm{cm}^{-1}\right)$

Anexo D. Valores dos parâmetros físico-químicos e concentrações dos elementos e compostos analisados na água subsuperficial do pasto

\begin{tabular}{|c|c|c|c|c|c|c|c|c|c|c|c|c|c|c|c|}
\hline Fonte & Hora & Data & Alc & $\mathrm{pH}$ & C.E & $\mathrm{Ca}(\mathrm{uM})$ & $\mathrm{Mg}$ (UM) & K(uM) & $\mathrm{NH} 4(\mathrm{UM})$ & $\mathrm{Na}(\mathrm{UM})$ & $\mathrm{Cl}(\mathrm{uM})$ & NO3(uM) & NDT(UM) & NID (uM) & NOD(uM) \\
\hline SS & $8: 51$ & 30-Jan-04 & -5 & 4.58 & 18.6 & 3.38 & 8.83 & 65.97 & $<$ l.d & 44.77 & 27.19 & $<\mathrm{l} . \mathrm{d}$ & $<$ l.d & n.c & n.c \\
\hline ss & $8: 35$ & 31-Jan-04 & 4.6 & 5.05 & 18.8 & 5.11 & 9.78 & 87.46 & 3.15 & 106.42 & 87.75 & $<I . d$ & $<1 . d$ & n.c & n.c \\
\hline ss & $15: 55$ & 31-Jan-04 & 1.6 & 4.76 & 17.4 & 4.72 & 10.14 & 71.15 & $<1 . d$ & 50.27 & 30.17 & $<$ I.d & 0.41 & n.c & n.c \\
\hline ss & 9:33 & 01-Fev-04 & 3 & 4.71 & 18 & 5.99 & 9.69 & 75.10 & 2.55 & 80.23 & 58.16 & $<$ I.d & 0.00 & n.c & n.c \\
\hline ss & $8: 40$ & 02-Fev-04 & 4 & 4.61 & 17.3 & 3.92 & 8.37 & 67.45 & 2.31 & 57.56 & 37.30 & $<1 . d$ & 2.31 & n.c & n.c \\
\hline SS & $8: 05$ & 03-Fev-04 & 7 & 5.22 & 16.1 & 4.46 & 9.82 & 68.80 & $<$ I.d & 54.37 & 34.10 & $<1 . d$ & $<1 . d$ & n.c & n.c \\
\hline ss & $8: 45$ & 04-Fev-04 & 5.4 & 4.85 & 19.7 & 4.09 & 8.19 & 61.10 & $<$ l.d & 45.56 & 22.55 & $<$ I.d & $<$ l.d & n.c & n.c \\
\hline ss & 9:05 & 05-Fev-04 & 8.2 & 4.97 & 19.8 & 15.24 & 11.39 & 132.97 & 12.09 & 258.17 & 256.35 & $<1 . d$ & $<$ I.d & n.c & n.c \\
\hline sS & $8: 10$ & 06-Fev-04 & 5.8 & 4.85 & 17.3 & 4.45 & 10.17 & 77.76 & $<1 . d$ & 55.12 & 21.76 & $<1 . d$ & 4.22 & n.c & n.c \\
\hline ss & $8: 10$ & $07-\mathrm{Fev}-04$ & 5 & 4.84 & 18.1 & 5.51 & 9.06 & 66.27 & $<$ I.d & 48.24 & 34.58 & $<$ I.d & $<1 . d$ & n.c & n.c \\
\hline ss & $9: 13$ & 08-Fev-04 & 6 & 5.11 & 17.7 & 4.15 & 9.32 & 67.28 & $<$ I.d & 48.00 & 26.13 & $<$ I.d & $<1 . d$ & n.c & n.c \\
\hline ss & $10: 35$ & 09-Fev-04 & 7.8 & 5.05 & 17.8 & 4.66 & 10.23 & 74.25 & $<$ I.d & 49.92 & 27.23 & $<$ I.d & $<$ I.d & n.c & n.c \\
\hline sS & $8: 43$ & $10-\mathrm{Fev}-04$ & n.a & 4.29 & 17.8 & 4.11 & 9.90 & 70.81 & $<$ I.d & 44.95 & 25.62 & $<$ I.d & 2.15 & n.c & n.c \\
\hline ss & $9: 15$ & $11-\mathrm{Fev}-04$ & 3.8 & 4.87 & 17.8 & 3.76 & 9.07 & 63.57 & $<$ I.d & 43.69 & 24.30 & $<$ I.d & $<I . d$ & n.c & n.c \\
\hline ss & $8: 30$ & $12-\mathrm{Fev}-04$ & 12.2 & 5.2 & 24.1 & 3.02 & 8.54 & 66.83 & $<$ I.d & 41.70 & 19.72 & $<$ I.d & $<$ I.d & n.c & n.c \\
\hline ss & 9:15 & 13-Fev-04 & 7.6 & 5.16 & 17.7 & 3.35 & 8.35 & 56.56 & $<$ I.d & 37.11 & 16.99 & $<$ I.d & $<1 . d$ & n.c & n.c \\
\hline SS & $9: 43$ & $14-\mathrm{Fev}-04$ & 6.6 & 5.14 & 17.6 & 2.95 & 7.26 & 55.01 & $<$ I.d & 38.28 & 25.10 & $<$ I.d & $<1 . d$ & n.c & n.c \\
\hline SS & $9: 22$ & $15-\mathrm{Fev}-04$ & 6.8 & 5.17 & 17.4 & 5.52 & 12.96 & 94.83 & $<$ I.d & 63.87 & 34.05 & $<1 . d$ & $<I . d$ & n.c & n.c \\
\hline ss & $8: 48$ & $16-\mathrm{Fev}-04$ & 7.8 & 5.09 & 17.7 & 4.58 & 11.11 & 79.86 & $<$ I.d & 53.20 & 30.33 & $<$ I.d & 6.12 & n.c & n.c \\
\hline ss & $8: 32$ & $17-\mathrm{Fev}-04$ & 6.8 & 5.13 & 17.5 & 4.20 & 8.63 & 62.39 & 3.02 & 48.29 & 31.47 & $<$ I.d & 0.66 & n.c & n.c \\
\hline SS & $8: 40$ & $18-\mathrm{Fev}-04$ & 6.6 & 5.14 & 17.4 & 4.64 & 10.06 & 73.53 & $<$ I.d & 49.38 & 33.22 & $<1 . d$ & $<1 . d$ & n.c & n.c \\
\hline ss & $9: 21$ & 19-Fev-04 & 6.6 & 5.05 & 17.3 & 4.63 & 10.34 & 74.35 & $<$ I.d & 47.12 & 13.19 & $<$ I.d & 1.82 & n.c & n.c \\
\hline ss & 9:17 & $20-\mathrm{Fev}-04$ & 10.6 & 6.56 & 17.7 & 4.15 & 9.95 & 71.37 & $<$ I.d & 48.69 & 39.57 & $<$ I.d & $<$ I.d & n.c & n.c \\
\hline ss & $10: 02$ & 21-Fev-04 & 5.8 & 5.12 & 17.4 & 5.02 & 10.62 & 78.73 & $<$ I.d & 58.49 & 39.10 & $<$ I.d & $<$ I.d & n.c & n.c \\
\hline ss & $9: 46$ & $22-\mathrm{Fev}-04$ & 6.2 & 5.1 & 19.8 & n.a & n.a & n.a & n.a & n.a & n.a & n.a & n.a & n.c & n.c \\
\hline ss & $8: 40$ & 23-Fev-04 & 5.4 & 4.89 & 18.1 & n.a & n.a & n.a & n.a & n.a & n.a & n.a & n.a & n.c & n.c \\
\hline ss & $10: 13$ & 24-Fev-04 & 8.8 & 5.23 & 18.2 & n.a & n.a & n.a & n.a & n.a & n.a & n.a & n.a & n.c & n.c \\
\hline SS & $9: 53$ & $25-\mathrm{Fev}-04$ & 5.8 & 4.5 & 18.1 & 7.81 & 9.79 & 81.48 & 8.78 & 98.41 & 57.89 & $<1 . d$ & 2.40 & n.c & n.c \\
\hline SS & 9:51 & $26-\mathrm{Fev}-04$ & n.a & 5.02 & 17.2 & 3.00 & 8.35 & 64.37 & $<$ I.d & 36.56 & 8.63 & $<1 . d$ & $<$ l.d & n.c & n.c \\
\hline SS & $7: 40$ & $27-f e v-04$ & n.a & 4.91 & 18.2 & 3.34 & 9.22 & 66.16 & $<1 . d$ & 37.37 & 19.51 & $<1 . d$ & 14.88 & n.c & n.c \\
\hline sS & $8: 38$ & 28-Fev-04 & n.a & 5 & 19.9 & 3.75 & 8.68 & 62.70 & $<$ I.d & 44.11 & 27.02 & $<I . d$ & 1.90 & n.c & n.c \\
\hline SS & $10: 33$ & 29 -fev-04 & n.a & 4.89 & 18 & 4.37 & 8.99 & 65.28 & $<$ I.d & 41.99 & 15.64 & $<$ I.d & $<$ I.d & n.c & n.c \\
\hline ss & $12: 55$ & 1-Mar-04 & n.a & 5.01 & 17.07 & 3.53 & 8.96 & 64.94 & $<$ I.d & 59.02 & 26.32 & $<$ I.d & $<I . d$ & n.c & n.c \\
\hline ss & $9: 47$ & 2-Mar-04 & n.a & 5 & 17.87 & 3.53 & 8.92 & 65.24 & $<$ I.d & 43.52 & 31.12 & $<$ I.d & $<$ l.d & n.c & n.c \\
\hline SS & $9: 35$ & 3-Mar-04 & n.a & 5.05 & 17.23 & 4.10 & 9.14 & 66.97 & $<$ I.d & 45.46 & 18.10 & $<$ I.d & 0.33 & n.c & n.c \\
\hline
\end{tabular}

$<$ l.d = menor ao limite de detecção

n.a = não analisado

n.c $=$ não calculado

Alc. $=$ Alcalinidade (ueq. $\mathrm{L}^{-1}$ )

C. $\mathrm{E}=$ Condutividade elétrica $\left(\mathrm{uS} . \mathrm{cm}^{-1}\right)$ 
Anexo E. Valores dos parâmetros físico-químicos e concentrações dos elementos e compostos analisados no escoamento base do igarapé do pasto

\begin{tabular}{|c|c|c|c|c|c|c|c|c|c|c|c|c|c|c|c|c|c|}
\hline Fonte & Data & Hora & Alc & $\mathrm{pH}$ & C.E & $\mathrm{Ca}(\mathrm{UM})$ & $\mathrm{Mg}(\mathrm{UM})$ & $\mathrm{K}(\mathrm{uM})$ & $\mathrm{NH} 4(\mathrm{uM})$ & $\mathrm{Na}(\mathrm{UM})$ & $\mathrm{Cl}(\mathrm{uM})$ & $\mathrm{NO} 3(\mathrm{uM})$ & NDT(uM) & NID (UM) & $\mathrm{NOD}(\mathrm{uM})$ & $\operatorname{STS}\left(\mathrm{mg}, \mathrm{L}^{-1}\right)$ & $\mathrm{NP}$ (uM) \\
\hline EB & 9:19 & 22-Jan-04 & 27.8 & 6.08 & 39.8 & 9.41 & 6.56 & 42.02 & 8.66 & 62.41 & 49.27 & $<$ l.d & 49.02 & n.c & n.c & n.a & n.a \\
\hline EB & 8:58 & 23-Jan-04 & 30 & 5.92 & 44.1 & 52.70 & 39.33 & 65.95 & 0.44 & 68.63 & 44.23 & $<$ I.d & 42.66 & n.c & n.c & n.a & n.a \\
\hline EB & 11:55 & 23-Jan-04 & 35 & 5.77 & 45.8 & 67.33 & 51.99 & 70.54 & 1.50 & 47.12 & 37.56 & $<$ I.d & 59.26 & n.c & n.c & n.a & n.a \\
\hline $\mathrm{EB}$ & $8: 13$ & 24-Jan-04 & 37.6 & 5.54 & 50.3 & 68.32 & 48.84 & 52.12 & 1.06 & 39.00 & 16.56 & 0.00 & 63.13 & 1.06 & 62.07 & 27.15 & 0.58 \\
\hline EB & 9:37 & 25-Jan-04 & 24.6 & 5.31 & 33.2 & 64.08 & 34.37 & 58.97 & 1.50 & 151.24 & 66.30 & 0.08 & 23.65 & 1.58 & 22.07 & 0.00 & 0.00 \\
\hline $\mathrm{EB}$ & $8: 35$ & 26-Jan-04 & 21 & 5.66 & 28.8 & 52.73 & 28.78 & 60.30 & 1.44 & 115.70 & 32.30 & 0.10 & 12.21 & 1.54 & 10.67 & 45.14 & 2.58 \\
\hline $\mathrm{EB}$ & $8: 05$ & 27-Jan-04 & 20 & 5.42 & 32.3 & 42.34 & $<$ l.d & 45.44 & 0.72 & 97.37 & 35.64 & $<$ <.d & 8.43 & n.c & n.c & 21.04 & 0.45 \\
\hline$E B$ & $8: 25$ & 28-Jan-04 & n.a & n.a. & n.a & 31.13 & 13.95 & 42.86 & 0.61 & 54.35 & 30.21 & 0.00 & 9.29 & 0.61 & 8.68 & 7.55 & 0.11 \\
\hline $\mathrm{EB}$ & 7:52 & 29-JJan-04 & 11.8 & 6.04 & 26 & 42.07 & 20.69 & 61.95 & 1.28 & 121.94 & 59.91 & $<1 . d$ & 18.66 & n.c & n.c & 6.33 & 0.09 \\
\hline EB & $8: 45$ & 30-Jan-04 & 20.6 & 5.36 & 29.9 & 42.63 & 19.50 & 40.63 & 1.56 & 68.38 & 31.93 & 0.00 & 10.84 & 1.56 & 9.28 & 15.63 & 0.33 \\
\hline EB & $8: 35$ & 31-Jan-04 & 19.2 & 5.05 & 26.6 & 48.51 & 17.23 & 37.96 & 0.83 & 82.24 & 31.57 & 0.00 & 0.09 & 0.83 & n.c & 18.69 & 0.53 \\
\hline EB & 9:35 & 01-Fev-04 & 16.4 & 5.68 & 22.2 & 45.06 & 16.69 & 47.01 & 0.56 & 76.28 & 18.63 & 0.00 & 5.33 & 0.56 & 4.78 & 12.77 & 0.27 \\
\hline EB & $8: 45$ & 02-Fev-04 & 15.6 & 5.64 & 22.4 & 37.68 & 11.71 & 31.50 & 0.61 & 49.81 & 22.67 & 0.00 & 0.52 & 0.61 & n.c & 17.20 & 0.61 \\
\hline EB & $8: 25$ & 03-Fev-04 & 17.4 & 6.24 & 19.3 & 49.95 & 11.87 & 33.89 & 0.50 & 51.52 & 19.84 & 0.00 & 0.00 & 0.50 & n.c & 9.92 & 0.28 \\
\hline $\mathrm{EB}$ & $8: 25$ & 04-Fev-04 & 15.2 & 5.91 & 24 & 45.83 & 9.87 & 26.89 & 0.78 & 49.03 & 18.02 & 0.00 & 0.00 & 0.78 & n.c & 9.08 & 0.26 \\
\hline EB & 9:07 & 05-Fev-04 & 19.2 & 6.08 & 28 & 60.46 & 15.27 & 64.50 & 0.72 & 71.97 & 33.55 & 0.00 & 17.63 & 0.72 & 16.91 & 5.60 & 0.16 \\
\hline $\mathrm{EB}$ & $8: 28$ & 06 -Fev-04 & 22.8 & 6.36 & 24.7 & 51.59 & 10.13 & 39.76 & 0.50 & 33.85 & 15.67 & 0.00 & 2.84 & 0.50 & 2.34 & 5.67 & 0.16 \\
\hline $\mathrm{EB}$ & $8: 15$ & 07-Fev-04 & 20 & 6.34 & 24.6 & 64.34 & 11.09 & 36.56 & 0.61 & 32.91 & 10.68 & 0.08 & 0.00 & 0.69 & n.c & 4.54 & 0.10 \\
\hline $\mathrm{EB}$ & 9:16 & 08-Fev-04 & 19 & 6.68 & 24.8 & 69.81 & 11.35 & 41.90 & 0.61 & 61.97 & 22.62 & 0.00 & 0.00 & 0.61 & n.c & 11.75 & 0.17 \\
\hline $\mathrm{EB}$ & $11: 07$ & 09-Fev-04 & 21.8 & 6.84 & 25.3 & 68.67 & 9.69 & 35.72 & 0.83 & 101.77 & 59.78 & 0.00 & 6.45 & 0.83 & 5.62 & 4.92 & 0.14 \\
\hline $\mathrm{EB}$ & 9:19 & 10-Fev-04 & 22 & 6.1 & 27.5 & 73.29 & 9.46 & 30.47 & 0.94 & 28.18 & 6.79 & 0.00 & 1.89 & 0.94 & 0.95 & 3.50 & 0.17 \\
\hline $\mathrm{EB}$ & 9:35 & 11-Fev-04 & 15 & 6.27 & 20 & 56.28 & 9.37 & 38.19 & 0.67 & 38.64 & 14.85 & 0.00 & 12.38 & 0.67 & 11.72 & 5.20 & 0.22 \\
\hline $\mathrm{EB}$ & $8: 35$ & 12-Fev-04 & n.a & n.a. & n.a & 87.97 & 8.04 & 40.60 & 0.67 & 42.50 & 18.22 & 0.00 & 4.04 & 0.67 & 3.38 & 7.06 & 0.15 \\
\hline $\mathrm{EB}$ & $9: 25$ & 13-Fev-04 & 26 & 7.41 & 32.2 & 89.57 & 10.40 & 35.98 & 0.50 & 33.10 & 11.19 & 0.00 & 2.06 & 0.50 & 1.56 & 1.77 & 0.05 \\
\hline $\mathrm{EB}$ & 9:47 & 14-Fev-04 & 22.2 & 7.19 & 28.3 & 95.65 & 11.25 & 45.75 & 1.00 & 44.67 & 26.60 & $<$ I.d & 12.81 & n.c & n.c & 1.73 & 0.05 \\
\hline $\mathrm{EB}$ & $9: 27$ & 15-Fev-04 & 26.8 & 7.4 & 31.5 & 113.51 & 10.82 & 40.47 & 0.61 & 38.78 & 21.07 & 0.16 & 8.60 & 0.77 & 7.83 & 2.25 & 0.08 \\
\hline $\mathrm{EB}$ & $8: 53$ & 16-Fev-04 & 21.8 & 7.21 & 28 & 77.96 & 9.49 & 47.90 & 0.89 & 30.07 & 8.94 & $<$ l.d & 9.46 & n.c & n.c & 1.80 & 0.05 \\
\hline $\mathrm{EB}$ & $8: 37$ & 17-Fev-04 & 30.8 & 7.15 & 34.6 & 123.33 & 13.16 & 51.14 & 0.67 & 39.36 & 12.25 & $<$ I.d & 2.41 & n.c & n.c & 1.38 & 0.04 \\
\hline $\mathrm{EB}$ & $8: 55$ & 18-Fev-04 & 22.6 & 6.99 & 28.4 & 57.77 & 9.81 & 62.66 & 0.67 & 29.41 & 13.06 & 0.00 & 14.28 & 0.67 & 13.61 & 2.79 & 0.08 \\
\hline EB & $9: 28$ & 19-Fev-04 & 19.4 & 6.87 & 23.7 & 68.15 & 10.12 & 59.03 & 0.56 & 56.09 & 24.69 & $<$ I.d & 9.03 & n.c & n.c & 1.40 & 0.03 \\
\hline $\mathrm{EB}$ & 9:00 & $20-F e v-04$ & 14.6 & 6.47 & 18.6 & 30.73 & 7.26 & 74.06 & 0.39 & 66.15 & 40.59 & 0.00 & 10.58 & 0.39 & 10.19 & 3.07 & 0.09 \\
\hline EB & 10:15 & 21-Fev-04 & 9.6 & 5.94 & 17.9 & 23.80 & 8.65 & 60.19 & 0.56 & 24.68 & 14.74 & 0.00 & 31.05 & 0.56 & 30.49 & 7.70 & 0.28 \\
\hline $\mathrm{EB}$ & $9: 53$ & 22-Fev-04 & 12.2 & 5.98 & 18.4 & 22.23 & 8.92 & 48.02 & 0.78 & 23.18 & 7.29 & 0.00 & 16.34 & 0.78 & 15.56 & 3.58 & 0.10 \\
\hline$E B$ & $8: 40$ & 23-Fev-04 & 14.2 & 6.25 & 19.7 & 38.26 & 12.58 & 56.26 & 0.78 & 28.85 & 7.22 & 0.00 & 9.55 & 0.78 & 8.77 & 2.93 & 0.06 \\
\hline $\mathrm{EB}$ & $10: 24$ & 24-Fev-04 & 17.8 & 6.01 & 21.9 & 41.18 & 10.81 & 39.69 & 1.22 & 24.62 & 4.94 & 0.00 & 11.70 & 1.22 & 10.47 & 1.07 & 0.03 \\
\hline EB & $10: 08$ & 25-Fev-04 & 17.4 & 6.27 & 22.2 & 46.22 & 12.35 & 44.10 & 0.94 & 37.57 & 8.14 & 0.00 & 7.83 & 0.94 & 6.88 & 3.92 & 0.08 \\
\hline $\mathrm{EB}$ & $9: 54$ & 26-Fev-04 & n.a & 6.19 & 20.9 & 28.72 & 14.67 & 82.88 & n.a & 26.85 & 20.57 & 0.00 & n.a & n.a & n.a & 6.54 & n.a \\
\hline $\mathrm{EB}$ & 8:50 & 27-fev-04 & n.a & 6.03 & 19.3 & 24.41 & 12.94 & 49.56 & 0.83 & 23.00 & 8.77 & 0.00 & 23.31 & 0.83 & 22.47 & 1.60 & 0.05 \\
\hline $\mathrm{EB}$ & $8: 41$ & 28-Fev-04 & n.a & 6.18 & 21.1 & 33.43 & 16.05 & 46.46 & 0.89 & 32.24 & 8.48 & 0.00 & 6.97 & 0.89 & 6.08 & 2.50 & 0.05 \\
\hline $\mathrm{EB}$ & $10: 50$ & 29-fev-04 & n.a & 6.51 & 21.8 & 40.28 & 17.96 & 46.39 & 0.56 & 34.80 & 9.11 & $<$ l.d & 14.88 & n.c & n.c & 2.31 & 0.07 \\
\hline $\mathrm{EB}$ & $13: 00$ & 1-Mar-04 & n.a & 6.07 & 24.9 & 51.38 & 18.60 & 45.08 & 0.50 & 62.67 & 16.05 & $<$ I.d & 6.54 & n.c & n.c & 36.33 & 1.30 \\
\hline $\mathrm{EB}$ & $9: 45$ & 2-Mar-04 & n.a & 6.63 & 21.8 & 50.28 & 17.37 & 43.20 & 0.72 & 34.75 & 8.43 & 0.00 & 7.40 & 0.72 & 6.67 & 4.40 & 0.13 \\
\hline EB & $9: 33$ & 3-Mar-04 & n.a & 6.51 & 24 & 46.96 & 15.04 & 38.55 & 0.50 & 34.11 & 6.46 & $<$ l.d & 4.73 & n.c & n.c & 5.07 & 0.18 \\
\hline
\end{tabular}

$<$ l.d $=$ menor ao limite de detecção

n.a $=$ não analisado

n.c $=$ não calculado

Alc. $=$ Alcalinidade (ueq. $\mathrm{L}^{-1}$ )

C. $\mathrm{E}=$ Condutividade elétrica (uS. $\mathrm{cm}^{-1}$ )

Anexo F. Valores dos parâmetros físico-químicos e concentrações dos elementos e compostos analisados na água subterrânea na microbacia da floresta

\begin{tabular}{|c|c|c|c|c|c|c|c|c|c|c|c|c|c|c|c|}
\hline Fonte & Hora & Data & Alc & $\mathrm{pH}$ & C.E & $\mathrm{Ca}(\mathrm{uM})$ & $\mathrm{Mg}(\mathrm{uM})$ & $\mathrm{K}(\mathrm{UM})$ & $\mathrm{NH} 4(\mathrm{uM})$ & $\mathrm{Na}(\mathrm{UM})$ & $\mathrm{Cl}(\mathrm{UM})$ & $\mathrm{NO} 3(\mathrm{uM})$ & TDN(UM) & $\mathrm{NID}(\mathrm{UM})$ & NOD(UM) \\
\hline SB1 & $12: 00$ & 22-Jan-04 & 7 & 5.29 & 21.2 & 20.38 & 20.67 & 58.49 & 16.50 & 41.74 & 24.80 & 9.05 & 17.42 & 25.55 & n.c \\
\hline SB2 & 11:50 & 22-Jan-04 & 10.8 & 5.6 & 21.5 & 23.22 & 12.55 & 43.77 & 14.83 & 61.03 & 16.60 & 5.56 & 3.89 & 20.40 & n.c \\
\hline SB3 & 11:40 & 22-Jan-04 & 16 & 6.54 & 25.1 & 48.25 & 11.87 & 31.77 & 13.22 & 64.58 & 6.50 & 1.61 & 7.70 & 14.84 & n.c \\
\hline SB1 & $15: 45$ & 27-Jan-04 & 13 & 5.12 & 26 & 38.17 & 17.79 & 62.68 & 12.40 & 90.96 & 57.23 & 1.93 & 17.10 & 14.33 & n.c \\
\hline SB2 & $15: 45$ & 27-Jan-04 & 15.2 & 5.03 & 24 & 19.63 & 10.34 & 43.21 & 6.44 & 69.66 & 14.91 & $<$ I.d & 14.34 & n.c & n.c \\
\hline SB3 & $15: 45$ & 27-Jan-04 & 7.8 & 5.03 & 18 & 22.50 & 9.52 & 33.75 & 6.88 & 71.52 & 17.49 & $<$ I.d & 2.67 & n.c & n.c \\
\hline SB1 & 9:00 & 28-Jan-04 & 12.2 & 4.89 & 25.4 & 30.67 & 16.00 & 55.35 & 8.29 & 96.05 & 35.92 & 0.89 & 12.88 & 9.18 & 3.70 \\
\hline SB2 & 9:07 & 28-Jan-04 & 17.2 & 5.06 & 21.9 & 21.84 & 10.19 & 44.51 & 5.59 & 95.62 & 24.99 & $<$ I.d & 7.05 & n.c & n.c \\
\hline SB3 & $9: 13$ & 28-Jan-04 & 6.6 & 4.89 & 18.1 & 20.05 & 8.64 & 30.14 & 4.67 & 86.79 & 7.22 & $<$ I.d & 10.29 & n.c & n.c \\
\hline SB1 & $9: 45$ & 29-Jan-04 & 12.6 & 5.6 & 22.3 & 24.62 & 14.14 & 47.71 & 5.44 & 60.20 & 3.18 & $<$ I.d & n.a & n.c & n.c \\
\hline SB2 & $9: 49$ & 29-Jan-04 & 11.2 & 5.39 & 20.1 & 20.84 & 10.10 & 50.23 & 7.59 & 83.24 & 27.24 & 1.02 & 2.92 & 8.62 & n.c \\
\hline SB3 & 9:53 & 29-Jan-04 & 11.2 & 5.59 & 18.6 & 20.21 & 9.46 & 31.98 & 5.03 & 64.38 & 8.24 & $<$ I.d & 3.89 & n.c & n.c \\
\hline SB1 & $8: 23$ & 30-Jan-04 & 7 & 4.78 & 25.9 & 25.78 & 15.03 & 47.33 & 4.35 & 58.24 & 2.31 & $<$ I.d & 5.67 & n.c & n.c \\
\hline SB2 & $8: 26$ & 30-Jan-04 & 6.8 & 4.86 & 21.5 & 21.77 & 10.66 & 42.96 & 3.84 & 63.46 & 5.21 & $<$ I.d & 2.11 & n.c & n.c \\
\hline SB3 & $8: 30$ & 30-Jan-04 & 6.2 & 4.86 & 19 & 21.86 & 9.95 & 31.59 & 4.67 & 59.39 & 5.81 & $<$ I.d & 4.21 & n.c & n.c \\
\hline SB1 & $9: 40$ & 31-Jan-04 & 14.4 & 5.3 & 22.6 & 28.75 & 13.84 & 49.18 & 6.87 & 68.92 & 16.30 & 0.93 & 5.10 & 7.79 & n.c \\
\hline SB2 & $9: 43$ & 31-Jan-04 & 11.6 & 5.41 & 19.5 & 55.63 & 13.63 & 170.88 & 53.71 & 372.19 & 305.61 & 8.62 & 1.38 & 62.32 & n.c \\
\hline SB3 & $9: 46$ & 31-Jan-04 & 8.8 & 5.42 & 16.1 & 9.48 & 4.49 & 24.05 & 12.04 & 57.89 & 6.56 & $<$ I.d & 1.70 & n.c & n.c \\
\hline SB1 & $8: 58$ & 01-Fev-04 & 8.2 & 4.82 & 22.7 & 31.40 & 13.96 & 45.97 & 8.72 & 74.02 & 11.37 & 2.92 & 9.08 & 11.64 & n.c \\
\hline SB2 & 9:00 & 01-Fev-04 & 6.8 & 4.94 & 19.5 & 17.71 & 9.05 & 43.85 & 9.54 & 79.46 & 17.06 & $<$ I.d & 7.13 & n.c & n.c \\
\hline SB3 & 9:03 & 01-Fev-04 & 9.4 & 5.13 & 16.9 & 22.80 & 9.02 & 31.49 & 5.16 & 71.26 & 9.93 & 4.07 & 5.02 & 9.22 & n.c \\
\hline SB1 & $9: 41$ & 02-Fev-04 & 1.2 & 4.63 & 22.5 & 23.50 & 13.04 & 43.46 & 5.69 & 68.05 & 9.85 & $<$ I.d & 5.35 & n.c & n.c \\
\hline SB2 & $9: 43$ & 02-Fev-04 & 2.6 & 4.68 & 19.3 & 17.54 & 8.98 & 42.12 & 8.97 & 63.60 & 2.45 & $<$ I.d & 1.86 & n.c & n.c \\
\hline SB3 & $9: 45$ & 02-Fev-04 & 2 & 4.61 & 16.3 & 15.46 & 7.06 & 28.84 & 8.94 & 60.87 & 2.81 & $<$ I.d & 2.59 & n.c & n.c \\
\hline SB1 & $7: 25$ & 03-Fev-04 & 12.8 & 5.29 & 20 & 23.12 & 11.73 & 43.00 & n.a & 65.49 & 21.45 & 4.29 & 2.03 & n.c & n.c \\
\hline SB2 & $7: 30$ & 03-Fev-04 & 9.4 & 5.4 & 18.4 & 20.08 & 9.87 & 42.95 & 8.81 & 66.62 & 12.16 & $<$ I.d & 0.81 & n.c & n.c \\
\hline SB3 & $7: 37$ & 03-Fev-04 & 8.8 & 5.46 & 15 & 16.37 & 8.54 & 29.20 & 3.73 & 58.26 & 6.62 & 1.35 & 0.00 & 5.07 & n.c \\
\hline SB1 & 9:35 & 04-Fev-04 & 10.8 & 5.1 & 20.9 & 24.02 & 12.36 & 41.28 & 16.72 & 66.31 & 3.68 & 0.65 & 6.16 & 17.37 & n.c \\
\hline SB2 & 9:37 & 04-Fev-04 & 9.2 & 5.05 & 19.6 & 24.99 & 10.48 & 46.78 & 16.83 & 100.01 & 129.02 & 0.55 & 3.16 & 17.38 & n.c \\
\hline SB3 & $9: 40$ & 04-Fev-04 & 5.4 & 5.06 & 16.1 & 19.70 & 7.63 & 33.28 & 15.83 & 90.90 & 11.35 & 0.08 & 2.19 & 15.91 & n.c \\
\hline
\end{tabular}


Anexo F. Valores dos parâmetros físico-químicos e concentrações dos elementos e compostos analisados na água subterrânea na microbacia da floresta

\begin{tabular}{|c|c|c|c|c|c|c|c|c|c|c|c|c|c|c|c|}
\hline Fonte & Hora & Data & Alc & $\mathrm{pH}$ & C.E & $\mathrm{Ca}(\mathrm{uM})$ & $\mathrm{Mg}(\mathrm{uM})$ & $\mathrm{K}(\mathrm{UM})$ & $\mathrm{NH} 4(\mathrm{uM})$ & $\mathrm{Na}(\mathrm{UM})$ & $\mathrm{Cl}(\mathrm{UM})$ & NO3(uM) & TDN(UM) & $\mathrm{NID}(\mathrm{uM})$ & NOD(uM) \\
\hline SB1 & $9: 25$ & $05-\mathrm{Fev}-04$ & 12.8 & 5.24 & 21.6 & 33.08 & 15.26 & 46.41 & n.a & 93.85 & 39.11 & $<$ l.d & 1.70 & n.c & n.c \\
\hline SB2 & 9:30 & 05-Fev-04 & 13 & 5.25 & 20.3 & 22.68 & 9.93 & 41.17 & n.a & 83.51 & 50.38 & 0.74 & 0.00 & n.c & n.c \\
\hline SB3 & 9:35 & 05-Fev-04 & 11.8 & 5.41 & 18 & 21.44 & 8.72 & 33.77 & 3.09 & 83.80 & 34.98 & $<1 . d$ & 1.13 & n.c & n.c \\
\hline SB1 & 7:38 & 06-Fev-04 & 12.2 & 5.12 & 20.6 & 22.43 & 11.80 & 40.07 & n.a & 67.82 & 22.37 & $<$ I.d & 4.46 & n.c & n.c \\
\hline SB2 & 7:41 & 06-Fev-04 & 12 & 5.21 & 18.6 & 17.38 & 8.77 & 44.60 & 2.53 & 73.99 & 16.88 & 1.60 & 1.94 & 4.13 & n.c \\
\hline SB3 & $7: 45$ & 06-Fev-04 & 9.8 & 5.32 & 15.7 & 16.62 & 8.94 & 31.47 & n.a & 75.86 & 7.76 & 1.37 & 1.70 & n.c & n.c \\
\hline SB1 & 7:40 & 07-Fev-04 & 11.8 & 5.03 & 20.5 & 26.71 & 15.28 & 46.52 & 3.80 & 72.92 & 1.38 & $<1 . d$ & 6.16 & n.c & n.c \\
\hline SB2 & 7:44 & 07-Fev-04 & 9.4 & 5.02 & 18.6 & 18.99 & 9.80 & 45.81 & 3.19 & 77.56 & 4.53 & $<1 . d$ & 7.05 & n.c & n.c \\
\hline SB3 & $7: 49$ & 07-Fev-04 & 8 & 5.05 & 15.3 & 17.86 & 9.86 & 34.00 & 3.36 & 72.17 & 17.17 & 1.51 & 1.13 & 4.88 & n.c \\
\hline SB1 & $10: 00$ & 08-Fev-04 & 10.8 & 5.22 & 20.8 & 25.88 & 13.49 & 42.84 & $<$ I.d & 81.60 & 32.51 & 1.97 & 6.40 & n.c & n.c \\
\hline SB2 & $10: 07$ & $08-\mathrm{Fev}-04$ & 12 & 5.34 & 18.3 & 18.20 & 10.32 & 50.29 & 2.98 & 96.30 & 5.35 & $<I . d$ & 2.59 & n.c & n.c \\
\hline SB3 & $10: 11$ & 08-Fev-04 & 8.6 & 5.32 & 16.1 & 18.96 & 9.38 & 35.04 & 3.49 & 86.95 & 15.16 & 2.79 & 1.86 & 6.28 & n.c \\
\hline SB1 & $10: 31$ & 09-Fev-04 & 12.4 & 5.3 & 20.1 & 26.72 & 14.94 & 45.88 & $<$ I.d & 80.98 & 7.44 & 1.37 & 4.13 & n.c & n.c \\
\hline SB2 & $10: 34$ & 09-Fev-04 & 11 & 5.33 & 18.3 & 17.73 & 10.41 & 47.37 & $<$ I.d & 81.94 & 5.16 & $<1 . d$ & 1.38 & n.c & n.c \\
\hline SB3 & $10: 37$ & 09-Fev-04 & 9.8 & 5.36 & 16 & 16.87 & 8.06 & 28.48 & 2.91 & 65.78 & 8.39 & 5.05 & 5.67 & 7.96 & n.c \\
\hline SB1 & $9: 25$ & 10-Fev-04 & 0.6 & 4.61 & 21.6 & 28.16 & 14.25 & 50.60 & 3.02 & 83.53 & 7.66 & 1.13 & 17.75 & 4.15 & 13.60 \\
\hline SB2 & 9:27 & 10-Fev-04 & 0 & 4.61 & 18 & 18.11 & 10.33 & 49.30 & $<$ I.d & 86.19 & 7.99 & 1.56 & 3.40 & n.c & n.c \\
\hline SB3 & 9:29 & $10-\mathrm{Fev}-04$ & & 4.45 & 15.5 & 17.00 & 9.11 & 32.75 & $<$ I.d & 74.11 & 6.67 & $<1 . d$ & 4.13 & n.c & n.c \\
\hline SB1 & $8: 25$ & $11-\mathrm{Fev}-04$ & 11.6 & 5.04 & 21.2 & 27.49 & 15.20 & 49.00 & 5.33 & 83.41 & 6.48 & 1.39 & 9.89 & 6.72 & 3.16 \\
\hline SB2 & $8: 30$ & $11-\mathrm{Fev}-04$ & 10 & 5.03 & 18.9 & 19.01 & 10.11 & 45.22 & $<$ I.d & 81.81 & 4.87 & $<1 . d$ & 1.05 & n.c & n.c \\
\hline SB3 & $8: 35$ & 11-Fev-04 & 8.8 & 5.02 & 16.3 & 17.45 & 9.86 & 34.69 & 2.93 & 79.70 & 3.35 & $<1 . d$ & 8.91 & n.c & n.c \\
\hline SB1 & $8: 10$ & $12-\mathrm{Fev}-04$ & 13.4 & 5.3 & 21.9 & 27.24 & 14.52 & 43.60 & $<$ I.d & 77.81 & 6.06 & 1.26 & 4.62 & n.c & n.c \\
\hline SB2 & 8:05 & $12-\mathrm{Fev}-04$ & 12.2 & 5.38 & 17.3 & 17.78 & 10.04 & 47.40 & $<$ I.d & 85.20 & 3.16 & $<1 . d$ & 3.08 & n.c & n.c \\
\hline SB3 & 8:00 & $12-\mathrm{Fev}-04$ & 8.6 & 5.26 & 15.1 & 17.81 & 9.60 & 32.26 & $<$ I.d & 77.29 & 5.23 & 6.35 & 1.54 & n.c & n.c \\
\hline SB1 & $8: 32$ & $13-\mathrm{Fev}-04$ & 13.6 & 5.72 & 21.9 & 27.15 & 15.17 & 45.37 & $<$ I.d & 78.91 & 6.08 & 3.22 & 2.27 & n.c & n.c \\
\hline SB2 & $8: 36$ & 13-Fev-04 & 12 & 5.62 & 18.7 & 18.64 & 10.17 & 47.18 & $<$ I.d & 84.14 & 6.19 & $<1 . d$ & 1.70 & n.c & n.c \\
\hline SB3 & $8: 40$ & $13-\mathrm{Fev}-04$ & 10.4 & 5.42 & 15.7 & 16.05 & 9.65 & 32.44 & $<$ I.d & 76.70 & 4.96 & 1.19 & 0.00 & n.c & n.c \\
\hline SB1 & $9: 10$ & $14-\mathrm{Fev}-04$ & 13.2 & 5.41 & 20.5 & 28.25 & 15.00 & 45.27 & $<$ I.d & 82.07 & 6.06 & $<1 . d$ & 5.19 & n.c & n.c \\
\hline SB2 & $9: 15$ & 14-Fev-04 & 12.4 & 5.42 & 18.8 & 17.29 & 9.93 & 49.17 & 2.56 & 89.26 & 4.06 & $<$ I.d & 8.35 & n.c & n.c \\
\hline SB3 & $9: 20$ & $14-\mathrm{Fev}-04$ & 10 & 5.45 & 16.5 & 22.37 & 10.45 & 44.41 & 6.26 & 109.98 & 30.85 & 8.37 & 4.13 & 14.63 & n.c \\
\hline SB1 & $8: 57$ & $15-\mathrm{Fev}-04$ & 12 & 5.41 & 18.8 & 20.68 & 14.06 & 42.41 & 16.33 & 81.25 & 6.45 & 0.45 & 4.29 & 16.78 & n.c \\
\hline SB2 & 9:03 & $15-\mathrm{Fev}-04$ & 11.8 & 5.4 & 18 & 19.49 & 10.24 & 46.63 & 16.39 & 87.60 & 10.36 & 0.39 & 4.54 & 16.78 & n.c \\
\hline SB3 & 9:07 & $15-\mathrm{Fev}-04$ & 8.8 & 5.39 & 14.7 & 12.55 & 9.58 & 31.33 & 16.06 & 72.67 & 4.33 & 0.23 & 0.81 & 16.28 & n.c \\
\hline SB1 & 9:43 & $16-\mathrm{Fev}-04$ & 12.8 & 5.33 & 20 & 24.53 & 14.06 & 42.27 & $<I . d$ & 83.61 & 7.80 & $<$ I.d & 3.16 & n.c & n.c \\
\hline SB2 & 9:45 & $16-\mathrm{Fev}-04$ & 10.4 & 5.23 & 18.6 & 16.75 & 10.05 & 47.43 & $<$ I.d & 86.09 & 8.28 & 0.76 & 1.46 & n.c & n.c \\
\hline SB3 & $9: 47$ & $16-\mathrm{Fev}-04$ & 8.8 & 5.3 & 15.6 & 14.51 & 9.64 & 33.85 & $<$ I.d & 77.60 & 7.77 & 0.98 & 3.16 & n.c & n.c \\
\hline SB1 & 9:10 & $17-\mathrm{Fev}-04$ & 13.2 & 5.4 & 18.8 & 22.71 & 14.00 & 42.10 & 15.28 & 76.80 & 3.68 & 0.55 & 3.24 & 15.83 & n.c \\
\hline SB2 & $9: 14$ & $17-\mathrm{Fev}-04$ & 12.8 & 5.34 & 17.9 & 17.25 & 10.04 & 47.20 & 18.11 & 80.97 & 4.83 & 0.34 & 0.97 & 18.45 & n.c \\
\hline SB3 & $9: 16$ & $17-\mathrm{Fev}-04$ & 9.4 & 5.25 & 15.7 & 15.11 & 10.03 & 34.00 & 18.78 & 76.34 & 5.94 & 0.13 & 3.08 & 18.91 & n.c \\
\hline SB1 & $9: 35$ & $18-\mathrm{Fev}-04$ & 12.2 & 5.34 & 19.6 & 23.76 & 14.27 & 41.75 & $<$ I.d & 73.01 & 2.39 & 0.85 & 5.83 & n.c & n.c \\
\hline SB2 & 9:37 & $18-\mathrm{Fev}-04$ & 11.6 & 5.32 & 17.9 & 14.44 & 10.00 & 46.48 & $<$ I.d & 75.28 & 2.39 & $<1 . d$ & 2.92 & n.c & n.c \\
\hline SB3 & 9:41 & $18-\mathrm{Fev}-04$ & 8.2 & 5.3 & 15.8 & 13.34 & 10.36 & 32.48 & $<I . d$ & 68.43 & 2.06 & 1.16 & 2.51 & n.c & n.c \\
\hline SB1 & $10: 00$ & $19-\mathrm{Fev}-04$ & 11.8 & 5.33 & 18.4 & 20.52 & 14.01 & 41.95 & 15.72 & 72.51 & 2.48 & $<1 . d$ & 1.86 & n.c & n.c \\
\hline SB2 & $10: 05$ & $19-\mathrm{Fev}-04$ & 9.6 & 5.34 & 18.1 & 13.88 & 9.87 & 46.87 & 14.83 & 75.77 & 4.00 & $<1 . d$ & 4.54 & n.c & n.c \\
\hline SB3 & $10: 07$ & $19-\mathrm{Fev}-04$ & 9.8 & 5.29 & 15.7 & 13.45 & 10.39 & 33.26 & 13.06 & 70.89 & 4.95 & 1.21 & 4.86 & 14.27 & n.c \\
\hline SB1 & $11: 26$ & $20-\mathrm{Fev}-04$ & 11 & 5.3 & 19.6 & 26.24 & 14.70 & 44.68 & $<1 . d$ & 81.05 & 6.64 & 2.57 & 7.54 & n.c & n.c \\
\hline SB2 & $11: 30$ & $20-\mathrm{Fev}-04$ & 10.2 & 5.45 & 16.8 & 14.68 & 9.77 & 48.85 & $<$ I.d & 86.02 & 6.32 & 1.07 & 2.84 & n.c & n.c \\
\hline SB3 & $11: 32$ & $20-\mathrm{Fev}-04$ & 8.2 & 5.22 & 15.2 & 13.98 & 10.44 & 35.30 & $<$ I.d & 74.14 & 4.21 & 2.17 & 9.40 & n.c & n.c \\
\hline SB1 & 9:05 & 21-Fev-04 & 10.6 & 5.32 & 18.8 & 17.69 & 11.22 & 37.10 & $<I . d$ & 66.50 & 3.63 & 1.54 & 9.97 & n.c & n.c \\
\hline SB2 & 9:08 & 21-Fev-04 & 9 & 5.38 & 17.2 & 14.43 & 9.96 & 46.01 & $<$ I.d & 74.45 & 3.85 & 0.74 & 5.10 & n.c & n.c \\
\hline SB3 & 9:13 & 21-Fev-04 & 8.8 & 5.3 & 15.4 & 10.64 & 0.07 & 29.61 & $<\mathrm{l} . \mathrm{d}$ & 59.32 & 3.35 & 2.18 & 5.02 & n.c & n.c \\
\hline SB1 & 9:00 & $25-\mathrm{Fev}-04$ & 11.2 & 5.22 & 19.6 & 18.42 & 10.19 & 33.26 & 14.58 & 63.10 & 16.72 & 0.73 & 16.21 & 15.32 & 0.89 \\
\hline SB2 & 9:07 & $25-\mathrm{Fev}-04$ & 9.6 & 5.25 & 17.8 & 13.23 & 8.26 & 41.37 & $<I . d$ & 70.90 & 5.09 & 0.87 & 4.38 & n.c & n.c \\
\hline SB3 & $9: 15$ & $25-\mathrm{Fev}-04$ & 7 & 5.17 & 15.2 & 11.64 & 9.83 & 32.98 & $<$ I.d & 71.84 & 5.19 & 0.66 & 0.32 & n.c & n.c \\
\hline SB1 & $17: 47$ & $25-\mathrm{Fev}-04$ & 11.6 & 5.5 & 19.9 & 18.05 & 12.25 & 38.09 & 3.47 & 73.64 & 7.06 & 2.16 & 2.92 & 5.63 & n.c \\
\hline SB2 & $17: 35$ & $25-\mathrm{Fev}-04$ & 11.6 & 5.69 & 19.5 & 14.30 & 8.87 & 43.73 & 3.33 & 77.87 & 8.83 & $<1 . d$ & 2.51 & n.c & n.c \\
\hline SB3 & 17:41 & $25-\mathrm{Fev}-04$ & 9.6 & 5.38 & 16.4 & 10.96 & 8.95 & 31.83 & 3.11 & 74.27 & 10.93 & $<1 . d$ & 4.86 & n.c & n.c \\
\hline SB1 & $10: 36$ & 26-Fev-04 & n.a & 5.33 & 19.2 & 21.73 & 12.58 & 37.85 & 5.27 & 66.00 & 5.47 & 2.35 & 13.78 & 7.62 & 6.15 \\
\hline SB2 & $10: 43$ & 26-Fev-04 & n.a & 5.35 & 16.4 & 10.57 & 8.34 & 40.37 & 2.74 & 68.06 & 2.30 & $<$ I.d & 1.46 & n.c & n.c \\
\hline SB3 & $10: 46$ & $26-\mathrm{Fev}-04$ & n.a & 5.3 & 15.2 & 10.95 & 7.98 & 28.29 & $<$ I.d & 59.66 & 3.25 & 0.92 & 1.22 & n.c & n.c \\
\hline SB1 & $9: 27$ & 27-fev-04 & n.a & 5.48 & 19.7 & 22.85 & 14.33 & 45.09 & 14.17 & 74.74 & 5.74 & 6.50 & 12.56 & 20.67 & n.c \\
\hline SB2 & 9:30 & 27 -fev-04 & n.a & 5.23 & 17.6 & 13.46 & 9.74 & 46.81 & 13.22 & 75.74 & 2.77 & 1.18 & 1.38 & 14.40 & n.c \\
\hline SB3 & 9:33 & 27-fev-04 & n.a & 5.16 & 15.5 & 10.29 & 8.59 & 29.75 & 14.06 & 65.79 & 6.34 & 1.05 & 0.57 & 15.10 & n.c \\
\hline
\end{tabular}

$<$ l.d = menor ao limite de detecção

n.a = não analisado

n.c $=$ não calculado

Alc. $=$ Alcalinidade (ueq. $\mathrm{L}^{-1}$ )

C. $\mathrm{E}=$ Condutividade elétrica $\left(\mathrm{uS} . \mathrm{cm}^{-1}\right)$

SB1 = poço 1; SB 2 = Poço 2; SB3 = Poço 3 
Anexo G. Valores dos parâmetros físico-químicos e concentrações dos elementos e compostos analisados na água subterrânea na microbacia do pasto

\begin{tabular}{|c|c|c|c|c|c|c|c|c|c|c|c|c|c|c|c|}
\hline Fonte & Hora & Data & Alc & $\mathrm{pH}$ & C.E & $\mathrm{Ca}(\mathrm{uM})$ & $\mathrm{Mg}$ (UM) & $\mathrm{K}(\mathrm{uM})$ & $\mathrm{NH} 4(\mathrm{uM})$ & $\mathrm{Na}$ (UM) & Cl(uM) & NO3(UM) & TDN(UM) & NID(UM) & NOD(UM) \\
\hline SB1 & $16: 35$ & 22-Jan-04 & 5 & 5.13 & 20.5 & 14.78 & 7.41 & 40.41 & 5.89 & 39.91 & 17.31 & 0.27 & 3.15 & 6.16 & n.c \\
\hline SB2 & $16: 40$ & 22-Jan-04 & 3 & 5.14 & 17.1 & 11.83 & 0.21 & 36.52 & 3.44 & 37.61 & 15.47 & 0.89 & 1.42 & 4.33 & n.c \\
\hline SB3 & $16: 45$ & 22-Jan-04 & 2.8 & 5.26 & 17.3 & 7.01 & 3.71 & 37.19 & 4.67 & 35.86 & 16.40 & 0.11 & $<$ l.d & 4.78 & n.c \\
\hline SB1 & $15: 00$ & 27-Jan-04 & 0 & 4.74 & 28 & 8.95 & 5.61 & 40.76 & $<$ I.d & 39.45 & 17.07 & $<1 . d$ & 6.60 & n.c & n.c \\
\hline SB2 & $15: 00$ & 27-Jan-04 & 0.2 & 4.71 & 18 & 9.37 & 5.41 & 50.35 & 5.69 & 61.08 & 13.06 & $<$ I.d & 3.60 & n.c & n.c \\
\hline SB3 & $15: 00$ & 27-Jan-04 & 1.2 & 4.76 & 20 & 7.11 & 4.35 & 49.76 & 2.54 & 45.70 & 20.29 & $<$ I.d & 4.50 & n.c & n.c \\
\hline SB1 & $9: 27$ & 28-Jan-04 & 0 & 4.61 & 17.9 & 6.86 & 5.23 & 47.36 & $<$ I.d & 60.38 & 20.43 & $<$ I.d & 1.05 & n.c & n.c \\
\hline SB2 & $9: 29$ & 28-Jan-04 & -0.2 & 4.59 & 17.8 & 6.51 & 4.87 & 42.96 & $<$ I.d & 59.70 & 20.16 & $<$ I.d & 9.00 & n.c & n.c \\
\hline SB3 & 9:33 & 28-Jan-04 & -9.6 & 4.5 & 17.1 & 6.09 & 4.43 & 48.19 & $<$ I.d & 67.14 & 22.91 & $<$ I.d & 9.22 & n.c & n.c \\
\hline SB1 & $8: 50$ & 29-Jan-04 & 4 & 4.96 & 21.4 & 5.95 & 4.79 & 47.78 & $<$ I.d & 43.19 & 9.79 & $<$ I.d & 5.02 & n.c & n.c \\
\hline SB2 & $8: 53$ & 29-Jan-04 & 7.4 & 4.98 & 17.5 & 5.58 & 4.78 & 45.69 & $<$ I.d & 36.49 & 6.36 & $<$ I.d & 2.02 & n.c & n.c \\
\hline SB3 & $8: 56$ & 29-Jan-04 & 4 & 5.1 & 17.8 & $<1 . d$ & 4.27 & 48.63 & $<1 . d$ & 40.04 & 11.50 & $<$ I.d & 3.15 & n.c & n.c \\
\hline SB1 & $8: 54$ & 30-Jan-04 & 0.6 & 4.6 & 17.7 & 5.36 & 5.38 & 50.97 & $<$ I.d & 33.04 & 10.59 & $<$ I.d & $<1 . d$ & n.c & n.c \\
\hline SB2 & 8:57 & 30-Jan-04 & 0.8 & 4.68 & 18.5 & 6.93 & 7.14 & 52.26 & 2.96 & 37.93 & 13.79 & $<1 . d$ & 8.17 & n.c & n.c \\
\hline SB3 & 9:01 & 30-Jan-04 & -1.6 & 4.6 & 16.8 & 6.04 & 4.51 & 47.51 & 3.83 & 37.26 & 8.97 & $<$ I.d & $<\mathrm{I} . \mathrm{d}$ & n.c & n.c \\
\hline SB1 & $8: 59$ & 31-Jan-04 & 4.8 & 5.13 & 23.3 & 13.09 & 6.95 & 48.33 & $<$ I.d & 33.77 & 10.21 & $<$ I.d & 0.22 & n.c & n.c \\
\hline SB2 & 9:01 & 31-Jan-04 & 2.6 & 5.05 & 19.2 & 8.20 & 5.62 & 53.60 & 4.43 & 49.99 & 22.63 & $<$ I.d & 5.02 & n.c & n.c \\
\hline SB3 & 9:05 & 31-Jan-04 & 5.2 & 5.06 & 16.5 & 4.30 & 4.07 & 49.64 & $<$ I.d & 37.11 & 8.51 & $<$ I.d & 5.40 & n.c & n.c \\
\hline SB1 & $9: 38$ & 01-Fev-04 & 2.8 & 4.72 & 16.8 & 4.90 & 5.42 & 48.34 & $<$ I.d & 36.19 & 11.06 & $<$ I.d & 1.35 & n.c & n.c \\
\hline SB2 & 9:41 & 01-Fev-04 & 2.4 & 4.72 & 17.1 & 9.49 & 6.88 & 49.59 & 2.79 & 38.53 & 12.30 & $<$ I.d & 2.02 & n.c & n.c \\
\hline SB3 & $9: 45$ & 01-Fev-04 & 2.8 & 4.79 & 15.6 & 3.77 & 4.53 & 50.06 & $<$ I.d & 37.79 & 12.06 & $<$ I.d & 3.30 & n.c & n.c \\
\hline SB1 & 9:00 & 02-Fev-04 & 2.8 & 4.69 & 16.1 & 0.12 & 4.76 & 40.75 & $<$ I.d & 31.37 & 5.99 & $<$ I.d & 1.27 & n.c & n.c \\
\hline SB2 & 9:03 & 02-Fev-04 & -0.4 & 4.64 & 16 & 5.52 & 5.78 & 48.34 & $<$ l.d & 38.33 & 12.96 & $<1 . d$ & 5.47 & n.c & n.c \\
\hline SB3 & 9:06 & 02-Fev-04 & 0 & 4.62 & 15.3 & 5.48 & 4.18 & 51.33 & $<$ I.d & 37.89 & 12.61 & $<$ I.d & $<$ I.d & n.c & n.c \\
\hline SB1 & $8: 10$ & 03-Fev-04 & 4 & 5.25 & 15.1 & 4.60 & 5.28 & 41.46 & $<$ I.d & 31.01 & 10.74 & $<$ I.d & 0.90 & n.c & n.c \\
\hline SB2 & $8: 15$ & 03-Fev-04 & 6.6 & 5.33 & 14.4 & 4.37 & 5.57 & 43.17 & $<$ I.d & 33.32 & 10.77 & $<$ I.d & 4.88 & n.c & n.c \\
\hline SB3 & $8: 17$ & 03-Fev-04 & 5.4 & 5.39 & 13.9 & 5.49 & 4.91 & 58.06 & $<$ I.d & 41.02 & 14.72 & $<$ I.d & 7.78 & n.c & n.c \\
\hline SB1 & $8: 55$ & 04-Fev-04 & 5 & 4.98 & 16.6 & 4.29 & 4.67 & 36.99 & 5.11 & 27.63 & 8.55 & 0.00 & 13.82 & 5.11 & 8.71 \\
\hline SB2 & $8: 57$ & 04-Fev-04 & 5 & 4.9 & 16.5 & 5.29 & 4.80 & 43.75 & 6.22 & 35.94 & 13.98 & 0.00 & 11.67 & 6.22 & 5.45 \\
\hline SB3 & 9:00 & 04-Fev-04 & 4.8 & 4.96 & 16.8 & 4.79 & 4.30 & 47.39 & 6.05 & 37.00 & 12.78 & 0.00 & 2.07 & 6.06 & n.c \\
\hline SB1 & $8: 50$ & 05-Fev-04 & 6.6 & 5 & 17 & 5.26 & 4.79 & 48.89 & $<$ I.d & 35.80 & 11.93 & $<1 . d$ & 8.03 & n.c & n.c \\
\hline SB2 & $8: 55$ & 05-Fev-04 & 6.2 & 4.92 & 18.6 & 6.39 & 5.35 & 42.00 & $<$ I.d & 37.75 & 17.22 & $<$ I.d & 5.21 & n.c & n.c \\
\hline SB3 & 9:00 & 05-Fev-04 & 3 & 4.9 & 17 & 4.56 & 3.18 & 44.05 & 2.53 & 40.92 & 17.02 & $<$ l.d & 7.12 & n.c & n.c \\
\hline SB1 & $8: 13$ & 06-Fev-04 & 5 & 4.7 & 23.3 & 5.05 & 4.66 & 41.59 & $<$ I.d & 27.45 & 7.97 & $<$ I.d & 2.40 & n.c & n.c \\
\hline SB2 & $8: 16$ & 06-Fev-04 & 3.2 & 4.8 & 16.7 & 9.80 & 4.64 & 56.96 & 9.65 & 94.89 & 79.33 & $<1 . d$ & 12.50 & n.c & n.c \\
\hline SB3 & $8: 19$ & 06-Fev-04 & 3.8 & 4.85 & 15.8 & 5.11 & 3.80 & 49.74 & 4.60 & 50.51 & 27.74 & $<1 . d$ & 8.03 & n.c & n.c \\
\hline SB1 & $8: 00$ & 07-Fev-04 & 0.6 & 4.72 & 16.7 & 7.28 & 6.56 & 51.71 & 8.31 & 57.59 & 33.98 & $<1 . d$ & 10.26 & n.c & n.c \\
\hline SB2 & 8:03 & 07-Fev-04 & 3.8 & 4.69 & 16.5 & 3.77 & 6.24 & 47.37 & 4.37 & 38.23 & 8.64 & $<1 . d$ & 10.43 & n.c & n.c \\
\hline SB3 & 8:07 & 07-Fev-04 & 2.8 & 4.82 & 15.7 & 3.32 & 5.49 & 51.82 & 22.71 & 39.66 & 53.28 & $<1 . d$ & 8.86 & n.c & n.c \\
\hline SB1 & $9: 21$ & 08-Fev-04 & 7.2 & 5.23 & 16.1 & 5.22 & 7.54 & 51.57 & 9.92 & 54.54 & 37.25 & $<1 . d$ & 14.15 & n.c & n.c \\
\hline SB2 & $9: 25$ & 08-Fev-04 & 6.4 & 5.21 & 16.4 & 5.33 & 6.91 & 47.76 & 3.70 & 47.22 & 26.77 & $<1 . d$ & 2.90 & n.c & n.c \\
\hline SB3 & $9: 27$ & 08-Fev-04 & 5 & 5.11 & 15.4 & 2.81 & 5.64 & 50.20 & 3.88 & 39.16 & 18.71 & $<1 . d$ & 9.35 & n.c & n.c \\
\hline SB1 & $10: 51$ & 09-Fev-04 & 10 & 5.14 & 16.2 & 4.52 & 8.19 & 48.24 & 3.99 & 35.44 & 9.94 & $<1 . d$ & 8.53 & n.c & n.c \\
\hline SB2 & $10: 54$ & 09-Fev-04 & 4 & 5.14 & 16.2 & 3.74 & 7.69 & 48.05 & 3.35 & 47.32 & 26.05 & $<1 . d$ & 12.75 & n.c & n.c \\
\hline SB3 & $10: 57$ & 09-Fev-04 & 6 & 5.08 & 15.5 & 3.21 & 5.95 & 53.55 & 5.50 & 40.72 & 21.09 & $<1 . d$ & 14.48 & n.c & n.c \\
\hline SB1 & $9: 04$ & 10-Fev-04 & n.a & 4 & 15.8 & 3.30 & 7.61 & 45.24 & 2.79 & 33.24 & 13.47 & $<1 . d$ & 3.72 & n.c & n.c \\
\hline SB2 & 9:06 & 10-Fev-04 & n.a & 4.16 & 16.3 & 4.76 & 6.99 & 48.10 & 4.45 & 41.46 & 24.50 & $<1 . d$ & 12.99 & n.c & n.c \\
\hline SB3 & 9:08 & 10-Fev-04 & n.a & 4.04 & 15.2 & n.a. & 5.77 & 52.83 & 6.25 & 38.55 & 20.35 & $<1 . d$ & 10.68 & n.c & n.c \\
\hline SB1 & 9:00 & 11-Fev-04 & 0.4 & 4.7 & 16.4 & 5.26 & 8.81 & 52.48 & 5.35 & 44.05 & 31.40 & $<1 . d$ & 10.10 & n.c & n.c \\
\hline SB2 & 9:05 & 11-Fev-04 & 3.2 & 4.73 & 16.6 & 3.72 & 8.11 & 49.24 & 4.33 & 44.99 & 23.89 & $<1 . d$ & 10.76 & n.c & n.c \\
\hline SB3 & 9:07 & 11-Fev-04 & 1.4 & 4.8 & 15.7 & 2.22 & 5.69 & 50.58 & 2.98 & 38.59 & 16.70 & $<1 . d$ & 8.94 & n.c & n.c \\
\hline SB1 & 9:07 & 12-Fev-04 & 6.4 & 5.11 & 20.6 & 7.72 & 8.56 & 56.37 & 10.87 & 74.26 & 80.91 & $<1 . d$ & 9.77 & n.c & n.c \\
\hline SB2 & 9:10 & $12-\mathrm{Fev}-04$ & 4.8 & 5.01 & 16.8 & 4.09 & 6.29 & 45.01 & 3.78 & 42.43 & 20.42 & $<$ I.d & 12.83 & n.c & n.c \\
\hline SB3 & $9: 15$ & 12-Fev-04 & 6.4 & 5.12 & 14 & 2.34 & 4.33 & 42.02 & 3.14 & 33.47 & 10.88 & $<$ I.d & 5.88 & n.c & n.c \\
\hline SB1 & 9:02 & 13-Fev-04 & 6.2 & 5.17 & 15.9 & 2.80 & 7.78 & 48.96 & 3.98 & 40.35 & 17.78 & $<1 . d$ & 8.03 & n.c & n.c \\
\hline SB2 & 9:07 & $13-F e v-04$ & 6 & 5.2 & 16.2 & 2.81 & 7.49 & 49.42 & 4.38 & 44.50 & 21.68 & $<1 . d$ & 9.60 & n.c & n.c \\
\hline SB3 & $9: 10$ & 13-Fev-04 & 5.8 & 5.17 & 15.4 & 1.86 & 5.06 & 46.18 & 2.92 & 34.31 & 16.70 & $<1 . d$ & 3.23 & n.c & n.c \\
\hline SB1 & 10:03 & 14-Fev-04 & 6 & 5.14 & 16.2 & 2.86 & 6.17 & 43.73 & 3.50 & 35.70 & 18.42 & $<1 . d$ & 11.17 & n.c & n.c \\
\hline SB2 & $10: 08$ & 14-Fev-04 & 7.6 & 5.17 & 16.4 & 4.20 & 6.58 & 48.34 & 4.30 & 38.60 & 16.84 & $<1 . d$ & 13.08 & n.c & n.c \\
\hline SB3 & $10: 11$ & 14-Fev-04 & 6 & 5.17 & 15.5 & 2.61 & 5.91 & 54.87 & 5.31 & 53.08 & 34.09 & $<1 . d$ & 8.19 & n.c & n.c \\
\hline SB1 & $9: 28$ & 15-Fev-04 & 6.4 & 5.14 & 15.7 & 3.19 & 7.78 & 49.84 & 6.22 & 38.17 & 8.47 & 0.00 & 10.59 & 6.22 & 4.37 \\
\hline SB2 & 9:31 & $15-\mathrm{Fev}-04$ & 6.6 & 5.24 & 16.1 & 3.18 & 7.85 & 52.08 & 4.89 & 45.71 & 26.77 & 0.00 & 12.17 & 4.89 & 7.28 \\
\hline SB3 & 9:35 & $15-\mathrm{Fev}-04$ & 5.6 & 5.2 & 15.4 & 2.14 & 5.97 & 54.24 & 9.00 & 41.38 & 20.06 & 0.00 & 3.15 & 9.00 & n.c \\
\hline SB1 & 9:00 & $16-\mathrm{Fev}-04$ & 6.4 & 5.03 & 15.9 & 3.82 & 8.10 & 49.24 & 5.10 & 41.46 & 20.06 & $<$ I.d & 12.00 & n.c & n.c \\
\hline SB2 & 9:04 & $16-F e v-04$ & 9 & 5.37 & 16 & 3.66 & 6.33 & 48.83 & 5.37 & 40.93 & 19.65 & $<1 . d$ & 9.44 & n.c & n.c \\
\hline SB3 & 9:07 & 16-Fev-04 & 6.2 & 5.09 & 15.2 & 1.36 & 4.25 & 41.79 & $<1 . d$ & 30.77 & 19.19 & $<1 . d$ & 3.39 & n.c & n.c \\
\hline SB1 & $8: 43$ & 17-Fev-04 & 5.4 & 4.99 & 16 & 3.53 & 8.06 & 49.56 & 4.94 & 38.96 & 19.77 & 0.06 & 5.55 & 5.01 & 0.54 \\
\hline SB2 & $8: 45$ & 17-Fev-04 & 5 & 5.05 & 16 & 2.71 & 7.55 & 51.40 & 6.67 & 42.27 & 20.44 & 0.00 & 0.58 & 6.67 & n.c \\
\hline SB3 & $8: 47$ & 17-Fev-04 & 4.6 & 5.05 & 15.2 & 2.71 & 6.59 & 55.44 & 5.44 & 43.74 & 22.60 & 0.00 & 1.41 & 5.44 & n.c \\
\hline SB1 & $8: 57$ & 18-Fev-04 & 6.8 & 5.09 & 15.6 & 2.55 & 8.93 & 46.86 & 3.45 & 31.53 & 15.12 & $<$ I.d & 1.66 & n.c & n.c \\
\hline SB2 & 9:03 & $18-\mathrm{Fev}-04$ & 5.8 & 5.11 & 15.6 & 4.20 & 6.86 & 47.68 & 5.27 & 35.72 & 10.17 & $<1 . d$ & 4.30 & n.c & n.c \\
\hline SB3 & $9: 08$ & 18 -Fev-04 & 5.2 & 5.08 & 15.5 & 2.15 & 6.18 & 53.08 & 3.80 & 33.10 & 16.69 & $<$ l.d & $<$ I.d & n.c & n.c \\
\hline
\end{tabular}


Anexo G. Valores dos parâmetros físico-químicos e concentrações dos elementos e compostos analisados na água subterrânea na microbacia do pasto

\begin{tabular}{|c|c|c|c|c|c|c|c|c|c|c|c|c|c|c|c|}
\hline Fonte & Hora & Data & Alc & $\mathrm{pH}$ & C.E & $\mathrm{Ca}(\mathrm{uM})$ & $\mathrm{Mg}$ (uM) & $\mathrm{K}$ (UM) & $\mathrm{NH} 4$ (uM) & $\mathrm{Na}(\mathrm{UM})$ & Cl(UM) & NO3(UM) & TDN(UM) & NID(uM) & NOD(UM) \\
\hline SB2 & $9: 32$ & $19-\mathrm{Fev}-04$ & 5.8 & 5.12 & 15.7 & 2.02 & 8.30 & 51.91 & 3.00 & 35.56 & 21.47 & 0.00 & 0.74 & 3.00 & n.c \\
\hline SB3 & 9:36 & $19-\mathrm{Fev}-04$ & 5 & 5.11 & 15.2 & 1.15 & 4.72 & 44.75 & 5.50 & 30.18 & 19.24 & 0.00 & 3.64 & 5.50 & n.c \\
\hline SB1 & 9:32 & 20-Fev-04 & 5.6 & 5.32 & 14.5 & 3.40 & 9.04 & 50.12 & 5.01 & 38.95 & 15.57 & $<$ I.d & $<$ I.d & n.c & n.c \\
\hline SB2 & 9:35 & $20-\mathrm{Fev}-04$ & 6 & 5.11 & 14.7 & 3.97 & 6.74 & 45.88 & 3.24 & 41.01 & 18.18 & $<1 . d$ & $<$ I.d & n.c & n.c \\
\hline SB3 & 9:38 & $20-\mathrm{Fev}-04$ & 6.6 & 5.27 & 15.1 & 1.85 & 5.92 & 52.51 & 3.74 & 39.56 & 17.27 & $<$ I.d & $<1 . d$ & n.c & n.c \\
\hline SB1 & 10:05 & 21-Fev-04 & 5.8 & 5.07 & 14.9 & 3.26 & 8.47 & 53.15 & $<$ I.d & 35.71 & 17.97 & $<$ I.d & 0.22 & n.c & n.c \\
\hline SB2 & 10:07 & 21-Fev-04 & 5.2 & 5.09 & 15 & 3.91 & 7.63 & 51.78 & $<$ I.d & 37.32 & 21.18 & $<$ I.d & $<I . d$ & n.c & n.c \\
\hline SB3 & 10:09 & 21-Fev-04 & 4.8 & 5.06 & 15.1 & 1.71 & 5.80 & 56.78 & $<$ I.d & 36.55 & 17.32 & $<$ I.d & $<$ I.d & n.c & n.c \\
\hline SB1 & 10:02 & $22-\mathrm{Fev}-04$ & 4.2 & 5.01 & 17.5 & n.a. & n.a. & n.a. & n.a. & n.a. & n.a. & n.a. & n.a. & n.a. & n.a. \\
\hline SB2 & 10:04 & 22-Fev-04 & 7 & 5.17 & 16.3 & n.a. & n.a. & n.a. & n.a. & n.a. & n.a. & n.a. & n.a. & n.a. & n.a. \\
\hline SB3 & 10:07 & $22-\mathrm{Fev}-04$ & 4.6 & 5.01 & 15.5 & n.a. & n.a. & n.a. & n.a. & n.a. & n.a. & n.a. & n.a. & n.a. & n.a. \\
\hline SB1 & $8: 55$ & 23-Fev-04 & 5 & 4.91 & 17.3 & n.a. & n.a. & n.a. & n.a. & n.a. & n.a. & n.a. & n.a. & n.a. & n.a. \\
\hline SB2 & 8:57 & 23-Fev-04 & 4.2 & 4.86 & 16.5 & n.a. & n.a. & n.a. & n.a. & n.a. & n.a. & n.a. & n.a. & n.a. & n.a. \\
\hline SB3 & 9:00 & 23-Fev-04 & 3.8 & 4.88 & 15.9 & n.a. & n.a. & n.a. & n.a. & n.a. & n.a. & n.a. & n.a. & n.a. & n.a. \\
\hline SB1 & $10: 26$ & 24-Fev-04 & 2.8 & & 4.85 & n.a. & n.a. & n.a. & n.a. & n.a. & n.a. & n.a. & n.a. & n.a. & n.a. \\
\hline SB2 & $10: 29$ & 24-Fev-04 & 4 & 4.92 & 15.5 & n.a. & n.a. & n.a. & n.a. & n.a. & n.a. & n.a. & n.a. & n.a. & n.a. \\
\hline SB3 & $10: 31$ & 24-Fev-04 & 3 & 4.86 & 15.6 & n.a. & n.a. & n.a. & n.a. & n.a. & n.a. & n.a. & n.a. & n.a. & n.a. \\
\hline SB1 & $9: 40$ & $25-\mathrm{Fev}-04$ & 3.4 & 4.87 & 16 & 3.63 & 8.35 & 53.69 & $<$ I.d & 39.70 & 20.48 & $<$ I.d & $<1 . d$ & n.c & n.c \\
\hline SB2 & $9: 43$ & $25-\mathrm{Fev}-04$ & 6.4 & 4.88 & 16.5 & 3.40 & 6.93 & 53.43 & $<$ I.d & 42.51 & 27.68 & $<$ I.d & $<1 . d$ & n.c & n.c \\
\hline SB3 & $9: 46$ & $25-\mathrm{Fev}-04$ & 5.4 & 5.03 & 15.8 & 5.37 & 6.73 & 66.73 & 4.16 & 63.56 & 32.33 & $<$ I.d & $<1 . d$ & n.c & n.c \\
\hline SB1 & $18: 25$ & $25-\mathrm{Fev}-04$ & 5.8 & 5.01 & 17.3 & 3.52 & 8.00 & 54.66 & $<$ I.d & 57.89 & 27.03 & $<$ I.d & $<$ I.d & n.c & n.c \\
\hline SB2 & $18: 28$ & $25-\mathrm{Fev}-04$ & 8 & 5.92 & 17.9 & 4.09 & 7.38 & 53.86 & $<$ I.d & 39.67 & 19.55 & $<$ I.d & $<1 . d$ & n.c & n.c \\
\hline SB3 & $18: 30$ & $25-\mathrm{Fev}-04$ & 5.4 & 5.12 & 16.9 & 3.00 & 6.21 & 56.44 & $<$ I.d & 38.86 & 16.25 & $<$ I.d & 0.22 & n.c & n.c \\
\hline SB1 & 10:06 & $26-\mathrm{Fev}-04$ & n.a & 5.01 & 14.9 & 3.57 & 8.51 & 54.74 & 2.72 & 39.46 & 25.76 & $<$ I.d & 3.60 & n.c & n.c \\
\hline SB2 & 10:09 & $26-\mathrm{Fev}-04$ & n.a & 5.03 & 15.9 & 4.61 & 6.62 & 50.62 & 3.22 & 37.84 & 22.31 & $<$ I.d & 1.57 & n.c & n.c \\
\hline SB3 & $10: 11$ & $26-\mathrm{Fev}-04$ & n.a & 5.19 & 15.2 & 2.00 & 5.77 & 56.30 & $<$ I.d & 34.93 & 20.18 & $<$ I.d & 2.25 & n.c & n.c \\
\hline SB1 & $8: 50$ & 27 -fev-04 & n.a & 5.03 & 16.1 & 2.52 & 8.26 & 43.84 & 3.67 & 24.52 & 10.36 & 0.00 & $<$ I.d & 3.67 & n.c \\
\hline SB2 & 8:52 & 27 -fev-04 & n.a & 4.95 & 16.3 & 2.83 & 7.75 & 54.18 & 3.33 & 32.74 & 18.32 & 0.00 & 0.45 & 3.33 & n.c \\
\hline SB3 & $8: 54$ & 27-fev-04 & n.a & 4.98 & 15.8 & 1.83 & 6.05 & 56.89 & 5.17 & 34.84 & 14.55 & 0.00 & 0.22 & 5.17 & n.c \\
\hline SB1 & $10: 20$ & 29-fev-04 & n.a & 5 & 16.8 & n.a. & n.a & n.a & n.a & n.a & n.a & n.a & n.a & n.a & n.a \\
\hline SB2 & $10: 25$ & 29-fev-04 & n.a & 4.36 & 16.9 & n.a. & n.a & n.a & n.a & n.a & n.a & n.a & n.a & n.a & n.a \\
\hline SB3 & $10: 30$ & 29-fev-04 & n.a & 4.79 & 16.8 & n.a. & n.a & n.a & n.a & n.a & n.a & n.a & n.a & ก.a & ก.a \\
\hline SB1 & $13: 15$ & 1-Mar-04 & n.a & 5.12 & 16.65 & n.a. & n.a & n.a & n.a & n.a & n.a & n.a & ก.a & ก.a & n.a \\
\hline SB2 & $13: 16$ & 1-Mar-04 & n.a & 5.02 & 15.49 & n.a. & n.a & n.a & n.a & n.a & n.a & n.a & ก.a & ก.a & n.a \\
\hline SB3 & $13: 18$ & 1-Mar-04 & n.a & 4.97 & 14.87 & n.a. & n.a & n.a & n.a & n.a & n.a & n.a & n.a & n.a & n.a \\
\hline SB1 & 9:37 & 2-Mar-04 & n.a & 4.93 & 15.45 & n.a. & n.a & n.a & n.a & n.a & n.a & n.a & n.a & n.a & n.a \\
\hline SB2 & 9:39 & 2-Mar-04 & n.a & 4.99 & 15.57 & n.a. & n.a & n.a & n.a & n.a & n.a & n.a & n.a & n.a & n.a \\
\hline SB3 & 9:41 & 2-Mar-04 & n.a & 4.99 & 14.85 & n.a. & n.a & n.a & n.a & n.a & n.a & n.a & n.a & n.a & n.a \\
\hline SB1 & 9:37 & 3-Mar-04 & n.a & 5 & 15.85 & n.a. & n.a & n.a & ก.a & n.a & n.a & ก.a & ก.a & n.a & ก.a \\
\hline SB2 & 9:38 & 3-Mar-04 & n.a & 5.02 & 15.8 & n.a. & n.a & n.a & n.a & n.a & n.a & n.a & n.a & n.a & n.a \\
\hline SB3 & 9:40 & 3-Mar-04 & n.a & 5.03 & 14.58 & n.a. & n.a & n.a & n.a & n.a & n.a & n.a & n.a & n.a & n.a \\
\hline
\end{tabular}

$<\mathrm{l} . \mathrm{d}=$ menor ao limite de detecção

n.a $=$ não analisado

n.c $=$ não calculado

Alc. $=$ Alcalinidade (ueq. $\mathrm{L}^{-1}$ )

C. $\mathrm{E}=$ Condutividade elétrica (uS. $\mathrm{cm}^{-1}$ )

SB1 = poço 1; SB 2 = Poço 2; SB3 = Poço 3 
Anexo H. Valores dos parâmetros físico-químicos e concentrações dos elementos e compostos analisados na precipitação interna na microbacia da floresta

\begin{tabular}{|c|c|c|c|c|c|c|c|c|c|c|c|c|c|c|c|c|}
\hline Fonte & Hora & Data & $\mathrm{PIC}(\mathrm{mm})$ & Alc & $\mathrm{pH}$ & C.E & $\mathrm{Ca}(\mathrm{UM})$ & $\mathrm{Mg}$ (uM) & $\mathrm{K}(\mathrm{UM})$ & $\mathrm{NH} 4$ (uM) & $\mathrm{Na}(\mathrm{UM})$ & $\mathrm{Cl}(\mathrm{UM})$ & NO3(uM) & TDN(UM) & NID(uM) & NOD(UM) \\
\hline TF1 & $8: 20$ & 22-Jan-04 & 16.22 & 10.5 & 6.6 & 43.5 & 57.21 & 15.53 & 227.15 & 12.63 & 105.72 & 146.57 & 24.63 & 104.09 & 37.27 & 66.82 \\
\hline TF2 & $8: 55$ & 22-Jan-04 & 9.59 & 6 & 6.26 & 18.5 & 60.45 & 11.58 & 69.97 & 14.22 & 83.22 & 106.11 & 16.54 & 46.67 & 30.76 & 15.91 \\
\hline TF4 & $8: 38$ & 22-Jan-04 & 24.58 & 5.2 & 6.29 & 19.6 & 24.00 & 5.33 & 35.64 & 3.82 & 30.58 & 70.72 & 13.34 & 27.85 & 17.17 & 10.69 \\
\hline TF5 & $8: 27$ & 22-Jan-04 & 24.58 & 2.3 & 6.12 & 13.7 & 27.97 & 9.32 & 41.95 & n.a & 42.08 & 48.29 & 7.37 & 30.91 & n.c & n.c \\
\hline TF1 & $7: 30$ & 28-Jan-04 & 9.59 & 4.1 & 5.72 & 31.6 & 28.09 & 13.22 & 158.08 & 8.17 & 49.36 & 47.72 & 4.74 & 104.54 & 12.91 & 91.63 \\
\hline TF2 & 9:00 & 28-Jan-04 & 4.08 & 3.6 & 5.67 & 25 & 29.41 & 12.27 & 92.11 & 16.29 & 65.55 & 72.00 & 9.71 & 107.15 & 26.01 & 81.14 \\
\hline TF3 & 9:06 & 28-Jan-04 & 6.68 & 2.9 & 5.62 & 19.1 & 39.66 & 15.27 & 74.69 & 11.84 & 74.16 & 77.23 & 13.79 & 70.56 & 25.63 & 44.93 \\
\hline TF4 & 8:09 & 28-Jan-04 & 9.49 & 7.2 & 5.61 & 22.3 & 30.45 & 11.81 & 72.88 & 9.22 & 47.99 & 46.17 & 4.70 & 48.98 & 13.92 & 35.06 \\
\hline TF5 & $7: 59$ & 28-Jan-04 & 14.18 & 2.3 & 5.47 & 10.7 & 24.89 & 6.72 & n.a & 7.27 & 62.15 & 51.69 & 7.09 & 29.94 & 14.36 & 15.58 \\
\hline TF1 & 8:05 & 29-Jan-04 & 5.92 & 13.2 & 6.93 & 59.1 & 28.71 & 17.93 & 178.42 & 17.78 & 8.38 & 20.94 & 2.10 & 168.68 & 19.89 & 148.79 \\
\hline TF2 & $7: 40$ & 29-Jan-04 & 6.17 & 4.7 & 6.57 & 22.7 & 34.70 & 14.81 & 87.58 & 28.29 & 18.83 & 32.76 & 8.16 & 80.12 & 36.45 & 43.67 \\
\hline TF3 & $7: 35$ & 29-Jan-04 & 6.68 & 5.9 & 6.53 & 34.7 & 43.42 & 22.76 & 136.32 & 7.23 & 41.37 & 74.77 & 10.52 & 87.44 & 17.75 & 69.69 \\
\hline TF4 & $8: 27$ & 29-Jan-04 & 12.70 & 5.5 & 6.6 & 32.9 & 48.34 & 15.50 & 152.28 & 14.53 & 21.20 & 67.40 & 2.77 & 64.22 & 17.31 & 46.91 \\
\hline TF5 & $8: 25$ & 29-Jan-04 & 10.66 & 1.7 & 6.53 & 17 & 38.42 & 6.28 & 53.57 & 4.63 & 18.31 & 25.18 & 2.76 & 27.33 & 7.39 & 19.94 \\
\hline TF1 & $15: 38$ & 31-Jan-04 & 8.62 & 8.5 & 6.45 & 45.6 & 41.91 & 26.67 & 240.72 & 57.40 & 26.42 & 56.82 & 6.40 & 251.56 & 63.80 & 187.76 \\
\hline TF2 & $15: 43$ & 31-Jan-04 & 8.20 & n.a & n.a & n.a & 149.41 & 40.92 & n.a & 216.80 & 137.88 & 130.33 & 11.70 & 705.85 & 228.50 & n.c \\
\hline TF3 & $15: 45$ & 31-Jan-04 & 2.87 & 4.7 & $\begin{array}{l}1 . a \\
6\end{array}$ & 26.8 & 36.67 & 19.66 & 100.09 & 20.01 & 16.03 & 61.49 & 3.03 & 89.38 & 23.04 & 66.34 \\
\hline TF4 & $15: 42$ & 31-Jan-04 & 4.70 & 6.4 & 5.99 & 28.9 & 56.65 & 16.83 & 133.69 & 24.51 & 103.71 & 120.23 & 11.37 & 112.75 & 35.87 & 76.88 \\
\hline TF5 & $15: 40$ & 31-Jan-04 & 4.13 & 3.5 & 5.85 & 16 & 21.31 & 6.40 & 69.05 & 8.68 & 11.29 & 37.21 & 1.43 & 42.79 & 10.10 & 32.68 \\
\hline TF4 & $8: 03$ & 04-Fev-04 & 3.11 & n.a & 6.47 & 50.6 & 58.90 & 26.75 & 234.87 & 34.14 & 113.55 & 139.88 & 3.86 & 200.86 & 38.00 & 162.86 \\
\hline TF5 & 7:59 & 04-Fev-04 & 1.60 & n.a & n.a & 27.2 & 59.79 & 15.52 & 150.43 & 26.53 & 127.31 & 178.99 & 11.69 & 87.21 & 38.22 & 48.99 \\
\hline TF1 & $20: 11$ & 04-Fev-04 & 12.44 & 7.8 & 6.2 & 41.4 & 35.39 & 17.65 & 248.10 & 33.51 & 63.66 & 89.11 & 5.06 & 130.82 & 38.58 & 92.24 \\
\hline TF2 & $20: 16$ & 04-Fev-04 & 5.56 & 8.7 & 6.23 & 39.2 & 147.28 & 26.75 & 191.69 & 30.04 & 277.43 & 321.52 & 26.95 & 102.00 & 57.00 & 45.00 \\
\hline TF3 & $20: 27$ & 04-Fev-04 & 12.55 & 4.1 & n.a & 5.94 & 47.84 & 18.15 & 95.56 & 21.26 & 148.08 & 173.01 & 8.48 & 48.53 & 29.74 & 18.80 \\
\hline TF4 & $20: 05$ & 04-Fev-04 & 16.91 & 4.3 & 5.92 & 19.8 & 26.79 & 10.32 & 81.12 & 15.95 & 72.84 & 43.38 & 2.02 & 57.27 & 17.97 & 39.30 \\
\hline TF5 & 19:58 & 04-Fev-04 & 14.43 & 3.1 & 6.05 & 13.7 & 36.37 & 10.27 & 76.43 & 24.63 & 70.13 & 152.91 & 7.65 & 20.76 & 32.28 & n.c \\
\hline TF1 & $17: 35$ & 08-Fev-04 & 1.94 & n.a & 7.28 & 57.6 & 47.61 & 29.68 & 374.02 & 43.00 & 31.86 & 183.42 & 4.57 & 213.55 & 47.57 & 165.98 \\
\hline TF2 & $17: 49$ & 08-Fev-04 & 1.07 & n.a & 7.32 & 70.3 & 163.97 & 46.45 & 283.98 & 5.24 & 63.36 & 192.65 & 1.05 & 188.61 & 6.30 & 182.32 \\
\hline TF3 & $17: 53$ & 08-Fev-04 & 2.75 & 7.9 & 6.81 & 38.3 & 50.78 & 27.16 & 164.28 & 6.68 & 37.35 & 132.08 & 1.37 & 114.77 & 8.06 & 106.71 \\
\hline TF4 & $17: 43$ & 08-Fev-04 & 3.88 & 6.8 & 6.85 & 33 & 39.26 & 19.55 & 162.64 & 27.54 & 45.88 & 77.33 & 3.68 & 106.63 & 31.22 & 75.41 \\
\hline TF5 & $17: 40$ & 08-Fev-04 & $\begin{array}{l}3.37 \\
3.37\end{array}$ & 3.9 & 6.75 & 19.9 & 29.39 & 10.43 & 89.46 & 6.59 & 45.42 & 77.29 & 2.44 & 58.91 & 9.03 & 49.88 \\
\hline TF1 & $15: 39$ & 10-Fev-04 & 5.00 & 10.8 & 6.7 & 53.2 & 49.35 & 30.99 & 297.72 & 40.18 & 32.39 & 86.33 & 6.83 & 208.55 & 47.01 & 161.54 \\
\hline TF2 & $15: 43$ & $10-F e v-04$ & 1.89 & n.a & 7.17 & 58.7 & 124.09 & 35.83 & 183.47 & 22.52 & 37.79 & 47.30 & $<$ l.d & 128.80 & n.c & n.c \\
\hline TF3 & $15: 47$ & $10-F e v-04$ & 4.69 & 7.2 & 6.62 & 38 & 37.50 & 21.79 & 121.78 & 31.83 & 35.26 & 42.68 & 1.57 & 119.55 & 33.40 & 86.14 \\
\hline TF4 & $15: 59$ & 10-Fev-04 & 8.21 & 5.9 & 6.44 & 28.6 & 36.00 & 16.71 & 127.67 & 27.01 & 22.29 & 49.33 & 2.04 & 91.92 & 29.05 & 62.87 \\
\hline TF5 & $15: 55$ & $10-F e v-04$ & 7.65 & 4.7 & 6.44 & 20.1 & 27.02 & 10.36 & 84.44 & 15.57 & 14.06 & 42.36 & 1.64 & 51.52 & 17.21 & 34.31 \\
\hline TF1 & 8:06 & $11-F e v-04$ & 2.70 & n.a & 6.81 & 65.3 & 74.07 & 44.22 & 323.92 & 29.09 & 17.71 & 87.78 & 4.83 & 190.56 & 33.93 & 156.63 \\
\hline TF2 & $8: 13$ & 11-Fev-04 & 2.52 & n.a & 6.58 & 40.6 & 79.49 & 27.23 & 143.65 & 13.43 & 19.43 & 73.21 & 2.34 & 74.22 & 15.77 & 58.45 \\
\hline TF3 & $8: 22$ & 11-Fev-04 & 2.96 & n.a & 6.86 & 50.4 & 23.38 & 14.10 & 124.40 & 55.36 & 32.21 & 157.99 & 1.35 & 125.74 & 56.70 & 69.04 \\
\hline TF4 & $8: 38$ & $11-F e v-04$ & 7.40 & 6 & 6.28 & 25.5 & 14.77 & 6.29 & 51.60 & 24.15 & 15.22 & 22.42 & $<$ l.d & 56.97 & n.c & n.c \\
\hline TF5 & $8: 45$ & 11-Fev-04 & 5.25 & 3.3 & 6.02 & 20.1 & 16.86 & 6.00 & 57.24 & 27.32 & 18.62 & 33.31 & $<$ <.d & 27.63 & n.c & n.c \\
\hline TF1 & $8: 40$ & 14-Fev-04 & 11.73 & 11.5 & 6.31 & 55.4 & 34.11 & 17.02 & 253.90 & 25.43 & 20.72 & 69.04 & $<$ l.d & 175.92 & n.c & n.c \\
\hline TF2 & $8: 50$ & $14-\mathrm{Fev}-04$ & 6.63 & 5.2 & 6.49 & 27 & 25.42 & 11.72 & 93.84 & 11.61 & 16.00 & 45.98 & 0.00 & 75.19 & 11.61 & 63.58 \\
\hline TF3 & $8: 53$ & 14-Fev-04 & 11.02 & 5.1 & 6.28 & 32.8 & 23.99 & 13.02 & 118.68 & 20.75 & 19.20 & 112.89 & $<$ l.d & 85.87 & n.c & n.c \\
\hline TF4 & $8: 30$ & 14-Fev-04 & 14.54 & 4.7 & 6.27 & 22.6 & 25.38 & 12.73 & 99.19 & 19.41 & 18.92 & 54.12 & 1.97 & 70.71 & 21.38 & 49.33 \\
\hline TF5 & $8: 26$ & 14-Fev-04 & 19.94 & 3.1 & 6.36 & 13 & 12.93 & 6.00 & 48.91 & 10.74 & 13.70 & 23.02 & 0.91 & 22.48 & 11.65 & 10.83 \\
\hline TF1 & 9:20 & $15-\mathrm{Fev}-04$ & 0.97 & n.a & 6.87 & 61.8 & 43.14 & 21.15 & 313.93 & 32.81 & 33.91 & 49.34 & 1.91 & 248.20 & 34.72 & 213.48 \\
\hline TF2 & 9:31 & $15-\mathrm{Fev}-04$ & 0.61 & n.a & 6.75 & 44.6 & 44.41 & 20.63 & 170.37 & 39.76 & 48.97 & 90.94 & 5.74 & 179.65 & 45.50 & 134.16 \\
\hline TF3 & 9:35 & $15-\mathrm{Fev}-04$ & 0.51 & n.a & 6.9 & 72.3 & 45.17 & 25.35 & 271.95 & 25.49 & 46.65 & 258.46 & 2.01 & 222.74 & 27.50 & 195.23 \\
\hline $\begin{array}{l}\text { TF4 } \\
\text { TF }\end{array}$ & 9:26 & $15-$ Fev-04 & 2.45 & $\begin{array}{l}\text { n.a } \\
\text { n.a }\end{array}$ & 6.56 & 26.6 & 27.46 & 13.76 & 87.60 & 24.62 & 19.47 & 29.19 & 2.09 & 129.40 & 26.71 & 102.69 \\
\hline TF5 & $9: 24$ & $15-F e v-04$ & 1.70 & n.a & 5.57 & 18.1 & 22.33 & 10.13 & 66.92 & $<$ l.d & 29.44 & 23.72 & $<$ l.d & 59.44 & n.c & n.c \\
\hline TF1 & $15: 55$ & $15-F e v-04$ & 4.34 & 8.5 & 6.48 & 35.8 & 31.32 & 14.55 & 165.84 & 11.60 & 13.10 & 34.65 & $<$ l.d & 110.36 & n.c & n.c \\
\hline TF2 & $15: 58$ & $15-\mathrm{Fev}-04$ & 3.06 & 5.3 & 6.5 & 20.7 & 24.51 & 11.52 & 78.91 & $<1 . d$ & 18.35 & 30.73 & $<1 . d$ & 24.72 & n.c & n.c \\
\hline TF3 & $16: 01$ & $15-F e v-04$ & 3.67 & 8.1 & 6.52 & 47.2 & 41.06 & 21.95 & 217.42 & n.a & 42.74 & 222.32 & $<$ l.d & 77.58 & n.c & n.c \\
\hline TF4 & $15: 50$ & $15-\mathrm{Fev}-04$ & 7.45 & 4.2 & 6.45 & 15 & 18.55 & 9.18 & 53.21 & 3.22 & 18.32 & 26.95 & $<$ l.d & 148.59 & n.c & n.c \\
\hline TF5 & $15: 46$ & 15-Fev-04 & 7.21 & 2.9 & 6.54 & 10.6 & 15.35 & 5.64 & 42.26 & 2.83 & 18.39 & 25.92 & $<1 . d$ & 15.01 & n.c & n.c \\
\hline TF1 & $8: 58$ & 16-Fev-04 & 2.50 & n.a & 6.87 & 69.5 & 74.69 & 39.97 & 317.22 & 2.52 & 18.09 & 51.02 & $<$ l.d & 185.26 & n.c & n.c \\
\hline TF2 & 9:12 & 16-Fev-04 & 2.65 & 8.4 & 6.85 & 33.5 & 54.13 & 25.81 & 176.80 & $\begin{array}{l}<1 . d \\
<-1\end{array}$ & 19.31 & 55.94 & 0.85 & 78.31 & n.c & n.c \\
\hline TF3 & $8: 49$ & $16-\mathrm{Fev}-04$ & 2.09 & 11.6 & 6.91 & 90.2 & 64.32 & 41.22 & 328.56 & 7.77 & 13.11 & 428.93 & 1.16 & 92.97 & 8.93 & 84.04 \\
\hline TF4 & 9:05 & 16-Fev-04 & 6.63 & 6 & 6.65 & 23.8 & 29.63 & 13.04 & 85.62 & 3.68 & 18.04 & 44.49 & $<$ l.d & 53.29 & n.c & n.c \\
\hline TF5 & $9: 03$ & 16-Fev-04 & 4.59 & 14.7 & 6.84 & 17.6 & 28.67 & 9.54 & 71.73 & 3.94 & 21.11 & 38.86 & $<$ l.d & 13.45 & n.c & n.c \\
\hline TF1 & $15: 28$ & 17-Fev-04 & 22.75 & 8.3 & 6.57 & 33.5 & 35.32 & 14.10 & 165.64 & 10.89 & 6.14 & 26.61 & 1.30 & 83.30 & 12.19 & 71.10 \\
\hline TF2 & $15: 45$ & 17-Fev-04 & 21.06 & 3.7 & 6.39 & 13.2 & 17.63 & 8.57 & 52.23 & 5.95 & 6.64 & 13.60 & 0.74 & 20.11 & 6.69 & 13.42 \\
\hline TF3 & $15: 52$ & 17-Fev-04 & 22.24 & 6.1 & 6.46 & 34.2 & 24.60 & 16.47 & 158.95 & 11.19 & 11.53 & 144.08 & $<$ I.d & 43.01 & n.c & n.c \\
\hline $\begin{array}{l}\text { TF4 } \\
\text { TF }\end{array}$ & $15: 35$ & 17 -Fev-04 & 34.78 & $\begin{array}{l}0.1 \\
3.8\end{array}$ & $\begin{array}{l}6.40 \\
6.41\end{array}$ & 13.2 & 16.42 & 7.85 & 51.77 & 8.44 & $\begin{array}{l}8.11 \\
8.11\end{array}$ & 18.07 & $<1 . d$ & 27.89 & n.c & n.c \\
\hline TF5 & $15: 33$ & 17-Fev-04 & 29.48 & 3.1 & 6.4 & 9.55 & 17.43 & 3.87 & 35.18 & 3.38 & 7.83 & 13.49 & $<$ l.d & 9.15 & n.c & n.c \\
\hline TF1 & 16:04 & $18-\mathrm{Fev}-04$ & 2.86 & 7.7 & 6.8 & 37.1 & 40.73 & 16.93 & 168.18 & 16.55 & 6.13 & 31.63 & 1.98 & 131.37 & 18.53 & 112.84 \\
\hline TF2 & $16: 32$ & $18-\mathrm{Fev}-04$ & 2.75 & 4.7 & 6.73 & 19.2 & 25.42 & 11.62 & 69.73 & 20.97 & 12.64 & 35.34 & 1.03 & 80.65 & 22.00 & 58.65 \\
\hline TF3 & $16: 39$ & $18-\mathrm{Fev}-04$ & 3.01 & 8 & 6.91 & 36.6 & 31.82 & 17.18 & 135.34 & 40.18 & 11.63 & 97.63 & 2.57 & 144.60 & 42.75 & 101.85 \\
\hline TF4 & $16: 17$ & 18 -Fev-04 & 5.20 & 4.9 & 6.64 & 19.3 & 28.44 & 12.12 & 66.66 & 13.32 & 6.05 & 21.91 & 0.84 & 60.54 & 14.16 & 46.39 \\
\hline TF5 & $16: 15$ & $18-\mathrm{Fev}-04$ & 5.30 & 4.4 & 6.68 & 13 & 20.58 & 6.42 & 40.79 & 6.07 & 5.35 & 19.21 & $<I . d$ & 23.20 & n.c & n.c \\
\hline TF1 & $9: 26$ & $19-\mathrm{Fev}-04$ & 1.58 & n.a & 6.75 & 86.6 & 116.61 & 64.07 & 495.85 & 11.93 & 18.36 & 77.94 & 5.84 & 129.48 & 17.77 & 111.71 \\
\hline
\end{tabular}


Anexo H. Valores dos parâmetros físico-químicos e concentrações dos elementos e compostos analisados na precipitação interna na microbacia da floresta

\begin{tabular}{|c|c|c|c|c|c|c|c|c|c|c|c|c|c|c|c|c|}
\hline Fonte & Hora & Data & $P I C(\mathrm{~mm})$ & Alc & $\mathrm{pH}$ & C.E & $\mathrm{Ca}(\mathrm{UM})$ & $\mathrm{Mg}$ (UM) & $\mathrm{K}(\mathrm{UM})$ & $\mathrm{NH4( \textrm {UM } )}$ & $\mathrm{Na(UM)}$ & Cl(UM) & NO3(uM) & $\mathrm{TDN}(\mathrm{UM})$ & NID(UM) & NOD(UM) \\
\hline TF3 & $9: 17$ & 19-Fev-04 & 1.02 & n.a & 7.26 & 90.3 & 48.41 & 30.65 & 377.63 & 42.62 & 39.47 & 276.14 & 2.03 & 187.60 & 44.65 & 142.95 \\
\hline TF4 & 9:35 & 19-Fev-04 & 4.13 & 5.6 & 6.63 & 21.7 & 42.02 & 21.82 & 147.38 & 15.17 & 14.57 & 72.06 & $<$ I.d & 37.64 & n.c & n.c \\
\hline TF5 & 9:38 & 19-Fev-04 & 2.91 & 5.2 & 6.88 & 18.5 & 25.82 & 9.87 & 57.87 & 6.77 & 6.52 & 27.56 & $<$ I.d & 38.17 & n.c & $\mathrm{n} . \mathrm{c}$ \\
\hline TF6 & 9:33 & 19-Fev-04 & 2.62 & n.a & n.a & 64.6 & 140.60 & 36.28 & 178.35 & 9.04 & 18.23 & 74.53 & 2.80 & 155.18 & 11.85 & 143.33 \\
\hline TF1 & 18:17 & 19-Fev-04 & 65.43 & 6.5 & 6.76 & 23.5 & 24.63 & 8.27 & 120.94 & 4.85 & 9.40 & 15.46 & $<1 . d$ & 39.46 & n.c & n.c \\
\hline TF2 & $18: 35$ & 19-Fev-04 & 40.95 & 1.7 & 6.3 & 6.33 & 12.12 & 3.92 & 22.95 & $<$ l.d & 8.81 & 8.41 & $<1 . d$ & 1.36 & n.c & n.c \\
\hline TF3 & 20:52 & 19-Fev-04 & 71.40 & 3.3 & 6.49 & 12.8 & 13.75 & 6.11 & 65.53 & $<$ l.d & 13.58 & 45.27 & 2.71 & 6.35 & n.c & n.c \\
\hline TF4 & $18: 45$ & 19-Fev-04 & 71.09 & 2.4 & 6.29 & 7.5 & 13.09 & 4.12 & 27.00 & $<1 . d$ & 9.13 & 9.12 & $<1 . d$ & 5.06 & n.c & n.c \\
\hline TF5 & $18: 45$ & $19-\mathrm{Fev}-04$ & 86.45 & 1.9 & 6.4 & 5.27 & 12.18 & 2.11 & 19.32 & $<1 . d$ & 15.05 & 14.02 & 1.04 & 0.00 & n.c & n.c \\
\hline TF6 & $18: 45$ & 19-Fev-04 & 66.81 & 5.7 & 6.676 & 15 & 31.38 & 6.79 & 54.47 & $<$ I.d & 15.07 & 18.87 & $<1 . d$ & 15.34 & n.c & n.c \\
\hline TF1 & $19: 33$ & 25-Fev-04 & 39.02 & 4.1 & 6.27 & 19.4 & 16.97 & 8.35 & 118.16 & 11.66 & 29.60 & 42.13 & 2.71 & 54.95 & 14.37 & 40.59 \\
\hline TF2 & $19: 40$ & 25-Fev-04 & 17.54 & 3.4 & 6.1 & 15.1 & 14.77 & 6.68 & 68.01 & 6.20 & 14.12 & 22.24 & 2.77 & 38.85 & 8.97 & 29.88 \\
\hline TF3 & $19: 48$ & 25-Fev-04 & 34.86 & 5.6 & 6.3 & 22.4 & 12.07 & 11.40 & 119.13 & 4.14 & 17.29 & 35.19 & 1.18 & 44.22 & 5.32 & 38.89 \\
\hline TF4 & $18: 58$ & 25-Fev-04 & 38.51 & 1.7 & 6 & 11.2 & 17.00 & 7.78 & 50.13 & 5.43 & 31.84 & 42.24 & 3.50 & 26.08 & 8.93 & 17.15 \\
\hline TF5 & 18:54 & 25-Fev-04 & 44.52 & 1.6 & 6.1 & 9 & 11.02 & 4.02 & 36.90 & 3.88 & 11.73 & 16.22 & 2.97 & 16.25 & 6.85 & 9.40 \\
\hline TF6 & 19:03 & 25-Fev-04 & 40.04 & 3.1 & 6.26 & 13.9 & 19.51 & 8.44 & 51.75 & 3.48 & 11.66 & 18.01 & 2.19 & 28.12 & 5.67 & 22.45 \\
\hline TF1 & $8: 17$ & 27 -fev-04 & 6.07 & n.a & 6.43 & 23.8 & 25.76 & 14.18 & 135.22 & 15.45 & 20.44 & 16.60 & 3.39 & 88.81 & 18.85 & 69.97 \\
\hline TF2 & 8:05 & $27-f e v-04$ & 6.53 & n.a & 6.19 & 12.2 & 15.33 & 5.94 & 58.65 & 8.20 & 16.73 & 18.86 & 1.64 & 35.90 & 9.84 & 26.06 \\
\hline TF3 & $7: 37$ & $27-f e v-04$ & 4.90 & n.a & 6.34 & 22 & 22.81 & 14.80 & 103.91 & 15.32 & 16.72 & 25.13 & 0.94 & 74.91 & 16.26 & 58.64 \\
\hline TF4 & $8: 31$ & $27-$ fev-04 & 8.82 & n.a & 6.05 & 12 & 18.91 & 7.52 & 43.23 & 14.17 & 15.22 & 18.37 & 2.79 & 46.33 & 16.95 & 29.38 \\
\hline TF5 & $8: 25$ & 27 -fev-04 & 6.99 & n.a & 6.12 & 8.01 & 13.81 & 3.46 & 34.15 & $<$ l.d & 15.15 & 17.59 & 1.20 & 14.21 & n.c & n.c \\
\hline TF6 & $6: 43$ & 27 -fev-04 & 7.19 & n.a & 6.49 & 23.2 & 37.49 & 13.74 & 97.02 & 5.61 & 11.25 & 21.89 & 6.43 & 75.06 & 12.04 & 63.02 \\
\hline TF7 & 8:03 & $27-f e v-04$ & 11.93 & n.a & 6.3 & 25.8 & 83.84 & 10.88 & 33.97 & 7.36 & 16.81 & 8.90 & 1.34 & 44.52 & 8.70 & 35.82 \\
\hline TF8 & $8: 12$ & $27-f e v-04$ & 8.31 & n.a & 6.45 & 26.7 & 68.78 & 14.18 & 86.14 & 3.56 & 31.47 & 42.87 & 3.07 & 40.67 & 6.62 & 34.04 \\
\hline TF9 & $7: 50$ & $27-f e v-04$ & 5.66 & n.a & 6.66 & 25.7 & 54.57 & 14.78 & 99.46 & 11.35 & 34.83 & 56.25 & 3.30 & 63.87 & 14.65 & 49.22 \\
\hline TF10 & $7: 47$ & 27 -fev-04 & 3.21 & n.a & 7.05 & 24.9 & 62.32 & 12.24 & 54.42 & 17.12 & 13.86 & 37.26 & 1.54 & 67.72 & 18.66 & 49.06 \\
\hline
\end{tabular}

$<$ l.d $=$ menor ao limite de detecção

n.a = não analisado

n.c $=$ não calculado

Alc. $=$ Alcalinidade (ueq. $\mathrm{L}^{-1}$ )

C. $\mathrm{E}=$ Condutividade elétrica (uS. $\left.\mathrm{cm}^{-1}\right)$

PIC = Quantidade precipitação interna por coletor expressa como mm

TF1 $=$ Coletor 1 ; TF 2 = Coletor 2; TF3 = Coletor 3; TF4 = Coletor 4; TF5 = Coletor 5

Anexo I. Valores dos parâmetros físico-químicos e concentrações dos elementos e compostos analisados na precipitação

\begin{tabular}{|c|c|c|c|c|c|c|c|c|c|c|c|c|c|c|c|c|}
\hline Fonte & Hora & Data & PT(mm) & Alk & $\mathrm{pH}$ & Cond & $\mathrm{Ca}(\mathrm{UM})$ & $\mathrm{Mg}(\mathrm{uM})$ & K(UM) & $\mathrm{NH} 4(\mathrm{uM})$ & $\mathrm{Na}(\mathrm{UM})$ & Cl(UM) & NO3(UM) & NDT(UM) & NID(UM) & NOD(UM) \\
\hline $\mathrm{P}$ & 9:31 & 22-Jan-04 & 20.40 & 2.6 & 5.93 & 8.1 & 18.63 & 4.60 & 17.03 & 2.00 & 43.40 & 37.61 & 3.00 & 9.37 & 5.00 & 4.37 \\
\hline$P$ & $8: 37$ & 28-Jan-04 & 11.53 & 0.4 & 5.46 & 6.35 & 19.42 & 2.23 & 14.24 & 5.22 & 72.07 & 30.29 & 4.19 & 19.12 & 4.19 & 14.93 \\
\hline $\mathrm{P}$ & $7: 33$ & 29-Jan-04 & 6.73 & -0.6 & 5.84 & 12.18 & 24.09 & 3.11 & 6.60 & 9.00 & 18.26 & 6.22 & 11.65 & 35.70 & 20.65 & 15.05 \\
\hline$P$ & $15: 30$ & 31-Jan-04 & 6.73 & 0.2 & 5.29 & 7.95 & 13.35 & 1.46 & 5.11 & 3.55 & 13.53 & 7.82 & 4.50 & 27.82 & 4.50 & 23.32 \\
\hline $\mathrm{P}$ & $8: 50$ & 03-Fev-04 & 1.02 & n.a. & 6.37 & 7.9 & 10.20 & 2.02 & 8.89 & n.a & 15.80 & 4.62 & n.a & 77.39 & 42.82 & 34.57 \\
\hline $\mathrm{P}$ & $8: 15$ & 04-Fev-04 & 1.94 & -0.2 & 5.41 & 4.73 & 9.61 & 1.51 & 5.38 & 3.33 & 14.92 & 8.90 & 4.95 & 19.20 & 8.28 & 10.91 \\
\hline$P$ & $21: 00$ & 04-Fev-04 & 14.54 & 1.6 & 5.73 & 5.66 & 4.35 & $<$ l.d & 1.60 & 1.39 & n.a. & 11.04 & 1.32 & 2.47 & 2.71 & n.c \\
\hline $\mathrm{P}$ & $8: 30$ & 07-Fev-04 & 1.02 & n.a. & n.a. & 6.65 & 27.04 & 2.76 & 9.09 & 3.89 & 50.27 & 25.21 & 1.26 & 23.77 & 5.15 & 18.63 \\
\hline $\mathrm{P}$ & $8: 50$ & 08-Fev-04 & 0.56 & n.a. & n.a. & 5.38 & 7.67 & $<$ I.d & 9.70 & 7.66 & 30.49 & 14.31 & 3.87 & 30.15 & 11.54 & 18.61 \\
\hline $\mathrm{P}$ & $16: 25$ & 08-Fev-04 & 3.57 & 0.2 & 5.34 & 6.15 & 8.26 & $<$ I.d & 5.15 & 6.94 & 15.47 & 5.98 & 4.02 & 20.25 & 10.96 & 9.29 \\
\hline P & $7: 30$ & 11-Fev-04 & 9.89 & 1.2 & 5.82 & 3.47 & 8.67 & $<$ I.d & 6.18 & 1.50 & 21.77 & 13.03 & 1.73 & 10.87 & 3.23 & 7.65 \\
\hline $\mathrm{P}$ & $6: 57$ & 14-Fev-04 & 6.43 & 1 & 5.77 & 7.35 & 19.69 & 3.83 & 9.04 & 14.77 & 25.99 & 15.76 & 8.32 & 41.62 & 23.10 & 18.52 \\
\hline $\mathrm{P}$ & 9:40 & $15-\mathrm{Fev}-04$ & 1.02 & n.a. & 5.64 & 6.76 & 8.31 & 1.73 & 12.41 & 11.83 & 23.13 & 15.07 & 4.40 & 82.19 & 16.24 & 65.95 \\
\hline P & $14: 52$ & 15-Fev-04 & 7.75 & 1.6 & 6.06 & 2.63 & 7.92 & $<$ l.d & 5.74 & 1.94 & 20.58 & 12.47 & 1.00 & 3.90 & 2.94 & 0.96 \\
\hline $\mathrm{P}$ & $7: 26$ & $16-F e v-04$ & 2.96 & 1.4 & 6.19 & 3.25 & 7.95 & $<$ I.d & 3.43 & 2.11 & 10.13 & 5.87 & 1.23 & 29.10 & 3.34 & 25.76 \\
\hline P & $15: 31$ & 17-Fev-04 & 29.58 & 2.2 & 6.48 & 4.2 & 13.07 & $<I . d$ & 2.36 & 1.06 & 6.74 & 3.98 & 0.44 & $<\mathrm{l} . \mathrm{d}$ & 1.49 & n.c \\
\hline P & $16: 59$ & 18-Fev-04 & 3.11 & 0.6 & 5.95 & 3.2 & 7.21 & $<$ l.d & 5.07 & 3.67 & 10.11 & 7.69 & 2.40 & 13.95 & 6.07 & 7.88 \\
\hline $\mathrm{P}$ & $20: 20$ & 19-Fev-04 & 1.02 & 1.2 & 6.28 & 2.8 & 8.18 & $<$ I.d & 1.15 & 1.39 & 2.44 & 1.06 & 0.50 & 0.82 & 1.89 & n.c \\
\hline $\mathrm{P}$ & $18: 17$ & 25 -Fev-04 & 36.57 & 1.4 & 5.82 & 5.07 & 5.84 & $<$ I.d & 4.39 & 7.66 & 10.09 & 8.79 & 2.81 & 11.40 & 10.47 & 0.93 \\
\hline$P$ & $7: 20$ & $27-f e v-04$ & 7.60 & n.a. & 6.11 & 5.16 & 11.09 & $<$ l.d & 3.69 & 8.33 & 5.92 & 2.89 & 2.85 & 22.72 & 11.19 & 11.53 \\
\hline
\end{tabular}

$<$ l.d = menor ao limite de detecção

n.a $=$ não analisado

n.c $=$ não calculado

Alc. $=$ Alcalinidade (ueq. $\mathrm{L}^{-1}$ )

C. $\mathrm{E}=$ Condutividade elétrica (uS. $\mathrm{cm}^{-1}$ )

PT = Precipitação total (coletor campo) 
Anexo J. Valores dos parâmetros físico-químicos e concentrações dos elementos e compostos analisados no igarapé da floresta

\begin{tabular}{|c|c|c|c|c|c|c|c|c|c|c|c|c|c|c|c|c|c|c|}
\hline Fonte & Hora & Data & Descarga (L.s-1) & Alc & $\mathrm{pH}$ & C.E & $\mathrm{Ca}(\mathrm{UM})$ & $\mathrm{Mg}(\mathrm{UM})$ & $\mathrm{K}(\mathrm{UM})$ & $\mathrm{NH} 4(\mathrm{uM})$ & $\mathrm{Na}(\mathrm{UM})$ & CI(UM) & NO3(UM) & $\operatorname{TDN(UM)}$ & $\operatorname{NID}(\mathrm{UM})$ & NOD(uM) & $\operatorname{STS}\left(\mathrm{mg}, \mathrm{L}^{-1}\right)$ & $\mathrm{NP}$ (uM) \\
\hline CF1 & 18:04 & 21-Jan-04 & n.c & 7.4 & 6.2 & 18.6 & 14.39 & 5.57 & 49.67 & 58.62 & 80.66 & 5.04 & $<1 . d$ & 52.91 & n.c & n.c & 58.90 & 4.63 \\
\hline CF2 & 18:09 & 21-Jan-04 & n.c & 5.6 & 6.23 & 17.3 & 16.00 & 5.89 & 53.30 & 34.48 & 75.92 & 57.52 & 4.29 & 58.64 & 38.77 & 19.87 & 137.98 & 13.80 \\
\hline $\mathrm{CF} 3$ & 18:14 & 21-Jan-04 & n.c & 0.2 & 5.55 & 20.1 & 20.32 & 8.00 & 55.23 & 26.55 & 86.06 & 65.86 & 3.49 & 55.13 & 30.04 & 25.09 & 113.54 & 10.54 \\
\hline CF4 & 18:19 & 21-Jan-04 & n.c & -8 & 4.66 & 40.2 & 36.27 & 13.32 & 58.04 & 25.41 & 86.01 & 45.80 & 6.86 & 65.74 & 32.27 & 33.47 & 314.78 & 65.20 \\
\hline CF5 & 18:24 & 21-Jan-04 & n.c & 4.6 & 6.16 & 16.3 & 20.23 & 8.31 & 53.32 & 15.48 & 65.93 & 55.68 & 11.59 & 87.20 & 27.07 & 60.12 & 104.95 & 9.00 \\
\hline CFG & $18: 29$ & 21-Jan-04 & n.c & 3.2 & 6.13 & 26.5 & n.a & 11.67 & 84.91 & 12.20 & 63.65 & 47.63 & 23.05 & 133.62 & 35.25 & 98.37 & 142.29 & 18.29 \\
\hline CF7 & 18:34 & 21-Jan-04 & n.c & 4.2 & 6.23 & 24.2 & 23.41 & 10.97 & 90.60 & 10.13 & 47.36 & 28.84 & 19.87 & 126.52 & 30.01 & 96.51 & 99.43 & 9.23 \\
\hline CF8 & 18:39 & 21-Jan-04 & n.c & 4.6 & 6.15 & 24.2 & 23.67 & 11.84 & 102.95 & 6.86 & 56.59 & 35.32 & 19.47 & 139.50 & 26.34 & 113.16 & 52.67 & 3.76 \\
\hline CF9 & $18: 44$ & 21-Jan-04 & n.c & 6 & 6.47 & 24.8 & 28.28 & 15.51 & 111.19 & 12.73 & 39.10 & 107.16 & 18.11 & 141.64 & 30.84 & 110.79 & 29.56 & 1.69 \\
\hline CF10 & $18: 49$ & 21-Jan-04 & n.c & 4.6 & 6.14 & 25 & 29.18 & 15.68 & 116.29 & 10.66 & 46.95 & 115.25 & 18.36 & 139.19 & 29.02 & 110.17 & 25.21 & 1.26 \\
\hline CF11 & 18:54 & 21-Jan-04 & n.c & 5.8 & 6.2 & 25.2 & 29.90 & 16.72 & 117.42 & 13.65 & 39.86 & 230.25 & 18.57 & 156.75 & 32.22 & 124.53 & 29.41 & 1.68 \\
\hline CF12 & 18:59 & 21-Jan-04 & n.c & 6.4 & 6.23 & 25.7 & 24.42 & 12.54 & 111.20 & 44.71 & 41.65 & 102.21 & 22.03 & 144.08 & 66.74 & 77.34 & 24.35 & 1.39 \\
\hline CF13 & 19:09 & 21-Jan-04 & n.c & 7.6 & 6.18 & 26.9 & 25.70 & 14.40 & 117.79 & 6.01 & 35.27 & 115.32 & 19.77 & 140.34 & 25.78 & 114.56 & 26.67 & 1.33 \\
\hline CF14 & 19:19 & 21-Jan-04 & n.c & 3.8 & 6.23 & 25.3 & 17.83 & 9.31 & 98.25 & 18.24 & 44.58 & 41.72 & 21.57 & 147.29 & 39.81 & 107.48 & 27.45 & 1.18 \\
\hline CF15 & $19: 39$ & 21-Jan-04 & n.c & 7.8 & 6.15 & 25.3 & 14.97 & 8.07 & 89.01 & 5.53 & 52.89 & 48.05 & 17.97 & 138.58 & 23.50 & 115.08 & 38.63 & 1.93 \\
\hline CF16 & 20:09 & 21-Jan-04 & n.c & 4 & 6.17 & 24.7 & 17.87 & 10.37 & 104.85 & 4.41 & 59.21 & 35.77 & 19.24 & 134.99 & 23.65 & 111.35 & 18.88 & 0.54 \\
\hline CF17 & 20:39 & 21-Jan-04 & n.c & 4.6 & 6.18 & 24.5 & 26.22 & 12.27 & 140.50 & 17.90 & 103.30 & 39.16 & 11.14 & 118.58 & 29.04 & 89.54 & 25.13 & 0.90 \\
\hline CF1 & $16: 04$ & 04-Fev-04 & 0.003 & 6.8 & 5.91 & 22 & 38.46 & 11.90 & 68.43 & 5.72 & 31.64 & 68.91 & 6.32 & 40.16 & 12.04 & 28.12 & 999.40 & n.a \\
\hline CF2 & $16: 09$ & 04-Fev-04 & 0.036 & 5.6 & 5.75 & 16.5 & 24.77 & 8.56 & 56.59 & 4.10 & 56.35 & 50.69 & 4.89 & 40.93 & 8.99 & 31.94 & 592.08 & 278.40 \\
\hline CF3 & $16: 14$ & 04-Fev-04 & 0.034 & 3.4 & 5.87 & 13.8 & 20.30 & 7.36 & 56.27 & 3.37 & 64.72 & 58.15 & 8.46 & 54.44 & 11.83 & 42.61 & 378.63 & 126.87 \\
\hline CF4 & $16: 19$ & 04-Fev-04 & 0.007 & 3.6 & 5.8 & 16 & 20.01 & 7.55 & 59.78 & 4.57 & 59.14 & 53.96 & 12.17 & 68.72 & 16.73 & 51.98 & 285.40 & 59.50 \\
\hline CF5 & $16: 24$ & 04-Fev-04 & 0.005 & 2.6 & 5.92 & 16.4 & 20.39 & 7.91 & 61.24 & 4.35 & 63.09 & 60.70 & 13.36 & 56.12 & 17.71 & 38.41 & 233.15 & 34.66 \\
\hline CF6 & $16: 29$ & 04-Fev-04 & 0.003 & 2.4 & 5.66 & 18.2 & 20.44 & 7.72 & 59.94 & 8.72 & 58.84 & 58.66 & 13.05 & 74.83 & 21.77 & 53.05 & 327.33 & 24.98 \\
\hline CF7 & $16: 34$ & 04-Fev-04 & 0.003 & 3.6 & 5.81 & 18.6 & 24.19 & 9.11 & 65.54 & 6.83 & 69.65 & 67.70 & 14.62 & 80.55 & 21.46 & 59.09 & 252.43 & 35.07 \\
\hline CF8 & 16:39 & 04-Fev-04 & 0.003 & 4 & 5.61 & 18.2 & 25.46 & 9.33 & 66.07 & 5.25 & 66.74 & 63.37 & 13.60 & 72.84 & 18.85 & 53.99 & 492.85 & 27.74 \\
\hline CF9 & $16: 44$ & 04-Fev-04 & 0.003 & 5.2 & 6 & 17.8 & 22.40 & 8.40 & 64.50 & 6.62 & 63.12 & 62.04 & 11.70 & 76.05 & 18.32 & 57.73 & 225.15 & 92.67 \\
\hline CF10 & $16: 49$ & 04-Fev-04 & 0.003 & 4.4 & 5.71 & 18.8 & 25.16 & 9.25 & 68.44 & 6.90 & 70.40 & 65.06 & 11.27 & 81.47 & 18.17 & 63.30 & 311.38 & 22.52 \\
\hline CF11 & $16: 54$ & 04-Fev-04 & 0.003 & 4.4 & 6.02 & 18.3 & 25.70 & 10.01 & 78.51 & 5.28 & 66.57 & 99.70 & 12.24 & 78.11 & 17.52 & 60.59 & 206.43 & 37.81 \\
\hline CF12 & 16:59 & 04-Fev-04 & 0.003 & 4.2 & 6.08 & 18.6 & 25.03 & 9.13 & 69.54 & 8.14 & 64.54 & 64.22 & 12.43 & 87.58 & 20.58 & 67.00 & 189.05 & n.a \\
\hline $\mathrm{CF} 1$ & 13:50 & 15-Fev-04 & 0.003 & 8.6 & 6.57 & 16.5 & 48.43 & 14.53 & 96.99 & 3.22 & 90.42 & 51.47 & 6.91 & 51.87 & 10.13 & 41.74 & 425.48 & 91.17 \\
\hline CF2 & 13:55 & 15-Fev-04 & 0.029 & 6.8 & 6.38 & 12.8 & 25.11 & 8.09 & 79.99 & 2.33 & 87.97 & 56.96 & 4.52 & 45.26 & 6.85 & 38.40 & 546.63 & 105.42 \\
\hline CF3 & 14:00 & 15-Fev-04 & 0.027 & 5 & 6.36 & 12.3 & n.a & 6.83 & 78.43 & 2.44 & 86.41 & 49.61 & 4.00 & 41.67 & 6.45 & 35.22 & 424.43 & 66.70 \\
\hline CF4 & $14: 05$ & 15-Fev-04 & 0.008 & 3.4 & 6.42 & 12.3 & 7.41 & 2.44 & 31.99 & 2.56 & 36.06 & 61.53 & 5.86 & 43.50 & 8.42 & 35.09 & 357.98 & 46.03 \\
\hline CF5 & 14:10 & 15-Fev-04 & 0.006 & 5.8 & 6.41 & 12.9 & 31.77 & 8.78 & 103.74 & 2.17 & 123.91 & 70.27 & 6.20 & 46.61 & 8.37 & 38.24 & 301.52 & 43.07 \\
\hline CF6 & 14:15 & 15-Fev-04 & 0.005 & 4.8 & 6.39 & 13.9 & 18.32 & 5.89 & 70.56 & 3.94 & 96.35 & 43.97 & 4.33 & 60.47 & 8.27 & 52.20 & 269.10 & 32.68 \\
\hline CF1 & 9:37 & 17-Fev-04 & 0.010 & 9.6 & 6.64 & 15.7 & 28.40 & 14.56 & 86.44 & 3.28 & 73.35 & 30.66 & 1.56 & 36.09 & 4.84 & 31.25 & 65.25 & 2.33 \\
\hline CF2 & 9:42 & 17-Fev-04 & 0.042 & 4.8 & 6.3 & 9.58 & 8.26 & 2.27 & 86.51 & 2.56 & 52.72 & 31.95 & 1.78 & 29.80 & 4.33 & 25.47 & n.a & n.a \\
\hline CF3 & 9:47 & 17-Fev-04 & 0.025 & 5 & 6.2 & 11.7 & 27.42 & 11.55 & 67.46 & 2.67 & 74.26 & 58.58 & 7.04 & 47.65 & 9.71 & 37.94 & 703.18 & 150.68 \\
\hline CF4 & 9:52 & 17- $\mathrm{Fev}-04$ & 0.006 & 5 & 6.3 & 12.9 & 30.26 & 8.72 & 87.32 & 2.78 & 106.19 & 35.17 & 5.56 & 55.37 & 8.34 & 47.04 & 744.18 & 170.10 \\
\hline CF5 & 9:57 & 17- $\mathrm{Fev}-04$ & 0.007 & 4.4 & 6.26 & 16.6 & 23.79 & 7.17 & 83.22 & 3.72 & 85.75 & 58.01 & 18.30 & 88.12 & 22.02 & 66.10 & 497.30 & 92.36 \\
\hline $\begin{array}{l}\text { CF6 } \\
\text {. }\end{array}$ & 10:02 & 17-Fev-04 & 0.006 & $\begin{array}{l}3.4 \\
3.2\end{array}$ & 6.07 & 26.2 & 37.73 & 11.94 & 99.17 & 14.06 & 86.80 & 79.07 & 51.97 & 217.19 & 66.03 & 151.16 & 318.25 & 45.46 \\
\hline CF7 & $10: 07$ & 17-Fev-04 & 0.003 & 5.8 & 6.04 & 34.5 & 37.57 & 12.87 & 95.42 & 25.39 & 63.31 & 74.40 & 73.08 & 295.12 & 98.48 & 196.64 & 168.20 & 16.82 \\
\hline CF8 & 10:12 & 17-Fev-04 & 0.002 & 4.2 & 5.97 & 38.7 & 60.21 & 21.88 & 128.63 & 14.57 & 75.38 & 80.83 & 94.89 & 343.64 & 109.46 & 234.17 & 133.88 & 11.48 \\
\hline CF9 & 10:17 & 17-Fev-04 & 0.002 & 4.6 & 5.99 & 37.3 & 68.79 & 25.48 & 146.39 & 11.86 & 87.02 & 72.29 & 76.05 & 178.23 & 87.92 & 90.31 & 149.45 & 13.88 \\
\hline CF10 & $10: 22$ & 17-Fev-04 & 0.001 & 4 & 6 & 37.3 & 50.52 & 18.31 & 115.20 & 12.71 & 66.93 & 79.76 & 90.22 & 323.64 & 102.94 & 220.70 & 142.15 & 13.20 \\
\hline CF11 & $10: 38$ & 17-Fev-04 & 0.001 & 3.4 & 6.15 & 24.5 & 34.53 & 13.41 & 94.19 & 11.26 & 70.59 & 65.39 & 49.04 & 194.09 & 60.31 & 133.78 & 347.90 & 47.22 \\
\hline CF12 & $10: 43$ & 17-Fev-04 & 0.009 & 3.6 & 6.05 & 17 & 19.88 & 7.31 & 65.58 & 13.74 & 62.35 & 56.82 & 27.51 & 118.87 & 41.25 & 77.63 & 493.18 & 81.02 \\
\hline CF13 & 10:48 & 17-Fev-04 & 0.032 & 3.6 & 6 & 29.1 & 32.45 & 12.15 & 86.87 & 8.48 & 62.35 & 78.60 & 67.68 & 239.82 & 76.17 & 163.65 & 272.25 & 33.06 \\
\hline CF14 & 10:53 & $17-\mathrm{Fev}-04$ & 0.031 & 2.8 & 5.98 & 34.8 & 48.11 & 17.86 & 102.82 & 6.19 & 64.30 & 40.06 & 40.68 & 288.98 & 46.87 & 242.11 & 244.98 & 28.00 \\
\hline CF15 & $10: 58$ & 17-Fev-04 & 0.031 & 3.2 & 5.91 & 37.1 & 39.37 & 14.84 & 97.51 & 13.51 & 49.03 & 70.56 & 93.62 & 300.77 & 107.13 & $\begin{array}{l}193.64 \\
19\end{array}$ & 162.03 & 12.73 \\
\hline CF16 & 11:03 & 17-Fev-04 & 0.012 & 3.2 & 5.92 & 39.4 & 41.14 & 15.94 & 92.37 & 11.64 & 35.48 & 44.5 & 65.85 & 320.85 & 77.50 & 243.35 & 103.03 & 5.89 \\
\hline CF17 & 11:08 & 17-Fev-04 & 0.009 & 4.4 & 5.97 & 37.2 & 51.50 & 20.29 & 113.13 & 9.24 & 42.43 & 63.46 & 91.21 & 296.63 & 100.46 & 196.17 & 131.50 & 9.39 \\
\hline CF18 & $11: 13$ & 17-Fev-04 & 0.008 & 3.6 & 6.01 & 35.1 & 41.34 & 16.10 & 102.99 & 9.61 & 54.05 & 61.00 & 78.78 & 271.37 & 88.39 & 182.98 & 133.00 & 9.50 \\
\hline CF19 & 11:33 & 17-Fev-04 & 0.007 & 4 & 6.09 & 34.5 & 48.65 & 19.04 & 107.47 & 10.21 & 41.94 & 53.23 & 82.12 & 265.00 & 92.34 & 172.66 & 99.90 & 5.00 \\
\hline $\mathrm{CF} 20$ & 11:53 & 17-Fev-04 & 0.007 & 3.8 & 6.08 & 21.1 & 41.24 & 16.35 & 98.18 & 9.42 & 43.39 & 49.17 & 60.42 & 242.45 & 69.85 & 172.60 & 123.05 & 7.03 \\
\hline CF21 & $12: 13$ & 17-Fev-04 & 0.010 & 4.2 & 6.09 & 32.2 & 43.47 & 16.93 & 111.29 & 5.62 & 51.74 & 83.64 & n.a & 232.73 & n.c & n.c & 115.78 & 8.27 \\
\hline CF22 & $12: 33$ & 17-Fev-04 & 0.009 & 3.8 & 6.1 & 32.5 & 41.25 & 16.26 & 98.41 & n.a & 41.77 & 34.4 & 41.99 & 236.24 & n.c & n.c & 86.80 & 6.20 \\
\hline CF23 & 12:53 & 17- $\mathrm{Fev}-04$ & 0.006 & 3.8 & 6.07 & 35 & 50.30 & 22.11 & 123.83 & 10.89 & 39.85 & 44.58 & 71.67 & 250.90 & 82.57 & 168.33 & 50.77 & 2.54 \\
\hline CF24 & $13: 13$ & 17-Fev-04 & 0.003 & 3 & 6.05 & 37.9 & 59.90 & 25.75 & 125.49 & $<$ l.d & 24.75 & 50.15 & 76.85 & 277.03 & n.c & n.c & 37.54 & 1.34 \\
\hline CF25 & $13: 33$ & 17-Fev-04 & 0.002 & 4.2 & 6.07 & 38.3 & 65.95 & 29.59 & 135.96 & n.a & 30.28 & 49.41 & 83.72 & 281.41 & n.c & $n . c$ & 34.21 & n.a \\
\hline CF1 & 13:40 & 19-Fev-04 & 0.008 & 4.6 & 6.2 & 13.4 & 23. & 8.8 & 57.09 & 3.00 & 107.45 & 95.5 & 0.00 & 50. & 3.00 & 47.59 & 809.46 & 254.40 \\
\hline CF2 & 13:45 & 19-Fev-04 & 0.002 & 5.2 & 6.21 & 11.6 & 21.89 & 7.24 & 59.54 & 2.67 & 108.34 & 82.78 & 0.00 & 45.57 & 2.67 & 42.91 & 609.68 & 161.13 \\
\hline $\mathrm{CF} 3$ & 13:50 & 19-Fev-04 & 0.001 & 3.8 & 6.27 & 11.5 & 13.78 & 4.07 & 38.01 & 3.06 & 68.22 & 72.04 & 2.34 & 47.96 & 5.40 & 42.57 & 528.08 & 120.70 \\
\hline CF4 & 13:55 & 19-Fev-04 & 0.001 & 5.6 & 6.34 & 11.6 & 13.18 & 4.11 & 42.83 & 2.9 & 53.69 & 71.1 & 2.2 & 48.8 & 5.2 & 43.60 & 394.18 & 64.76 \\
\hline CF5 & $14: 00$ & 19-Fev-04 & 0.000 & 5.8 & 6. & 11 & & 5.2 & 46.8 & 2.5 & 75.7 & 76.0 & 2.9 & 49.4 & 5. & 44.03 & 314.88 & 44.98 \\
\hline CF6 & 14:05 & 19-Fev-04 & 0.000 & 5.4 & 6.27 & 12.3 & 20.32 & 6.46 & 51.99 & 1.78 & 46.30 & 32.96 & 3.13 & 43.82 & 4.91 & 38.91 & 238.40 & 30.65 \\
\hline CF7 & $14: 10$ & $19-\mathrm{Fev}-04$ & 0.000 & 4.6 & 6.39 & 12.6 & 17.87 & 5.30 & 50.71 & 1.72 & 36.87 & 37.61 & 2.98 & 43.10 & 4.70 & 38.40 & 210.87 & 25.61 \\
\hline CF8 & $14: 40$ & 19-Fev-04 & 0.126 & $\begin{array}{l}3.2 \\
\end{array}$ & 6.13 & 10.2 & 12.63 & 4.23 & 44.91 & 1.78 & 31.83 & 26.39 & 3.74 & 32.75 & 5.51 & 27.23 & n.a & n.a \\
\hline CF9 & $14: 45$ & 19-Fev-04 & 0.884 & 4.6 & 6.02 & 17.4 & 19.93 & 7.43 & 66.23 & 3.8 & 26.70 & 24.62 & 16.36 & 97.84 & 20.19 & 77.65 & 546.34 & 117.07 \\
\hline CF10 & $14: 50$ & 19-Fev-04 & 4.3 & 4 & 6.1 & 18. & & 10. & & 4.0 & & 27. & 14.10 & 100. & 18.10 & 82.45 & & 30.63 \\
\hline CF11 & $14: 55$ & 19-Fev-04 & 5.060 & 6.2 & 6.12 & 17.8 & 22.52 & 8.74 & 78.55 & 3.11 & 30.08 & 25.90 & 11.92 & 124.29 & 15.03 & 109.26 & 167.00 & 21.47 \\
\hline CF12 & $15: 15$ & 19-Fev-04 & 14.902 & 6.2 & 6.25 & 18.1 & 27.65 & 11.30 & 92.30 & 3.06 & 28.43 & 25.79 & 13.26 & 87.01 & 16.31 & $\begin{array}{l}70.69 \\
\end{array}$ & 242.97 & 39.92 \\
\hline
\end{tabular}


Anexo J. Valores dos parâmetros físico-químicos e concentrações dos elementos e compostos analisados no igarapé da floresta

\begin{tabular}{|c|c|c|c|c|c|c|c|c|c|c|c|c|c|c|c|c|c|c|}
\hline Fonte & Hora & Data & Descarga (L.s-1) & Alc & $\mathrm{pH}$ & C.E & $\mathrm{Ca}(\mathrm{UM})$ & $\mathrm{Mg}(\mathrm{uM})$ & K(UM) & NH4(uM) & $\mathrm{Na}(\mathrm{UM})$ & Cl(uM) & NO3(UM) & TDN(UM) & NID(uM) & & $\operatorname{STS}\left(m g . L^{-1}\right)$ & NP (UM) \\
\hline CF14 & $15: 55$ & $19-\mathrm{Fev}-04$ & 2.879 & 7.4 & 6.27 & 19.7 & 32.17 & 12.69 & 94.21 & 4.33 & 38.83 & 30.11 & 14.07 & 82.07 & 18.41 & 63.66 & 38.27 & 2.46 \\
\hline CF15 & $16: 15$ & 19-Fev-04 & 0.768 & 7 & 6.15 & 22 & 32.03 & 14.89 & 100.83 & 3.72 & 23.37 & 24.96 & 18.38 & 118.48 & 22.11 & 96.37 & 35.38 & 1.77 \\
\hline CF16 & $16: 35$ & 19-Fev-04 & 0.290 & 6.8 & 6.21 & 24.4 & 30.89 & 14.17 & 96.70 & 3.78 & 18.89 & 26.24 & 23.92 & 136.48 & 27.70 & 108.78 & 37.93 & 2.17 \\
\hline CF17 & $16: 55$ & 19-Fev-04 & 0.196 & 8.6 & 6.16 & 26.1 & 38.92 & 18.36 & 111.46 & 4.72 & 20.39 & 17.87 & 26.38 & 145.65 & 31.11 & 114.54 & 38.60 & 1.93 \\
\hline CF18 & 17:15 & 19-Fev-04 & 0.101 & 8.8 & 6.15 & 27.5 & 38.72 & 18.82 & 113.54 & 4.28 & 16.08 & 20.36 & 30.31 & 153.29 & 34.59 & 118.70 & 30.62 & 1.31 \\
\hline CF19 & $17: 35$ & 19-Fev-04 & 0.060 & 6.8 & 6.21 & 28.2 & 36.25 & 17.48 & 117.02 & 4.78 & 17.48 & 15.82 & 27.45 & 164.61 & 32.23 & 132.37 & 36.58 & 1.57 \\
\hline $\mathrm{CF} 20$ & $17: 56$ & 19-Fev-04 & 0.031 & 7.4 & 6.36 & 29.8 & 58.12 & 28.80 & 176.97 & 2.00 & 27.12 & 26.45 & 41.05 & 176.08 & 43.06 & 133.02 & 32.18 & 1.38 \\
\hline CF21 & $18: 16$ & 19-Fev-04 & 0.009 & 8 & 6.1 & 30 & 39.10 & 25.45 & 147.79 & 2.06 & 34.53 & 33.91 & 43.08 & 180.38 & 45.14 & 135.24 & 234.14 & 46.83 \\
\hline CF22 & $18: 36$ & 19-Fev-04 & 0.004 & 7.4 & 6.31 & 30.1 & 38.20 & 25.83 & 147.82 & 2.17 & 34.22 & 28.61 & 45.87 & 189.31 & 48.04 & 141.27 & 33.08 & 1.42 \\
\hline CF23 & 18:56 & 19-Fev-04 & 0.001 & 7.2 & 6.07 & 29.3 & 58.04 & 27.89 & 170.16 & 2.33 & 41.26 & 16.60 & 23.77 & 171.94 & 26.10 & 145.84 & 29.46 & 1.05 \\
\hline CF1 & $16: 10$ & 25-Fev-04 & n.c & 8 & 6.14 & 24.6 & 55.44 & 24.54 & 141.05 & 5.13 & 79.46 & 55.32 & 16.27 & 122.54 & 21.40 & 101.14 & 333.70 & n.a \\
\hline CF2 & $16: 15$ & 25-Fev-04 & n.c & 3.2 & 5.8 & 16.1 & 24.15 & 9.56 & 70.33 & n.a & 55.89 & 39.15 & 20.70 & 94.57 & n.c & $\mathrm{n} . \mathrm{c}$ & 757.23 & 162.26 \\
\hline CF3 & $16: 20$ & 25-Fev-04 & n.c & 4.4 & 6.02 & 16.4 & 23.50 & 9.28 & 76.33 & 0.99 & 42.19 & 29.26 & 13.56 & 96.65 & 14.56 & 82.09 & 279.53 & 39.93 \\
\hline CF4 & $16: 25$ & 25-Fev-04 & n.c & 4.2 & 6.17 & 16 & 24.25 & 10.24 & 78.77 & 7.77 & 40.32 & 19.47 & 8.00 & 89.00 & 15.77 & 73.23 & 169.60 & 15.75 \\
\hline CF5 & $16: 30$ & 25 -Fev-04 & n.c & 5 & 6.22 & 17.2 & 21.66 & 9.38 & 73.06 & 7.20 & 30.50 & 19.45 & 9.08 & 81.75 & 16.28 & 65.47 & 132.62 & 16.10 \\
\hline CF6 & $16: 35$ & $25-\mathrm{Fev}-04$ & n.c & 5.4 & 6.27 & 18 & 22.51 & 10.09 & 77.52 & 5.87 & 22.79 & 22.62 & 16.78 & 74.50 & 22.65 & 51.85 & 72.92 & 5.73 \\
\hline CF7 & $16: 40$ & 25 -Fev-04 & n.c & 5 & 6.27 & 19.8 & 33.50 & 15.16 & 101.44 & 5.25 & 22.66 & 12.50 & 14.87 & 111.23 & 20.13 & 91.10 & 47.51 & 4.07 \\
\hline CF8 & $16: 45$ & $25-\mathrm{Fev}-04$ & n.c & 6.6 & 6.26 & 21.9 & 34.57 & 16.40 & 98.16 & 6.63 & 16.94 & 19.67 & 24.51 & 123.74 & 31.14 & 92.60 & 36.31 & 2.85 \\
\hline CF9 & 16:50 & 25 -Fev-04 & n.c & 6.4 & 6.32 & 22.8 & 43.24 & 19.70 & 114.84 & 6.44 & 25.62 & 15.52 & 16.07 & 132.74 & 22.51 & 110.23 & 34.89 & 2.74 \\
\hline CF10 & $16: 55$ & 25-Fev-04 & n.c & 6.4 & 6.34 & 23.4 & 48.88 & 22.29 & $\begin{array}{l}138.59 \\
\end{array}$ & n.a & 67.88 & 21.95 & 27.75 & 142.78 & n.c & n.c & 26.63 & 2.28 \\
\hline CF11 & $17: 00$ & $25-\mathrm{Fev}-04$ & n.c & 6.8 & 6.32 & 23.8 & 49.99 & 23.38 & 134.41 & $<$ l.d & 32.95 & 26.90 & 28.77 & 143.26 & n.c & n.c & 30.25 & 2.38 \\
\hline CF12 & 17:05 & 25 -Fev-04 & n.c & 6.2 & 6.29 & 24.3 & 39.99 & 20.11 & 114.93 & $<1 . d$ & 21.44 & 21.91 & 31.20 & 149.95 & n.c & n.c & 26.94 & 1.92 \\
\hline $\mathrm{CF} 13$ & $17: 10$ & 25 -Fev-04 & n.c & 5.6 & 6.25 & 24.9 & 41.85 & 20.41 & 118.74 & $<$ l.d & 26.43 & 23.17 & 31.78 & 152.26 & n.c & n.c & 25.39 & 1.81 \\
\hline CF14 & $17: 15$ & 25 -Fev-04 & n.c & 7 & 6.24 & 25.3 & 41.34 & 20.22 & 119.41 & 2.57 & 34.79 & 45.51 & 33.79 & 157.12 & 36.36 & 120.76 & 20.47 & 1.32 \\
\hline CF15 & $17: 20$ & 25-Fev-04 & n.c & 6.2 & $\begin{array}{l}6.25 \\
6.25\end{array}$ & 25.8 & 33.45 & 21.83 & 109.57 & 8.84 & 19.03 & 23.38 & 35.26 & $\begin{array}{l}161.58 \\
\end{array}$ & 44.11 & $\begin{array}{l}117.48 \\
\end{array}$ & 25.15 & 1.26 \\
\hline CF16 & $17: 25$ & 25 - Fev- 04 & n.c & 4.6 & 6.19 & 26.3 & 33.55 & 22.01 & 109.33 & 7.14 & 15.18 & 18.54 & 36.90 & 170.82 & 44.04 & 126.78 & 24.65 & 1.23 \\
\hline $\begin{array}{l}\text { CF17 } \\
\text { (a) }\end{array}$ & $\begin{array}{l}17: 45 \\
17.25\end{array}$ & 25-Fev-04 & n.c & 5.8 & 6.15 & 27.4 & 33.37 & 22.20 & 113.51 & 6.59 & 16.11 & 12.12 & 27.88 & 170.03 & 34.47 & 135.55 & 24.58 & 1.23 \\
\hline CF18 & 18:05 & 25-Fev-04 & n.c & 4.6 & 6.18 & 28.2 & 35.40 & 23.14 & 117.14 & 7.88 & 27.96 & 29.37 & 48.64 & 196.48 & 56.53 & 139.95 & 30.61 & 1.53 \\
\hline CF 1 & 3:17 & 27-fev-04 & n.c & n.a & 5.98 & 15.3 & 19.82 & 12.17 & 66.29 & 7.53 & 67.56 & 52.68 & 6.33 & 63.18 & 13.87 & 49.32 & 333.30 & 47.61 \\
\hline CF2 & 3:22 & 27-fev-04 & n.c & n.a & 6.09 & 13.8 & 18.12 & 9.60 & 61.70 & 8.46 & 71.09 & 56.97 & 6.18 & 58.48 & 14.64 & 43.84 & 250.40 & 30.41 \\
\hline CF3 & $\begin{array}{l}3.22 \\
3: 27\end{array}$ & 27-fev-04 & n.c & n.a & 6.16 & 15.7 & 21.27 & 10.42 & 66.69 & 7.61 & 70.80 & 56.06 & 7.65 & 67.01 & 15.25 & 51.75 & 206.50 & 22.13 \\
\hline CF4 & 3:32 & 27-fev-04 & n.c & n.a & 6.16 & 16.5 & 22.68 & 10.91 & 71.62 & 7.54 & 70.66 & 54.31 & 8.82 & 65.33 & 16.36 & 48.97 & 164.74 & 12.94 \\
\hline CF5 & 3:37 & 27-fev-04 & n.c & n.a & 6.29 & 17.9 & 19.06 & 9.76 & 66.13 & 5.87 & 55.86 & 51.61 & 11.47 & 77.68 & 17.34 & 60.34 & 121.58 & 9.55 \\
\hline
\end{tabular}

$<$ l.d = menor ao limite de detecção

n.a = não analisado

n.c $=$ não calculado

Alc. $=$ Alcalinidade (ueq. $\mathrm{L}^{-1}$ )

C. $\mathrm{E}=$ Condutividade elétrica (uS. $\mathrm{cm}^{-1}$ )

$\mathrm{CF}=$ Amostras do igarapé durante o evento de chuva

Anexo K. Valores dos parâmetros físico-químicos e concentrações dos elementos e compostos analisados no igarapé da pastagem

\begin{tabular}{|c|c|c|c|c|c|c|c|c|c|c|c|c|c|c|c|c|c|c|}
\hline Fonte & Hora & Data & Descarga $\left(\right.$ L. $\left.\mathrm{s}^{-1}\right)$ & Alc & $\mathrm{pH}$ & C.E & $\mathrm{Ca}(\mathrm{UM})$ & $\mathrm{Mg}(\mathrm{uM})$ & $\mathrm{K}(\mathrm{UM})$ & $\mathrm{NH} 4(\mathrm{uM})$ & $\mathrm{Na}(\mathrm{UM})$ & $\mathrm{Cl}(\mathrm{UM})$ & $\mathrm{NO} 3(\mathrm{uM})$ & NDT(UM) & NID (uM) & NOD(uM) & STS $\left(m g . L^{-1}\right)$ & NP (UM) \\
\hline CF1 & 16:04 & 21-Jan-04 & n.c & 43 & 6.05 & 54.6 & 116.67 & 95.55 & 103.94 & 2.50 & 206.54 & 228.41 & 2.61 & 79.82 & 5.11 & 74.71 & 95.75 & 6.84 \\
\hline CF2 & 17:57 & 21-Jan-04 & n.c & 31.4 & 6.14 & 45.7 & 111.37 & 66.70 & 119.17 & 1.67 & 184.78 & 146.33 & 0.31 & 73.65 & 1.97 & 71.68 & 103.00 & 8.83 \\
\hline $\mathrm{CF} 3$ & 18:11 & 21-Jan-04 & n.c & 28.2 & 6.13 & 41.1 & 89.29 & 57.12 & 114.77 & 1.72 & 163.57 & 89.89 & 0.31 & 52.67 & 2.03 & 50.64 & n.a & n.a \\
\hline CF4 & 18:13 & 21-Jan-04 & n.c & 20.2 & 6.19 & 38.9 & 94.81 & 57.88 & 173.30 & 1.83 & 262.07 & 117.43 & 0.27 & 63.61 & 2.11 & 61.50 & 314.00 & 58.31 \\
\hline CF5 & 18:17 & 21-Jan-04 & n.c & 17.2 & 6.03 & 39.8 & 85.00 & 55.92 & 113.58 & 6.64 & 151.47 & 107.69 & n.a & 64.35 & n.c & n.c & 144.25 & 25.76 \\
\hline CF6 & 18:20 & 21-Jan-04 & n.c & 18.4 & 6.2 & 38.3 & 99.18 & 67.16 & 144.87 & 6.58 & 171.47 & 118.39 & n.a & 80.15 & n.c & n.c & 50.00 & 3.21 \\
\hline CF7 & $18: 23$ & 21-Jan-04 & n.c & 14.2 & 6.11 & 33.8 & 84.14 & 61.91 & 165.67 & 2.61 & 190.71 & 107.99 & 0.35 & 71.18 & 2.97 & 68.22 & 26.75 & 1.15 \\
\hline CF8 & 18:26 & 21-Jan-04 & n.c & 12.2 & 6.2 & 31.7 & 59.60 & 41.44 & 91.38 & 3.00 & 98.46 & 103.80 & 0.47 & 64.52 & 3.47 & 61.05 & 20.17 & 1.15 \\
\hline CF9 & 18:36 & 21-Jan-04 & n.c & 10 & 6.13 & 24.3 & 43.67 & 32.64 & 85.54 & 3.11 & 97.06 & 76.90 & 0.32 & 54.48 & 3.43 & 51.04 & 12.33 & 0.44 \\
\hline CF10 & 18:50 & 21-Jan-04 & n.c & 9.6 & 6.2 & 25.2 & 29.47 & 22.15 & 66.05 & 3.05 & 61.20 & 88.00 & 0.26 & 48.22 & 3.31 & 44.91 & 11.00 & 0.47 \\
\hline CF11 & 19:04 & 21-Jan-04 & n.c & 5 & 6.15 & 27.6 & 92.21 & 64.16 & 156.22 & 4.44 & 117.48 & 236.10 & 0.23 & 51.35 & 4.67 & 46.68 & 12.60 & 0.63 \\
\hline CF12 & 19:15 & 21-Jan-04 & n.c & 12 & 6.08 & 25.2 & 53.37 & 37.85 & 109.72 & 2.67 & 66.87 & 112.33 & 0.27 & 48.63 & 2.94 & 45.69 & 10.60 & 0.53 \\
\hline $\mathrm{CF} 13$ & 19:30 & 21-Jan-04 & n.c & 7 & 6.2 & 25.7 & 27.59 & 20.61 & 70.58 & n.a & 29.53 & 93.65 & 0.21 & 45.84 & n.c & n.c & 10.20 & 0.58 \\
\hline CF14 & $19: 45$ & 21-Jan-04 & n.c & 8.6 & 6.2 & 27.7 & 65.78 & 51.41 & 166.30 & n.a & 107.43 & 88.99 & 0.23 & 51.27 & n.c & n.c & 9.90 & 0.57 \\
\hline CF15 & 20:05 & 21-Jan-04 & n.c & 9.2 & 6.25 & 27.1 & 84.67 & 64.73 & 226.21 & 2.39 & 169.14 & 89.83 & 0.26 & 51.60 & 2.65 & 48.95 & 8.90 & 0.38 \\
\hline CF 16 & $20: 25$ & 21-Jan-04 & n.c & 9.6 & 6.15 & 27.4 & 52.47 & 40.65 & 145.98 & n.a & 109.86 & 84.71 & 0.39 & 42.13 & n.c & n.c & 0.00 & 0.00 \\
\hline CF17 & 20:45 & 21-Jan-04 & n.c & 9.4 & 6.21 & 26.7 & 43.91 & 35.53 & 122.95 & n.a & 105.66 & 80.31 & 0.34 & 37.03 & n.c & n.c & 10.77 & 0.77 \\
\hline CF18 & 0:00 & 21-Jan-04 & n.c & 14.4 & 6.16 & 29 & 77.74 & 60.04 & 159.99 & 2.06 & 125.33 & 55.21 & 0.23 & 49.37 & 2.28 & 47.09 & 16.38 & 0.82 \\
\hline CF1 & 20:27 & 27-Jan-04 & 0.757 & 5 & 5.6 & 22.5 & 52.86 & 33.21 & 62.35 & 2.93 & 105.57 & 107.36 & 1.02 & 35.88 & 3.94 & 31.93 & 117.41 & n.a \\
\hline $\mathrm{CF} 2$ & 20:32 & 27-Jan-04 & 3.399 & 4.2 & 5.63 & 23.5 & 39.85 & 24.04 & 88.97 & n.a & 88.57 & 98.80 & 0.85 & 41.06 & n.c & n.c & 32.65 & n.a \\
\hline CF3 & 20:37 & 27-Jan-04 & 2.206 & 4.6 & 5.64 & 25.6 & 33.43 & 23.31 & 85.43 & n.a & 67.18 & 79.33 & 0.87 & 44.93 & n.c & n.c & 13.24 & n.a \\
\hline CF 4 & 20:47 & 27-Jan-04 & 1.441 & 7.2 & 5.63 & 28.5 & 32.68 & 23.40 & 79.45 & n.a & 55.84 & 82.71 & 0.37 & 47.56 & n.c & n.c & 10.57 & n.a \\
\hline CF5 & 20:57 & 27-Jan-04 & 0.691 & 6 & 5.61 & 28.3 & 35.13 & 24.26 & 75.12 & n.a & 54.04 & 95.63 & 0.27 & 45.92 & n.c & n.c & 9.08 & n.a \\
\hline CF6 & 21:17 & 27-Jan-04 & 0.235 & 3.6 & 5.4 & 25.7 & 36.33 & 25.11 & 80.32 & n.a & 62.94 & 85.78 & 0.21 & 0.00 & n.c & n.c & 8.27 & n.a \\
\hline CF7 & 21:37 & 27-Jan-04 & 0.128 & 3 & 5.3 & 26.5 & 24.08 & 9.05 & 33.30 & 8.19 & 31.87 & 88.33 & 0.11 & 39.42 & 8.30 & 31.12 & 9.07 & n.a \\
\hline CF1 & $14: 20$ & 31-Jan-04 & 0.099 & 5.6 & 5.79 & 20.3 & 29.32 & 21.72 & 63.53 & 9.59 & 97.32 & 75.70 & 0.39 & 34.15 & 0.39 & 33.76 & 89.56 & n.a \\
\hline CF2 & 14:25 & 31-Jan-04 & 0.246 & 4.6 & 5.69 & 19.8 & 26.82 & 15.36 & 58.95 & 2.96 & 79.69 & 105.24 & 0.26 & 37.20 & 3.22 & 33.98 & 33.40 & n.a \\
\hline CF3 & 14:30 & 31-Jan-04 & 0.256 & 4.2 & 5.72 & 21.3 & 26.59 & 16.47 & 58.28 & 4.33 & 74.57 & 106.94 & 0.16 & 36.04 & 4.49 & 31.55 & 25.17 & n.a \\
\hline CF4 & 14:35 & 31-Jan-04 & 0.242 & 3.8 & 5.72 & 19.8 & 26.66 & 15.50 & 68.57 & 7.08 & 90.09 & 104.73 & 0.11 & 43.37 & 7.19 & 36.18 & 16.46 & n.a \\
\hline CF5 & $14: 40$ & 31-Jan-04 & 0.177 & 3.6 & 5.71 & 21 & 28.21 & 16.39 & 68.90 & 15.18 & 72.64 & 90.05 & 0.11 & 41.80 & 15.30 & 26.51 & 14.31 & n.a \\
\hline CF6 & $14: 45$ & 31-Jan-04 & 0.133 & 4.2 & 5.69 & 20 & 31.66 & 18.60 & 76.09 & 5.49 & 83.29 & 93.00 & 0.11 & 39.01 & 5.61 & 33.40 & 11.57 & n.a \\
\hline CF8 & $14: 55$ & 31-Jan-04 & 0.089 & 3.6 & 5.6 & 19.6 & 27.14 & 16.03 & 73.54 & 7.98 & 85.47 & 90.35 & 0.08 & 39.09 & 8.06 & 31.03 & 5.43 & n.a \\
\hline CF10 & 15:05 & 31-Jan-04 & 0.071 & 4.8 & 5.65 & 19.4 & 24.85 & 14.83 & 53.51 & 2.99 & 65.65 & 91.34 & 0.10 & 40.40 & 3.09 & 37.32 & 10.00 & n.a \\
\hline $\mathrm{CF}$ & 15:55 & 31-Jan-04 & 0.026 & 4.2 & 5.41 & 18.4 & 27.65 & 13.69 & 55.01 & $<$ I.d & 65.50 & 87.54 & 0.08 & 23.54 & n.c & n.c & 10.20 & n.a \\
\hline
\end{tabular}


Anexo K. Valores dos parâmetros físico-químicos e concentrações dos elementos e compostos analisados no igarapé da pastagem

\begin{tabular}{|c|c|c|c|c|c|c|c|c|c|c|c|c|c|c|c|c|c|c|}
\hline Fonte & Hora & Data & Descarga $\left.(\text { L. s s })^{-1}\right)$ & Alc & $\mathrm{pH}$ & C.E & $\mathrm{Ca}(\mathrm{UM})$ & $\mathrm{Mg}(\mathrm{uM})$ & $\mathrm{K}(\mathrm{UM})$ & $\mathrm{NH} 4(\mathrm{uM})$ & $\mathrm{Na}(\mathrm{UM})$ & $\mathrm{Cl}(\mathrm{UM})$ & $\mathrm{NO} 3(\mathrm{uM})$ & $\mathrm{NDT}(\mathrm{uM})$ & NID (UM) & NOD(uM) & STS $\left(m g . L^{-1}\right)$ & $\mathrm{NP}(\mathrm{uM})$ \\
\hline CF1 & $16: 15$ & 04-Fev-04 & 0.171 & 2.4 & 5.42 & 20.9 & 31.56 & 14.40 & 87.23 & 3.33 & 97.89 & 98.11 & 0.27 & 33.74 & 3.61 & 30.13 & 54.90 & 9.41 \\
\hline $\mathrm{CF} 2$ & $16: 20$ & 04-Fev-04 & 0.362 & 4.2 & 5.69 & 34.6 & 32.17 & 15.34 & 147.72 & 11.33 & 75.86 & 131.03 & 0.40 & 81.14 & 11.74 & 69.40 & 23.80 & 2.89 \\
\hline $\mathrm{CF} 3$ & $16: 25$ & 04-Fev-04 & 0.427 & 6.6 & 5.65 & 35.8 & 29.84 & 20.93 & 187.79 & 14.16 & 75.99 & 127.46 & n.a & 86.90 & n.c & n.c & 16.60 & 1.66 \\
\hline CF 4 & $16: 30$ & 04-Fev-04 & 0.742 & 4.2 & 5.81 & 31.1 & 26.11 & 13.85 & 152.14 & 7.66 & 43.31 & 99.93 & 0.29 & 65.67 & 7.96 & 57.71 & 23.40 & 2.34 \\
\hline CF5 & $16: 35$ & 04-Fev-04 & 2.285 & -1 & 4.62 & 35.1 & 30.37 & 16.57 & 131.25 & 30.10 & 52.00 & 90.68 & 0.37 & 82.13 & 30.48 & 51.64 & 17.50 & 1.62 \\
\hline CF6 & $16: 40$ & 04-Fev-04 & 2.261 & 3.2 & 5.6 & 27 & 31.96 & 17.86 & 135.03 & 4.39 & 50.93 & 91.76 & 0.19 & 61.06 & 4.58 & 56.48 & 5.67 & 0.45 \\
\hline CF7 & $16: 45$ & 04-Fev-04 & 1.790 & 3.2 & 5.65 & 29.3 & 36.84 & 17.69 & 131.17 & n.a & 58.88 & 105.44 & n.a & 79.99 & n.c & n.c & 9.83 & 0.77 \\
\hline CF8 & $16: 50$ & 04-Fev-04 & 1.336 & 3.4 & 5.63 & 30.1 & 34.27 & 19.90 & 131.04 & n.a & 46.18 & 110.87 & n.a & 87.80 & n.c & n.c & 9.92 & 0.78 \\
\hline CF9 & $16: 55$ & 04-Fev-04 & 0.997 & 3.8 & 5.56 & 30.7 & 39.57 & 22.26 & 156.06 & 4.44 & 69.23 & 115.49 & 0.32 & 86.82 & 4.77 & 82.05 & 9.25 & 0.66 \\
\hline CF10 & 17:00 & 04-Fev-04 & 0.734 & 3 & 5.57 & 30.7 & 37.10 & 20.94 & 147.06 & 4.44 & 67.12 & 74.47 & 0.37 & 89.94 & 4.82 & 85.13 & 9.08 & 0.65 \\
\hline CF11 & 17:05 & 04-Fev-04 & 0.533 & 4.4 & 5.53 & 30.1 & 30.85 & 17.92 & 123.89 & 8.05 & 48.12 & 109.82 & 0.24 & 96.28 & 8.30 & 87.98 & 9.30 & 0.60 \\
\hline $\mathrm{CF} 12$ & $17: 10$ & 04-Fev-04 & 0.447 & 3 & 5.61 & 30.4 & 32.80 & 19.06 & 128.22 & 6.33 & 55.43 & 113.18 & 0.21 & 89.78 & 6.54 & 83.24 & 8.70 & 0.50 \\
\hline CF13 & $17: 15$ & 04-Fev-04 & 0.420 & 4.6 & 5.61 & 29.4 & 33.09 & 20.14 & 140.70 & n.a & 52.69 & 107.07 & 0.21 & 96.12 & n.c & n.c & 8.40 & 0.48 \\
\hline CF14 & $17: 20$ & 04-Fev-04 & 0.419 & 5.2 & 5.66 & 29.8 & 28.80 & 17.15 & 119.49 & 3.11 & 65.18 & 121.15 & 0.24 & 81.22 & 3.35 & 77.87 & 10.40 & 0.82 \\
\hline CF15 & $17: 25$ & 04-Fev-04 & 0.422 & 5.6 & 5.64 & 29.5 & 30.50 & 17.67 & 123.91 & n.a & 79.24 & 128.27 & 0.19 & 84.60 & n.c & n.c & 9.40 & 0.67 \\
\hline CF16 & 17:30 & 04-Fev-04 & 0.466 & 6 & 5.64 & 29.9 & 37.42 & 21.73 & 139.28 & 6.33 & 86.24 & 134.20 & 0.19 & 87.15 & 6.53 & 80.62 & 12.80 & 1.01 \\
\hline CF17 & 17:50 & 04-Fev-04 & 0.427 & 5.4 & 5.74 & 33 & 42.22 & 25.53 & 149.97 & n.a & 87.37 & 158.32 & n.a & 97.02 & n.c & n.c & 25.80 & 2.03 \\
\hline CF18 & $18: 10$ & 04-Fev-04 & 0.272 & 5.4 & 5.73 & 33.6 & 41.27 & 24.64 & 137.87 & 6.22 & 78.55 & 175.55 & 0.21 & 100.81 & 6.43 & 94.37 & 11.40 & 0.90 \\
\hline CF19 & 18:30 & 04-Fev-04 & 0.163 & 4 & 5.58 & 32.6 & 38.74 & 23.07 & 138.97 & $<$ l.d & 78.16 & 163.58 & 0.26 & 95.46 & n.c & n.c & 5.60 & 0.40 \\
\hline CF2O & 18:50 & 04-Fev-04 & 0.100 & 2.4 & 5.47 & 31.6 & 38.52 & 23.17 & 145.80 & n.a & 55.98 & 137.78 & 0.18 & 92.99 & n.c & n.c & n.a & n.a \\
\hline CF 21 & 19:10 & 04-Fev-04 & 0.067 & 4 & 5.55 & 29.7 & 37.68 & 19.62 & 123.08 & 5.02 & 67.05 & 153.46 & 1.61 & 95.46 & 6.63 & 88.83 & 12.11 & 0.78 \\
\hline CF22 & 19:30 & 04-Fev-04 & 0.046 & 4 & 5.46 & 28.5 & 28.56 & 16.48 & 110.73 & 5.15 & 44.26 & 130.00 & 0.16 & 89.04 & 5.31 & 83.73 & 12.11 & 0.78 \\
\hline CF 23 & 19:50 & 04-Fev-04 & 0.034 & 2 & 5.5 & 28.1 & 40.52 & 22.03 & 161.51 & 5.77 & 62.00 & 85.49 & 0.10 & 76.12 & 5.87 & 70.25 & 12.60 & n.a \\
\hline CF24 & 20:10 & 04-Fev-04 & 0.029 & 3.6 & 5.35 & 27.1 & 31.69 & 23.81 & 140.53 & 2.55 & 57.33 & 117.31 & 0.10 & 72.25 & 2.65 & 69.60 & 11.47 & 0.57 \\
\hline CF1 & 13:58 & $15-\mathrm{Fev}-04$ & 0.037 & 1.8 & 5.84 & 15.3 & 26.74 & 12.83 & 66.09 & 2.33 & 58.58 & 72.19 & 0.29 & 32.90 & 2.62 & 30.27 & 38.94 & 3.62 \\
\hline CF2 & 14:03 & 15-Fev-04 & 0.153 & 1.4 & 5.72 & 14.8 & 29.61 & 11.91 & 73.03 & 2.61 & 61.14 & 63.15 & 0.23 & 41.27 & 2.84 & 38.43 & 18.53 & 1.59 \\
\hline $\mathrm{CF} 3$ & 14:08 & $15-\mathrm{Fev}-04$ & 0.240 & 2 & 5.66 & 15.4 & 34.72 & 14.95 & 104.86 & 2.83 & 82.84 & 60.25 & 0.16 & 40.01 & 2.99 & 37.02 & 11.80 & 0.84 \\
\hline CF4 & 14:13 & $15-\mathrm{Fev}-04$ & 0.268 & 2 & 5.64 & 19.1 & 44.41 & 20.60 & 142.93 & 3.39 & 84.89 & 66.99 & 0.21 & 66.24 & 3.60 & 62.64 & 9.20 & 0.72 \\
\hline CF5 & 14:18 & $15-\mathrm{Fev}-04$ & 0.244 & 2.8 & 5.58 & 27.5 & 42.08 & 20.06 & 156.98 & 8.03 & 78.69 & 94.23 & n.a & 115.37 & n.c & n.c & 7.90 & 0.51 \\
\hline CF6 & $14: 23$ & 15-Fev-04 & 0.241 & 3.4 & 5.61 & 29 & 33.67 & 16.15 & 149.18 & 7.00 & 42.55 & 88.78 & 0.11 & 111.14 & 7.11 & 104.03 & 8.50 & 0.61 \\
\hline CF7 & $14: 28$ & $15-\mathrm{Fev}-04$ & 0.204 & 2.6 & 5.63 & 27.3 & 27.73 & 13.44 & 143.46 & 5.39 & 32.45 & 85.33 & 0.16 & 94.92 & 5.55 & 89.37 & 8.70 & 0.62 \\
\hline CF8 & $14: 33$ & $15-\mathrm{Fev}-04$ & 0.162 & 4 & 5.62 & 25.9 & 26.77 & 16.45 & 112.09 & 3.61 & 45.93 & 81.36 & 0.19 & 80.47 & 3.80 & 76.66 & 9.40 & 0.67 \\
\hline CF9 & $14: 38$ & 15-Fev-04 & 0.127 & 2.6 & 5.61 & 25.2 & 24.52 & 15.63 & 125.43 & 3.55 & 41.03 & 43.88 & 0.16 & 73.36 & 3.72 & 69.64 & 9.90 & 0.71 \\
\hline CF 10 & $14: 43$ & 15-Fev-04 & 0.103 & 3.8 & 5.78 & 25.5 & 23.85 & 10.77 & 121.35 & 13.72 & 35.48 & 77.62 & 0.24 & 79.73 & 13.96 & 65.76 & 8.33 & 0.54 \\
\hline CF11 & $14: 48$ & 15-Fev-04 & 0.084 & & 3.85 & 95.7 & 24.78 & 15.77 & 126.19 & 7.34 & 31.00 & 74.23 & 0.10 & 119.59 & 7.44 & 112.15 & 11.25 & 0.72 \\
\hline CF12 & $14: 53$ & 15-Fev-04 & 0.069 & 3.2 & 5.62 & 23.8 & 22.57 & 8.67 & 111.67 & 3.44 & 28.74 & 78.49 & 0.19 & 65.06 & 3.64 & 61.42 & 9.20 & 0.53 \\
\hline $\mathrm{CF} 13$ & $14: 58$ & $15-\mathrm{Fev}-04$ & 0.057 & 1.8 & 5.66 & 23.2 & 24.77 & 10.36 & 120.74 & 4.80 & 46.02 & 80.14 & 0.16 & 63.80 & 4.96 & 58.84 & 9.56 & 0.61 \\
\hline CF14 & 15:03 & $15-\mathrm{Fev}-04$ & 0.047 & 3.2 & 5.65 & 22.8 & 22.10 & 9.30 & 109.35 & $<$ I.d & 34.99 & 80.77 & 0.16 & 60.98 & n.c & n.c & 8.67 & 0.50 \\
\hline CF15 & 15:08 & 15-Fev-04 & 0.040 & 3.2 & 5.68 & 22.5 & 19.42 & 0.06 & 100.51 & 3.72 & 35.45 & 81.62 & 0.13 & 62.09 & 3.85 & 58.24 & n.a & n.a \\
\hline CF16 & $15: 13$ & 15-Fev-04 & 0.033 & 2.6 & 5.7 & 22.2 & 18.87 & 7.84 & 99.15 & 2.52 & 30.50 & 75.69 & 0.10 & 60.09 & 2.62 & 57.47 & 8.43 & 0.42 \\
\hline CF17 & $15: 33$ & 15-Fev-04 & 0.010 & 4.8 & 5.74 & 21.2 & 21.91 & 8.50 & 99.07 & $<1 . d$ & 32.07 & 72.96 & 0.10 & 52.39 & n.c & n.c & 8.14 & 0.35 \\
\hline CF18 & $15: 53$ & 15-Fev-04 & 0.008 & 3.2 & 5.92 & 20.1 & 24.82 & 8.42 & 92.41 & 3.05 & 39.51 & 71.02 & 0.16 & 48.53 & 3.22 & 45.32 & 8.29 & 0.36 \\
\hline CF1 & $9: 41$ & 17- $\mathrm{Fev}-04$ & 0.026 & 2.8 & 5.87 & 14.5 & 13.65 & 5.00 & 54.80 & 0.94 & 36.69 & 47.25 & 0.37 & 24.45 & 1.32 & 23.14 & 35.63 & 3.31 \\
\hline $\mathrm{CF} 2$ & $9: 46$ & 17- $\mathrm{Fev}-04$ & 1.151 & 3.2 & 5.91 & 14.6 & 19.20 & 8.97 & 87.65 & 1.33 & 38.55 & 40.46 & 0.10 & 30.38 & 1.43 & 28.95 & 6.37 & 0.46 \\
\hline $\mathrm{CF} 3$ & 9:51 & 17-Fev-04 & 3.473 & 3.6 & 5.96 & 17.5 & 19.42 & 9.18 & 87.48 & 1.28 & 39.30 & 50.09 & 0.11 & 36.90 & 1.39 & 35.51 & 7.75 & 0.50 \\
\hline CF 4 & 9:56 & 17-Fev-04 & 3.404 & 3.8 & 5.93 & 19.8 & 16.63 & 9.24 & 81.29 & 1.78 & 30.03 & 63.49 & 0.26 & 42.75 & 2.04 & 40.72 & 4.25 & 0.30 \\
\hline CF5 & 10:01 & 17-Fev-04 & 3.215 & 4.6 & 5.92 & 20.1 & 25.80 & 14.02 & 118.79 & 1.56 & 38.51 & 58.70 & 0.13 & 42.68 & 0.13 & 42.55 & 8.50 & 0.49 \\
\hline CF6 & 10:06 & 17-Fev-04 & 3.217 & 4.2 & 5.99 & 20.9 & 19.25 & 12.02 & 107.74 & 2.17 & 29.46 & 59.19 & 0.26 & 45.42 & 2.42 & 43.00 & 8.87 & 0.51 \\
\hline CF7 & $10: 11$ & 17-Fev-04 & 3.785 & 5 & 5.97 & 23.8 & 17.81 & 11.44 & 93.68 & 2.44 & 30.65 & 79.78 & 0.29 & 51.50 & 0.29 & 51.21 & 10.13 & 0.65 \\
\hline CF8 & $10: 16$ & 17-Fev-04 & 4.308 & 5.2 & 6.04 & 25 & 22.47 & 20.20 & 142.37 & 2.77 & 34.37 & 79.46 & 0.23 & 47.64 & 2.99 & 44.65 & 10.25 & 0.66 \\
\hline CF9 & $10: 21$ & 17-Fev-04 & 5.294 & 6 & 6.02 & 26.2 & 24.55 & 22.44 & 149.53 & 1.89 & 37.34 & 82.66 & 0.39 & 53.57 & 2.28 & 51.30 & 9.75 & 0.56 \\
\hline CF10 & 10:26 & 17- $\mathrm{Fev}-04$ & 6.182 & 6.4 & 6.08 & 25.8 & 22.66 & 22.08 & 149.72 & 2.61 & 35.75 & 34.38 & 0.21 & 56.91 & 2.82 & 54.08 & 11.50 & 0.74 \\
\hline CF11 & $10: 31$ & 17-Fev-04 & 6.028 & 6.2 & 6.1 & 26.1 & 24.25 & 22.79 & 150.21 & 2.50 & 31.00 & 35.86 & n.a & 59.94 & n.c & n.c & 9.30 & 0.66 \\
\hline CF12 & $10: 36$ & 17-Fev-04 & 5.369 & 7.2 & 6.18 & 26.1 & 24.65 & 23.26 & 150.56 & 3.00 & 34.92 & 77.09 & 0.21 & 62.69 & 3.21 & 59.48 & 8.00 & 0.57 \\
\hline CF13 & $10: 41$ & 17-Fev-04 & 5.090 & 6.8 & 6.17 & 24.9 & 18.97 & 18.61 & 125.03 & 2.28 & 29.23 & 71.94 & 0.19 & 58.68 & 2.47 & 56.21 & 10.00 & 0.79 \\
\hline CF14 & $10: 46$ & 17-Fev-04 & 6.352 & 6.4 & 6.19 & 24.1 & 15.12 & 15.58 & 118.36 & 3.33 & 34.40 & 69.64 & 0.21 & 57.72 & 3.54 & 54.18 & 9.60 & 0.69 \\
\hline CF15 & $10: 51$ & 17-Fev-04 & 6.923 & 8 & 6.21 & 24 & 18.10 & 17.45 & 118.81 & 2.39 & 33.79 & 70.51 & 0.19 & 59.13 & 2.58 & 56.55 & 2.91 & 0.23 \\
\hline CF16 & $10: 56$ & 17-Fev-04 & 6.974 & 7.2 & 6.21 & 24 & 23.19 & 21.94 & 142.29 & 3.61 & 37.99 & 69.93 & 0.21 & 55.13 & 3.82 & 51.31 & 8.06 & 0.58 \\
\hline CF17 & 11:16 & 17- $\mathrm{Fev}-04$ & 6.356 & 7.6 & 6.24 & 24.2 & 20.87 & 20.85 & 133.23 & n.a & 30.14 & 60.56 & 0.24 & 56.68 & n.c & n.c & 8.35 & 0.60 \\
\hline CF18 & 11:36 & 17- $\mathrm{Fev}-04$ & 5.562 & 7.4 & 6.26 & 23.5 & 22.29 & 21.23 & 140.06 & 3.28 & 37.04 & 56.44 & 0.19 & 56.24 & 3.47 & 52.77 & 6.08 & 0.39 \\
\hline CF19 & 11:56 & 17-Fev-04 & 4.268 & 7.4 & 6.32 & 22.9 & 17.59 & 16.84 & 116.44 & n.a & 27.29 & 54.38 & 0.18 & 57.28 & n.c & n.c & 6.25 & 0.40 \\
\hline CF2O & $12: 16$ & 17-Fev-04 & 3.953 & 8.6 & & 22 & 15.60 & 14.32 & 106.93 & 2.89 & 26.25 & 49.23 & 0.15 & 56.39 & 3.03 & 53.35 & 4.33 & 0.28 \\
\hline CF21 & $12: 36$ & 17-Fev-04 & 3.687 & 8.2 & 6.38 & 21.5 & 18.56 & 16.70 & 121.33 & n.a & 29.50 & 44.55 & 0.21 & 55.57 & n.c & n.c & 3.75 & 0.21 \\
\hline CF22 & 12:56 & 17-Fev-04 & 3.085 & 8.4 & 6.39 & 21.7 & 18.24 & 15.93 & 124.08 & n.a & 31.08 & 44.76 & 0.19 & 54.68 & n.c & n.c & 5.50 & 0.31 \\
\hline CF23 & 13:16 & 17-Fev-04 & 1.545 & 10 & 6.39 & 21.6 & 16.33 & 14.14 & 123.82 & n.a & 29.76 & 43.75 & 0.19 & 54.09 & n.c & n.c & 6.50 & 0.37 \\
\hline CF24 & $13: 36$ & 17-Fev-04 & 1.342 & 7.8 & 6.17 & 21.7 & 15.03 & 10.09 & 102.57 & 4.05 & 35.63 & 49.85 & 0.19 & 58.83 & 0.19 & 58.64 & 5.50 & 0.28 \\
\hline CF1 & $14: 38$ & 19-Fev-04 & 0.031 & 4.6 & 6.03 & 14.5 & 15.50 & 7.12 & 71.06 & 9.88 & 34.95 & 68.58 & 0.10 & 27.19 & 9.98 & 17.21 & n.a & n.a \\
\hline CF2 & $14: 43$ & 19-Fev-04 & 0.163 & 3.6 & 6.06 & 12.6 & 6.79 & 2.75 & 38.27 & 1.11 & 35.64 & 21.99 & $<$ l.d & 25.64 & n.c & n.c & 18.00 & n.a \\
\hline $\mathrm{CF} 3$ & $14: 48$ & 19-Fev-04 & 13.163 & 4.4 & 6.1 & 12.5 & 5.70 & 2.13 & 34.80 & 3.05 & 30.99 & 20.14 & 0.18 & 23.41 & 3.23 & 20.18 & 11.60 & n.a \\
\hline CF 4 & $14: 53$ & 19-Fev-04 & 23.053 & 4.2 & 6.13 & 12 & 8.38 & 4.70 & 61.02 & 1.83 & 26.52 & 23.95 & 0.06 & 13.86 & 1.90 & 11.96 & 10.58 & n.a \\
\hline CF5 & $14: 58$ & 19-Fev-04 & 37.769 & 4.8 & 6.19 & 11.7 & 6.23 & 3.93 & 49.92 & 1.1 & 26.24 & 29.31 & 0.21 & 18.52 & 1.38 & 17.15 & 8.58 & n.a \\
\hline CF6 & 15:03 & 19-Fev-04 & 56.403 & 7 & 6.2 & 11.8 & 9.06 & 6.40 & 62.75 & 2.33 & 38.09 & 33.18 & 0.16 & 20.38 & 2.49 & 17.88 & 7.33 & n.a \\
\hline CF7 & $\begin{array}{l}15: 08 \\
15\end{array}$ & 19-Fev-04 & 65.302 & 4.6 & 6.27 & 11.2 & 7.74 & 6.62 & 62.11 & 1.89 & 80.22 & 26.73 & 0.08 & 19.71 & 1.97 & 17.74 & 7.71 & n.a \\
\hline
\end{tabular}


Anexo K. Valores dos parâmetros físico-químicos e concentrações dos elementos e compostos analisados no igarapé da pastagem

\begin{tabular}{|c|c|c|c|c|c|c|c|c|c|c|c|c|c|c|c|c|c|c|}
\hline Fonte & Hora & Data & Descarga $\left(\right.$ L. s $\left.\mathrm{s}^{-1}\right)$ & Alc & $\mathrm{pH}$ & C.E & Ca(UM) & $\mathrm{Mg}(\mathrm{UM})$ & K(UM) & $\mathrm{NH} 4(\mathrm{uM})$ & $\mathrm{Na}(\mathrm{UM})$ & Cl(uM) & NO3(uM) & NDT(UM/L) & NID (UM) & NOD(uM/L) & $\mathrm{STS}\left(\mathrm{mg} \cdot \mathrm{L}^{-1}\right)$ & $\mathrm{NP}(\mathrm{uM})$ \\
\hline CF8 & $15: 13$ & 19-Fev-04 & 66.483 & 4.4 & 6.27 & 10.9 & 6.55 & 6.68 & 59.25 & $<I . d$ & 22.82 & 19.68 & $<1 . d$ & 16.23 & n.c & n.c & 7.93 & n.a \\
\hline CF9 & 15:18 & 19-Fev-04 & 65.335 & 5.4 & 6.31 & 10.4 & 6.17 & 6.43 & 56.33 & $<1 . d$ & 21.74 & 16.91 & $<$ I.d & 14.82 & n.c & n.c & 7.64 & n.a \\
\hline CF10 & $15: 23$ & 19-Fev-04 & 67.349 & 4.8 & 6.37 & 10.1 & 4.41 & 5.09 & 46.41 & 3.50 & 16.70 & 13.81 & $<$ I.d & 15.56 & n.c & n.c & 8.50 & n.a \\
\hline CF11 & $15: 28$ & 19-Fev-04 & 65.593 & 6.4 & 6.38 & 10.2 & 5.02 & 5.48 & 46.28 & $<$ I.d & 18.40 & 15.06 & $<$ I.d & 0.00 & n.c & n.c & 9.43 & n.a \\
\hline CF12 & $15: 33$ & 19-Fev-04 & 64.440 & 5.2 & 6.38 & 10.5 & 4.75 & 5.32 & 41.49 & $<1 . d$ & 19.93 & 13.56 & $<$ I.d & 15.93 & n.c & n.c & 8.64 & n.a \\
\hline $\mathrm{CF} 13$ & $15: 38$ & 19-Fev-04 & 61.659 & 5.6 & 6.39 & 10.7 & 4.46 & 5.25 & 39.77 & 3.28 & 14.82 & 11.92 & $<$ I.d & 21.12 & n.c & n.c & 10.21 & n.a \\
\hline CF14 & 15:43 & 19-Fev-04 & 57.904 & 6 & 6.4 & 10.6 & 6.67 & 7.92 & 58.37 & 3.33 & 30.43 & 21.87 & $<$ I.d & 21.34 & n.c & n.c & 8.71 & n.a \\
\hline CF15 & $15: 48$ & 19-Fev-04 & 54.572 & 6.6 & 6.46 & 10.9 & 5.31 & 7.00 & 46.07 & $<$ I.d & 17.60 & 11.49 & $<$ I.d & 17.04 & n.c & n.c & 10.07 & n.a \\
\hline CF16 & 15:53 & 19-Fev-04 & 45.093 & 6.2 & 6.39 & 11 & 6.08 & 7.93 & 52.91 & 3.72 & 22.54 & 14.89 & 0.08 & 17.26 & 3.80 & 13.46 & 8.31 & n.a \\
\hline CF17 & $16: 13$ & 19-Fev-04 & 21.156 & 6.6 & 6.43 & 11.8 & 6.51 & 8.62 & 54.65 & 5.43 & 16.16 & 11.69 & $<$ I.d & 18.30 & n.c & n.c & 9.25 & n.a \\
\hline CF18 & $16: 33$ & 19-Fev-04 & 10.512 & 6.6 & 6.42 & 12.8 & 7.20 & 9.15 & 55.67 & 3.94 & 24.92 & 16.78 & 0.74 & 21.71 & 4.69 & 17.02 & 6.56 & n.a \\
\hline CF19 & $16: 53$ & 19-Fev-04 & 6.232 & 6.6 & 6.44 & 14.3 & 8.43 & 9.79 & 56.87 & 4.33 & 17.73 & 14.83 & $<$ I.d & 24.67 & n.c & n.c & 6.50 & n.a \\
\hline CF20 & $17: 13$ & 19-Fev-04 & 3.606 & 7.6 & 6.39 & 15.1 & 9.69 & 8.83 & 73.70 & 2.49 & 24.09 & 47.03 & 1.08 & 27.56 & 3.57 & 23.99 & 6.62 & n.a \\
\hline CF21 & 17:33 & 19-Fev-04 & 2.272 & 6.6 & 6.31 & 15.2 & 8.47 & 10.01 & 60.14 & $<$ I.d & 21.94 & 16.01 & $<$ I.d & 27.56 & n.c & n.c & 17.11 & n.a \\
\hline CF22 & $17: 53$ & 19-Fev-04 & 1.397 & 7 & 6.38 & 15.8 & 8.69 & 10.41 & 60.94 & 2.82 & 23.79 & 18.16 & $<$ I.d & 32.60 & n.c & n.c & 7.09 & n.a \\
\hline $\mathrm{CF} 23$ & 18:13 & 19-Fev-04 & 0.841 & 7 & 6.33 & 15.8 & 10.69 & 11.83 & 66.37 & $<1 . d$ & 23.02 & 17.44 & $<$ I.d & 35.49 & n.c & n.c & 7.31 & n.a \\
\hline CF24 & 18:33 & 19-Fev-04 & 0.485 & 5.8 & 6.28 & 15.9 & 9.13 & 10.65 & 65.64 & 4.28 & 21.56 & 19.26 & $<$ I.d & 36.16 & n.c & n.c & 7.11 & n.a \\
\hline CF1 & 16:11 & $25-$ Fev-04 & 0.003 & 4.2 & 5.91 & 20.3 & 12.35 & 12.70 & 64.05 & 4.76 & 35.71 & 57.37 & n.a & n.a & n.c & n.c & 173.00 & n.a \\
\hline CF2 & $16: 16$ & 25-Fev-04 & 4.956 & 4.6 & 6.09 & 15.5 & 9.57 & 10.92 & 59.70 & $<$ I.d & 21.60 & 36.16 & $<$ I.d & 12.56 & n.c & n.c & 12.60 & n.a \\
\hline CF3 & $16: 21$ & 25-Fev-04 & 30.658 & 3.8 & 6.16 & 16.4 & 9.42 & 10.85 & 64.62 & $<$ I.d & 30.20 & 43.72 & $<$ I.d & 13.50 & n.c & n.c & 9.47 & n.a \\
\hline CF4 & $16: 26$ & $25-\mathrm{Fev}-04$ & 45.666 & 4.8 & 6.19 & 18.3 & 9.46 & 12.26 & 71.27 & $<1 . d$ & 22.36 & 49.94 & $<$ I.d & 13.50 & n.c & n.c & 6.31 & n.a \\
\hline CF5 & $16: 31$ & 25-Fev-04 & 57.167 & 4.4 & 6.18 & 19.2 & 9.39 & 13.84 & 81.80 & 2.54 & 20.73 & 55.55 & $<$ I.d & 14.54 & n.c & n.c & 1.77 & n.a \\
\hline CF6 & $16: 36$ & 25 -Fev-04 & 62.042 & 5.2 & 6.17 & 20.4 & 9.02 & 14.47 & 82.37 & $<1 . d$ & 20.03 & 55.27 & $<$ I.d & 14.54 & n.c & n.c & 6.07 & n.a \\
\hline CF7 & $16: 41$ & $25-\mathrm{Fev}-04$ & 62.291 & 5.2 & 6.23 & 21.2 & 8.12 & 12.64 & 71.04 & $<$ I.d & 17.91 & 54.56 & $<$ I.d & 17.55 & n.c & n.c & 0.93 & n.a \\
\hline CF8 & $16: 46$ & 25 -Fev-04 & 57.6 & 6.8 & 6.3 & 21.6 & 10.99 & 16.69 & 86.13 & $<1 . d$ & 19.30 & 57.09 & $<$ I.d & 18.41 & n.c & n.c & 5.00 & n.a \\
\hline CF9 & $16: 51$ & 25-Fev-04 & 51.138 & 5.8 & 6.28 & 22.3 & 10.29 & 15.69 & 81.62 & $<1 . d$ & 18.52 & 53.34 & $<$ I.d & 20.90 & n.c & n.c & 2.35 & n.a \\
\hline CF10 & $16: 56$ & 25-Fev-04 & 38.748 & 6.6 & 6.34 & 23 & 15.11 & 19.38 & 96.31 & $<1 . d$ & 20.56 & 60.65 & $<$ I.d & 22.02 & n.c & n.c & 2.50 & n.a \\
\hline CF11 & $17: 01$ & 25 -Fev-04 & 28.928 & 6.6 & 6.37 & 22.9 & 14.46 & 19.91 & 96.83 & $<$ I.d & 21.08 & 62.18 & $<$ I.d & 22.62 & n.c & n.c & 1.00 & n.a \\
\hline CF12 & $17: 06$ & $25-\mathrm{Fev}-04$ & 21.848 & 5.8 & 6.47 & 22.5 & 15.47 & 19.49 & 92.66 & 2.68 & 23.66 & 59.08 & $<$ I.d & 24.68 & n.c & n.c & 1.61 & n.a \\
\hline $\mathrm{CF} 13$ & $17: 11$ & $25-\mathrm{Fev}-04$ & 16.894 & 6.8 & 6.34 & 23.2 & 11.81 & 16.75 & 83.56 & $<$ I.d & 22.36 & 62.66 & $<$ I.d & 27.52 & n.c & n.c & 2.06 & n.a \\
\hline CF14 & $17: 16$ & $25-$ Fev-04 & 12.81 & 7 & 6.35 & 23.4 & 15.43 & 19.64 & 94.67 & $<1 . d$ & 23.30 & 59.90 & $<$ I.d & 27.18 & n.c & n.c & 2.11 & n.a \\
\hline CF15 & $17: 21$ & $25-$ Fev-04 & 9.752 & 6 & 6.33 & 23.5 & 16.03 & 20.29 & 96.73 & $<1 . d$ & 24.60 & 63.89 & $<$ I.d & 29.07 & n.c & n.c & 5.33 & n.a \\
\hline CF16 & $17: 26$ & 25 -Fev-04 & 7.457 & 6.8 & 6.34 & 23.5 & 16.90 & 20.80 & 93.25 & $<$ I.d & 24.06 & 62.38 & n.a & 32.34 & n.c & n.c & 4.39 & n.a \\
\hline CF17 & $17: 46$ & 25-Fev-04 & 2.616 & 6.6 & 6.34 & 23.3 & 15.85 & 19.23 & 86.28 & 2.81 & 23.78 & 57.16 & n.a & 35.69 & n.c & n.c & 3.50 & n.a \\
\hline CF18 & 18:06 & 25-Fev-04 & 1.128 & 5.6 & 6.28 & 21.1 & 15.14 & 18.98 & 91.17 & 3.43 & 30.05 & 61.69 & n.a & 38.19 & n.c & n.c & 4.44 & n.a \\
\hline CF19 & $18: 26$ & 25 -Fev-04 & 0.492 & 6.6 & 6.17 & 20.5 & 16.32 & 18.56 & 87.86 & 3.28 & 22.09 & 55.99 & n.a & 39.74 & n.c & n.c & 6.21 & n.a \\
\hline CF20 & 18:46 & $25-\mathrm{Fev}-04$ & 0.233 & 5 & 6.19 & 19.6 & 13.83 & 16.05 & 70.52 & 3.35 & 24.13 & 48.60 & n.a & 39.22 & n.c & n.c & 6.07 & n.a \\
\hline CF21 & 19:06 & 25 -Fev-04 & 0.123 & 6.2 & 6.22 & 19 & 14.52 & 14.24 & 74.77 & 4.97 & 20.43 & 50.04 & n.a & 43.00 & n.c & n.c & 7.45 & n.a \\
\hline CF22 & 19:26 & $25-\mathrm{Fev}-04$ & 0.072 & 7 & 6.29 & 19 & 14.64 & 14.31 & 76.36 & 4.08 & 22.57 & 35.40 & n.a & 38.01 & n.c & n.c & 7.00 & n.a \\
\hline $\mathrm{CF} 23$ & 19:46 & $25-\mathrm{Fev}-04$ & 0.044 & 7 & 6.21 & 18.6 & 15.29 & 13.89 & 72.18 & 4.52 & 21.15 & 43.43 & n.a & 38.70 & n.c & n.c & 4.86 & n.a \\
\hline CF24 & 20:06 & $25-$ Fev-04 & 0.03 & 7 & 6.19 & 18.2 & 20.05 & 13.79 & 71.61 & 3.76 & 26.03 & 42.02 & n.a & 35.95 & n.c & n.c & 8.16 & n.a \\
\hline CF1 & 3:16 & $27-$ fev-04 & n.c & n.a & 6.03 & 19 & 23.95 & 17.88 & 57.59 & 1.67 & 37.47 & 28.15 & 1.13 & 24.17 & 2.80 & 21.37 & 65.75 & 9.39 \\
\hline CF2 & 3:21 & $27-$ fev-04 & n.c & n.a & 6.01 & 16.9 & 18.54 & 13.36 & 51.33 & 1.83 & 48.03 & 35.31 & 0.45 & 31.22 & 2.28 & 28.94 & 21.27 & 1.37 \\
\hline $\mathrm{CF} 3$ & $3: 26$ & 27-fev-04 & n.c & n.a & 6.11 & 16.3 & 17.50 & 15.59 & 54.12 & 2.33 & 28.77 & 30.49 & 0.23 & 32.51 & 2.56 & 29.95 & 12.77 & 0.73 \\
\hline CF4 & 3:31 & $27-f e v-04$ & n.c & n.a & 6.27 & 16.2 & 17.27 & & 53.60 & 4.28 & 27.90 & 30.07 & 0.18 & 30.70 & 4.46 & 26.25 & 9.13 & 0.52 \\
\hline CF5 & 3:36 & $27-$ fev-04 & n.c & n.a & 6.33 & 16.2 & 21.03 & 15.28 & 53.24 & 2.17 & 26.72 & 31.76 & 0.19 & 33.46 & 2.36 & 31.10 & 7.68 & 0.38 \\
\hline CF6 & 3:41 & $27-f e v-04$ & n.c & n.a & 6.33 & 16.4 & 17.57 & 16.45 & 55.33 & 2.94 & 24.72 & 33.89 & 0.16 & 32.17 & 3.11 & 29.06 & 7.40 & 0.37 \\
\hline CF7 & $3: 46$ & $27-f e v-04$ & n.c & n.a & 6.07 & 16.9 & 17.29 & 15.95 & 54.89 & 3.39 & 24.79 & 32.58 & 0.19 & 36.04 & 3.58 & 32.45 & 7.40 & 0.32 \\
\hline CF8 & 3:51 & $27-f e v-04$ & n.c & n.a & 5.97 & 18 & 17.64 & 16.73 & 55.66 & 3.83 & 24.00 & 31.45 & 0.10 & 39.99 & 3.93 & 36.06 & 7.30 & 0.36 \\
\hline CF9 & 3:56 & 27-fev-04 & n.c & n.a & 6.22 & 19.1 & 21.16 & 18.97 & 64.16 & 3.58 & 33.17 & 45.56 & 0.21 & 37.58 & 3.79 & 33.79 & 6.50 & 0.28 \\
\hline CF10 & 4:01 & 27-fev-04 & n.c & n.a & 6.17 & 17.7 & 22.12 & 19.94 & 65.39 & 3.55 & 34.59 & 43.34 & 0.10 & 38.44 & 0.10 & 38.35 & 7.60 & 0.38 \\
\hline CF11 & 4:06 & $27-$ fev-04 & n.c & n.a & 6.1 & 17.8 & 18.06 & 15.91 & 57.02 & $<1 . d$ & 34.17 & 51.18 & 0.08 & 38.96 & n.c & n.c & 8.20 & 0.41 \\
\hline CF12 & $4: 11$ & $27-$ fev-04 & n.c & n.a & 6.15 & 18.1 & 23.32 & 20.00 & 68.36 & 4.22 & 42.65 & 49.98 & $<$ I.d & 40.68 & n.c & n.c & 7.40 & 0.37 \\
\hline CF13 & $4: 16$ & 27 -fev-04 & n.c & n.a & 6.1 & 18.2 & 22.98 & 19.89 & 67.70 & n.a & & 44.78 & 0.13 & 41.28 & n.c & n.c & 7.60 & 0.38 \\
\hline CF14 & $4: 21$ & $27-f e v-04$ & n.c & n.a & 6.19 & 18.2 & 22.62 & 19.55 & 67.36 & n.a & 33.95 & 39.49 & 0.10 & 40.08 & n.c & n.c & 9.20 & 0.46 \\
\hline CF15 & 4:26 & 27-fev-04 & n.c & n.a & 6.11 & 18 & 23.19 & 18.65 & 68.76 & $<1 . d$ & 57.75 & 29.51 & 0.06 & 38.27 & n.c & n.c & 6.90 & 0.30 \\
\hline CF16 & $4: 31$ & 27-fev-04 & n.c & n.a & 6.13 & 18.2 & 23.05 & 18.52 & 66.82 & 3.50 & 35.39 & 40.59 & 0.08 & 41.28 & 3.58 & 37.70 & 7.30 & 0.36 \\
\hline CF17 & 5:11 & 27-fev-04 & n.c & n.a & 6.15 & 17.9 & 22.54 & 17.35 & 63.36 & $<$ I.d & 29.06 & 29.86 & 0.08 & 42.32 & n.c & n.c & 9.30 & 0.40 \\
\hline CF18 & 5:51 & 27-fev-04 & n.c & n.a & 6.49 & 17.9 & 23.91 & 16.47 & 63.89 & $<1 . d$ & 31.83 & 24.86 & $<$ I.d & 35.61 & n.c & n.c & 7.80 & 0.28 \\
\hline CF19 & $6: 31$ & $27-$ fev-04 & n.c & n.a & 6.13 & 18.2 & 25.98 & 15.66 & 69.01 & $<1 . d$ & 58.07 & 40.82 & 0.16 & 33.63 & n.c & n.c & 8.00 & 0.29 \\
\hline CF2O & 7:11 & $27-f e v-04$ & n.c & n.a & 6.45 & 18.4 & 24.26 & 12.68 & 66.36 & 3.50 & 72.60 & 37.24 & 0.00 & 31.56 & 3.50 & 28.06 & 5.60 & 0.20 \\
\hline
\end{tabular}

$<$ l.d = menor ao limite de detecção

n.a = não analisado

n.c $=$ não calculado

Alc. = Alcalinidade (ueq. $\mathrm{L}^{-1}$ )

C. $\mathrm{E}=$ Condutividade elétrica $\left(\mathrm{uS} . \mathrm{cm}^{-1}\right)$

$\mathrm{CF}=$ Amostras do igarapé durante o evento de chuva

Nos eventos de chuva do 19 e 25 de fevereiro o vertedouro do pasto transbordou, portanto, os valores de descarga podem estar subestimados 


\section{REFERÊNCIAS BIBLIOGRÁFICAS}

ALVES, D.S. Space-time dynamics of deforestation in Brazilian Amazônia. International Journal of Remote Sensing, v.23, n.14, p.2903-2908, 2002.

ALVES, D.S.; ESCADA, M.I.S.; PEREIRA, J.L.G.; DE ALBUQUERQUE LINHARES, C. Land use intensification and abandonment in Rondônia, Brazilian Amazônia. International Journal of Remote Sensing, v.24, n.4, p.899-903, 2003.

BOS, M.G. Discharge measurement structures: delft hydraulics laboratory. Wageningen: International Institute for Land Reclamation and Improvement, 1978. 400p.

BRUIJNZEEL, L.A. Predicting the hydrological impacts of land cover transformation in the humid tropics: the need for integraded research. In: GASH, J.H.C.; NOBRE, C.A.; ROBERTS, J.M.; VICTORIA, R.L. (Ed.). Amazonian deforestation and climate. Chichester: John Wiley, 1996. cap.2, p.15-55.

CERRI, C.C.; VOLKOFF, B.; EDUARDO, B.P. Efeito do desmatamento sobre a biomassa microbiana em latossolo Amarelo da Amazônia. Revista Brasileira de Ciência do Solo, v.9, n.1, p.1-4, 1985.

CHAPIN III, F.S.; MATSON, P.A.; MOONEY, H.A. Principles of terrestrial ecosystem ecology. New York: Springer - Verlag, 2002. cap.9, p.197-223: Terrestrial nutrient cycling.

CONN, C. Literature review: nitrogen sequestration in headwater streams. Columbia: Straughan Environmental Services, INC. December, 2003. 48p. http://www.esm.versar.com/pprp/bibliography/LiteratureReviews/NitrogenSequestra tionReport.pdf ( 2 fevereiro 2005)

DIAZ FILHO, M.B.; DAVIDSON, E.A.; REIS DE CARVALHO C.J. Linking biogeochemical cycles to cattle pasture management and sustainability in the Amazon basin. In: MCCLAIN M.E.; VICTORIA, R.L.; RICHEY, J.E. (Ed.) The Biogeochemistry of the Amazon Basin. Oxford: University Press, 2001. cap.6, p.84-105. 
DIEZ, J.A.; POLO, A.; DIAZ-BURGOS, M.A.; CERRI, C.C.; FIEGL, B.J.; PICCOLO, M.C. Effect of fallow land, cultivated pasture and abandoned pasture on soil fertility in two deforest Amazonian regions. Scientia Agricola, v.54, p.45-52, 1997.

DOWING, J.A.; MCCLAIN M.; TWILLEY, R.; MELACK, J.E.; RABALAIS, N.N.; LEWIS, W.M Jr.; TURNER R.E.; CORRESDOR, J.; SOTO, D.; YANEZARANCIBIA, A.; KOPASKA J.A.; HOWARTH, R.W. The impact of accelerating land-use change on the N-Cycle of tropical aquatic ecosystems: Current conditions and projected changes. Biogeochemistry, v.46, p.109-148, 1999.

ELSENBEER, H.; LACK, A. Hydrometric and hydrochemical evidence for fast flowpaths at La Cuenca, Western Amazonia. Journal of Hydrology, v.180, p. 237250, 1996a.

ELSENBEER, H.; LACK, A. Hydrological pathways and water chemistry in Amazonian rain forests. In: ANDERSON, M.G.; BROOKS, S.M. (Ed.) Advances in hillslope processes. Chichester: John Wiley, 1996b. v.2, cap.43, p.939-958.

ELSENBEER, H.; LACK A.; CASSEL, K. Chemical fingerprints of hydrological compartments and flow paths at La Cuenca, western Amazonia. Water Resources Research, v.31, n.12, p. 3051-3058, 1995.

ELSENBEER, H.; WEST, A.; BONELL, M. Hydrologic pathways and stormflow hydrochemistry at South Creek, northeast Queensland. Journal of Hydrology, v.162, p. 1-21, 1994.

ELSENBEER, H.; NEWTON, B.A.; DUNNE, T.; MORAES, J. Soil hydraulic conductivities of latosols under pasture, forest and teak in Rondônia, Brazil. Hydrological Processes, v.13, p.1417 -1422, 1999.

EMPRESA BRASILERA DE PESQUISA AGROPECUÁRIA. Sistema brasileiro de classificação de solos. Brasília: SPI, 1999. 370p

FEARNSIDE, P.M. Amazonian deforestation and global warming: carbon stocks in vegetation replacing Brazil's Amazon Forest. Forest Ecology and Management, v.80, n.1/3, p.21-34, 1996.

FOLLET, R.F.; DELGADO, J.A. Nitrogen fate and transport in agricultural systems. Journal of Soil and Water Conservation, v.52, n.6, p.402-408, 2002.

GALLOWAY, J.N. The global nitrogen cycle: changes and consequences. Environmental Pollution, v.102, p.15-24, 1998. 
GARCIA-MONTIEL, D.C.; STEUDLER, P.A.; PICCOLO, M.C.; MELILLO, J.M.; NEILL, C.; CERRI, C.C. Controls on soil nitrogen oxide emissions from forest and pastures in the Brazilian Amazon. Global Biogeochemical Cycles, v.15, n.4, p.1021-1030, 2001.

GODSEY, S.; ELSENBEER, H. The soil hydrologic response to forest regrowth: a case study from southwestern Amazonia. Hydrological Processes, v.16, p.1519-1522, 2002.

GOODALE, C.L.; ABER, J.D.; MCDOWELL, W.H. The long-term effects of disturbance on organic and inorganic nitrogen export in the White Mountains, new Hampshire. Ecosystems, v.3, p. 433-450, 2000.

GROFFMAN, P.M.; GOLD, A.J.; SIMMONS, R.C. Nitrate dynamics in riparian forests: Microbial studies. Journal of Environmental Quality, v.21, p.666-671, 1992.

HAUPERT, C.L.; NEILL, C.; DEEGAN, L.; KRUSHE, A.V.; VICTORIA, R.L.; BALLESTER, V.R. Stream size influences morphology and biogeochemistry of pasture streams. In: III Conferência científica do LBA (Experimento de Grande Escala da Biosfera-Atmosfera na Amazônia), Brasilia-DF, 2004. Anais. Brasília-DF Academia de Tênis Resort, 2004. p.175.

HILL, A.R. Nitrate removal in stream riparian zones. Journal of Environmental Quality, v.25, p.743-755, 1996.

INSTITUTO NACIONAL DE PESQUISAS ESPACIAIS. Monitoramento da floresta amazônica por satélites. http://www.obt.inpe.br/prodes/prodes_1988-2003.htm. (10 janeiro 2005).

JORDAN, C.F. Nutrient cycling in tropical forest ecosystems: principles and their application in management and conservation. Chichester: John Wiley and Sons, 1985. 190p.

JORDAN, T.E.; CORREL, D.L.; WELLER, D.E. Relating nutrient discharges from watersheds to land use and streamflow variability. Water Resources Research, v.33, n.11, p.2579-2590, 1997.

MARTINS P.F.S.; CERRI, C.C.; VOLKOFF, B.; ANDREUX F.; CHAUVEL, A. Consequences of clearing and tillage on the soil of a natural Amazonian ecosystem. Forest Ecology and Management, v.38, p.273-282, 1991.

MATSON, P.A.; MCDOWELL, M.H.; TOWNSEND, A.R.; VITOUSEK, P.M. The globalization of $\mathrm{N}$ deposition: ecosystem consequences in tropical environments. Biogeochemistry, v.46. p.67-81, 1999. 
MCCLAIN, M.E.; ELSEENBER, H. Terrestrial inputs to Amazon streams and internal biogeochemical processing. In: MCCLAIN, M.E; VICTORIA, R.; RICHEY, J.E. (Ed.). The biogeochemistry of the Amazon Basin. Oxford: University Press, 2001. cap.12, p.185-208.

MCCLAIN, M.E.; RICHEY, J.E.; PIMENTEL, T.P. Groundawater nitrogen dynamics at the terrestrial - lotic interface of a small catchment in the Central Amazon Basin. Biogeochemistry, v.00, p. 1-15, 1994.

MCDOWELL, W.H.; BODWEN, W.B.; ASBURY, C.E. Riparian nitrogen dynamics in two geomorphologically distinct tropical rain forest watersheds: subsurface solute patterns. Biogeochemistry, v.18, p.53-75, 1992.

MELILLO, J.M.; STEUDLER, P.A.; FEIGL, B.J.; NEILL, C.; GARCIA, D.; PICCOLO, M.C.; CERRI, C.C.; TIAN, H. Nitrous oxide emissions from forests and pastures of various ages in the Brazilian Amazon. Journal of Geophysical Research - Atmospheres, v.106, p.34179-34188, 2001.

MORAES J.F.L. de; VOLKOFF, B.; CERRI, C.C.; BERNOUX, M. Soil properties under Amazon Forest and changes due pasture installation in Rondônia, Brazil. Geoderma. v.70, p.63-81, 1996.

NEFF, J.C.; HOBBIE, S.E.; VITOUSEK, P.M. Nutrient and mineralogical control on dissolved organic $\mathrm{C}, \mathrm{N}$ and $\mathrm{P}$ fluxes and stoichiometry in Hawaiian soils. Biogeochemistry, v.51, p.283-302, 2000.

NEILL, C.; DEEGAN, L.; THOMAS, S.M.; CERRI, C.C. Deforestation for pasture alters nitrogen and phosphorus in small Amazonian streams. Ecological Applications, v.11, n.6, p.1817-1828, 2001.

NEILL, C.; PICCOLO, M.C.; MELILLO, J.M.; STEUDLER, P.A.; CERRI, C.C. Nitrogen dynamics in Amazon forest and pasture soils measured by ${ }^{15} \mathrm{~N}$ pool dilution. Soil Biology and Biogeochemistry, v.31, p. 567-572, 1999.

NEILL, C.; PICCOLO, M.C.; CERRI, C.C.; STEUDLER, P.A.; MELILLO, J.M.; BRITO, M. Net mineralization and net nitrification rates in soils following deforestation for pasture across the southwestern Brazilian Amazon Basin landscape. Oecologia, v.110, n.2, p.243-252, 1997.

NEILL, C.; PICCOLO, M.C.; STEUDLER, P.A.; MELILLO, J.M.; FEIGL, B.J.; CERRI, C.C. Nitrogen dynamics in soils of forests and active pastures in the Western Brazilian Amazon Basin. Soil Biology \& Biochemsitry, v.27, n.9, p.11671175, 1995. 
PAUL, E.A.; CLARK, F.E. Soil microbiology and biochemistry. San Diego: Academic Press, 1989. 272p

PEDLOWSKI, M.A.; DALE, V.A.; MATRICARDI, E.A.T.; PEREIRA DA SILVA FILHO, E. Patterns and impacts of deforestation in Rondônia, Brazil. Landscape and Urban Planning, v.38, p.149-157, 1997.

PETERSON, B.J.; WOLLHEIM, W.M.; MULHOLLAND, P.J.; WEBSTER, J.R.; MEYER, J.L.; TANK, J.L.; MARTI, E.; BODWDEN, W.B.; VALETT, H.M.; HERSHEY, AA.E.; MCDOWELL, W.H.; DODDS, W.K.; HAMILTON, S.K.; GREGORY, S.; MORRAL, D.D. Control of nitrogen export from watersheds by headwater streams. Science, v.292, p.86-90, 2001.

PICCOLO M.C.; NEILL, C.; CERRI, C.C. Net nitrogen mineralization and net nitrification along a tropical forest -to-pasture chronosequence. Plant and Soil, v.162, p.61-70, 1994.

PICCOLO M.C.; NEILL, C.; MELILLO, J.M.; CERRI, C.C.; STEUDLER, P.A. ${ }^{15} \mathrm{~N}$ natural abundance in forest and pasture soils of the Brazilian Amazon Basin. Plant and Soil, v.182, p.249-258, 1996.

QUALLS, R.G. Comparison of the behavior of soluble organic and inorganic nutrients in forest soils. Forest Ecology and Management, v.138, p.29-50, 2000.

QUALLS, R.G.; HAINES, B.L.; SWANK, W.T.; TYLER, S.W. Soluble organic and inorganic nutrient fluxes in clearcut and mature deciduos forets. Soil Science Society of Ameica Journal, v.64, p.1068-1077, 2000.

RABALAIS, N.N. Nitrogen in aquatic ecosystem. AMBIO, v.31, n.2, p.102-112, 2002.

ROLDÁN, G. Fundamentos de limnologia neotropical. Medellín: Universidad de Antioquia, 1992. cap.9, p.251-267: El sistema dióxido de carbono, alcalinidad y pH.

ROSS, S.M.; THORNES, J.B.; NORTCLIFF, S. II. Soil hydrology, nutrient and erosional response to the clearance of terra firme forest, Maracá Island, Roraima, northen Brazil. The Geographical Journal, v.156, n.3, p.267-282, 1990

SCHULER, A.E. Fluxos hidrológicos em microbacias com floresta e pastagem na Amazônia Oriental, Paragominas, Pará. Piracicaba, 2003. 119p. Tese (Doutorado) Centro de Energia Nuclear na Agricultura, Universidade de São Paulo.

SMIL,V. Global population and the nitrogen cycle. Scientific American, v.277, n.1, p.76-81, july, 1997. 
THOMAS, S.M.; NEILL, C.; DEEGAN, L.A.; KRUSCHE, A.V.; BALLESTER, V.M.; VICTORIA, R.L. Influences of land use and stream size on particulate and dissolved materials in a small Amazonian stream network. Biogeochemistry, v.68, p.135-151, 2004.

VITOUSEK, P.M.; MOONEY, H.A.; LUBCHENCO, J.; MELILLO, J.M. Human domination of earth's ecosystems. Science, v.277, p. 494-499, 1997a.

VITOUSEK, P.M.; ABER, J.D.; HOWART, R.W.; LIKENS, G.E.; MATSON, P.A.; SCHINDLER, D.W.; SCHLESINGER, W.H.; TILMAN, D.G. Human alteration of the global nitrogen cycle: sources and consequences. Ecological Applications, v.7, n.3, p.737-750, 1997b.

WILLIAMS, M.R.; FISHER, T.R.; MELACK, J.M. Solute dynamics in soil water and groundwater in a central Amazon catchment undergoing deforestation. Biogeochemistry, v.38, p.303-335, 1997. 